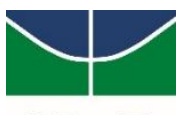

UNIVERSIDADE DE BRASÍLIA- UnB

INSTITUTO DE GEOCIÊNCIAS- IG

UnB

GÊNESE DO DEPÓSITO DE OURO TOCANTINZINHO, PROVÍNCIA AURÍFERA TAPAJÓS (PA): EVIDÊNCIAS A

PARTIR DE DADOS DE GEOLOGIA, PETROLOGIA E INCLUSÕES FLUIDAS

DISSERTAÇÃO DE MESTRADO

$\mathbf{N}^{\circ} 353$

ADRIANA ARAÚJO CASTRO

BRASÍLIA -DF

2015 


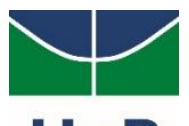

UNIVERSIDADE DE BRASÍLIA INSTITUTO DE GEOCIÊNCIAS

UnB PROGRAMA DE PÓS-GRADUAÇÃO EM GEOLOGIA

DISSERTAÇÃO DE MESTRADO

\section{GÊNESE DO DEPÓSITO DE OURO TOCANTINZINHO, PROVÍNCIA AURÍFERA TAPAJÓS (PA): EVIDÊNCIAS A PARTIR DE DADOS DE GEOLOGIA, PETROLOGIA E INCLUSÕES FLUIDAS}

Dissertação apresentada por:

ADRIANA ARAÚJO CASTRO

Orientadora: Profa. Dra. Márcia Abrahão Moura (UnB)

Banca examinadora:

Prof. Dra. Márcia Abrahão Moura

(Orientadora - IG/UnB)

Prof. Dr. Caetano Juliani

(Membro externo - IG/USP)

Prof. Dr. Bernhard Manfred Buhn

(Membro interno - IG/UnB) 
A grandeza não consiste em receber honras, mas em merecê-las.

(Aristóteles, $350 \mathrm{AC}$ ) 


\section{RESUMO}

O depósito de ouro Tocantinzinho está situado na Província Mineral do Tapajós, a aproximadamente $200 \mathrm{~km}$ ao sul de Itaituba (PA). Trata-se de depósito de ouro em vênulas e disseminado, sem orientação preferencial, em estilo stockwork, hospedado em monzogranito de $\sim 1982 \pm 8 \mathrm{Ma}$, atribuído à suíte intrusiva Creporizão. O ouro associa-se a disseminações de sulfetos, em especial pirita. Diques máficos de composição de basalto cálcio-alcalino, muito alterados, cortam o granito. Diques de composição riolítica cortam as rochas graníticas e o dique máfico, constituindo as manifestações ígneas mais jovens da área. Petrograficamente, o granito apresenta granulação média a grossa e textura alotriomórfica, sendo essencialmente constituído de quartzo, microclínio, plagioclásio $\left(\mathrm{Ab}_{0,88} \mathrm{An}_{0,12}\right)$ e biotita. É uma rocha rica em $\mathrm{SiO}_{2}(72 \%), \mathrm{Al}_{2} \mathrm{O}_{3}(14 \%), \mathrm{K}_{2} \mathrm{O}(5,3 \%)$ e $\mathrm{Na}_{2} \mathrm{O}(3,9 \%)$ e pobre em $\mathrm{Fe}_{2} \mathrm{O}_{3} \mathrm{t}(1,7 \%), \mathrm{MgO}$ $(0,3 \%)$ e $\mathrm{CaO}(0,9 \%)$. Em diagramas de discriminação geotectônica, situa-se predominantemente entre granitos de, ambientes de arcos vulcânicos. O monzogranito foi submetido a 4 estágios de alteração hidrotermal. O estágio inicial, aqui designado de fase pósmagmática precoce, teve início com metassomatismo que provocou alteração do oligoclásio para albita e do ortoclásio para microclínio. A fase seguinte é caracterizada por forte microclinização, representando o estágio de microclinização, e forte cloritização e mineralização, representada por rochas atribuídas ao grupo MAT-I. O terceiro estágio, designado MAT-II, compreende alteração fílica. Nesta fase há maior expressão de sericitização e silicificação, constituindo o principal estágio da mineralização. O estágio final da alteração hidrotermal condiz com o estágio de alteração tardia, na qual houve significativa carbonatação e cloritização tardia. Quimicamente, as variedades alteradas e mineralizadas são muito similares, embora as rochas do grupo MAT-II possuam teores mais elevados de $\mathrm{Fe}_{2} \mathrm{O}_{3}$, $\mathrm{MgO}$ e $\mathrm{CaO}$ e menores conteúdos de $\mathrm{Al}_{2} \mathrm{O}_{3}$ e $\mathrm{K}_{2} \mathrm{O}$. Da mesma forma, os teores médios de $\mathrm{Au}$ (7090,2 ppb), Cu (145 ppm), Pb (145 ppm), Zn (163 ppm), Bi (0,6 ppm) e Cd (1,88 ppm) são superiores aos da fácies MAT-I. Registra-se relação simpatética entre os teores de Au e os de $\mathrm{As}, \mathrm{Zn}$ e $\mathrm{Pb}$. Os sulfetos associados à mineralização são pirita, calcopirita, esfalerita, galena e altaíta, nessa ordem de abundância. A clorita substitui minerais primários ou está presente em vênulas monominerálicas e poliminerálicas associadas, ou não, à mineralização. Análises químicas permitem distinguir as variedades chamosita $\left(\mathrm{X}_{\mathrm{Fe}}=0,60\right)$ e clinocloro $\left(\mathrm{X}_{\mathrm{Fe}}=0,45\right)$, que ocorrem em vênulas (Chl2 e Chl3) ou como resultado da alteração da biotita (Chl1). Estudos de inclusões fluidas revelaram que as inclusões fluidas presentes, em especial em amostras do granito mineralizado do Depósito Tocantinzinho (MAT-I e MAT-II), são aquosas 
e não saturadas. Ocorrem cinco tipos diferentes de inclusões e a maior parte apresenta caráter aquoso bifásico, indicando fluidos de salinidade moderada, com máxima de 20,14 wt.\% de $\mathrm{NaCl}$ eq. e mínima de 0,17 wt.\% de $\mathrm{NaCl}$ eq. Microtermometricamente, as inclusões com maiores valores de $\mathrm{Tf}_{\text {(gelo) }}$ mostram intervalos de $-16{ }^{\circ} \mathrm{C}$ a $-2,5{ }^{\circ} \mathrm{C}$ para inclusões do tipo I, enquanto as do tipo IV apresentam valores de $-0,1{ }^{\circ} \mathrm{C}$ a $-3,9{ }^{\circ} \mathrm{C}$. Th (t) alcançam $432,6{ }^{\circ} \mathrm{C}$ em inclusões do tipo I, e as do tipo IV apresentam $\mathrm{Th}_{(\mathrm{t})}$ mínima de $98,6{ }^{\circ} \mathrm{C}$. O sistema fluido do Depósito Tocantinzinho é interpretado como $\mathrm{H}_{2} \mathrm{O}-\mathrm{NaCl}$. Dados de fluidos hidrotermais e do geotermômetro da clorita mostram que a temperatura de aprisionamento de fluidos mineralizantes é estimada entre $289^{\circ} \mathrm{C}$ a $382{ }^{\circ} \mathrm{C}$, condizente com temperaturas resultantes de mistura de fluidos magmáticos e hidrotermais. A associação do ouro com sulfetos permite inferir que os fluidos continham espécies dissolvidas de enxofre e, sob aquelas condições de temperatura e pressão, o ouro deve ter sido dominantemente transportado como complexos de bissulfeto. A deposição do ouro no Depósito Tocantinzinho pode ter sido devida à mistura de fluido salino precoce quente com água meteórica e/ou de boiling. O transporte do ouro se deu por meio de $\mathrm{AuCl}_{2}^{-}$ou $\mathrm{Au}(\mathrm{HS})_{2}{ }^{-}$, este último fluido sendo responsável pela principal associação de minério reconhecida no Depósito (sericita + quartzo + pirita + ouro). As características petrográficas, químicas e mineralógicas, no que diz respeito ao controle da mineralização e ao estilo de alteração hidrotermal, além de semelhanças com tipos de depósitos relacionados a magmatismo félsico, permitem sugerir que o Depósito Tocantinzinho é semelhante a depósitos do tipo Au Pórfiro. Deve-se, no entanto, aprofundar os estudos para a melhor caracterização das condições físico-químicas da mineralização e entendimento do papel do monzogranito e do dique de composição basáltica como fonte de metais e ligantes. Os dados obtidos, além de contribuir para o melhor entendimento do depósito Tocantinzinho e de depósitos semelhantes na Província Mineral Tapajós, podem ser usados para elaborar e orientar modelos prospectivos na região e em terrenos proterozóicos semelhantes.

Palavras-chave: Província Mineral do Tapajós, ouro, alteração hidrotermal, inclusões fluidas, pórfiro, metalogenia, petrologia. 


\begin{abstract}
The Tocantinzinho gold Deposit is located in the Tapajós Mineral Province about $200 \mathrm{~km}$ south of Itaituba (PA). It is a gold deposit in veins/ veinlets and disseminated, without considerable orientation, comprising stockwork style, hosted in monzogranite of $\sim 1982 \pm 8$ Ma. of the Creporizão Intrusive Suite. Gold is associated with sulphide disseminations, particularly pyrite. Mafic calc-alkaline dykes with basaltic composition, very altered, cut the monzogranite. Dykes of riolitic composition cut the granitic and basaltic rocks, representing the youngest igneous manifestations in the area. Petrographically, the granite has medium to coarse grained, being essentially composed of quartz, microcline, plagioclase $\left(\mathrm{Ab}_{0,88} \mathrm{An}_{0,12}\right)$ and biotite. It is rich in $\mathrm{SiO}_{2}(72 \%), \mathrm{Al}_{2} \mathrm{O}_{3}(14 \%), \mathrm{K}_{2} \mathrm{O}(5.3 \%)$ and $\mathrm{Na}_{2} \mathrm{O}(3.9 \%)$ and has low contents of $\mathrm{Fe}_{2} \mathrm{O}_{3} \mathrm{t}(1.7 \%), \mathrm{MgO}(0.3 \%)$ and $\mathrm{CaO}(0.9 \%)$. In tectonic discrimination diagrams, it lies predominantly in the volcanic arc granite fields. The monzogranite underwent four hydrothermal alteration stages. The initial stage, refered as Early Post-magmatic Stage, began with incipient metasomatism, which caused alteration of oligoclase to albite and of orthoclase to microcline. The next phase is characterized by strong microclinization, chloritization and $\mathrm{Au}$ mineralization, representing the Microclinization Stage, represented by MAT-I rock group. The third stage comprises Phyllic Alteration Stage. At this stage, there is greater expression of sericitization, silicification and gold. It is the main mineralization stage. After that, a significant carbonatization and late chloritization occurred, comprising the Late Alteration Stage. Chemically, altered and mineralized varieties are very similar, although the MAT-II rocks group has higher contents of $\mathrm{Fe}_{2} \mathrm{O}_{3}, \mathrm{MgO}$ and $\mathrm{CaO}$ and lower contents of $\mathrm{Al}_{2} \mathrm{O}_{3}$ and $\mathrm{K}_{2} \mathrm{O}$. Likewise, the average content of $\mathrm{Au}$ (7090.2 ppb) $\mathrm{Cu}$ (145 ppm), $\mathrm{Pb}$ (145 ppm), zinc (163 ppm), Bi (0.6 ppm) and Cd (1.88 ppm) is higher than in the MAT-I facies. It is observed sympathetic relationship between $\mathrm{Au}$ and $\mathrm{As}, \mathrm{Zn}$ and $\mathrm{Pb}$ contents. The sulphides related to mineralization are pyrite, chalcopyrite, sphalerite, galena and altaite, in that order of abundance. Chlorite replaces primary minerals or is in veinlets associated or not to mineralization. Chemical analysis allow distinguishing chamosite $(\mathrm{XFe}=0.60)$ and clinochlore $(\mathrm{XFe}=0.45)$ varieties, which occur in veinlets $(\mathrm{Chl} 2$ and $\mathrm{Chl} 3)$ or as a result of biotite alteration (CHL1). Fluid inclusion studies revealed that the flluids present in mineralized granite samples of Tocantinzinho deposit (MAT-I and MAT-II) are not saturated.
\end{abstract}


Five different types of fluid inclusions are described. They are two-phase aqueous fluid inclusions, indicating moderate salinity fluid with a maximum of $20.14 \mathrm{wt} \% \mathrm{NaCl}$ and a minimum of $0.17 \mathrm{wt} \% \mathrm{NaCl}$. Inclusions with higher Tm (ice) values show ranges from $-16^{\circ} \mathrm{C}$ to $-2.5{ }^{\circ} \mathrm{C}$ for type I, while type IV inclusions have $\mathrm{Tm}$ (ice) of $-0.1{ }^{\circ} \mathrm{C}$ to $-3.9{ }^{\circ} \mathrm{C}$. Th (t) reaches $432.6{ }^{\circ} \mathrm{C}$ in inclusions of type I, while type IV have the minimum Th (t) of $98.6{ }^{\circ} \mathrm{C}$. The whole system was interpreted as $\mathrm{H}_{2} \mathrm{O}-\mathrm{NaCl}$. Based on chlorite geothermometer, the temperature mineralizing fluids are estimated to lie near between $289^{\circ} \mathrm{C}$ to $382{ }^{\circ} \mathrm{C}$, consistent with temperatures resulting from mixing of magmatic and hydrothermal fluids. The association between sulfides and gold can help suggest that the fluids contained dissolved sulfur species. Under such temperature and pressure conditions, the gold should have been transported predominantly as disulfide complexes. The gold deposition in the Tocantinzinho deposit may have resulted from hot early saline fluid mixture with meteoric water and/or boiling. Gold transport took place through $\mathrm{AuCl}_{2^{-}}$or $\mathrm{Au}(\mathrm{HS})_{2^{-}}$, the latter fluid being probably responsible for the main ore association recognized in the deposit (quartz + sericite + pyrite + gold). Petrographic, chemical and mineralogical characteristics, with regard to the control of mineralization and hydrothermal alteration style, in addition to the similarities with different types of deposits related to felsic magmatic, allow suggest that the Tocantizinho Deposit is similar to porphyry gold deposit types. However, further studies are needed to better characterize the physical and chemical conditions of the mineralization and to understand the role of the monzogranite and the basalt dykes as source of metals and ligands. The obtained data, besides contributing to a better understanding of the Tocantinzinho deposit and of similar deposits in the Tapajós Mineral Province, can be used to elaborate and guide prospective models in the region and in similar Proterozoic terrains.

Keywords: Tapajós Mineral Province, gold, hydrothermal alteration, fluid inclusions, porphyry, metallogeny, petrology. 


\section{LISTA DE ILUSTRAÇÕES}

FIGURA 1: MAPA DE LOCALIZAÇÃO DO DEPÓSITO TOCANTINZINHO (VILlAS ET AL. 2013)

FIGURA 2: PROVÍNCIAS GEOCRONOLÓGICAS COMPARTIMENTADAS EM DOMÍNIOS TECTÔNICOS ESTRATIGRÁFICOS DO CRÁtON AMAZÔNICO (SANTOS ET AL. 2000).

FIGURA 3: LOCALIZAÇÃO GEOGRÁFICA DOS QUATRO DOMÍNIOS REFERENTES AO CINTURÃO OROGÊNICO TAPAJÓS - PARIMA, COM DESTAQUE EM PONTILHADO PARA O DOMÍNIO TAPAJÓS (SANTOS ET AL. 2004).

FIGURA 4: MAPA GEOLÓGICO DO DOMÍNIO TAPAJÓS INDICANDO ALGUNS DOS PRINCIPAIS DEPÓSITOS DE OURO, INCLUINDO O DEPÓSITO TOCANTINZINHO (VASQUEZ ET AL. 2008B).

Figura 5: MAPA GEOLÓGICO DO DEPÓSITO TOCANTINZINHO (MODIFICADO DE JURAS ET AL. 2011).

Figura 6: A) MAPA GEOLÓGICO do DEPÓsito TOCANTINZINHO, COM DESTAQUE PARA A SEÇÃo GEOLÓGICA SW 315NE. A estrela corresponde ao furo TOC-05-24 (Adaptado de Mello 2007); B) SEÇÃO GEOLÓGICA 315NE, FURO TOC-05-24 (MODIFICADO DE JURAS ET AL. 2011).

Figura 7 PERfil Litológico DO FURO DE SONDAGEM TOC-05-24 REPRESENTATIVO DO DEPÓSITO TOCANTINZINHO MOSTRANDO ALGUMAS VARIEDADES DE ROCHAS GRANÍTICAS: 1) GRANITO NÃO ALTERADO; 2) AMOSTRA DO DIQUE FÉLSICO; 3)VARIEDADE GRANÍTICA ALTERADA E MINERALIZADA DO DEPÓSITO TOCANTINZINHO; 4) VARIEDADE DE ROCHA ALTERADA E MINERALIZADA DO DEPÓSITO; 5) DIQUE MÁFICO; 6) VARIEDADE GRANÍTICA ALTERADA DO DEPÓSITO TOCANTINZINHO.

Figura 8: Foto dE AMOSTRA DE MÃo E FOTOMICROGRAFIAS DO GRANITO. A) ASPECTO MESOSCÓPICO DO MONZOGRANITO; B) FOTOMICROGRAFIA MOSTRANDO A TEXTURA PRINCIPAL DA AMOSTRA (NX; 2,5X); C) ASSOCIAÇÃO ENTRE: QTZ + PLG +FK + BT (NX; 2,5X); D) ASSOCIAÇÃO DE MINERAIS OPACOS PRIMÁRIOS: TITANITA, ZIRCÃO E MAGNETITA (NX; 5X).

Figura 9: A) Fotografia dE AMOSTRA DE MÃo DO DIQUE FÉlSiCO E SUAS VÊNULAS PREENCHIDAS POR QUARTZO, CLORITA E CARBONATO, ESPECIALMENTE (AMOSTRA 11_24); B) FOTOMICROGRAFIA DA LÂMINA DELGADA EM LUZ TRANSMITIDA MOSTRANDO A TRAMA PRINCIPAL DA ROCHA COM GRÃOS DE QUARTZO, PLAGIOCLÁSIO E FELDSPATO POTÁSSICO E CRISTAIS DE PIRITA (NX; 2,5X); C) TEXTURA FINA ENCONTRADA, LOCALMENTE, NA ROCHA (QTZ + Plg; NX, 5X); D) CRISTAL DE BIOTITA ALTERADO PARA ClORITA ASSOCIADO A CRISTAIS DE ZIRCÃO, MAGNETITA E PIRITA (NX; 5X).

FIGURA 10: FOTOMICROGRAFIA DE UMA DAS ZONAS DE ALTERAÇÃO DO DIQUE FÉLSICO. VÊNULAS DE QUARTZO, CARBONATO E MICA BRANCA CORTANDO A MASSA DE AGLOMERAÇÃO DE GRÃOS DE QUARTZO, PLAGIOCLÁSIO E OPACOS.

Figura 11: A) AMOSTRA DE MÃo DO DIQUE MÁfiCO (FURO DE SONDAGEM TOC-45-24); B E C) FOTOMICROGRAFIAS MOSTRANDO A TEXTURA PRINCIPAL DA AMOSTRA COM CARBONATO E CLORITA NA MATRIZ (N//, NX; 2,5X).

FIGURA 12: FOTOMICROGRAFIAS MOSTRANDO ALGUNS PADRÕES DAS DIFERENTES ALTERAÇÕES HIDROTERMAIS QUE OCORREM NO DEPÓSITO TOCANTINZINHO: A) VÊNULA DE QUARTZO SENDO TRUNCADA POR VÊNULAS DE CARBONATO (LÂMINA 36-24-14); B) MASSA/ AGLOMERADO RESULTANTE DA SILICIFICAÇÃO CONTENDO GRANDE QUANTIDADE DE PIRITA (LÂMINA 26-24); C) VÊNULA DE QUARTZO TRUNCADA POR VÊNULA CONTENDO SERICITA E SERICITA ENVOLVENDO PARTE DA VÊNULA DE QUARTZO, MOSTRANDO-SE 
POSTERIOR (LÂMINA 19-24); D) PADRÃO STOCKWORK EM CRISTAL DE FELDSPATO, SERICITIZAÇÃO INTENSA PREENCHENDO AS VÊNULAS QUE RECORTAM OS CRISTAIS E AGLOMERADOS DE SULFETOS (PIRITA + CALCOPIRITA) (LÂMINA 8-57); E) CLORITA MARROM PREENCHENDO VÊNULA TRUNCANDO PORÇÃO SILICIFICADA (LÂMINA 19-48); F) MASSA DE RUTILO E CLORITA EM VÊNULAS (LÂMINA 8-48). 44

Figura 13: Fotomicrografias dAS FASES DE ALTERAÇÃO PRECOCE EM CRISTAIS DE PLAGIOCLÁSIO E FELDSPATO POTÁSSICO: A) CRISTAL DE PLAGIOCLÁSIO ZONADO, COM SERICITIZAÇÃO FRACA; B) CRISTAL DE MICROCLÍNIO COM INCLUSÕES DE QUARTZO; C) CRISTAIS DE BIOTITA JÁ APRESENTANDO COMPOSIÇÃO DE CLORITA JUNTO COM TITANITA, PIRITA E ZIRCÃO; D) CRISTAIS DE QUARTZO DA PRIMEIRA GERAÇÃO. .. 45

FIGURA 14: A) AMOSTRA REPRESENTATIVA DO GRUPO MAT-I MOSTRANDO CRISTAIS DE FELDSPATO POTÁSSICO SUBSTITUÍDOS POR MICROCLÍNIO E GRÃOS DE QUARTZO LEITOSO ASSOCIADOS; B) AMOSTRA DO GRUPO MAT-II. SERICITIZAÇÃO E SILICIFICAÇÃO INTENSAS SÃO OS PRINCIPAIS PROCESSOS HIDROTERMAIS DESSAS ROCHAS. 45

FIGURA 15: A) FOTOMICROGRAFIA MOSTRANDO CRISTAIS DE PLAGIOCLÁSIO FRATURADOS E MICROCLÍNIO EM MASSA DE ALTERAÇÃO; B) MICROCLÍNIO COM INCLUSÕES DE QUARTZO; C) BIOTITA CLORITIZADA, LEVEMENTE ORIENTADA, E TITANITA; D) CRISTAL DE PLAGIOCLÁSIO COM NÚCLEO SERICITIZADO E BORDAS PRESERVADAS EM PARAGÊNESE COM GRÃOS DE QUARTZO.

FIGURA 16: FOTOMICROGRAFIA DE AMOSTRAS HIDROTERMALIZADAS COM NICÓIS CRUZADOS: A) CRISTAL DE PLAGIOCLÁSIO ALTERADO PARA CARBONATO; B) PLAGIOCLÁSIO SERICITIZADO EM PARAGÊNESE COM QUARTZO1; C) TEXTURA HIPIDIOMÓRFICA COM CRISTAIS DE PLAGIOCLÁSIO SERICITIZADOS E VÊNULAS DE CLORITA E CARBONATO; AGLOMERADOS OU MASSA DE QUARTZO RECRISTALIZADO E CRISTAIS DE PLAGIOCLÁSIO, EM PARAGÊNESE COM CRISTAIS DE PIRITA; E) AGLOMERADO/ MASSA DE CRISTAIS DE PLAGIOCLÁSIO E QUARTZO ASSOCIADOS A SULFETOS; F) SERICITIZAÇÃO INTENSA EM PARAGÊNESE COM SULFETOS (PIRITA + CALCOPIRITA + MAGNETITA) E OPACOS (ZIRCÃO). 50

Figura 17: DiAgRAMA DE ÍNDICE DE SATURAÇÃO EM ALUMinA (ISA) ONDE A/CNK $=\mathrm{AL}_{2} \mathrm{O}_{3} /\left(\mathrm{CAO}+\mathrm{NA}_{2} \mathrm{O}+\right.$ $\mathrm{K}_{2} \mathrm{O}$ ). A AMOSTRA DO GRANITO (•), ASSIM COMO A MAIOR PARTE DAS AMOSTRAS COM POUCO HIDROTERMALIZADAS E O DIQUE FÉLSICO, LOCALIZA-SE ENTRE O INTERVALO DE 1,1 .............................54

Figura 18: Diagrama de AlCALINIDAdE DE SHAND (1943) MOSTRANDO O CARÁter PERALUMinOSO A METALUMINOSO DAS AMOSTRAS MAIS PRESERVADAS DO DEPÓSITO TOCANTINZINHO. .54

Figura 19: DiAgRAMA DE NORMALIZAÇÃO A GRANitos DE CADEIAS OCEÂNICAS (ORG) DE AMOSTRAS GRANÍTICAS DO DEPÓSITO TOCANTINZINHO (A) E PADRÃO PARA GRANITOS DE ARCO VULCÂNICO (B), COM

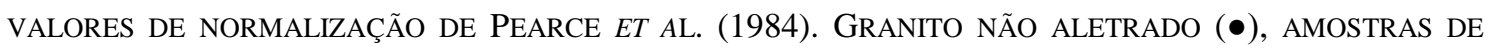

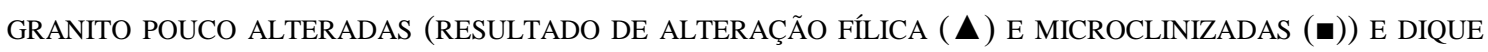
FÉLSICO (X).

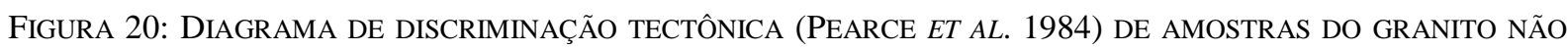
ALTERADO (•) JUNTAMENTE COM AMOSTRAS POUCO ALTERADAS DE GRANITOS HIDROTERMALIZADOS (MICROCLINIZADAS (ם) E RESULTADO DA ALTERAÇÃo FÍlICA( $\mathbf{\Delta})$ ), ALÉM DA AMOSTRA DO DIQUE FÉLSICO (X). Post-COLG= PÓS-COLISIONAL; ORG= CADEIA MESO-OCEÂNICA; SYN-COLG= SIN-COLISIONAL;

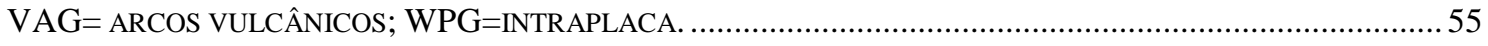

FIGURA 21: PADRÃO DE DISTRIBUIÇÃO, NO GRANITO, DOS ETR NORMALIZADOS AO CONDRITO (NAKAMURA 1974), MOSTRANDO A ANOMALIA NEGATIVA DO EU E O PADRÃO SEMELHANTE ENTRE AS AMOSTRAS DOS 


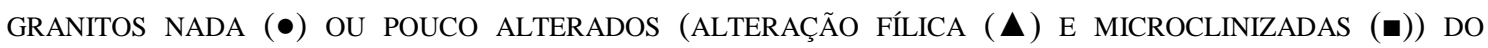

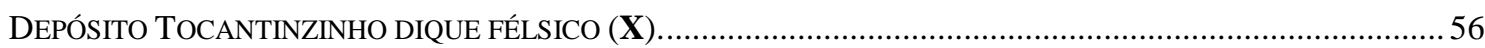

FIGURA 22: DiAGRAMA DE VARIAÇÃO DO TIPO HARKER PARA ELEMENTOS MAIORES DAS AMOSTRAS DO DIQUE

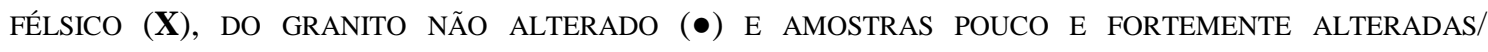
HIDROTERMALIZADAS POR MICROCLINIZAÇÃO (घ) E ALTERADAS POR ALTERAÇÃO FÍLICA $(\boldsymbol{\Delta})$....................58

FIGURA 23: DiAGRAMA DE DiSTRIBUIÇÃO DO TIPO HARKER PARA OS ELEMENTOS TRAÇO (PPM) VS.SIO2(WT\%), DO DIQUE FÉLSICO $(\mathrm{X})$ AMOSTRAS DO GRANITO NÃO ALTERADO $(\bullet)$ E AMOSTRAS DO GRANITO POUCO E MUITO ALTERADOS/ HIDROTERMALIZADOS ( $\boldsymbol{\Delta}$ E $\boldsymbol{\square})$ DO DEPÓSITO TOCANTINZINHO. .59

Figura 24: Diagrama de AlCALINIDAde DE Shand (1943) MOSTRANDO O CARÁter PERALUMinOSO E METALUMINOSO DE AMOSTRAS DO DEPÓSITO TOCANTINZINHO: 1) PERALUMINOSO: GRANITO NÃO ALTERADO; AMOSTRAS DE GRANITO POUCO HIDROTERMALIZADOS (10_48 A, 4_56, 4_48 A, 4_48B, 27_24, 23_24, 37_24) E GRANITO MUITO HIDROTERMALIZADO (7_27); 2) METALUMINOSO: DIQUE FÉLSICO (X); AMOSTRAS DO GRANITO POUCO ALTERADO (18_24, 10_48B, 25_24) E DO GRANITO FORTEMENTE HIDROTERMALIZADO (9_48, 19_48, 54_24, 55_24).

FIGURA 25: DIAGRAMA DE VARIAÇÃO DO TIPO HARKER MOSTRANDO O COMPORTAMENTO DOS PRINCIPAIS ELEMENTOS-TRAÇO DAS AMOSTRAS ALTERADAS/ HIDROTERMALIZADAS (MAT-I E MAT-II) DO DEPÓSITO TOCANTINZINHO. 62

FIGURA 26: PADRÕES DE DISTRIBUIÇÃO DOS ELEMENTOS TERRAS RARAS REFERENTES AOS MONZOGRANITOS ALTERADOS NORMALIZADAS AO CONDRITO (NAKAMURA 1974). A) AS AMOSTRAS DE GRANITO MICROCLINIZADO; B) AMOSTRAS RESULTADAS DE ALTERAÇÃO FÍLICA.

Figura 27: AMOSTRAS DE diQUE MÁFICO (*) E FÉLSICO (X) NO DIAGRAMA TAS DE LE BAS ET AL. (1992): DIQUE MÁFICO APRESENTA COMPOSIÇÃO BASÁLTICA E O DIQUE FÉLSICO, COMPOSIÇÃO RIOLÍTICA. 65

Figura 28: Diagrama de PEARCE \& CANN (1973) PARA DisCRIMINAÇÃo DE AMBIENTE TECTÔNICO. A AMOSTRA DO DIQUE MÁFICO SE POSICIONOU NO CAMPO DOS BASALTOS CALCIO-ALCALINOS. IAT: THOLEÍTO DE ARCO DE ILHA: MORB: BASALTO DE CADEIAS MESO-OCEÂNICAS; CAB: BASALTO CÁlCIO-ALCALINO; WPB: BASALTO INTRA-PLACA.

FIGURA 29: DiAgRAMA DE DISTRIBUIÇÃO DE ELEMENTOS PARA DIQUES MÁFICOS NORMALIZADOS AO MANTO PRIMORDIAL (VALORES DE NORMALIZAÇÃO PROPOSTOS POR SUN \& MCDONOUGH 1989).

FIGURA 30: PADRÃO DE ElEMENTOS TERRAS RARAS PARA O DIQUE MÁFICO, NORMALIZADO AO CONDRITO (NAKAMURA 1974) 66

Figura 31: Fotomicrografias de amostras de Clorita anAliSAdas: A) Clorita do tiPO 1 (CHL1), RESULTADO DA ALTERAÇÃO DA BIOTITA; B) CHL2, EM PARAGÊNESE COM SULFETOS (PIRITA E ESFALERITA) E SILICA;B-1) FOTO ANTERIOR, NICÓIS X; C) CHL3 FORMANDO MASSAS/ VÊNULAS MONOMINERÁLICAS.... 72

FIGURA 32: DiAgRAMA DE COMPOSIÇÃO QUÍMICA FE/ (FE+MG) VS. AL- ${ }^{\text {IV }}$ DOS TIPOS DE CLORITAS DO DEPÓSITO. A LINHA QUE MARCA 0,50 NO EIXO HORIZONTAL REPRESENTA O LIMITE DOS CAMPOS ENTRE OS CRISTAIS DE CLORITA DE COMPOSIÇÃO CLINOCLORO (BAIXO DE 0,50), ENCONTRADAS EM AMOSTRAS MENOS ALTERADAS DO DEPÓSITO E CHAMOSITA (ACIMA DE 0,50), ENCONTRADAS NAS PORÇÕES MAIS ALTERADAS E EVOLUÍDAS DO DEPÓSITO TOCANTINZINHO. 
FIGURA 33: FotOMICROGRAFIA DE CRISTAL DE TITANITA ASSOCIADO À MASSA DE ALTERAÇÃO E EM CONTATO COM PLAGIOCLÁSIO (AMOSTRA 55-24); B) FOTOMICROGRAFIA DE CRISTAIS DO GRUPO DO RUTILO INSERIDOS EM MASSA DE CHL (AMOSTRA 19-48 A). .78

FIGURA 34: IMAGENS DE ELÉTRONS RETROESPALHADOS DE ANÁLISE DE MICROSSONDA ELETRÔNICA MOSTRANDO AS PRINCIPAIS OCORRÊNCIAS DE OURO NATIVO NO DEPÓSITO TOCANTINZINHO: A) OURO LIVRE EM MASSA DE SILICIFICAÇÃO E VEIO DE PIRITA (AMOSTRA S18_24); B) OURO EM FRATURA NA PIRITA (AMOSTRA 8_57); C) OURO INCLUSO E PREENCHENDO FRATURAS DE PIRITA (AMOSTRA 8_57); D) OURO INCLUSO EM PIRITA.

FIGURA 35: FOTOMICROGRAFIAS DE AMOSTRAS SULFETADAS E MINERALIZADAS DO DEPÓSITO TOCANTINZINHO: A/ B/C) PARAGÊNESE DE Py + Au, DESTAque PARA O CRISTAL DE PIRITA COM POUCAS A NENHUMA INCLUSÃO DE SULFETOS. EM A E C O AU ESTÁ INCLUSO EM FRATURAS E EM B ELE ESTÁ LIVRE, EM CRISTAL DE QTZ; D/E/F) PY EM PARAGÊNESE COM DEMAIS SULFETOS; EM D A PY APRESENTA INTERCRESCIMENTO/SUBSTITUIÇÃO POR ESFALERITA, ALÉM DO AU INCLUSO EM PY; EM E HÁ O INTERCRESCIMENTO/SUBSTITUIÇÃO DA CALCOPIRITA E ESFALERITA. EM D TEM-SE CRISTAL DE PIRITA SOFRENDO SUBSTITUIÇÃO/ INTERCRESCIMENTO POR ESFALERITA, ALÉM DE CCP E ALT PREENCHENDO FRATURAS DA PY; G) GRÃOS DE ESFALERITA (SP), CALCOPIRITA (CCP) E GALENA (GN) (AMOSTRA 18_24); H) ASSOCIAÇÃo de PIRITA (Py), SP E OURO (Au) (AMOSTRA S18_24); PARAGDE Py, SP E Alt (TEluRETO DE CHUMBO-TEPB) (AMOSTRA S18_24).

FIGURA 36: FOTOMICROGRAFIAS DE AMOSTRAS DE QUARTZO SELECIONADAS PARA O ESTUDO DE INCLUSÕES FLUIDAS. A) QTZ1 MOSTRANDO OS CONTATOS POLIGONAIS EXISTENTES NOS GRÃOS; B) QTZ2 FORTEMENTE FRATURADO E INCLUSO POR MATERIAL DE ALTERAÇÃO HIDROTERMAL (SERICITA + CLORITA); C) QTZ2 ENVOLTO POR MINERAIS OPACOS, DENTRE ELES A PIRITA (PY); D) QTZ1: CONTORNOS POLIGONAIS E GRÃO POUCO ALTERADO.

FIGURA 37: FotOMICROGRAFIAS MOSTRANDO OS DIFERENTES TIPOS DE INCLUSÕES FLUIDAS: A, B E C= TIPO I; D $=$ TIPOS II E V; E = TIPO III; F = TIPO IV.

FIGURA 38: HiSTOGRAMAS DE VARIAÇÃO DE TEMPERATURAS DE FUSÃO DO GELO (TF(GELO)) VS. FREQUÊNCIA DOS QUATRO PRINCIPAIS TIPOS DE INCLUSÕES FLUIDAS DO DEPÓSITO TOCANTINZINHO...... 102

Figura 39: Histogramas de TEMPERATURA DE hOMOGENEIZAÇÃO TOTAL (TH (T)) VS. FREQUÊNCIA, EM INCLUSÕES FLUIDAS PRIMÁRIAS (GRÁFICOS A, B E C) E SECUNDÁRIAS (GRÁFICO D). 103

Figura 40: GRÁficos de Plotagem REPRESENTANdo A TEMPERATURA DE HOMOGENEIZAÇÃO (TH (T) VS. SALINIDADE DE INCLUSÕES FLUIDAS PRIMÁRIAS (A, B E C) E SECUNDÁRIAS (D).

FIGURA 41: GRÁFICO MOSTRANDO A RELAÇÃO ENTRE TEMPERATURA DE HOMOGENEIZAÇÃO TOTAL VS. CÁLCULO DA DENSIDADE DE INCLUSÕES FLUIDAS DOS TIPOS PRIMÁRIAS (GRÁFICOS A, B E C), SECUNDÁRIAS (D). . 105

FIGURA 42: DiAgramas dE VARIAÇÃO: A) TEMPERATURA $\left(\mathrm{T}^{\circ} \mathrm{C}\right)$ VS. COMPOSIÇÃO FERROMAGNESIANA $\left(\mathrm{FE}^{+2} /\right.$

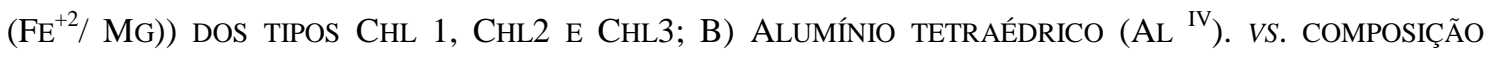
FERROMAGNESIANA $\left(\mathrm{FE}^{+2} /\left(\mathrm{FE}^{+2} / \mathrm{MG}\right)\right)$. 108

Figura 43: DiAgRAMA DE VARIAÇÃO DE ElEMENTOS NORMALIZAdOS AO MANTO PRIMORDIAL (SUN \& MCDONOUGH 1989) DAS AMOSTRAS DE GRANITO NÃO ALTERAdO (•), GRANITOS POUCO ALTERADOS

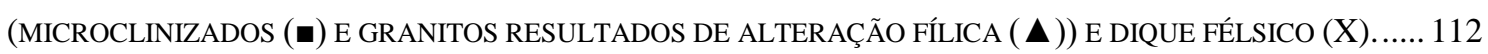




\section{LISTA DE TABELAS}

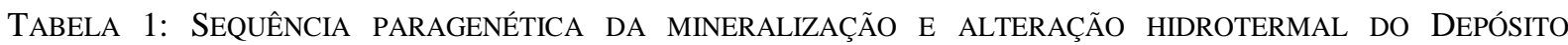

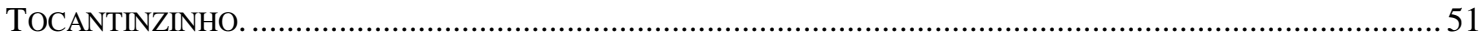

TABELA 2: ANÁLISE DE ROCHA TOTAL REPRESENTATIVA DOS ELEMENTOS MAIORES E TRAÇOS. ...........................67

TABELA 3: ANÁLISES OBTIDAS A PARTIR DE DADOS DE MICROSSONDA ELETRÔNICA DE CLORITAS........................73

TABELA 4: DADOS DE ANÁLISE QUÍMICA OBTIDOS POR MICROSSONDA ELETRÔNICA DE MUSCOVITA..................... 76

TABELA 5: DADOS DE ANÁLISE DE MICROSSONDA ELETRÔNICA DE RUTILO E TITANITA....................................... 78

TABEla 6: Resultados REPRESENTATIVOS DE ANÁLISE DE MICROSSONDA ELETRÔNICA EM MINERAIS DE ESFALERITA, PIRITA, GALENA E ALTAÍTA.

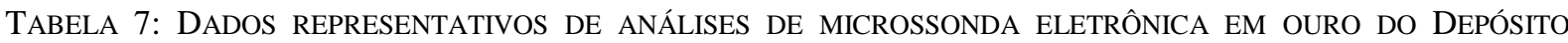

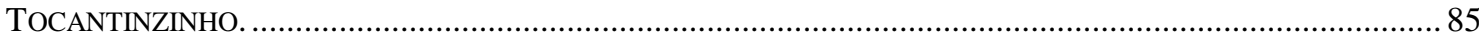

TABELA 8: RESUMO DOS DADOS DAS AMOSTRAS SELECIONADAS PARA O ESTUDO DE INCLUSÕES FLUIDAS. ...........88

TABEla 9: DADOS PETROGRÁFICOS E MICROTERMOMÉTRICOS DOS TIPOS DE INCLUSÕES FLUIDAS DO DEPÓSITO TOCANTINZINHO.

TABELA 10: OS PRINCIPAIS DADOS MICROTERMOMÉTRICOS DAS INCLUSÕES FLUIDAS ANALISADAS CORRESPONDENTES AOS TIPOS I, II, III E IV DO DEPÓSITO TOCANTINZINHO .95

TABELA 11: TEMPE 108

TABELA 12 TABELA COM AS PRINCIPAIS CARACTERÍSTICAS DO DEPÓSITO TOCANTINZINHO EM COMPARAÇÃO COM DEPÓSITOS DE OURO PÓRFIRO E DEPÓSITOS DO TIPO REDUCED-INTRUSION-RELATED-GOLD SISTEMS (RIRGIS). OS PARÂMETROS DO DEPÓSITO DE OURO PÓRFIRO SÃO EMBASADOS EM SILLITOE (2000) E SINCLAIR (2007); OS PARÂMETROS DOS RIRGIS ESTÃO DE ACORDO COM HART (2007). 


\section{SUMÁRIO}

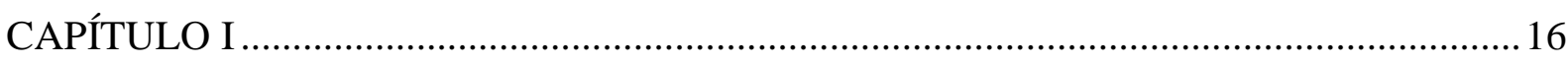

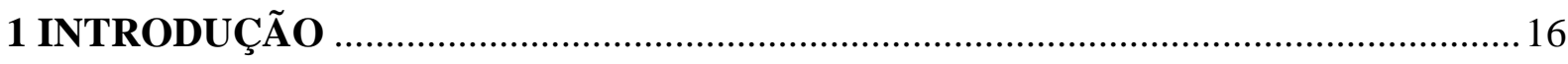

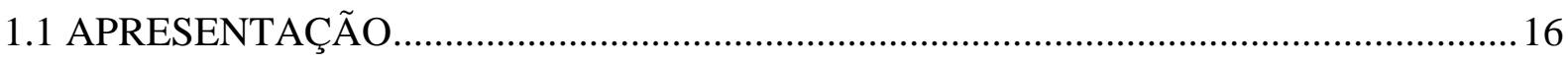

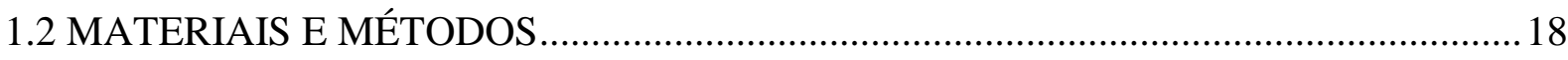

1.2.1 Campanhas de campo e amostragem .................................................................................... 18

1.2.2 Seleção e tratamento das amostras ........................................................................................18

1.2.3 Análises químicas........................................................................................................................18

1.2.4 Microssonda Eletrônica .............................................................................................................19

1.2.5 Inclusões fluidas................................................................................................................................19

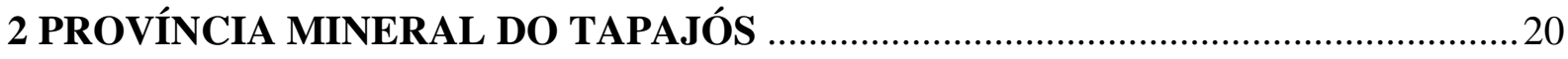

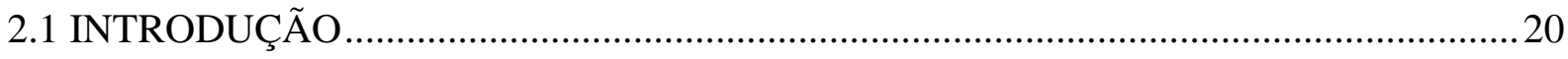

2.2 PRINCIPAIS EVENTOS E LITOESTRATIGRAFIA ……………………………….....21

2.2.1 Associação de Embasamento ................................................................................................21

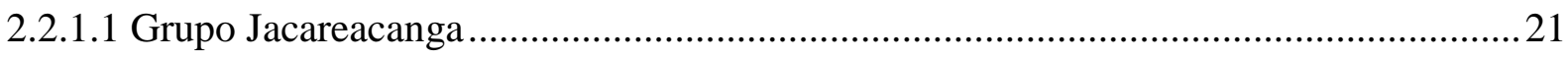

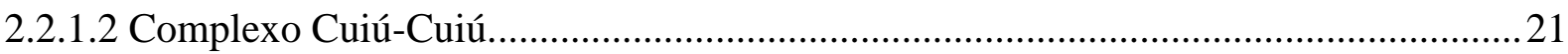

2.2.2 Vulcano-plutonismo Paleoproterozóio (Orosiriano) ........................................................22

2.2.2.1 Formação Vila Riozinho.............................................................................................22

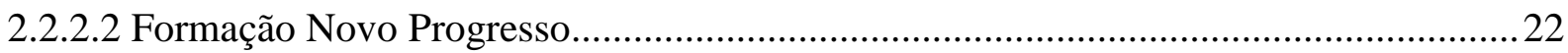

2.2.2.3 Suíte Intrusiva Creporizão ………………………………………………………....22

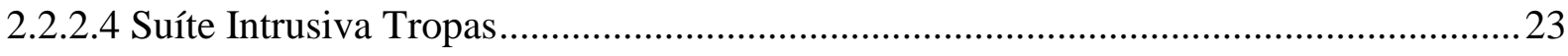

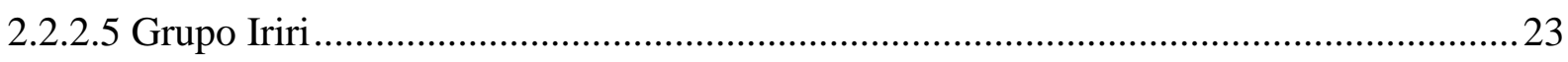

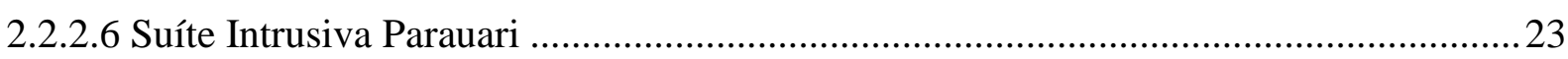

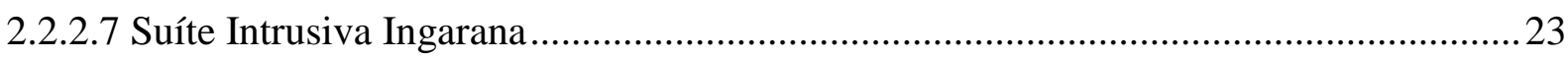

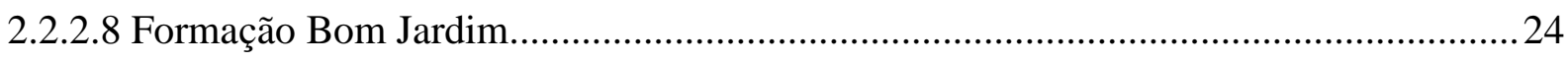

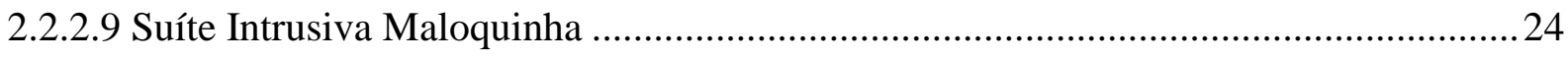

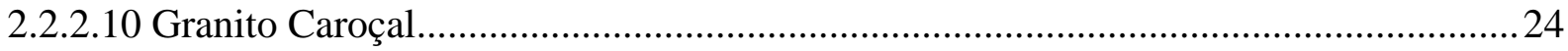

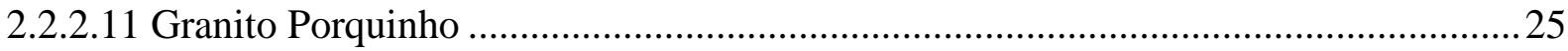


2.2.2.12 Formação Buiuçu 25

2.2.3.1 Diabásio Crepori 25

2.2.3.2 Suíte Intrusiva Cachoeira Seca 25

CAPÍTULO II: Geologia, petrografia e alteração hidrotermal do Depósito Tocantinzinho .... 30

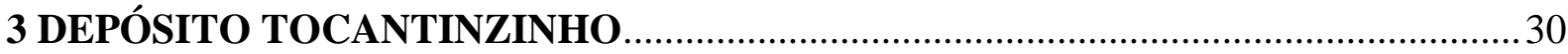

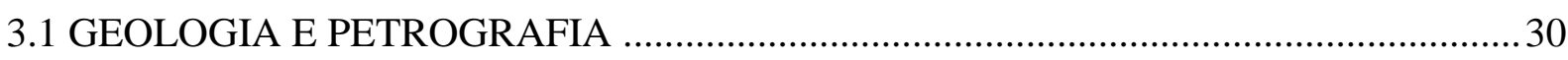

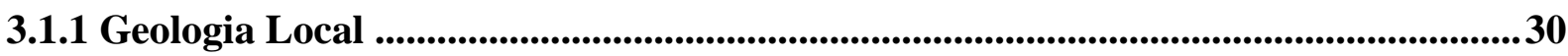

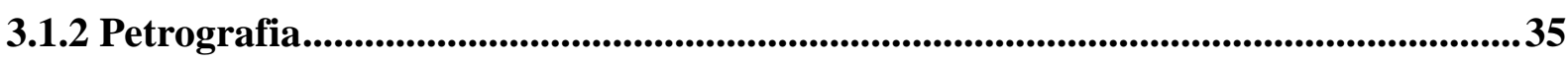

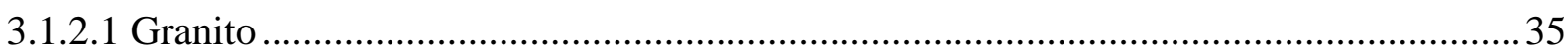

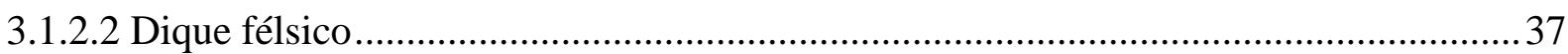

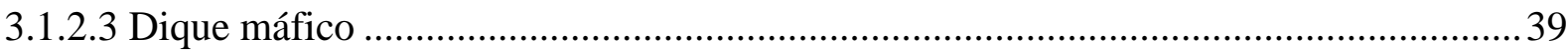

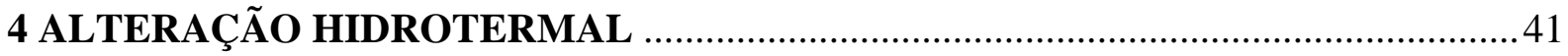

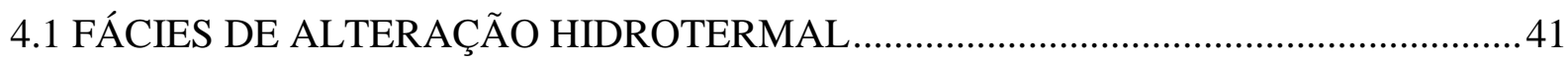

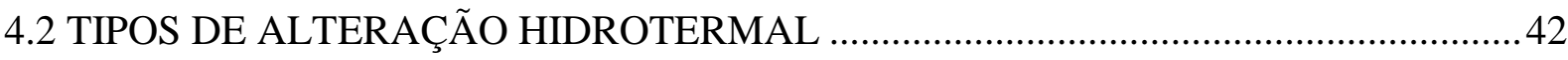

4.3 FASES/ ESTÁGIOS DA ALTERAÇÃO HIDROTERMAL............................................46

CAPÍTULO III: Caracterização geoquímica e mineralógica das rochas do Depósito

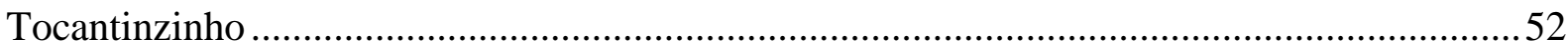

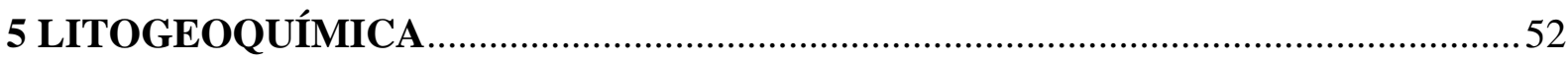

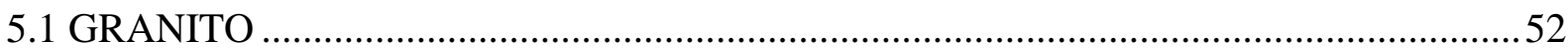

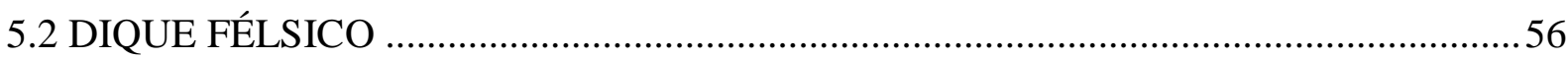

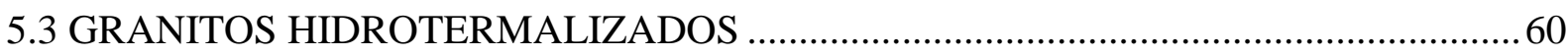

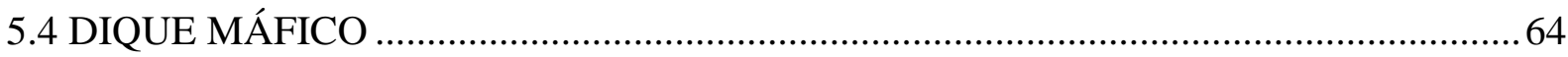

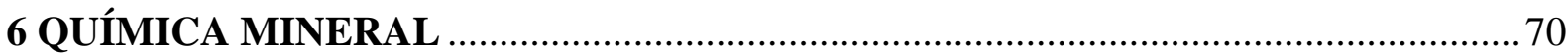

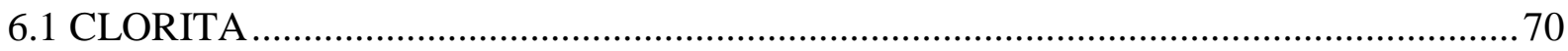

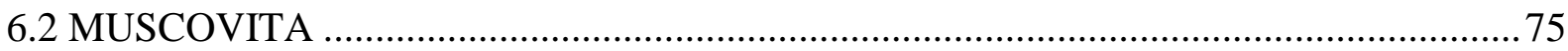

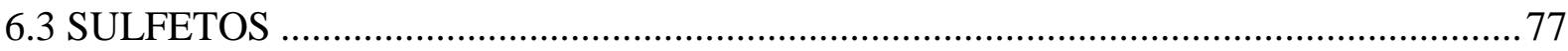

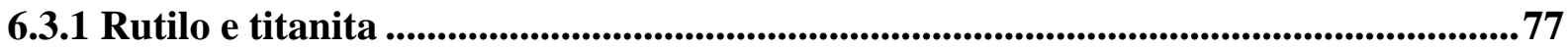




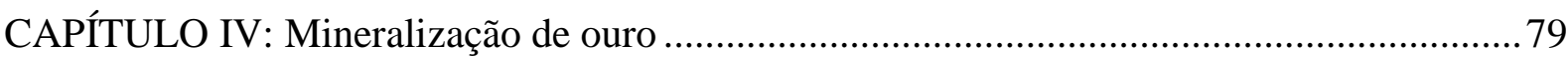

7 MINERALOGIA DO OURO E MINERAIS ASSOCIADOS …................................ 79

7.1 QUÍMICA E DISTRIBUIÇÃO DO OURO NO DEPÓSITO TOCANTINZINHO ..........82

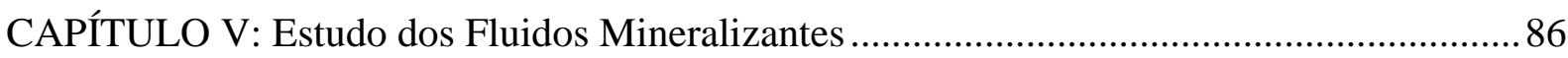

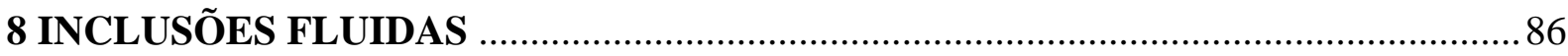

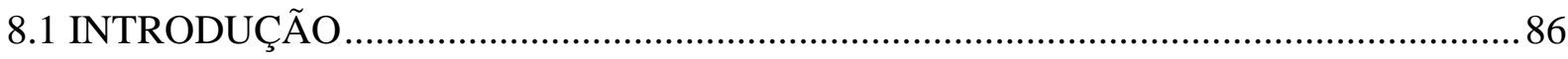

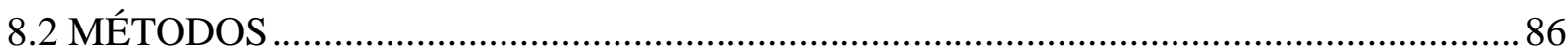

8.3 PETROGRAFIA E DADOS MICROTERMOMÉTRICOS ............................................8 87

8.3.1 Interpretação dos dados de inclusões fluidas ....................................................99

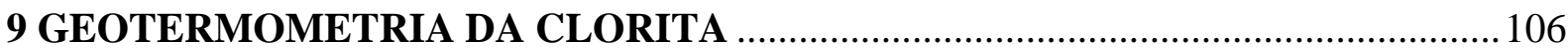

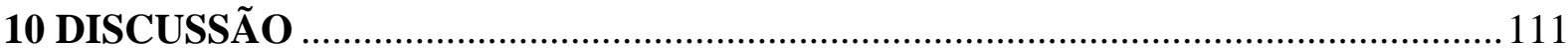

10.1 PETOGRAFIA E CARACTERIZAÇÃO LITOGEOQUÍMICA DO MONZOGRANITO E DIQUES

10.2 SISTEMA HIDROTERMAL FORMADOR DA MINERALIZAÇÃO DO DEPÓSITO

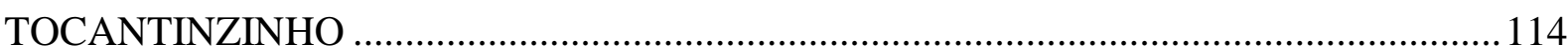

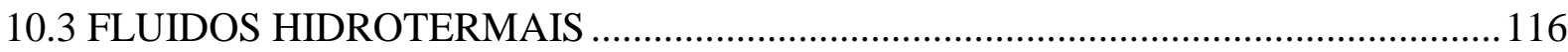

10.4 MINERALIZAÇÃO DO OURO: FONTE, TRANSPORTE E DEPOSIÇÃO..............117

10.5 MODELO GENÉTICO DO DEPÓSITO TOCANTINZINHO ....................................119

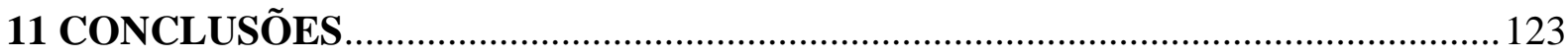

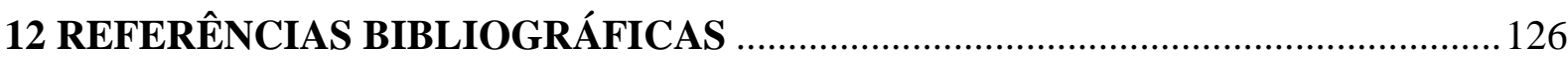




\section{CAPÍTULO I}

\section{INTRODUÇÃO}

\subsection{APRESENTAÇÃO}

O depósito Tocantinzinho está localizado a cerca de $200 \mathrm{~km}$ ao sul da cidade de Itaituba, região sudoeste do Estado do Pará (figura 1). Fica na parte central da Província Mineral do Tapajós (PMT). É um depósito de ouro, com padrão stockwork e apresenta grande influência de alteração hidrotermal. A litologia local é considerada vasta: sienogranito, monzogranito, monzonito, quartzo sienito, tonalito, além de diques de composição andesítica e riolítica (Mello 2007).

A Província está localizada na porção central do Cráton Amazônico, abrangendo o SW do Pará e parte do SE do Amazonas, cobrindo uma área de cerca de $80.650 \mathrm{~km}^{2}$ (Coutinho 2008). Faz parte da província geocronológica Ventuari-Tapajós (Tassinari \& Macambira 1999) ou cinturão orogênico Parima-Tapajós (Santos et al. 2000), de idade paleoproterozóica.

O conhecimento geológico da Província foi incrementado a partir dos programas de mapeamento geológico executados pelo DNPM e CPRM-Serviço Geológico do Brasil, além de trabalhos acadêmicos desenvolvidos no âmbito de universidades e instituições de pesquisa, os quais passaram a dar destaque para essa região do Brasil (Dreher et al. 1998, Faraco et al. 1996, 1997, Klein et al. 2002, Jacobi 1999, Nunes et al. 2000, Nunes 2001, Lamarão 2001, Juliani et al. 2002, 2005), estes últimos, porém, em grande parte, voltados ao estudo de depósitos minerais específicos.

As características geológicas da região do Tapajós indicam a existência de vários arcos magmáticos que teriam gerado ambientes propícios à formação de depósitos de ouro de estilos diversos, incluindo aqueles relacionados a intrusões graníticas ou a zonas de cisalhamento e epitermais (Faraco et al. 1997). Ao norte da Província, vários depósitos de ouro estão distribuídos entre os rios Jamanxim e Crepori, ao longo de um corredor estrutural de direção geral NW-SE, o qual, em mapas regionais, tem sido identificado como uma zona de cisalhamento, porém nem sempre é claramente discernível em mapas de maior escala. 
Dentre aqueles depósitos, figura o Depósito Tocantinzinho, que é considerado, hoje, o maior depósito de ouro da região (Mello 2007).

Estudos recentes apontaram que a rocha hospedeira no Depósito Tocantinzinho é classificada como biotita monzogranito tardi-tectônico a pós-tectônico, do subtipo oxidado, da série da ilmenita, e que foi alojado a profundidade de 6-9 km e, tipologicamente, foi classificado como depósito relacionado a intrusões (Santiago 2012; Santiago et al. 2013).

Os estudos de processos hidrotermais no Brasil associados com mineralizações de ouro em granitos cresceram significativamente (Botelho \& Moura, 1998, Juliani et al. 2002, Tallarico et al. 2004, Botelho et al. 2005, Lindenmayer et al. 2005, Moura et al. 2006). Este trabalho visa complementar a caracterização geológica e petrológica das rochas encaixantes e hospedeiras da mineralização do Depósito Tocantinzinho, determinar a natureza e a origem dos fluidos hidrotermais e mineralizantes, usando dados de inclusões fluidas dos fluidos mineralizantes para, com isso, propor um modelo metalogenético da mineralização de ouro.

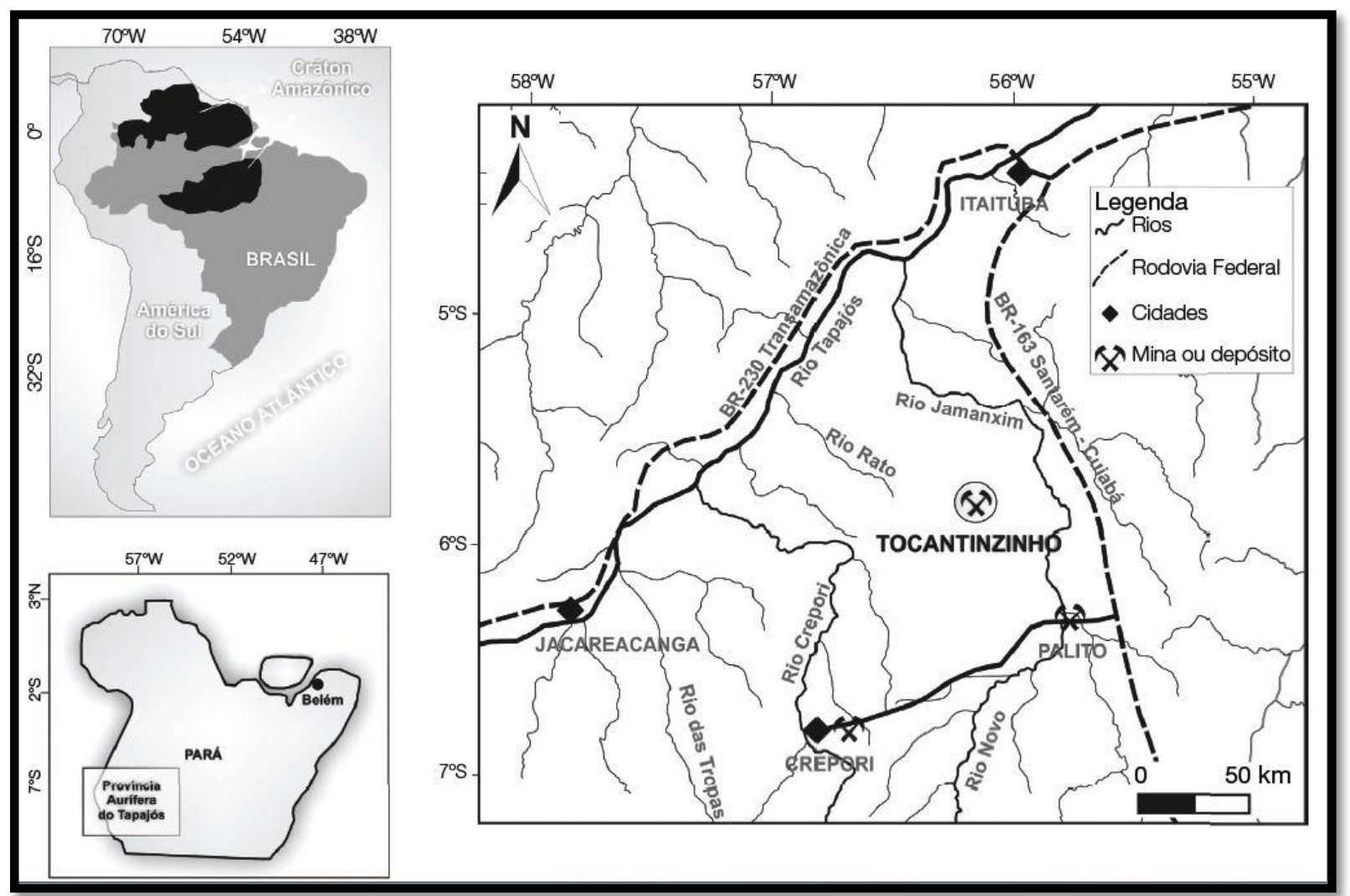

Figura 1: Mapa de localização do Depósito Tocantinzinho (Villas et al. 2013). 


\subsection{MATERIAIS E MÉTODOS}

\subsubsection{Campanhas de campo e amostragem}

Foram realizadas duas campanhas de campo, para o reconhecimento da área de estudo e coleta de amostras de testemunhos de sondagem. Os trabalhos de campo foram realizados sob a supervisão do Professor da UFPA Raimundo Netuno Villas, com o apoio logístico da Empresa de Mineração Brazauro Resources Corporation e, posteriormente, com apoio da Empresa Eldorado Gold Corporation. Com base na representatividade dos furos, foram coletadas amostras pertencentes a 11 testemunhos de sondagem (TOC-05-24/ TOC-0526/ TOC-05-27/ TOC-05-30/ TOC-07-48/ TOC-07-57/ TOC-08-97/ TOC-08-98/ TOC-08101/ TOC-08-102/ TOC-08-103).

\subsubsection{Seleção e tratamento das amostras}

Foram confeccionadas 44 lâminas para estudo petrográfico em microscópio de luz transmitida e refletida, de amostras consideradas representativas dos diferentes tipos de rocha, da alteração hidrotermal e da mineralização. Os estudos petrográficos foram realizados na UFPA, utilizando-se um microscópio petrográfico modelo Zeiss Axioplam 2, e na UnB, em microscópio modelo Axioplan 2 para a petrografia convencional das rochas alteradas e de inclusões fluidas.

\subsubsection{Análises químicas}

Com base nos dados de campo e de petrografia, 18 amostras, de diferentes testemunhos de sondagem, foram preparadas, britadas na Oficina de Preparação de Amostras (OPA) do IG-UFPA, e pulverizadas em panela de ágata para análise química de rocha total no laboratório de preparação e análises de amostras da UFPA. As análises químicas em rocha total foram realizadas no Acme Analytical Laboratories Ltda (Vancouver, Canadá) por ICPMS. Foram analisados elementos maiores $\left(\mathrm{SiO}_{2}, \mathrm{Al}_{2} \mathrm{O}_{3}, \mathrm{Fe}_{2} \mathrm{O}_{3}, \mathrm{MgO}, \mathrm{CaO}, \mathrm{Na}_{2} \mathrm{O}, \mathrm{K}_{2} \mathrm{O}, \mathrm{MnO}\right.$, $\mathrm{TiO}_{2}, \mathrm{P}_{2} \mathrm{O}_{5}$ ), elementos traços ( $\mathrm{Zn}, \mathrm{Cu}, \mathrm{Pb}, \mathrm{Ba}, \mathrm{Be}, \mathrm{Cs}, \mathrm{Ga}, \mathrm{Hf}, \mathrm{Nb}, \mathrm{Rb}, \mathrm{Sn}, \mathrm{Sr}, \mathrm{Ta}, \mathrm{Th}, \mathrm{U}, \mathrm{W}$, $\mathrm{Zr}$ e Bi), incluindo os terras raras ( $\mathrm{La}, \mathrm{Ce}, \mathrm{Pr}, \mathrm{Nd}, \mathrm{Sm}, \mathrm{Eu}, \mathrm{Gd}, \mathrm{Tb}, \mathrm{Dy}, \mathrm{Ho}, \mathrm{Er}, \mathrm{Tm}, \mathrm{Yb}$ e Lu), $\mathrm{C}, \mathrm{S}$ e perda ao fogo (PF). Os elementos maiores foram analisados por Inductively Coupled Plasma-Emission Espectroscopy (ICP-ES), enquanto os elementos traços e terras raras o foram por Inductively Coupled Plasma-Mass Spectrometry (ICP-MS). Perda ao fogo foi determinada por calcinação a $1000{ }^{\circ} \mathrm{C}$. 


\subsubsection{Microssonda Eletrônica}

A análise química de minerais pontual de alguns minerais foi realizada em laboratórios de microssonda eletrônica da USP e na UnB. Inicialmente, nove lâminas delgadas foram analisadas para a determinação da composição química de feldspato, clorita, muscovita, rutilo e titanita, no laboratório de Microssonda Eletrônica do IG-USP, sob a supervisão do técnico Carlos Mansueto. O equipamento utilizado foi JEOL Superprobe JXA8600 e as condições operacionais foram de $15 \mathrm{kv}$ e voltagem de $20 \mathrm{nA}$, usando-se feixe de 5 $\mu \mathrm{m}$ de diâmetro. Para a análise do rutilo foi utilizada voltagem de $20 \mathrm{kv}$. Análises complementares foram realizadas no laboratório de Microssonda Eletrônica do Instituto de Geociências da Universidade de Brasília em 2014. Foram analisados sulfetos (pirita, calcopirita, esfalerita, galena e altaíta), biotita cloritizada, clorita e ouro em oito lâminas delgadas e duas seções polidas. Para a análise do ouro as condições operacionais foram: tempo de contagem $=10 \mathrm{~s}$; voltagem $=20 \mathrm{KV}$ e corrente de $40 \mathrm{nA}$.

\subsubsection{Inclusões fluidas}

Nesta etapa, foram selecionadas amostras representativas do sistema mineralizante e amostras com paragênese menos hidrotermalizada. Foram escolhidas oito amostras e preparadas no Laboratório de Laminação do Instituto de Geociências da UnB. A petrografia das inclusões foi realizada com o auxílio de microscópio petrográfico Zeiss modelo Axioskop 2, do Laboratório de Geologia Econômica da UFPA, e também no laboratório de Microscopia do Instituto de Geociências da UnB.

Para estudos microtermométricos de inclusões fluidas foi utilizada a platina Linkam THMSG600 acoplada a um microscópio Olympus BX-50 do laboratório de Inclusões Fluidas do Instituto de Geociências da UnB. 


\section{PROVÍNCIA MINERAL DO TAPAJÓS}

\subsection{INTRODUÇÃO}

A Província Mineral do Tapajós faz parte da província geocronológica TapajósParima (Santos et al. 2000) ou Ventuari-Tapajós (Tassinari \& Macambira 1999, 2004) (figura 2). Limita-se, geologicamente, a leste com a Província Amazônia Central, do Paleoproterozóico, e a oeste com as províncias Rio Negro (Escudo das Guianas) e RondôniaJuruena (Escudo Brasil Central), ambas do Mesoproterozóico. De NW para SE, foram reconhecidos na província Tapajós-Parima quatro domínios: Parima, Uaimiri, Tapajós e Peixoto de Azevedo (figura 3), os dois primeiros cortados pelo cinturão orogênico K'Mudku e o domínio Uaimiri separado do domínio Tapajós pela bacia Paleozóica do Amazonas (Santos et al. 2004).

Apesar das diferenças quanto à evolução geotectônica, há consenso na separação de dois domínios: o orogênico, a oeste, constituído por sequências de retroarco e basaltos oceânicos, além de plútons alcalinos de arcos magmáticos anorogênico; a leste, de magmatismo alcalino intracontinental resultante do evento Uatumã (Santos et al. 2000, Santos et al. 2001, Vasquez et al. 2002). Segundo Santos et al. (2000), duas orogêneses foram responsáveis pela formação da Província Tapajós, a qual tem idade entre 2,10 - 1,87 Ga. Mundurucus (2040- 1957 Ma.) e Tropas (1906 - 1886 Ma.).

A Orogênese Mundurucus teve início com o magmatismo de arco de ilha e sedimentação turbidítica em retroarco ou fossa oceânica e, nesse caso, estruturas bem preservadas em rochas da porção centro-leste são reconhecidas em direção NE-SW, desde a xistosidade de rochas do Grupo Jacareacanga até o bandamento dos gnaisses do Complexo Cuiú-Cuiú. Na figura 4 encontram-se o mapa geológico com as principais unidades litoestratigráficas e domínios geotectônicos da região da Província Tapajós.

O segundo evento deformacional na Província Tapajós foi de caráter rúptil-dúctil em zonas de cisalhamento transcorrentes NW-SE, de alto ângulo e cinemática sinistrógira, o qual foi responsável pela colocação de plutons cálcio-alcalinos de alto a médio potássio dos arcos magmáticos Creporizão e Tropas. 


\subsection{PRINCIPAIS EVENTOS E LITOESTRATIGRAFIA}

\subsubsection{Associação de Embasamento}

\subsubsection{Grupo Jacareacanga}

Está exposto a oeste e corresponde às unidades mais antigas da província. Consta de rochas supracrustais de natureza vulcanossedimentar de baixo grau metamórfico representadas por quartzo micaxistos, micaxistos quartzosos e feldspáticos, talco xistos, metassilexitos e quartzitos micáceos e ferruginosos (CPRM 2008). Datações recentes forneceram idades U-Pb em grãos detríticos de zircão em torno de 2,1Ga (CPRM 2008), indicando que esses grãos seriam provenientes de rochas transamazônicas e que o processo de sedimentação foi posterior a 2,1 Ga (Santos et al. 2000).

\subsubsection{Complexo Cuiú-Cuiú.}

É composto de ortognaisses dominantemente tonalíticos e granodioríticos bandados e alongados segundo o trend regional NW-SE, bem como de granitos isotrópicos a pouco foliados (Klein et al. 2001, Coutinho, 2008). Datações geocronológicas U-Pb (SHRIMP) em cristais de zircão forneceram idade entre $2033 \pm 7$ e $2005 \pm 7$ Ma para as rochas do Complexo Cuiú-Cuiú (Santos et al. 2000, 2001). O complexo Cuiú-Cuiú foi interpretado como componente de um arco magmático primitivo de afinidade cálcio-alcalina, onde vários depósitos de ouro foram formados (Santos et al. 2001, 2004). Dados isotópicos de $\mathrm{Nd}(\varepsilon \mathrm{Nd}$ 2,01 Ga de +2,6 a +1,8 e $\mathrm{T}_{\mathrm{DM}}$ de 2,09 e 2,16 Ga), obtidos em tonalitos provavelmente relacionados ao Complexo Cuiú-Cuiú, marcariam uma assinatura juvenil paleoproterozóica (Sato \& Tassinari 1997).

De acordo com Vasquez e Rosa-Costa (2008), o Grupo Jacareacanga e o complexo Cuiú-Cuiú representam o arco magmático Cuiú-Cuiú. As rochas do Grupo Jacareacanga estariam relacionadas a bacias de retroarco e de fossa oceânica (Santos et al. 2001, 2004), enquanto os ortognaisses e granitos do Complexo Cuiú-Cuiú à fase de arco, o que é sustentado pelas estruturas de cavalgamento e feições de migmatização encontradas nessas rochas. 


\subsubsection{Vulcano-plutonismo Paleoproterozóio (Orosiriano)}

\subsubsection{Formação Vila Riozinho}

A Formação Vila Riozinho compreende andesitos basálticos, traquiandesitos basálticos, traquitos e riolitos, que forneceram idade de cristalização por evaporação de $\mathrm{Pb}$ em zircão de $2000 \pm 3$ Ma (Lamarão et al. 2002, 2005). Geoquimicamente, elas revelam assinatura cálcio-alcalina de alto potássio a shoshonítica, similar à de arcos magmáticos maduros (Lamarão et al. 2002).

Segundo Lamarão et al. (2005), a assinatura dos isótopos de $\mathrm{Nd}(\varepsilon \mathrm{Nd} 2,0 \mathrm{Ga}$ de $-1,09$ a -3,71 e $\mathrm{T}_{\mathrm{DM}}$ de 2,49 e 2,28 Ga.) sugere que essas rochas vulcânicas possam ter se formado a partir de magma juvenil paleoproterozóico provavelmente contaminado pela assimilação de rochas arqueanas ou pela interação com um magma derivado de fonte arqueana, o que é ratificado pela presença de cristais de zircão desta idade. Por outro lado, essas rochas podem representar a (re) fusão de uma crosta siliática formada a cerca de 2,2 Ga. a partir de underplating de magmas máficos.

\subsubsection{Formação Novo Progresso}

As rochas vulcanoclásticas e epiclásticas que ocorrem nas proximidades do município de Novo Progresso e foram reunidas na Formação Novo Progresso por Ferreira et al. (2000). Esta unidade é constituída por arenitos líticos e arcosianos, siltitos e argilitos tufáceos e conglomerados de fonte detríticas de material vulcânico muito provavelmente originados da Formação Vila Riozinho.

\subsubsection{Suíte Intrusiva Creporizão}

É constituída de batólitos de afinidade calcioalcalina. Sienogranitos e monzogranitos com granodioritos e tonalitos subordinados são os litotipos representativos desta suíte, a qual se distribui segundo um trend regional de cisalhamento NW-SE (Ricci et al. 1999). Datações $\mathrm{U}-\mathrm{Pb}$ em cristais de zircão dos granitos forneceram idades de $1957 \pm 6 \mathrm{Ma}$ (Lamarão et al. 2005). As rochas graníticas desta suíte apresentam assinatura calcioalcalina mais evoluída que a das rochas do Complexo Cuiú-Cuiú. O Granito São Jorge Velho parece representar as primeiras manifestações magmáticas da evolução do arco magmático Creporizão (Lamarão et al. 2002). Santos et al. (2004) interpretam a natureza cálcio-alcalina dos granitos da Suíte Intrusiva Creporizão como relacionada a outro arco magmático mais jovem que o dos granitos do Complexo Cuiú-Cuiú. Interpretam também o Monzogranito Jamanxim, de idade $1997 \pm 5$ 
Ma (U-Pb SHRIMP), como um arco magmático intermediário entre o arco magmático do Complexo Cuiú-Cuiú e o da Suíte Intrusiva Creporizão.

\subsubsection{Suíte Intrusiva Tropas}

Parte dos granitos da porção oeste do Domínio Tapajós, que afloram no rio Tropas e se estendem aos igarapés Coatá Grande e Coatá Pequeno, eram cartografados como Complexo Cuiú-Cuiú (Almeida et al. 2000, Ferreira et al. 2000). No entanto, Santos et al. (2001), baseados na origem ígnea e não metamórfica da biotita desses granitos e nas idades mais jovens que a do Complexo Cuiú-Cuiú, propuseram incluí-los em unidade independente designada como Suíte Intrusiva Tropas. Ferreira et al. (2004) descreveram tonalitos, quartzo dioritos, granodioritos, monzogranitos, andesitos e basaltos, que forneceram idades $\mathrm{U}-\mathrm{Pb}$ em grãos de zircão e titanita deles extraídos entre 1892 ×6 Ma, com base em Lamarão et al. 2005.

\subsubsection{Grupo Iriri}

Neste grupo foram individualizadas a Formação Salustiano e pela Formação Aruri (Pessoa et al. 1997). A Formação Salustiano representa os derrames félsicos a intermediários do magmatismo Uatumã e é composta por riolitos, riodacitos e dacitos porfiríticos. A Formação Aruri, por sua vez, é constituída por ignimbritos, brechas vulcânicas, tufos félsicos, conglomerados, arenitos e siltitos.

Os riolitos e ignimbritos do Grupo Iriri no Domínio Tapajós forneceram idades de cristalização por evaporação de Pb em zircão entre $1870 \pm 8$ Ma (Dall'Agnol et al. 1999, Santos et al. 2001, Lamarão et al. 2002).

\subsubsection{Suíte Intrusiva Parauari}

É a unidade que se encontra em maior área de exposição dentro da PAT e apresenta, majoritariamente, monzogranitos e granodioritos. Os granitos desta suíte constituem batólitos e stocks elípticos, alongados segundo o trend NE-SW, formando segmentos irregulares e retangulares. Vários corpos, mapeados nas folhas Vila Mamãe Anã e Jacareacanga, foram datados pelo método U-Pb em zircão e titanita e forneceram idades entre $1891 \pm 2$ e $1879 \pm 14$ Ma. (Santos et al. 1999).

\subsubsection{Suíte Intrusiva Ingarana}

É representada por rochas gabróicas (augita gabros, gabronoritos, leuconoritos, diabásios e micrograbos), as quais afloram conspicuamente nos leitos do igarapé Bom Jardim e de seu afluente Ingarana. Corpos desta suíte cortam granitos da Suíte Intrusiva Parauari, relações estas confirmadas por datações U-Pb (SHRIMP) em grãos de titanita, zircão e 


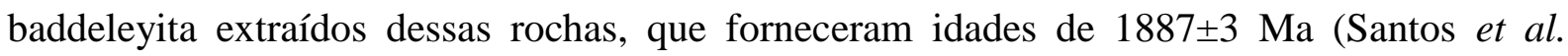
1997).

\subsubsection{Formação Bom Jardim}

Esta formação é composta predominantemente por andesitos, com basaltos, traquitos e latitos subordinados, que formam corpos vulcânicos e subvulcânicos associados com granitos da Suíte Intrusiva Parauari e com rochas vulcânicas do Grupo Iriri. Lamarão et al. (2002) dataram, pelo método de evaporação de $\mathrm{Pb}$ em zircão, um corpo de traquito localizado próximo à localidade de Moraes Almeida e obtiveram uma idade de cristalização de $1881 \pm 4$ Ma. Os dados de isótopos de $\mathrm{Nd}$ dos diques andesíticos ( $\varepsilon \mathrm{Nd} 1,9 \mathrm{Ga}$ de $-2,38$ e $\mathrm{T}_{\mathrm{DM}}$ de 2,26 $\mathrm{Ga}$ - Santos et al. 2000) e do traquito de Moraes Almeida ( $\varepsilon N d$ 1,88 Ga de -1,98 e $\mathrm{T}_{\mathrm{DM}}$ de 2,29 Ga - Lamarão et al. 2005) sugerem fontes paleoproterozóicas para as rochas desta unidade, com pequena contribuição crustal.

\subsubsection{Suíte Intrusiva Maloquinha}

É representada principalmente por álcali-granitos e, de forma subordinada, por biotita granitos, anfibólio biotita granitos e fácies graníticas subvulcânicas (Juliani et al. 2002). São corpos graníticos circulares, batólitos e stocks, subvulcânicos e plutônicos, intrusivos em rochas do Complexo Cuiú-Cuiú, granitos das suítes Parauari e Creporizão, e rochas vulcânicas do Grupo Iriri. O magmatismo Maloquinha apresenta características geoquímicas de granitogênese tipo A, típica de ambientes extensionais intracontinentais (Vasquez et al. 2002, Lamarão et al. 2002). Os granitos dessa Suíte apresentam idades com base em análises de U-Pb em zircão entre $1882 \pm 4$ a $1877 \pm 12$ e $1864 \pm 18$ Ma (Santos et al. 2001, Vasquez et al. 2008) e foram identificadas populações de cristais de zircão herdados do Neoarqueano ao Orosiriano.

\subsubsection{Granito Caroçal}

É composto por sienogranitos e monzogranitos com biotita, sendo leucocráticos, de cor vermelha e cinza-rosado e assinatura cálcio-alcalina de alto potássio, contrastando com a assinatura alcalina (tipo-A) dos granitos da Suíte Intrusiva Maloquinha. Santos et al. (2004) obtiveram uma idade de cristalização de $1870 \pm 4$ Ma por U-Pb SHRIMP em zircão. Almeida et al. (2000) denominaram esse Granito como manifestação pós-Maloquinha orientado segundo trend NW-SE. 


\subsubsection{Granito Porquinho}

Bahia \& Quadros (2000) propuseram essa denominação para um batólito pós Maloquinha. O corpo apresenta forma elíptica e se destaca pelo relevo mais acidentado e radiação cintilométrica mais alta que suas rochas encaixantes. Prazeres et al. (1979) identificaram duas fácies neste corpo, ambas com afinidade subalcalina a alcalina: a) granitos a duas micas compostos por álcali-feldspato granitos e microgranitos com biotita que, localmente, coexiste com muscovita; e b) granitos com anfibólio. Santos et al. (2004) obtiveram idade de cristalização de $1786 \pm 14$ Ma. pelo método U-Pb SHRIMP em zircão.

\subsubsection{Formação Buiuçu}

É representada por rochas sedimentares siliciclásticas proterozóicas como arcósios, arcósios líticos, conglomerados e, subordinadamente, siltitos e argilitos. O mais expressivo segmento da Formação Buiuçu está na bacia do rio Crepori, que se estende para noroeste aflorando ao longo dos igarapés Coatá Grande e Coatá Pequeno, afluentes da margem esquerda do rio Tapajós. Existem seixos vulcânicos e tufos félsicos intercalados nas sucessões siliciclásticas desta formação, os quais colocam em dúvida se esses materiais estão relacionados ao vulcanismo de 1,88 Ga do Grupo Iriri ou a um evento magmático mais jovem, como o magmatismo estateriano da Suíte Intrusiva Teles Pires, do Domínio Juruena. No entanto, o fato de a Formação Buiuçu ser seccionada pelo Diabásio Crepori, datado em torno de $1780 \pm 7$ Ma (Santos et al. 2002, 2004), sugere que os sedimentos da Formação Buiuçu foram depositados antes do Estateriano.

\subsubsection{Magmatismo tholeiítico Proterozóico e Fanerozóico}

\subsubsection{Diabásio Crepori}

Ocorre como soleiras e diques orientados segundo N10 ${ }^{\circ} \mathrm{E}$ que cortam as coberturas da Formação Buiuçu no segmento do Rio Crepori. Constituídas por diabásio, olivina diabásio e microgabro. Por revelarem quartzo (normativo e modal), as rochas do Diabásio Crepori foram relacionadas a basaltos tholeiíticos continentais. Santos et al. (2002) obtiveram idade de cristalização de $1780 \pm 7$ Ma para o Diabásio Crepori pelo método U-Pb (SHRIMP) em baddeleyita.

\subsubsection{Suíte Intrusiva Cachoeira Seca}

É representada por rochas básicas que ocorrem na região do médio curso do rio Tocantins e na Folha Vila Riozinho. Trata-se, basicamente, de um platô de olivina gabros, 
diabásios, olivina diabásios, gabronoritos e troctolitos (Bahia \& Quadros 2000). Pessoa et al. (1977) obtiveram idades K-Ar em plagioclásio de $1086 \pm 18$ e $1046 \pm 27$ Ma para as rochas da Suíte Intrusiva Cachoeira Seca. Posteriormente, Santos et al. (2002) obtiveram uma idade mais precisa (1186 $\pm 12 \mathrm{Ma})$ em um troctolito desta unidade, pelo método U-Pb em baddeleyita. 


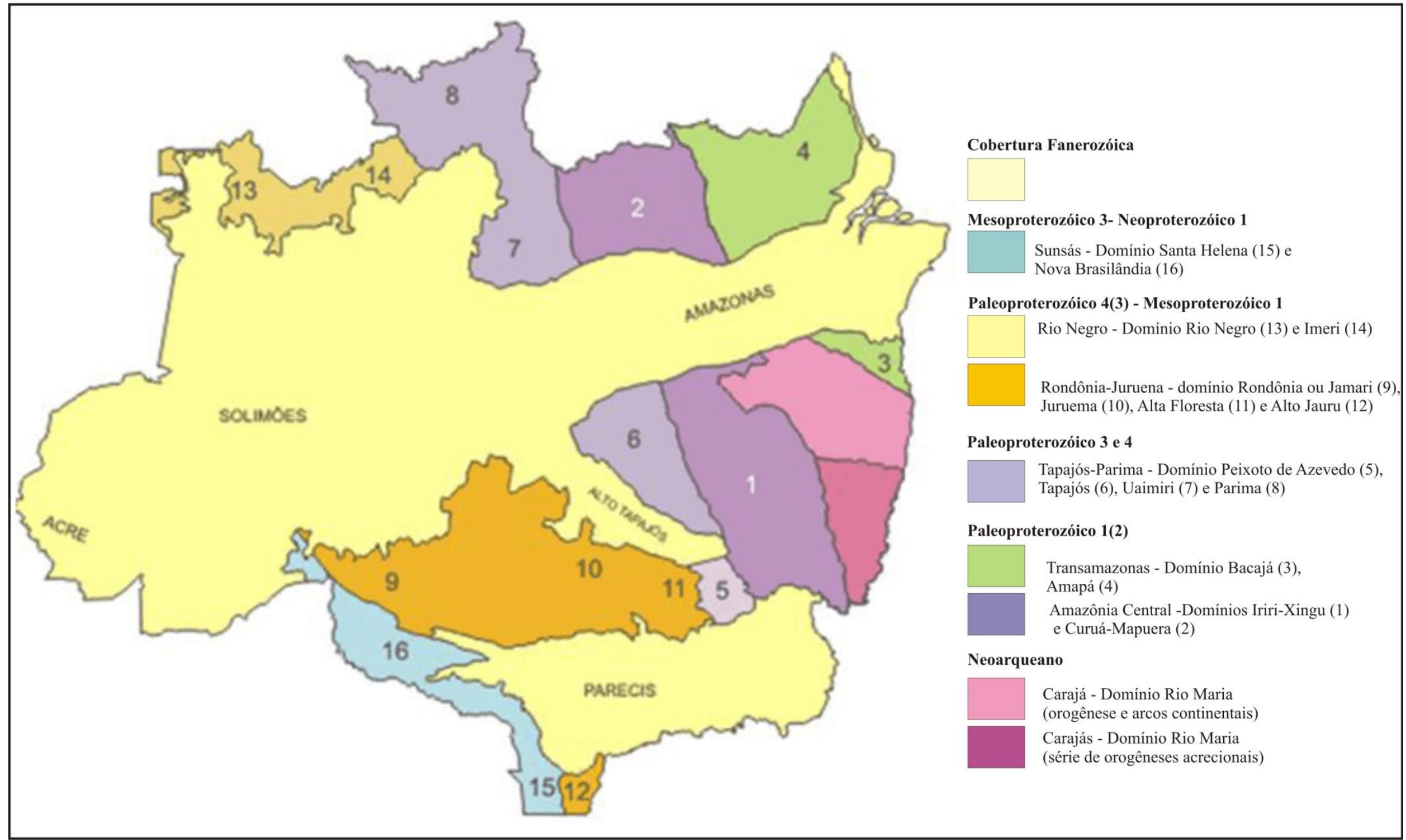

Figura 2: Províncias geocronológicas compartimentadas em domínios tectônicos estratigráficos do Cráton Amazônico (Santos et al. 2000). 


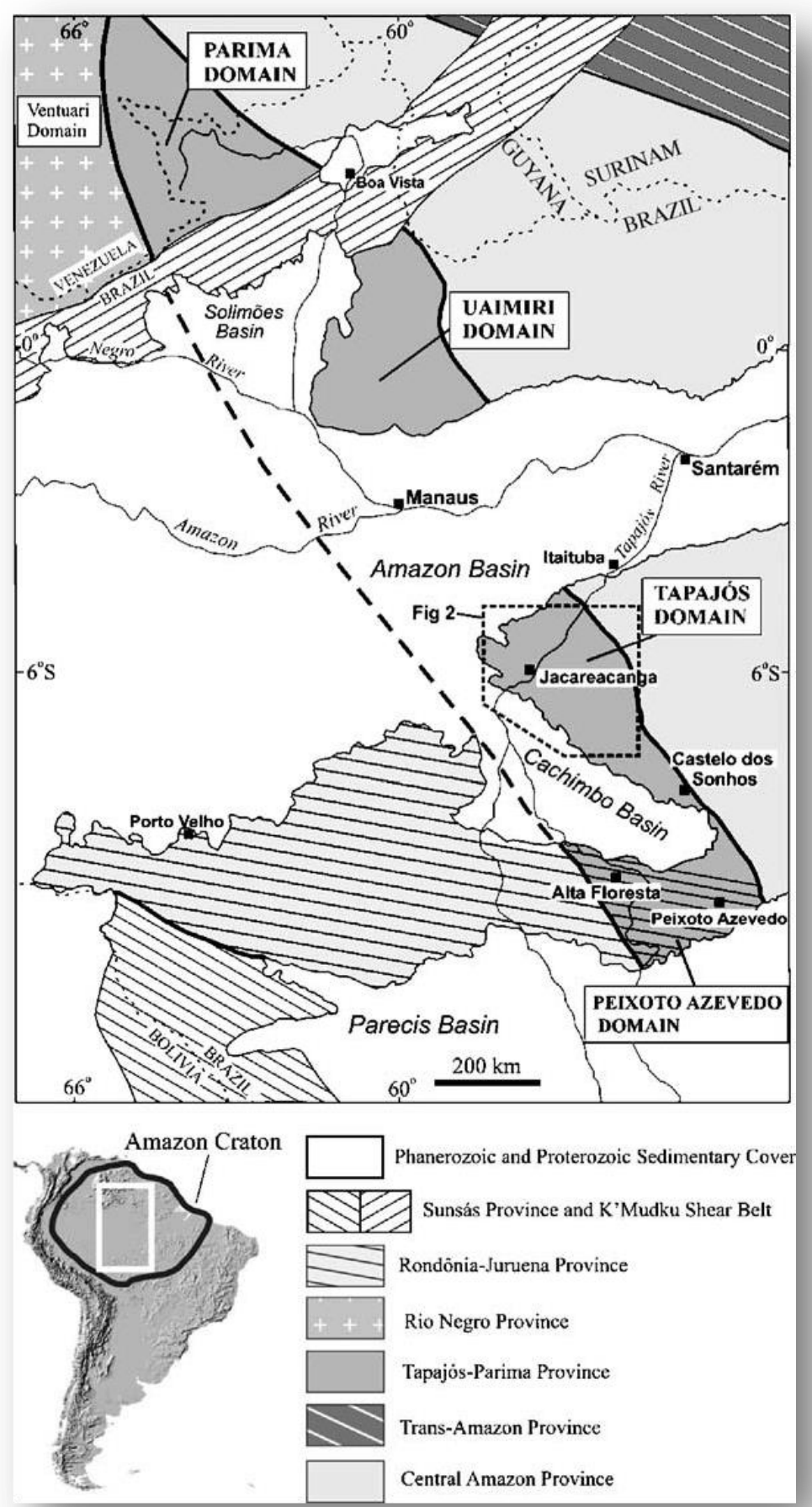

Figura 3: Localização geográfica dos quatro domínios referentes ao Cinturão Orogênico Tapajós - Parima, com destaque em pontilhado para o Domínio Tapajós (Santos et al. 2004). 


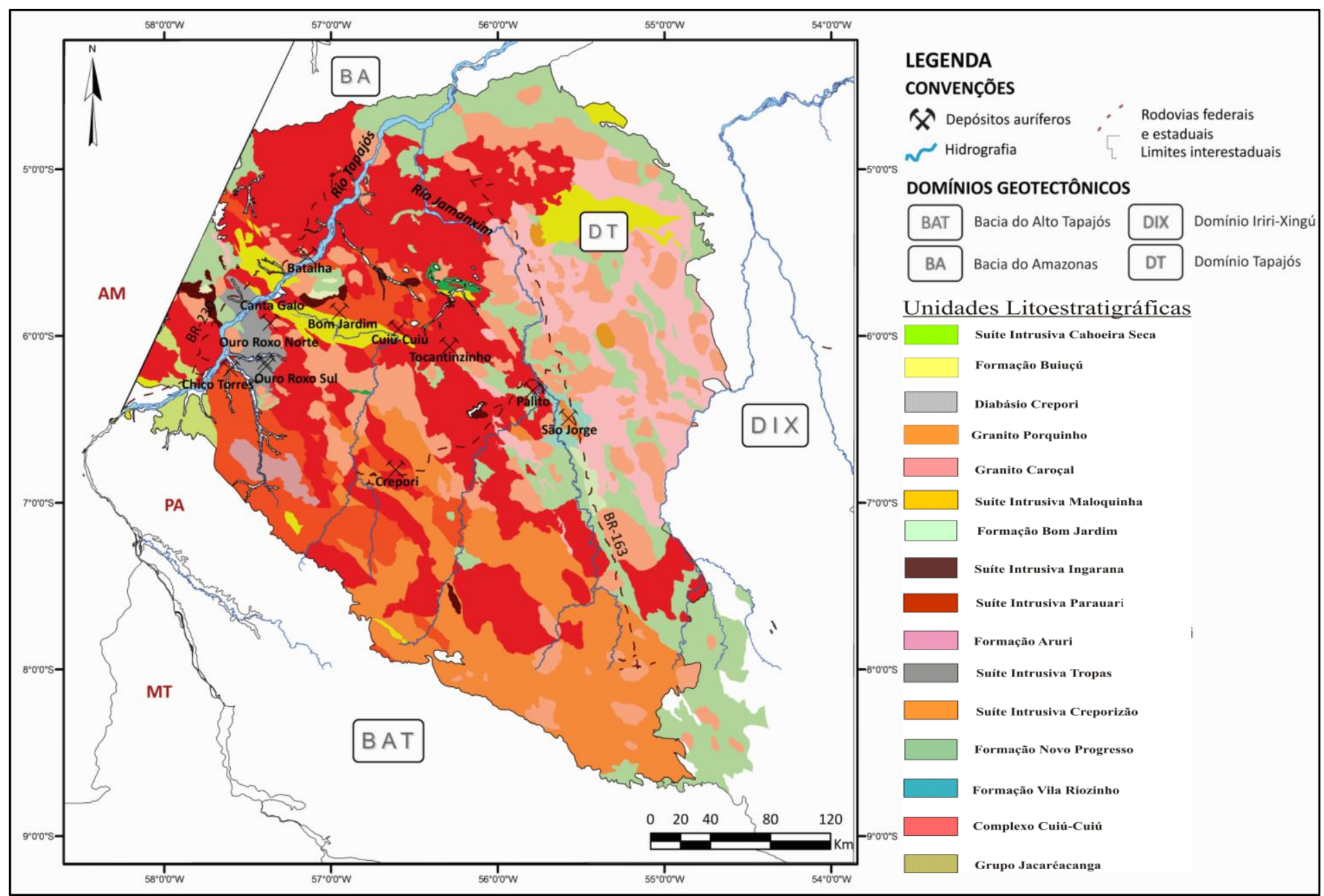

Figura 4: Mapa geológico do Domínio Tapajós indicando alguns dos principais depósitos de ouro, incluindo o Depósito Tocantinzinho (Vasquez et al. 2008b). 


\section{CAPÍTULO II: Geologia, petrografia e alteração hidrotermal do Depósito Tocantinzinho}

\section{DEPÓSITO TOCANTINZINHO}

\subsection{GEOLOGIA E PETROGRAFIA}

\subsubsection{Geologia Local}

O depósito Tocantinzinho está hospedado em rocha granítica atribuída a uma manifestação precoce da Suíte Intrusiva Creporizão e que se instalou na Província nos estágios finais da Orogênese Mundurucus com idade de $1982 \pm 8$ Ma. (evaporação de $\mathrm{Pb}$ em zircão) (Villas et al. 2013). Na área do depósito, a forte ação hidrotermal produziu granito alterado e diferentes rochas hidrotermais, nas quais se hospeda a mineralização. Diques máficos, intermediários e félsicos também ocorrem na área (figura 5).

Muito embora o depósito não apresente características de deformação dúctil, são comuns evidências de brechação e forte faturamento, os quais podem ter causa em processos hidráulicos explosivos e/ ou pneumáticos (Mello 2007). Esses processos hidráulicos podem ter sido resultado da exsolução de soluções aquosas dissolvidas no magma granítico, os quais migraram pelos espaços que foram abertos e neles precipitaram quartzo + clorita + sericita + carbonato (Villas et al. 2013). Em todo caso, a falta de afloramentos dificultou a determinação do padrão das fraturas no Depósito.

Na figura 6 encontra-se o mapa geológico simplificado do Depósito Tocantinzinho adaptado de relatório interno de Mello (2007) além de a seção geológica 315N, adaptada de relatório interno de Juras et al. (2011). Nesta seção há o destaque para o furo de sondagem TOC-05-24, um dos furos de sondagem mais amostrados e bem detalhados neste estudo. Constam, também, na figura as principais ocorrências rochosas do Depósito Tocantinzinho: granito (preservado e hidrotermalizado), diques máfico e félsico.

O monzonito não foi estudado neste trabalho pois não fora selecionado para o estudo do perfil do Depósito. Contudo, para fiz de informação, o monzonito ocorre em algumas porções do Depósito, como descrevem os relatórios internos das empresas de mineração que atuaram e atuam no local. 
A figura 7 ilustra o perfil geológico, produzido com base no estudo petrográfico e petrológico do furo TOC-05-24. A figura 7-1 destaca a fotografia de uma amostra de mão representativa do granito encaixante e em 7-2 a amostra representativa do dique félsico; em 73, 7-4 E 7-6 as amostras são variedades do granito, resultantes da alteração hidrotermal atuante no Depósito; em 7-5 a figura representa o dique máfico recorrente no local.

Segundo Mello (2007) e relatórios internos produzidos por empresas que trabalham e trabalharam na região, ocorrem também os tipos granodiorito, tonalito e álcali-feldspato granito, porém todos de forma pouco expressiva e não apresentam associação com mineralização.

Os diques máficos e félsicos ocorrem posteriormente ao corpo granítico, sendo que os diques félsicos, segundo observações de campo, são ainda posteriores aos máficos, pois os cortam em algumas porções do Depósito. os dique máficos apresentam composição basáltica cálcio-alcalina. Os diques ou injeções félsicas correspondem a rochas de composição riolítica, com espessuras que oscilam desde centimétricas a métricas, ocorrendo em todo o Depósito Tocantinzinho.

Segundo Santiago (2012), apesar do alto grau de alteração, foi possível deduzir, com base em análise modal e balanço de massa, que as variedades de rochas resultantes da alteração hidrotermal provieram da rocha encaixante original classificada como biotita monzogranito. Os diques ainda não foram datados, mas, devido às evidências de campo, são interpretados como posteriores ao granito. 


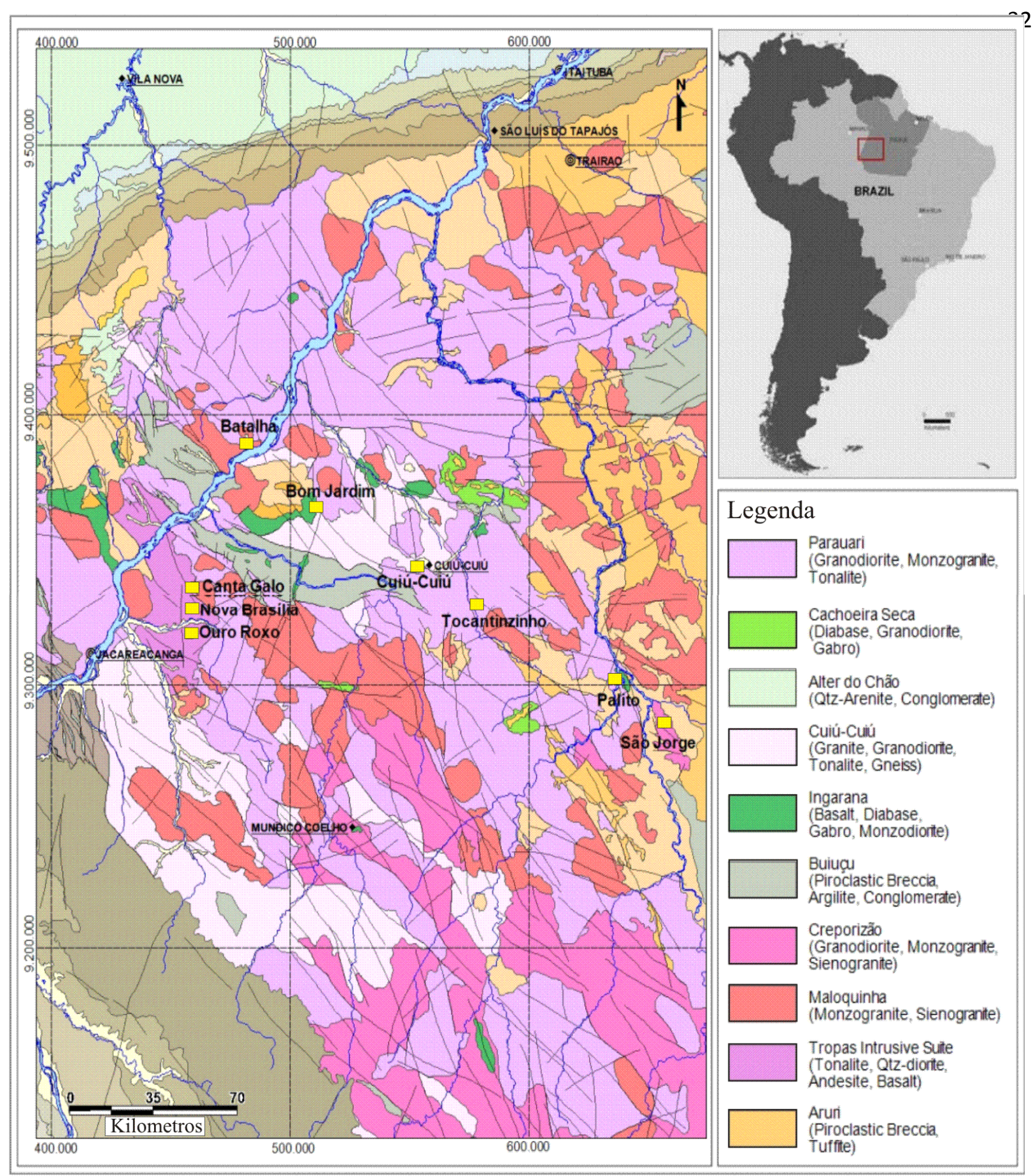

Figura 5: Mapa geológico do Depósito Tocantinzinho (modificado de Juras et al. 2011). 

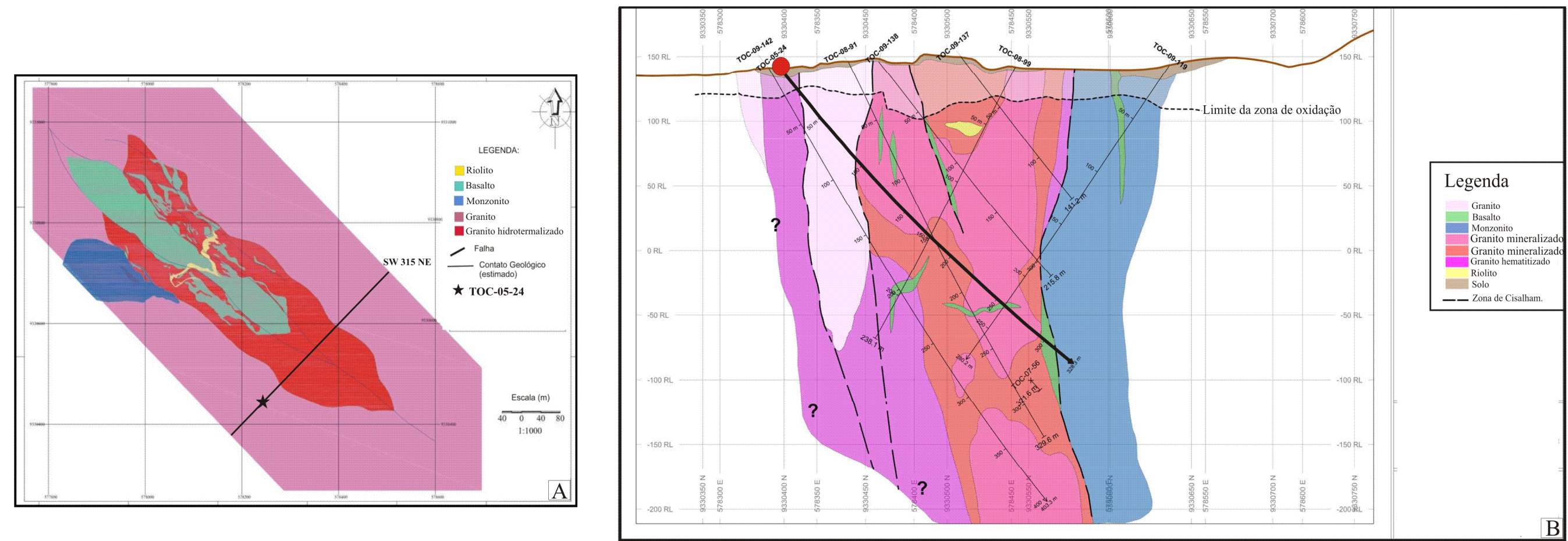

Figura 6: A) Mapa geológico do Depósito Tocantinzinho, com destaque para a seção geológica SW 315NE. A estrela corresponde ao furo TOC-05-24 (Adaptado de Mello 2007); B) seção geológica 315NE, furo TOC-05-24 (modificado de Juras et al. 2011). 


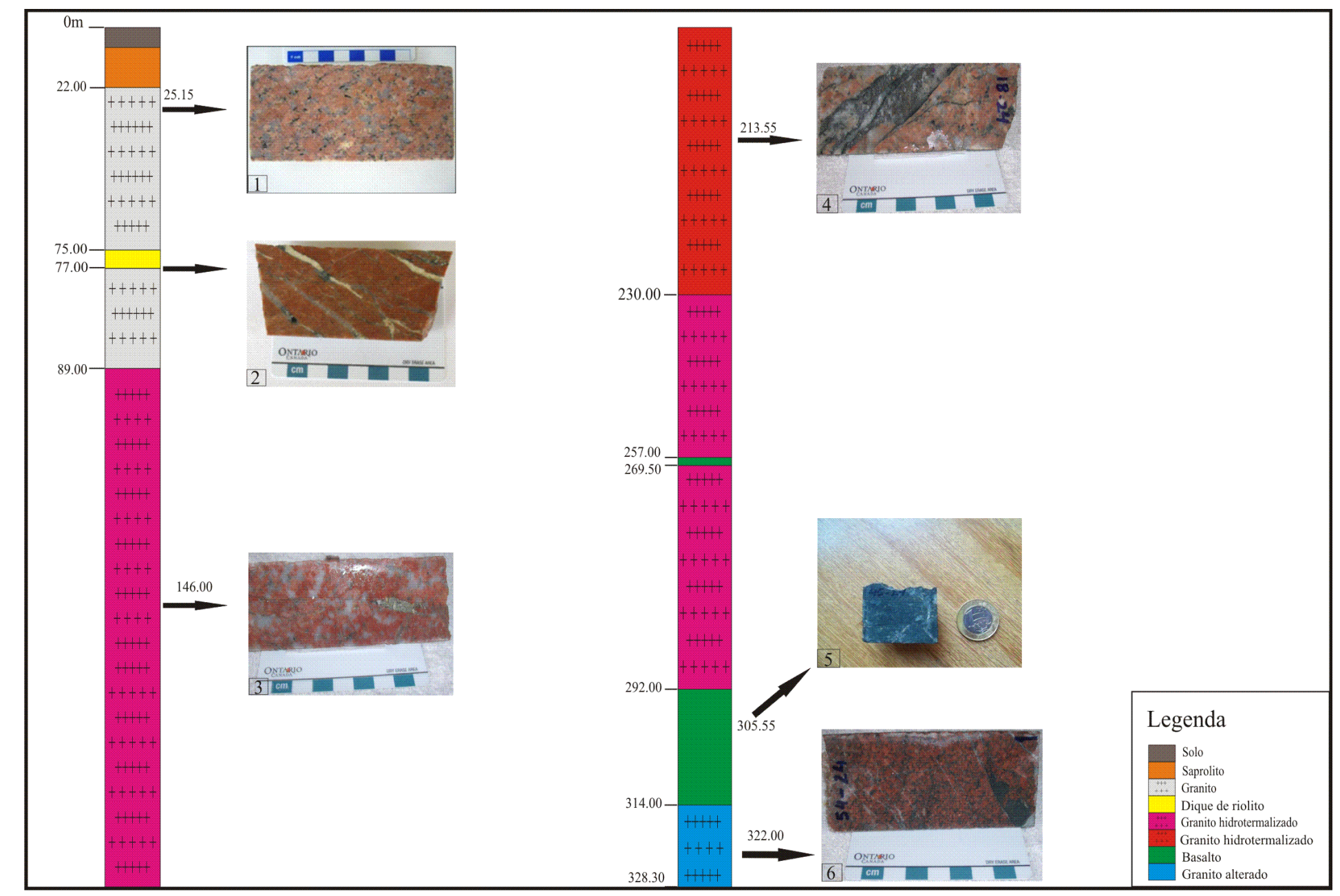

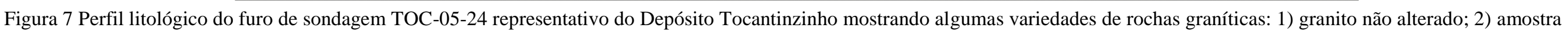

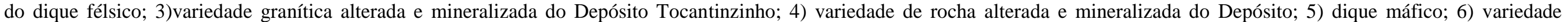
granítica alterada do Depósito Tocantinzinho. 


\subsubsection{Petrografia}

\subsubsection{Granito}

O estudo petrográfico das rochas graníticas não alteradas, encaixantes do Depósito Tocantinzinho, mostrou que se trata de granito isotrópico, de granulação média, com textura fanerítica alotriomórfica inequigranular, com magnetismo de intensidade média (figura 8).

Os minerais essenciais do granito são: quartzo (25\% - 30\%), oligoclásio (30\% - 35\%) e microclínio (35\% - 40\%), além de biotita (3\% - 5\%). Os minerais acessórios e opacos são: zircão, titanita, pirita e magnetita, os quais perfazem cerca de $5 \%$ da composição do granito; os secundários são representados por epidoto, sericita e clorita (aproximadamente 3\%). De acordo com a classificação obtida a partir do diagrama QAP Streckeisen (1979), o granito encaixante do Depósito Tocantinzinho é monzogranito.

Os cristais de plagioclásio são representados pelo oligoclásio e são, em geral, subédricos, de tamanho médio $(0,3$ a $1 \mathrm{~mm})$ e de hábito tabular. Outra ocorrência se dá como exsolução de albita, micrométricas a milimétricas, em pertitas. É recorrente observar sericita e muscovita e/ou epidoto como produtos de alteração de cristais de plagioclásio, mostrando leve sericitização e, localmente, alterando para carbonato.

Grãos de feldspato potássico são representados pela microclínio e ocorrem como cristais subédricos, de granulação média $(0,2$ a $1 \mathrm{~mm})$ e de hábito tabular. Alguns cristais apresentam maclamento em grade (xadrez) e textura pertítica. Esporadicamente, observa-se substituição, de forma incipiente, para argilominerais.

Os grãos de quartzo são anédricos, ocorrem em geral com granulação grossa (0,5 a 1 $\mathrm{mm}$ ) mostrando forte extinção ondulante, contatos suturados entre si e com os demais cristais próximos, o que sugere fraco processo de recristalização. Outra forma recorrente é reconhecida com granulação fina $(0,2 \mathrm{~mm})$ em aglomerados fraturados ou recristalizados.

A biotita ocorre como lamelas ou palhetas de tamanho médio a fino (0,2 a $1 \mathrm{~mm})$.

Em geral esses cristais já se encontram em processo de alteração incipiente para clorita, em especial ao longo de planos de clivagem. Geralmente apresentam inclusões de zircão e titanita.

Os minerais acessórios ocorrem de forma isolada e dispersos pela rocha ou inclusos em cristas de biotita. $\mathrm{O}$ zircão está geralmente associado à biotita e a outros minerais máficos como titanita e magnetita. Geralmente é subédrico e com hábito prismático, com tamanho médio de $15 \mu \mathrm{m}$. Os cristais de titanita ocorrem com coloração castanha a castanha avermelhada, subédrica a euédrica e podendo alcançar $1,8 \mathrm{~mm}$ de comprimento (figura 8-D). 
Os cristais de magnetita são euédricos a subédricos, finos, com tamanhos variando entre 10 a $20 \mu \mathrm{m}$ e coloração acinzentada em luz refletida. Ocorrem inclusos em biotita e nos demais acessórios e também em quartzo, plagioclásio e feldspatos.

Sulfetos como pirita e calcopirita são raros e, quando ocorrem, estão associados a produtos de alteração associados aos minerais acessórios, em aglomerados máficos. Geralmente são finos $(0,1$ a $0,2 \mathrm{~mm})$, subédricos no caso da pirita e anédrico no caso da calcopirita.

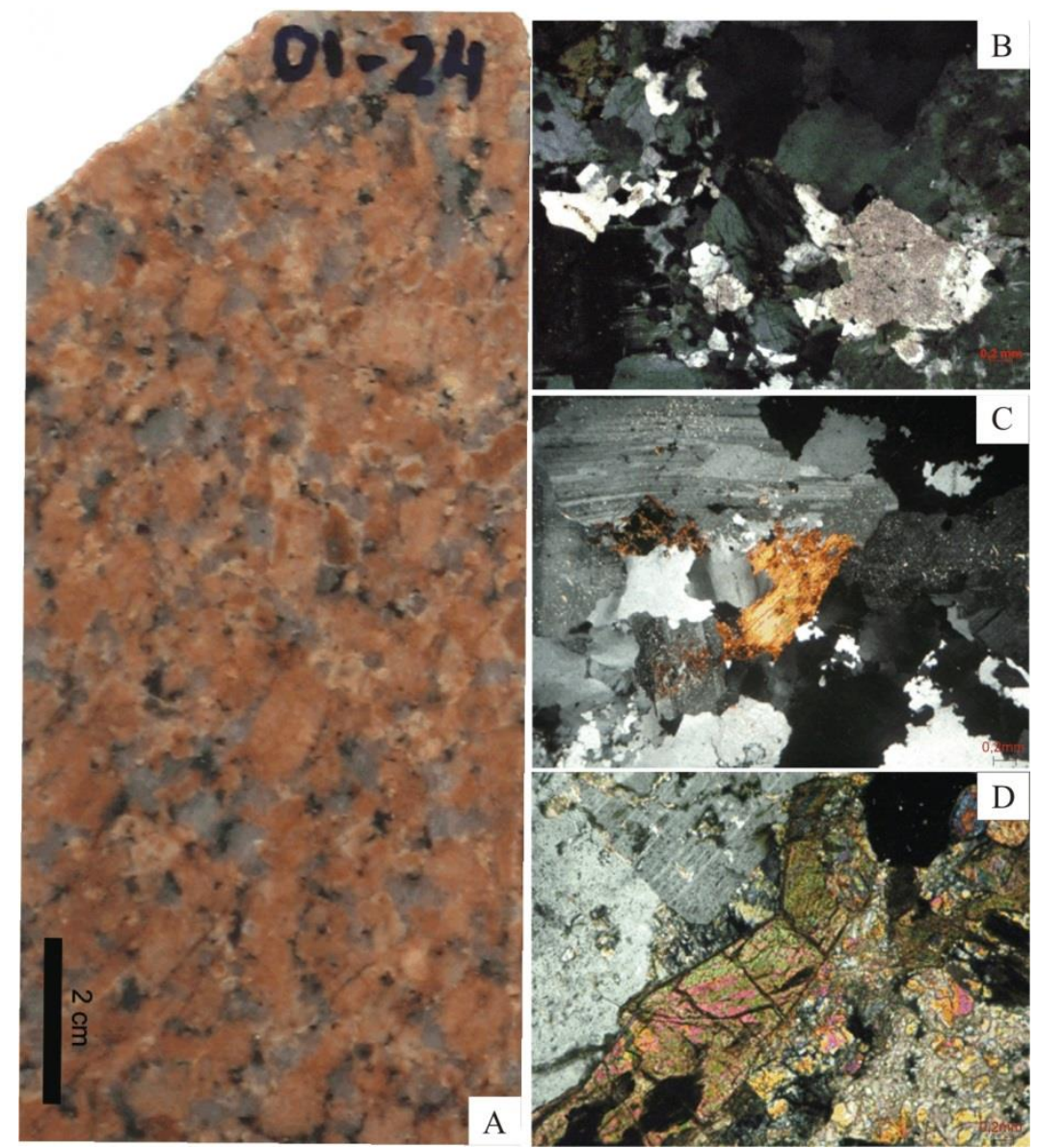

Figura 8: Foto de amostra de mão e fotomicrografias do granito. A) aspecto mesoscópico do monzogranito; B) fotomicrografia mostrando a textura principal da amostra (NX; 2,5X); C) associação entre: Qtz $+\mathrm{Plg}+\mathrm{Fk}+\mathrm{Bt}$ $(\mathrm{NX} ; 2,5 \mathrm{X})$; D) associação de minerais opacos primários: titanita, zircão e magnetita (NX; 5X). 


\subsubsection{Dique félsico}

Macroscopicamente, é uma rocha porfirítica, alotriomórfica e inequigranular, com granulação variando de fina a média e trama isótropa. É constituída por quartzo (35\%), plagioclásio (albita) (25\% a 30\%) e feldspato potássico (15\% a 20\%) como minerais essenciais e biotita cloritizada (5\%) como mineral varietal. Magnetita e pirita ocorrem como minerais opacos (3\%). Sericita, epidoto e carbonatos são minerais de alteração (5\%).

Na figura 9-A tem-se a fotografia da amostra de mão representativa do dique félsico que ocorre no Depósito Tocantinzinho; em 9-B/ 9-C/ 9-D estão algumas das fotomicrografias representativas do dique félsico. Em 9-B tem-se a textura principal encontrada na amostra; em 9-C tem-se a textura localizada de aglomerados de grãos de quartzo e plagioclásio, geralmente associados a minerais opacos que, neste caso, é a pirita; em 9-D tem-se um cristal de biotita já mostrando alteração para clorita, associado a minerais opacos (zircão, magnetita e pirita).

Os grãos de quartzo variam entre médios e finos $(0,5$ a $1 \mathrm{~mm})$, são subédricos a anédricos, e possuem extinção ondulante. Em geral ocorrem dispersos pela rocha, mas também como uma massa de agregados mais fina por vezes monominerálica, mas também agregada com o plagioclásio, preenchendo os espaços entre os fenocristais de plagioclásio e feldspato. Adicionalmente, encontram-se esses concentrados e/ou aglomerados preenchendo veios e vênulas, juntamente com carbonato e clorita.

Os cristais de plagioclásio são médios $(0,8$ a $1 \mathrm{~mm})$, subédricos a anédricos, inequigranulares, geralmente alterados para sericita e carbonato. Os contatos entre si e com outros minerais são tipicamente retos a irregulares com feições de corrosão. Apresentam geminação por vezes preservada.

O feldspato potássico ocorre em menor proporção na rocha em relação aos demais minerais essenciais. Os cristais são médios (0,6 a 0,8 mm), anédricos a subédricos, localmente cortados por vênulas com um grau de alteração fraco. A alteração mais típica é a carbonatação.

A clorita ocorre como resultados de alteração de biotita, mas, principalmente, se dá como material de alteração hidrotermal nas vênulas. Geralmente, apresenta-se azulada em filtro de polarizador cruzados variando para um tom mais acizentado. A textura principal é radiada. O carbonato ocorre como mineral de alteração hidrotermal, preenchendo vênulas ou substituindo cristais de feldspato, estando em geral associado aos demais minerais de alteração como a clorita e a sericita. Porém, localmente, há cristais de carbonato de tamanho pequeno a médio $(0,2$ a $0,5 \mathrm{~mm})$, com contatos retilíneos e com maclas em xadrez, geralmente em meio a massa de grãos de quartzo. 
Na figura 10 observa-se um dos comportamentos mais comuns dos veios e vênulas nessa rocha, onde vênulas de carbonato + quartzo + (clorita +sericita) atravessam a rocha. Neste caso a vênula de carbonato apresenta o mineral bem preservado.

Como minerais opacos, tem-se pirita, ocorrendo dentro de vênulas, com feições de corrosão. Observam-se ainda diminutos e esporádicos cristais de magnetita disseminada, localmente apresentando porções alteradas para hematita.

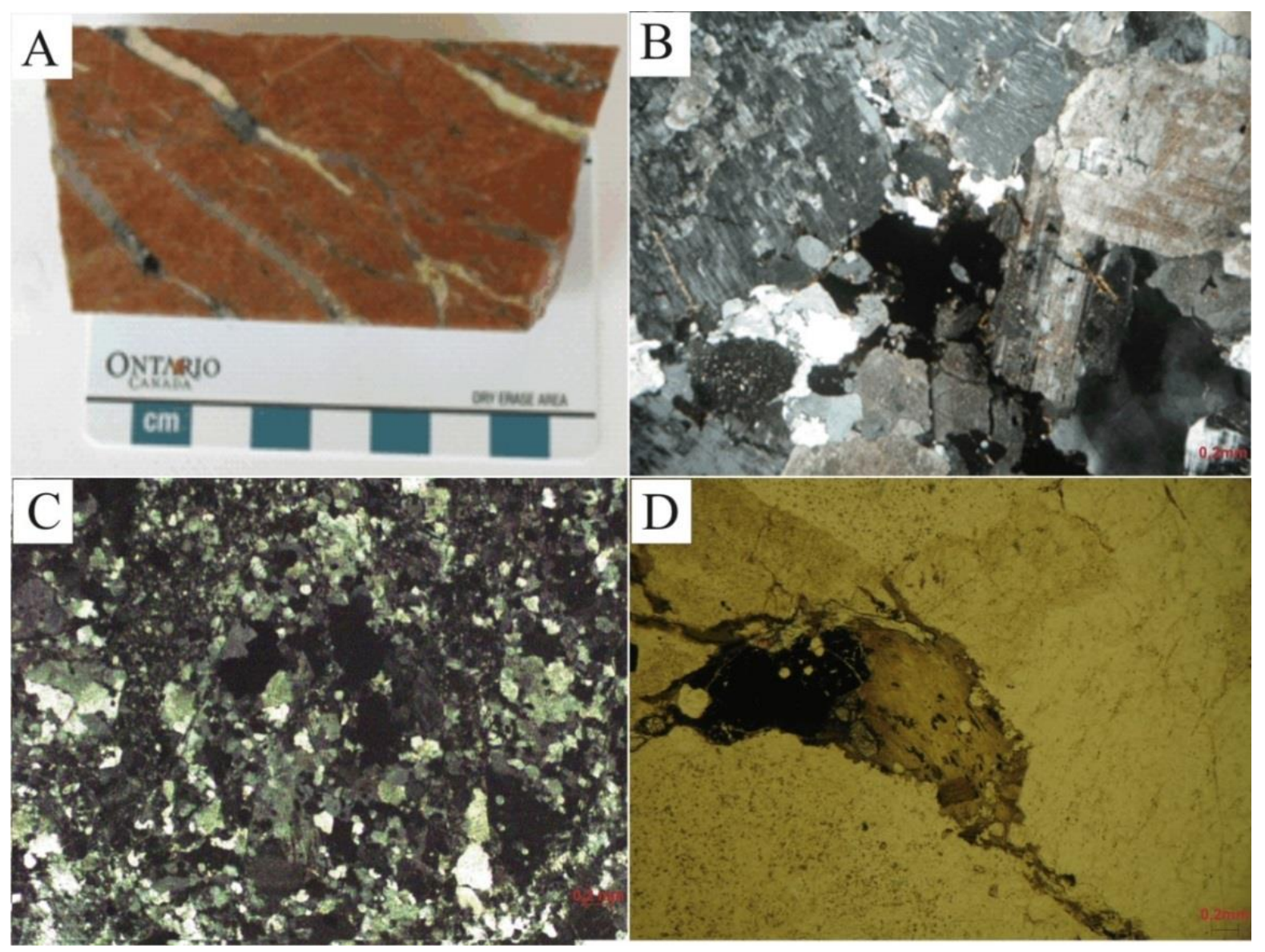

Figura 9: A) Fotografia de amostra de mão do dique félsico e suas vênulas preenchidas por quartzo, clorita e carbonato, especialmente (amostra 11_24); B) fotomicrografia da lâmina delgada em luz transmitida mostrando a trama principal da rocha com grãos de quartzo, plagioclásio e feldspato potássico e cristais de pirita (NX; 2,5X); C) textura fina encontrada, localmente, na rocha (Qtz + Plg; NX, 5X); D) cristal de biotita alterado para clorita associado a cristais de zircão, magnetita e pirita (NX; 5X). 


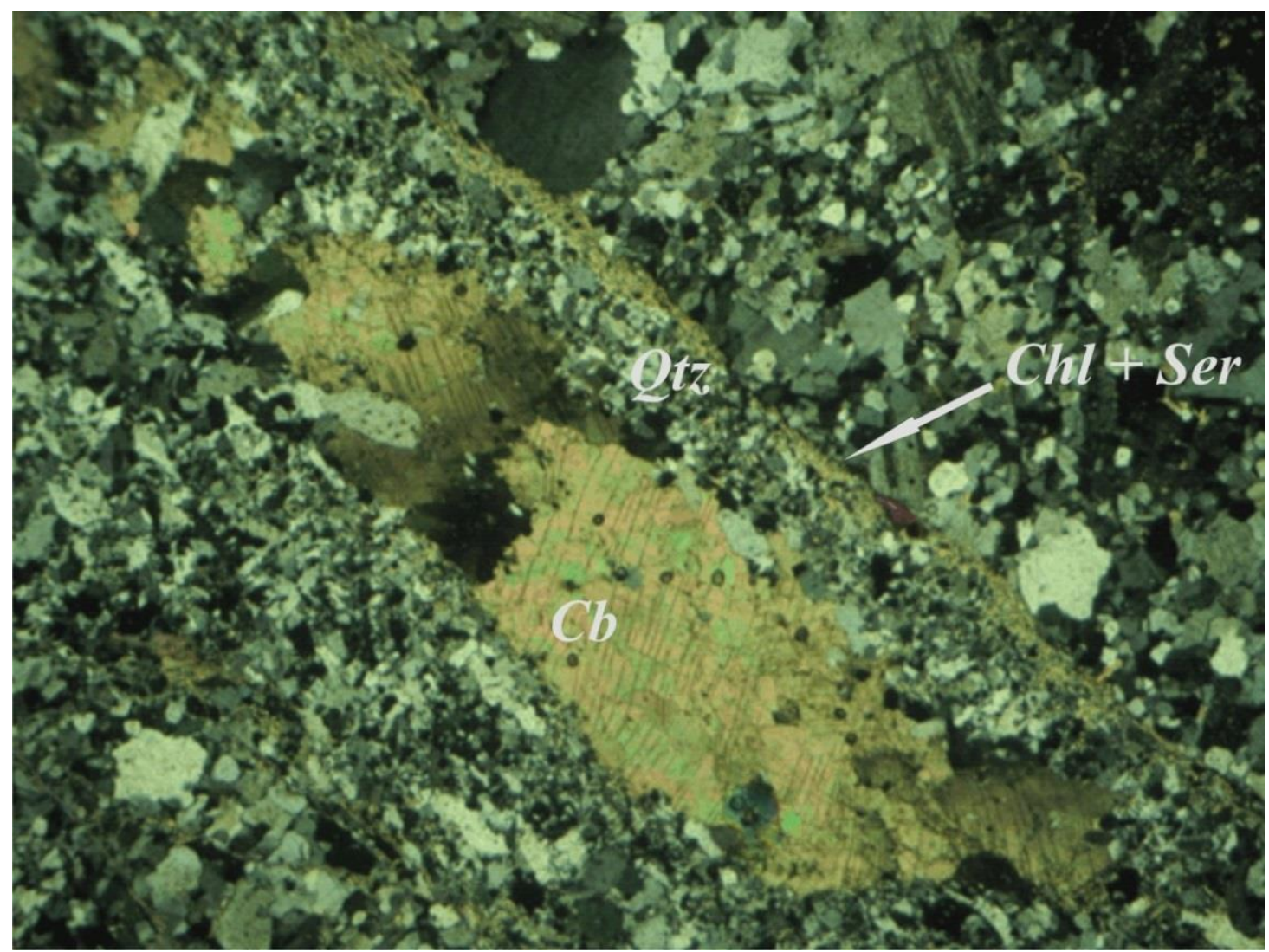

Figura 10: Fotomicrografia de uma das zonas de alteração do dique félsico. Vênulas de quartzo, carbonato e mica branca cortando a massa de aglomeração de grãos de quartzo, plagioclásio e opacos.

\subsubsection{Dique máfico}

Apesar de não datadas, é consenso pela literatura da Província Tapajós que os diques máficos na região são posteriores às rochas graníticas (Mello 2007, Lamarão et al. 2005).

O dique máfico que ocorre no Depósito Tocantinzinho apresenta textura granular hipidiomórfica média a fina, com fenocristais em geral de plagioclásio, de tamanho médio $(0,6 \mathrm{~mm})$, imersos na matriz afanítica, de cor verde-escuro. Em sua matriz ocorre carbonato, clorita e sericita. É comum a formação de veios de carbonato associado à sericita e, de forma secundária, ocorrem veios de quartzo. Na figura 11-A, tem-se a fotografia de uma amostra de mão representativa do dique máfico. Nas figuras 11-B/ 11-C têm-se fotomicrografias representando detalhes do comportamento de alguns dos minerais mais frequentes na amostra, como o carbonato + clorita + anfibólio (Act) + magnetita.

O dique máfico apresenta, com base em sua composição modal aproximada, matriz vítrea (40\%-45\%), cristais de plagioclásio (10\% a 15\%), anfibólio (10\% a 15\%), quartzo (8\% a $10 \%)$ e feldspato potássico (5\%) como minerais essenciais, além de lamelas de biotita cloritizadas $(5 \%)$. Clorita, carbonato e sericita constituem os minerais secundários, os quais 
perfazem cerca de $5 \%$ da composição total. Opacos como magnetita, pirita e calcopirita, ficando em torno de $2 \%$ a $3 \%$ na rocha.

Os cristais de plagioclásio são de tamanho médio $(0,8$ a $1 \mathrm{~mm})$ e estão fortemente fraturados. A maior parte dos cristais está alterada para carbonato, preservando raramente a gemilação.

Os cristais de anfibólio (actinolita) se apresentam de forma subédrica, com tamanhos médios $(0,5$ a $1 \mathrm{~mm})$. Têm coloração verde clara, estão fortemente alterados e fraturados e a maior parte dos cristais já se encontra alterada para clorita. Os grãos de quartzo são finos a médios $(0,2$ a $0,5 \mathrm{~mm})$ e estão fortemente fraturados devido às diversas microfraturas inter e intracristalinas que ocorre na maior parte desses grãos. Essas microestruturas estão preenchidas por material de alteração (clorita +carbonato+ sericita). Carbonato e sericita ocorrem, especialmente, como resultado da alteração de cristais de plagioclásio. A clorita é resultado da alteração de cristais de biotita primária e anfibólio. Os opacos são representados pela pirita, calcopirita, magnetita e, mais raramente, esfalerita. A pirita encontra-se em tamanho fino a médio $(0,2$ a $0,4 \mathrm{~mm})$, subédrica e está distribuída uniformemente na rocha, porém em quantidade pouco representativa $(>1 \%)$. A calcopirita está em quantidade pequena $(>0,5 \%)$ e, quando ocorre, está associada aos cristais de pirita em vênulas de alteração. Os cristais de magnetita são finos $(0,2$ a $0,3 \mathrm{~mm})$ e anédricos, encontram-se associados a outros opacos e, mais raramente, preenchendo vênulas e microfraturas.
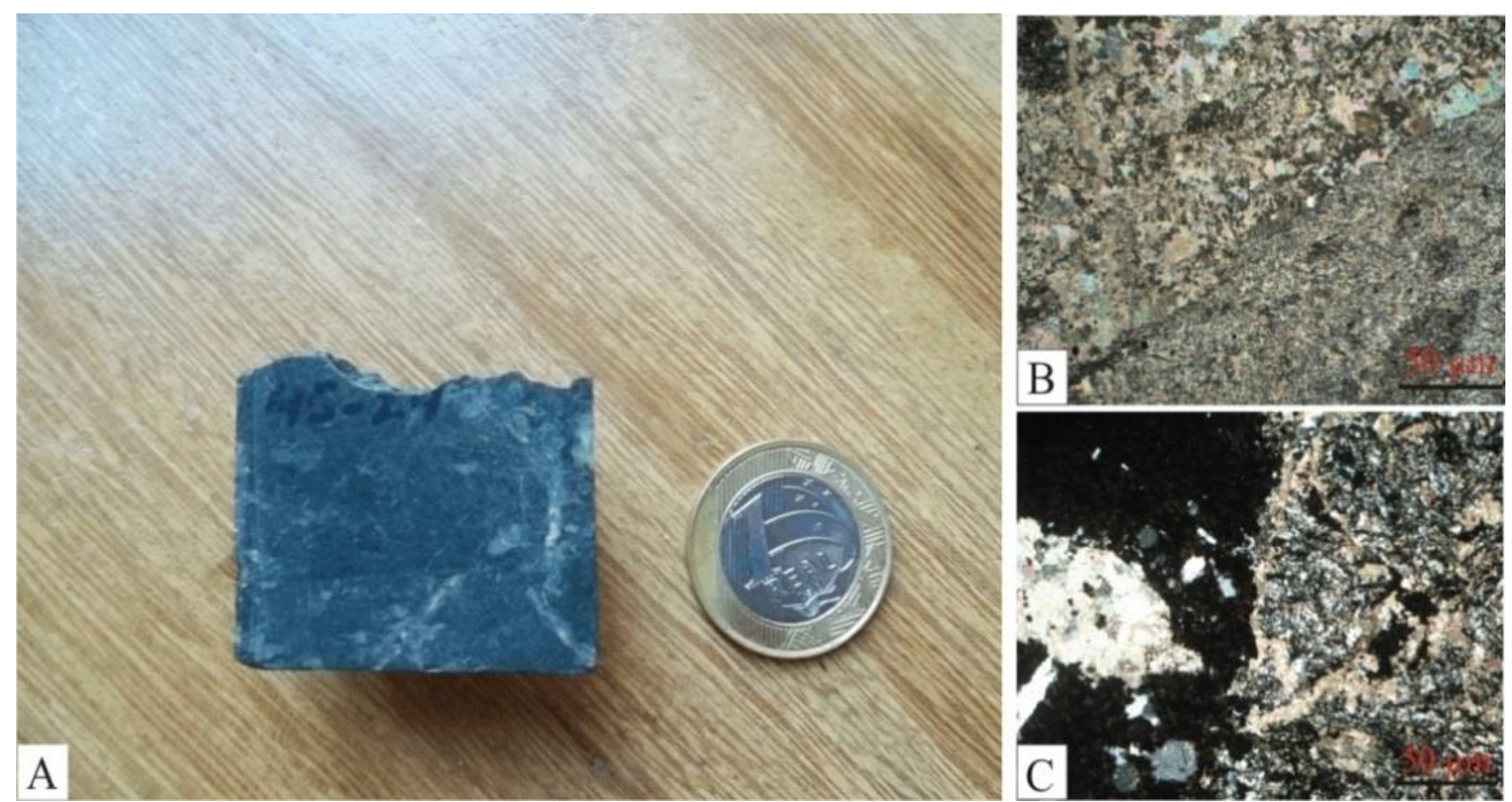

Figura 11: A) Amostra de mão do dique máfico (furo de sondagem TOC-45-24); B e C) fotomicrografias mostrando a textura principal da amostra com carbonato e clorita na matriz (N//, NX; 2,5X). 


\section{ALTERAÇÃO HIDROTERMAL}

\subsection{FÁCIES DE ALTERAÇÃO HIDROTERMAL}

O processo hidrotermal no Depósito Tocantinzinho ocorreu de forma moderada a forte, generalizadamente, e foi determinante para a distinção das fácies mineralizadas.

As rochas hidrotermais do Depósito Tocantinzinho apresentam o mesmo protólito, correspondente à rocha monzogranítica não alterada e encaixante.

$\mathrm{Na}$ área de estudo as duas principais variedades de rochas alteradas e mineralizadas são comumente classificadas, por nativos da área, como Salame e Smoky, mas também já foram assim citadas na literatura da região por Villas et al. (2012), Santiago et al. (2013), Queiroz (2013). As rochas do tipo Salame recebem essa classificação por apresentarem cor vermelha e branca, devido a forte coloração dos cristais de K-feldspato e quartzo leitoso recorrentes nessas amostras. São também enriquecidas em carbonato (carbonatação) e, sericita (sericitização), de forma secundária. As amostras do tipo Smoky são enriquecidas em clorita (cloritização), em quartzo secundário resultante da alteração hidrotermal (silicificação) e sericita (sericitização), o que lhes denota coloração acinzentadada.

Neste trabalho foram analisadas 15 amostras de rochas graníticas, apresentando diversos graus de alteração hidrotermal, do Depósito Tocantinzinho. Com base em estudos petrográficos e levando em consideração suas características macroscópicas, foi possível dividi-las em duas categorias: monzogranito alterado Tipo I (MAT-I), rochas que corresponderiam às do tipo Salame, e monzogranito alterado Tipo II (MAT-II), correspondentes às Smoky.

As rochas que compões o grupo MAT-I apresentam, macroscopicamente, granulação média, são inequigranulares e os principais minerais constituintes são o quartzo, feldspato e plagioclásio. Apresenta coloração avermelhada devido à forte microclinização dos cristais de feldspato. Microscopicamente, os grãos de quartzo são classificados como Qtz1, pois já não apresentam as características da formação magmática. Estão em granulação média a grossa (0,5 a 1,0 mm), com extinção ondulante e contato suturado entre si. Ocorrem nessas rochas, de forma menos frequente, os grãos de quartzo 2 (Qtz2), em resultado da silicificação incipiente. O feldspato potássico predominante é o microclínio e, e o plagioclásio é a albita, mostrando zonamento frequente e maclas raramente presentes. Em geral vênulas de clorita + 
sílica ocorrem recortando as amostras. E a paragênese mineralizada mais comum é pirita + ouro.

As rochas agrupadas em MAT-II (monzogranito alterado tipo II) ocorrem, macroscopicamente, também com granulação média e o arranjo de seus cristais é inequigranular. Têm coloração acinzentada e os principais constituintes dessas rochas são o quartzo 1 e quartzo 2, microclínio e albita. Aqui, o fraturamento e o grau de alteração são mais intensos em relação às rochas do grupo MAT-I; a ocorrência de Qtz1 aqui é localizada e o Qtz2, resultado de uma fase hidrotermal mais intensa, predomina: são grãos finos $(\geq 0,2$ $\mathrm{mm}$ ) e ocorrem de forma aglomerada entre si (vênulas monominerálicas de sílica) ou com cristais de albita e microclínio. A coloração acinzentada se deve muito por conta do forte emaranhado de vênulas sem orientação preferencial, formadas por sericita, além de sílica e sulfetos (pirita + calcopirita + esfalerita + galena + altaíta). Em geral, em paragênese mineralizada dessas amostras é sericita + pirita (pirita + demais sulfetos) + sílica + ouro, reconhecida como alteração fílica, o que faz dessas amostras as mais enriquecidas em ouro.

\subsection{TIPOS DE ALTERAÇÃO HIDROTERMAL}

Os principais tipos são a microclinização, silicificação, cloritização, sericitização e carbonatização. Segundo relatórios internos da empresa Eldorado Gold Corporation, ocorrem também a epidotização e hematização, porém, por serem esporádicas e estarem associadas a rochas não mineralizadas, não foram consideradas como representativas desse sistema.

$\mathrm{Na}$ figura 12, as fotomicrografias mostram porções contendo vênulas e outros padrões recorrentes da alteração hidrotermal no depósito. Os minerais hidrotermais ocorrem comumente em substituição a minerais primários na massa rochosa, entretanto são também encontrados ao longo de fraturas, gerando vênulas mono- ou poliminerálicas, cuja distribuição espacial caracteriza o estilo stockwork.

$\mathrm{Na}$ fase inicial e/ou precoce do processo de alteração tem-se o metassomatismo incipiente, o qual modificou a mineralogia primária das rochas graníticas: o ortoclásio foi microclinizado e; cristais de oligoclásio alterando-se para albita e mostrando zonamento fraco. A biotita magmática está raramente preservada e, em geral, alterada para clorita. Reconhece-se a primeira geração de quartzo corresponde ao quartzo magmático e o quartzo 1, representante das fases mais brandas do processo hidrotermal (figura 13).

A fase metassomática no Depósito Tocantinzinho, a qual resultou em massas de microclínio micropertítico, corresponde à microclinização, especificamente encontrada nas 
amostras do grupo MAT-I. Esse processo foi decisivo, pois levou à caracterização dessa fácies de rochas: A substituição do feldspato potássico primário por microclínio hidrotermal se deu de forma intensa, ao passo que os grãos de quartzo estavam em processo de sobrecrescimento e alteração e adquiriu aspecto leitoso (figura 14-A).

O processo de cloritização, em um primeiro momento, se deu pela substituição de fases máficas principalmente da biotita. Posteriormente, outro processo de cloritização foi reconhecido identificado por conta de vênulas mono- e poliminerálicas com a seguinte paragênese: quartzo + rutilo + clorita + pirita.

A sericitização com o avanço do processo hidrotermal, seu caráter foi expandido, ocorrendo de forma abundante também na alteração de plagioclásio e em vênulas poliminerálicas e, mais raramente, monominerálicas. Segundo análises petrológicas, o caráter mais abundante da sericitização está diretamente relacionado ao fluido mineralizante com paragênese comum sericita + pirita + ouro \pm quartzo 2 + ouro. As amostras do grupo MAT-II, são fortemente e especialmente afetadas pela sericitização e silicificação, o que denota a cor acinzentada característica da maioria dessas rochas (figura 14-B).

A silicificação, apesar de ter havido prévia geração de quartzo hidrotermal, ocorre sequencialmente à sericitização, formando vênulas mono- e poliminerálicas em grande quantidade. A comum paragênese mineralizada dessas vênulas é Qtz2 + sericita + pirita + ouro (fase de alteração fílica) ou quartzo + pirita + ouro (fase de microclinização). A silicificação de deu de forma mais intensa em zonas fortemente fraturadas (padrão stockwork), geralmente associada à sericitização e a mineralização (ouro + pirita + Qtz2 + sericita). 


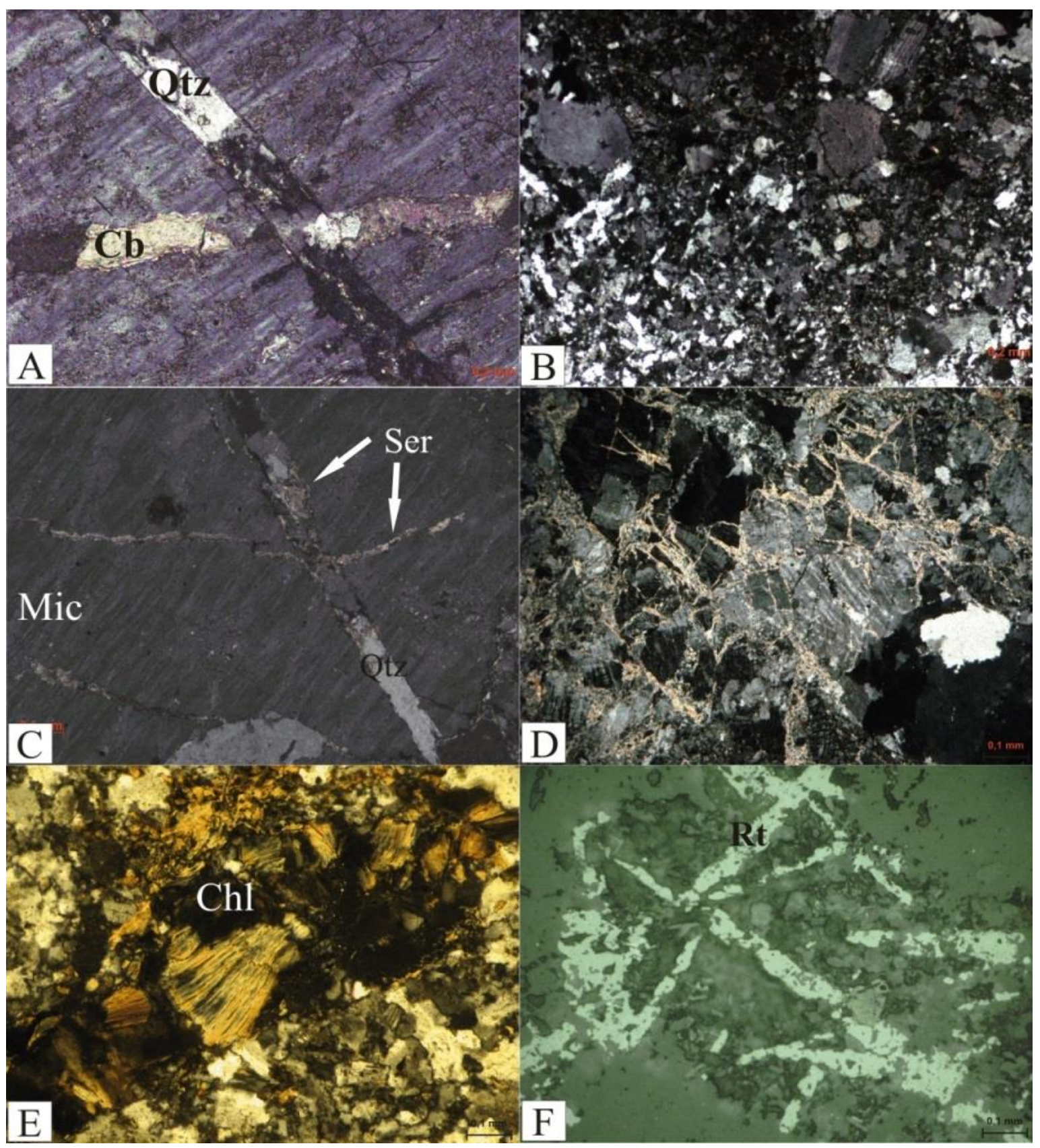

Figura 12: Fotomicrografias mostrando alguns padrões das diferentes alterações hidrotermais que ocorrem no Depósito Tocantinzinho: A) vênula de quartzo sendo truncada por vênulas de carbonato (lâmina 36-24-14); B) massa/ aglomerado resultante da silicificação contendo grande quantidade de pirita (lâmina 26-24); C) vênula de quartzo truncada por vênula contendo sericita e sericita envolvendo parte da vênula de quartzo, mostrandose posterior (lâmina 19-24); D) padrão stockwork em cristal de feldspato, sericitização intensa preenchendo as vênulas que recortam os cristais e aglomerados de sulfetos (pirita + calcopirita) (lâmina 8-57); E) clorita marrom preenchendo vênula truncando porção silicificada (lâmina 19-48); F) massa de rutilo e clorita em vênulas (lâmina 8-48). 

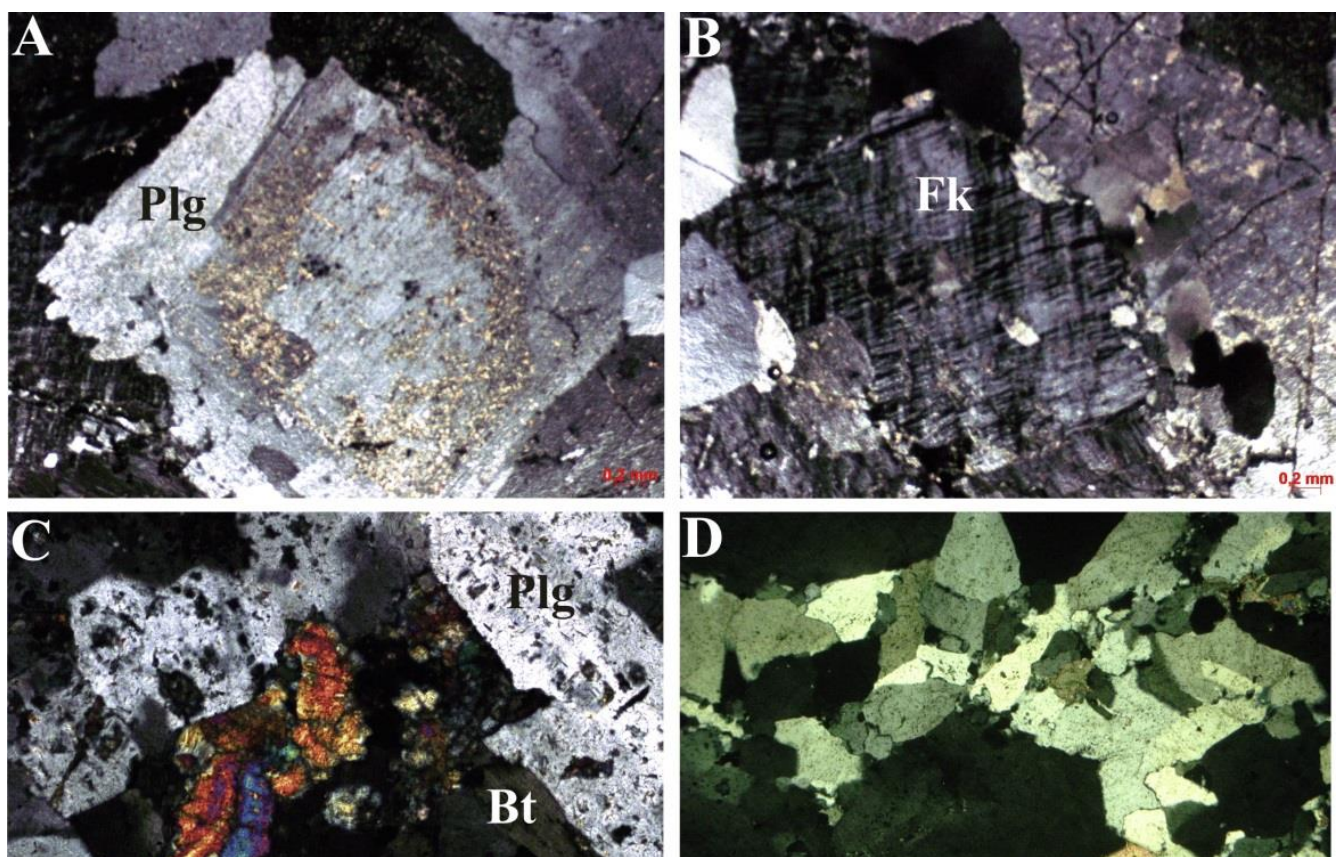

Figura 13: Fotomicrografias das fases de alteração precoce em cristais de plagioclásio e feldspato potássico: A) cristal de plagioclásio zonado, com sericitização fraca; B) cristal de microclínio com inclusões de quartzo; C) cristais de biotita já apresentando composição de clorita junto com titanita, pirita e zircão; D) cristais de quartzo da primeira geração.

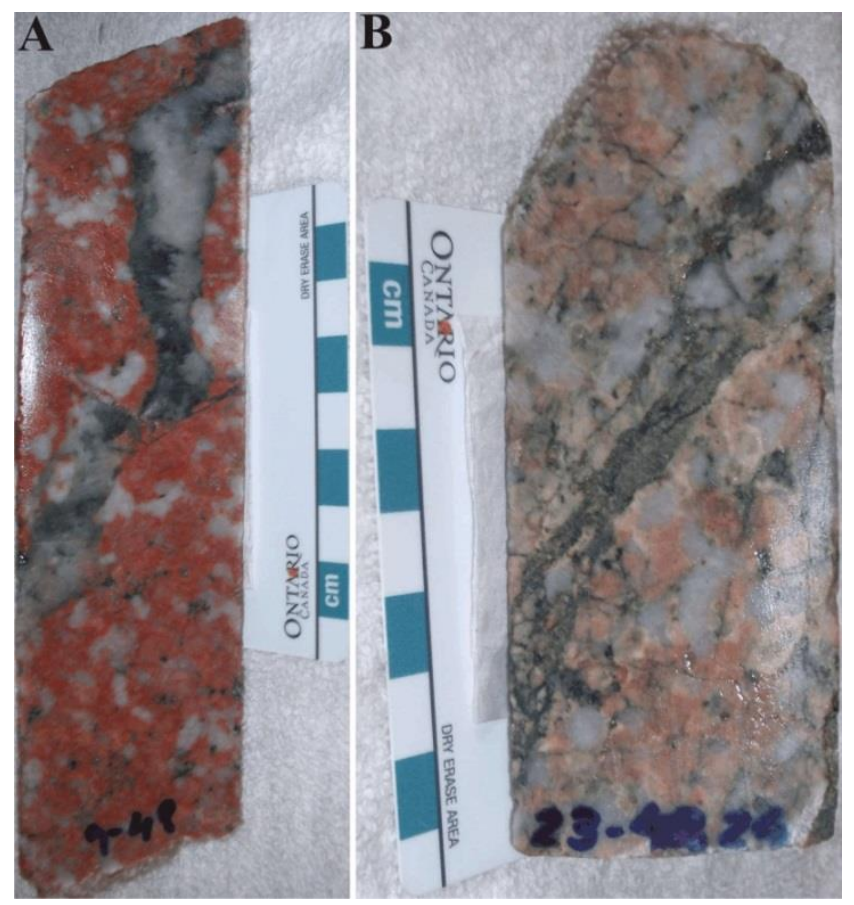

Figura 14: A) amostra representativa do grupo MAT-I mostrando cristais de feldspato potássico substituídos por microclínio e grãos de quartzo leitoso associados; B) amostra do grupo MAT-II. Sericitização e silicificação intensas são os principais processos hidrotermais dessas rochas. 
Marcando o processo de alteração hidrotermal mais tardio do Depósito Tocantinzinho, tem-se a carbonatização. Vênulas monominerálicas ocorrem em geral truncando as demais vênulas resultantes de outros processos hidrotermais.

\subsection{FASES/ ESTÁGIOS DA ALTERAÇÃO HIDROTERMAL}

Apesar da complexidade do sistema hidrotermal que atuou no Depósito Tocantinzinho, foram identificados, com base em dados macroscópicos, estudo petrográfico e geoquímico, quatro estágios da paragênese hidrotermal. A tabela 1 apresenta o resumo dos dados dos estágios de alteração hidrotermal do depósito Tocantinzinho

No entanto, a primeira fase mineral reconhecida no estudo corresponde à fase magmática. Nesta etapa inicial ocorrem os minerais de origem magmática como o quartzo magmático e o feldspato potássico (ortoclásio); o plagioclásio de composição andesina sódica e oligoclásio; a presença de biotita marrom associada a minerais máficos como titanita, magnetita, zircão e epidoto. Essa associação é a que mais se aproxima daquela formada em condições magmáticas e o monzogranito não alterado é coerentemente relacionado a esta fase.

A- O estágio seguinte, representante do início do processo hidrotermal no depósito, é definido como fase pós-magmática precoce. É um estágio de alteração fraco. Nessa fase há o início do processo de alteração dos minerais primários como o ortoclásio dando lugar ao microclínio, e a total substituição da biotita pseudomorfisada alterando para clorita verde. A clorita está, normalmente, acompanhada por carbonatos e micas brancas. A titanita, bem como magnetita, mostram evidências de substituição por minerais opacos e/ou corrosão/ substituição que, no caso da magnetita, mostra porções de hematita. Ocorrem, localmente, porções silicificadas associadas a plagioclásio e microclínio micropertítico. Sulfetos como pirita, calcopirita e já são encontrados, porém em quantidade pouco representativa. Aqui nesta fase são enquadradas amostras de granito com baixo grau de alteração, as quais ainda preservam características de rocha fresca. A figura 15 mostra fotomicrografias representantes de alguns estágios dos minerais no início do processo de alteração. Em 15-A a fotomicrografia do microclínio; em 15-B o cristal de microclínio aparece com inclusões de grãos de quartzo; em 15-C cristal de biotita cloritizadas associada a cristal de titanita; em 15-D cristais de plagioclásio mostrando núcleo sericitizados, porém com as bordas ainda preservadas. As rochas pouco alteradas do Depósito Tocantinzinho, aquelas que mesmo com certo grau de alteração ainda apresentam-se muito próximas ao granito não alterado e/ ou com baixo grau de alteração estão representadas nesta fase da alteração hidrotermal. 
B- A segunda fase hidrotermalizada, classificada como Estágio de Microclinização, tem como principal característica a forte alteração do feldspato potássico, o que resultou nas rochas que formam o grupo MAT-I. Os grãos de quartzo hidrotermal estão totalmente disseminados e adquiriram aspecto leitoso. Nesta fase também há o surgimento de um segundo processo de cloritização, o qual tem como produto a clorita marrom (Chl2). Há aumento de representatividade em relação aos sulfetos (pirita e calcopirita). O rutilo ocorre como subproduto da cloritização (Chl1) da biotita, sendo comumente encontrado incluso ao longo de clivagens de clorita.

C- O terceiro estágio de alteração hidrotermal, caracterizado como Estágio de Alteração Fílica, é caracterizado pela recorrente associação de sericita + pirita + Qtz2. Adicionalmente, nesta fase já não ocorrem mais minerais preservados ou em fase de alteração pertencentes ao estágio magmático, pois deram lugar a uma vasta assembleia de minerais secundários, incluindo os grãos de quartzo neoformados. Além disso, a mineralização predomina nessa fase. Ocorre exclusivamente o microclínio; e o plagioclásio de composição albita, o qual está, em geral, totalmente alterado para sericita. Há aqui aumento no aporte e variedade de sulfetos (pirita, calcopirita, esfalerita, galena e altaíta) e estão em paragênese com a mineração, a qual tem nesse estágio sua principal fase: Qtz2 + sericita+ pirita + calcopirita + galena + esfalerita + ouro \pm altaíta. As rochas do grupo MAT-II são resultado desta fase da alteração hidrotermal no sistema Tocantinzinho.

Na figura 16-A o cristal de plagioclásio substituído por carbonato; em 16-B o cristal de plagioclásio com intensa sericitização, em paragênese com o quartzo; em 16-C a fotomicrografia apresenta textura hipidiomórfica cristais de plagioclásio sericitizados e vênulas de clorita e carbonato; 16-D mostra massas de quartzo recristalizado em equilíbrio com pirita; 16-E os cristais de plagioclásio fraturados, massa de quartzo e pirita; 16-F mostra porções localizadas alteradas com forte sericitização, associada a sulfetos (pirita + calcopirita + magnetita) e opacos (zircão).

D- Nesta última fase, classificada por Estágio de Alteração Tardia, a característica principal é a ocorrência da carbonatização e, na sequência, o início do declínio do processo hidrotermal. Nesta fase tem-se uma terceira geração de clorita (Chl3) tardia, a qual ocorre em vênulas monominerálicas. A carbonatização é forte e, cronologicamente, mostra-se posterior aos demais tipos de alteração. 
Santiago (2012) realizou estudos no Depósito Tocantinzinho que incluíam balanço de massa e concluiu que durante o processo hidrotermal houve maior ganho de massa por unidade de volume nas rochas pertencentes ao grupo MAT-II em relação ao MAT-I.

Segundo Pereira (2006), os diferentes estilos da mineralização compreendem disseminações de sulfetos no granito hospedeiro (MAT-I e MAT-II) e sistemas de veios em zonas de stockwork que apresentam trends predominantemente N20-30 ${ }^{\circ} \mathrm{E} / \mathrm{N} 70-80^{\circ} \mathrm{E}$. Ainda segundo o Autor, dois tipos principais de veios e vênulas são identificados: (1) vênulas milimétricas com quartzo-clorita \pm pirita e (2) veios centimétricos formados por quartzoclorita-carbonato-pirita \pm calcopirita \pm galena \pm esfalerita.

No entanto, a partir dos estudos realizados neste trabalho as evidências apontam para uma mineralização que não ocorre restrita a veios/vênulas, mas também de forma disseminada na rocha, porém em quantidade e frequência inferior em comparação ao primeiro padrão. 

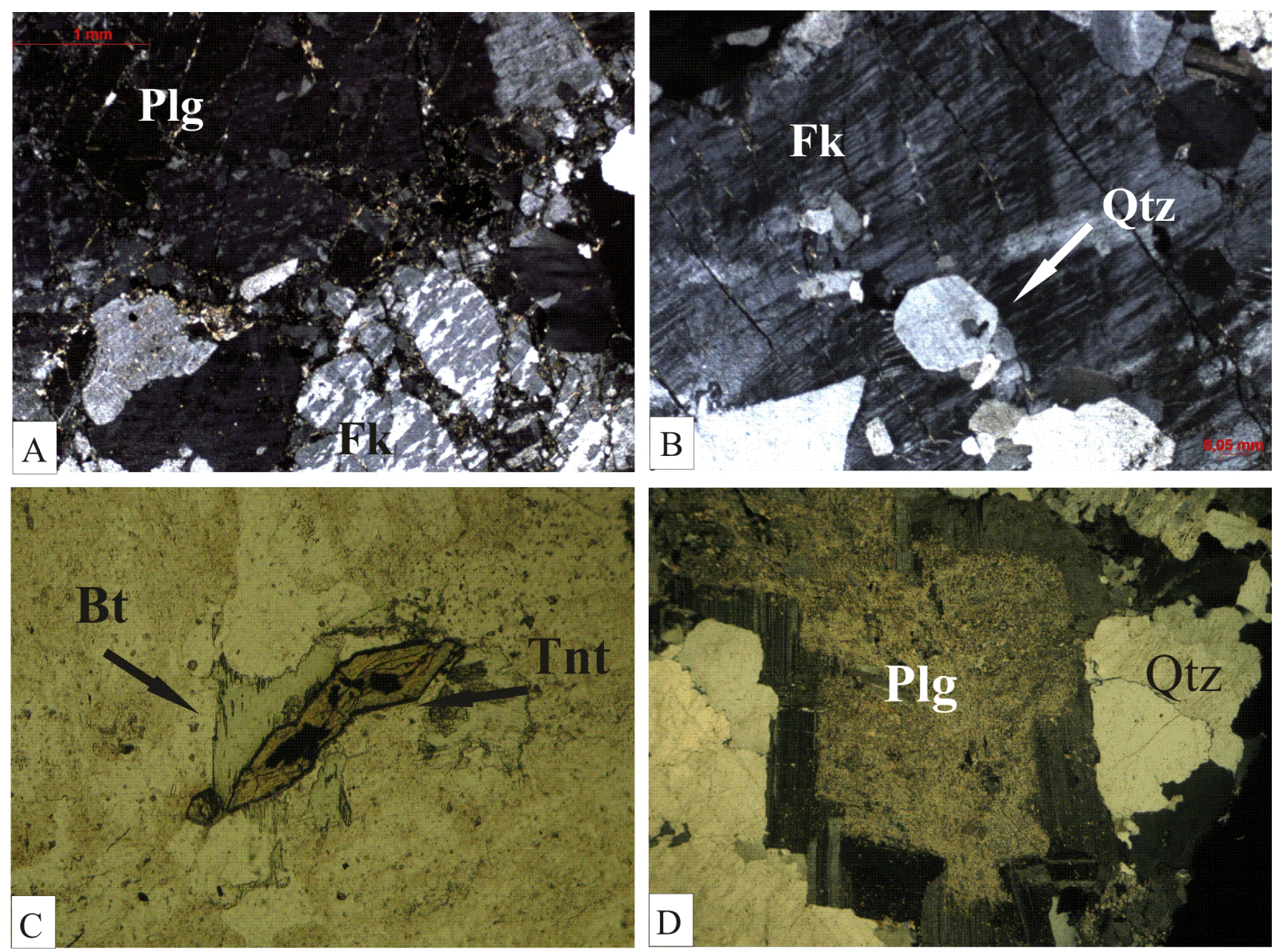

Figura 15: A) fotomicrografia mostrando cristais de plagioclásio fraturados e microclínio em massa de alteração; B) microclínio com inclusões de quartzo; C) biotita cloritizada, levemente orientada, e titanita; D) cristal de plagioclásio com núcleo sericitizado e bordas preservadas em paragênese com grãos de quartzo. 

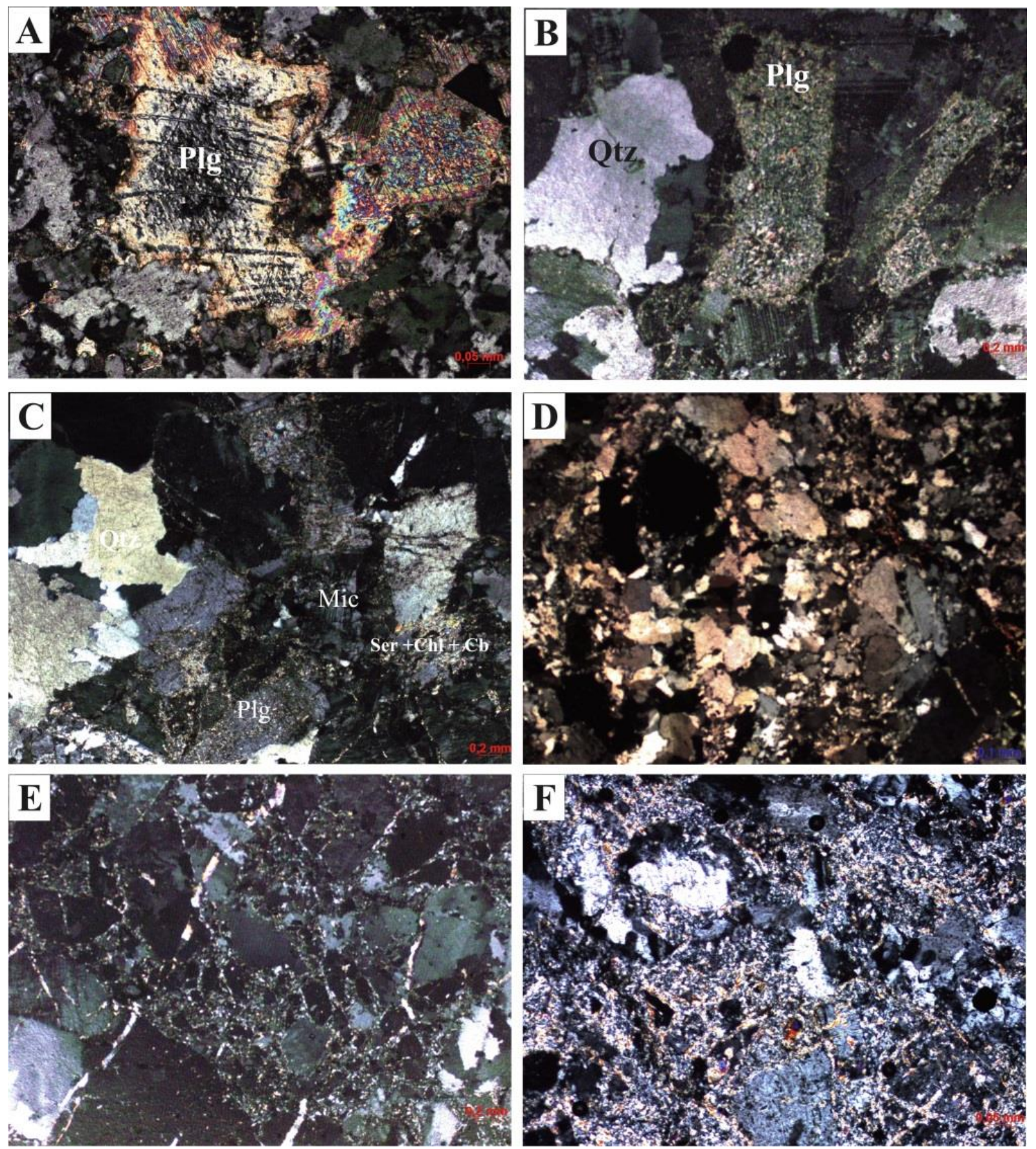

Figura 16: Fotomicrografia de amostras hidrotermalizadas com nicóis cruzados: A) cristal de plagioclásio alterado para carbonato; B) plagioclásio sericitizado em paragênese com quartzo1; C) textura hipidiomórfica com cristais de plagioclásio sericitizados e vênulas de clorita e carbonato; aglomerados ou massa de quartzo recristalizado e cristais de plagioclásio, em paragênese com cristais de pirita; E) aglomerado/ massa de cristais de plagioclásio e quartzo associados a sulfetos; F) sericitização intensa em paragênese com sulfetos (pirita + calcopirita + magnetita) e opacos (zircão). 
Tabela 1: Sequência paragenética da mineralização e alteração hidrotermal do Depósito Tocantinzinho.

\begin{tabular}{|c|c|c|c|c|c|}
\hline $\begin{array}{l}\text { Estágios } \\
\text { Evolutivos }\end{array}$ & $\begin{array}{c}\text { Fase } \\
\text { Magmática }\end{array}$ & $\begin{array}{l}\text { Estágio pós- } \\
\text { magmático } \\
\text { precoce }\end{array}$ & $\begin{array}{c}\text { Estágio de } \\
\text { Microclinização }\end{array}$ & $\begin{array}{l}\text { Estágio de } \\
\text { Alteração } \\
\text { Fílica }\end{array}$ & $\begin{array}{l}\text { Estádio de } \\
\text { alteração } \\
\text { tardia }\end{array}$ \\
\hline
\end{tabular}

Quartzo Magmático

Quartzo 1

Quartzo 2

Ortoclásio

Microclínio

And-Olig

Albita

Biotita

Titanita

Clorita Verde

Magnetita

Hematita

Zircão

Apatita

Epidoto

Clorita Marrom

Clorita tardia

Calcita

Sericita

Rutilo

Pirita

Calcopirita

Esfalerita

Galena

Altaíta

Ouro 
Gênese do depósito de ouro Tocantinzinho, Província Mineral do Tapajós (PA): evidências a partir de dados de geologia, petrologia e inclusões fluidas

\section{CAPÍTULO III: Caracterização geoquímica e mineralógica das rochas do Depósito Tocantinzinho}

\section{LITOGEOQUÍMICA}

Foram feitas análises químicas de elementos maiores e traços em 18 amostras da área estudada, representativas das rochas graníticas preservadas e alteradas, e dos diques máfico e félsico encontrados nos furos de sondagem amostrados (tabela 1).

Em razão da alteração hidrotermal que ocorreu na região e com o intuito de produzir diagramas representativos de suas características químicas, foram selecionadas amostras para estudos petrológicos com valores de perda ao fogo (P.F.) $<2 \%$ (tabela 1).

\subsection{GRANITO}

O monzogranito do Depósito Tocantinzinho apresenta $72 \%$ de $\mathrm{SiO}_{2}$, razão $\mathrm{MgO} /$ $\mathrm{TiO}_{2}$ moderada (1,15), razão de $\mathrm{K}_{2} \mathrm{O} / \mathrm{Na}_{2} \mathrm{O}$ equivalente a 2,3; além de $14,04 \% \mathrm{Al}_{2} \mathrm{O}_{3} 3,87 \%$ de $\mathrm{Na}_{2} \mathrm{O}$; baixos valores de $\mathrm{CaO}(0,98 \%)$ e $\mathrm{MgO}(0,38 \%)$ (tabela 1). Outras amostras graníticas (10_48 A, 4_57, 37_24, 23_24, 27_24, 4_48 B, 4_48, 25_24,18_24 e 10_48B) apresentam valores de $\mathrm{PF}, \mathrm{SiO}_{2}, \mathrm{Na}_{2} \mathrm{O}, \mathrm{K}_{2} \mathrm{O}$ e $\mathrm{CaO}$ semelhantes à amostra não alterada, além de baixo grau de alteração hidrotermal e, por conta dessas semelhança, foi possível relacionar todas essas amostras nos diagramas seguintes para a melhor compreensão do comportamento e padrão das rochas graníticas do Depósito.

$\mathrm{Na}$ figura 17, o diagrama que apresenta o índice de saturação em alumina (ISA = $\left(\mathrm{Al}_{2} \mathrm{O}_{3} / \mathrm{CaO}+\mathrm{Na}_{2} \mathrm{O}+\mathrm{K}_{2} \mathrm{O}\right)$ vs. $\mathrm{SiO}_{2}$; (Shand 1943, Maniar \& Piccoli 1989) diz que as amostras com valores de ISA superiores a 1.2 têm enriquecimento em $\mathrm{Na}_{2} \mathrm{O}$, principalmente. Valores de ISA inferiores a 1.1, intervalo no qual se encaixa a maioria das rochas graníticas do Depósito Tocantinzinho, são comuns nos granitos proterozóicos australianos e rochas vulcânicas comagmáticas, classificados como do tipo I, da série magnetita, metaluminosos a peraluminosos e com valores iguais ou superiores a $72 \%$ de $\mathrm{SiO}_{2}$ (Chappell \& White 1974).

A figura 18 representa o diagrama de alcalinidade de Shand para as amostras mais preservadas do Depósito Tocantinzinho. O caráter peraluminoso corresponde às amostras do granito preservado e outras com mais baixo grau de alteração. (10_48 A, 4_57, 37_24, 23_24, 27_24, 4_48 B e 4_48 A). Outras amostras, com grau de alteração baixo, mostraram caráter metaluminoso (25_24,18_24 e 10_48B) além do dique félsico (11_24), colocando em 
evidência que, mesmo entre as amostras mais preservadas, o grau de alteração hidrotermal se mostra representativo.

Os metais ocorrem com boa representatividade nessas rochas, mostrando altos valores de $\mathrm{Cu}$ (131 ppm), baixos valores de $\mathrm{Ag}$ (2 ppm) e As (7 ppm).

No diagrama de normalização a granitos de cadeias oceânicas (ORG) (figura 19) de Pearce et al. (1984), as amostras de granito mais preservadas e do dique félsico do Depósito Tocantinzinho estão na figura 19-A e o padrão para amostras de arco vulcânico (figura 19-B). As amostras do Depósito Tocantinzinho apresentam comportamento homogêneo e são semelhantes ao padrão para rochas andinas (diagrama 19-B). Aponta-se anomalia positiva de $\mathrm{Rb}$, Th (padrão característico de magmas de séries cálcio-alcalinas e shoshoníticas) além de Ce e Sm, que agem como elementos discriminatórios entre os diferentes tipos de granitos, para valores acima de $65 \%$ de $\mathrm{SiO}_{2}$ a anomalia negativa desses elementos sugere a cristalização fracionada no sistema além de uma possível contaminação crustal pelo magma, características essas que se assemelham às composições de granitos de arco vulcânico andino de Pearce et al. (1984). Anomalia negativa de K, Ba, Ta, Nb, Hf e Zr. Fraca anomalia negativa de Y. Elementos como $\mathrm{Nb}$ e Ta ocorrem em maior proporção em granitos intraplaca em relação aos demais tipos de granitos. A anomalia negativa do Ba levanta a hipótese de maior substituição de $\mathrm{Ca}$ por Ba durante a cristalização do plagioclásio. Zr e Hf diminuem progressivamente de valores com o aumento de $\mathrm{SiO}_{2}(>68 \%$ ) devido ao fracionamento do zircão e a uma possível assimilação crustal.

A figura 20 mostra os diagramas de discriminação tectônica (Pearce et al. 1984) das amostras mais preservadas e do dique félsico do depósito. Segue a leitura dos campos do diagrama: Post-COLG= pós-colisional; $\mathrm{ORG}=$ cadeia meso-oceânica; syn-COLG= sincolisional; $\mathrm{VAG}=$ arcos vulcânicos; WPG=intraplaca. Nos quatro diagramas apresentados $(\mathrm{Rb}$ vs. $\mathrm{Y}+\mathrm{Nb}$; $\mathrm{Nb}$ vs. $\mathrm{Y} ; \mathrm{Rb}$ vs. $\mathrm{Ta}+\mathrm{Yb}$; Ta $v s . \mathrm{Yb})$, as amostras plotam no campo dos granitos de arco vulcânico a pós colisional, conotação já observada na figura 19.

Os valores de ETR foram normalizados ao condrito de Nakamura (1974) e a somatória deles equivale a $\Sigma_{\mathrm{ETR}}=264,78 \mathrm{ppm}$ para o granito não alterado e $\Sigma_{\mathrm{ETR}}=14$ para as amostras de granito pouco alteradas. Além disso, o padrão de fracionamento dos ETRL em relação aos ETRP é moderado, apresentando razões de valores de 15,22 para a razão $(\mathrm{La} / \mathrm{Yb})_{\mathrm{N}}$ e de 15,22 para $(\mathrm{Gd} / \mathrm{Yb})_{\mathrm{N}}$, no granito não alterado. Para as amostras pouco alteradas relacionadas tem-se: razão $(\mathrm{La} / \mathrm{Yb})_{\mathrm{N}}$ de 14,73 e razão média de $(\mathrm{Gd} / \mathrm{Yb})_{\mathrm{N}}$ igual a 2,02. Todas as amostras de granito possuem anomalia negativa de Eu (figura 21). 


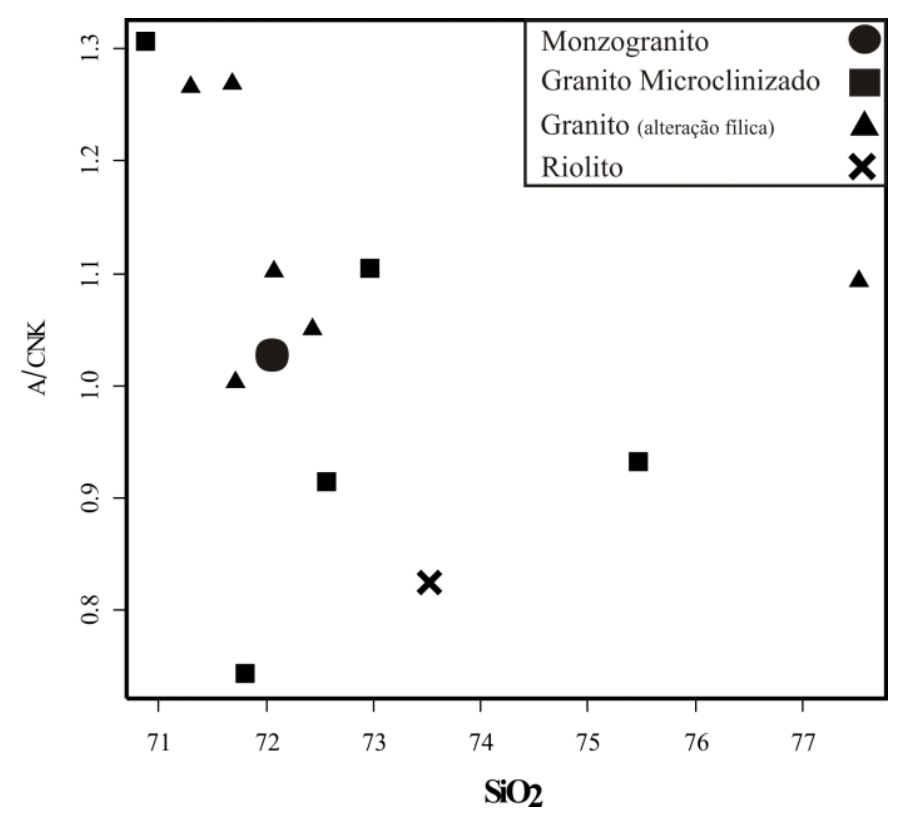

Figura 17: Diagrama de índice de saturação em alumina (ISA) onde A/CNK $=\mathrm{Al}_{2} \mathrm{O}_{3} /\left(\mathrm{CaO}+\mathrm{Na}_{2} \mathrm{O}+\mathrm{K}_{2} \mathrm{O}\right)$. $\mathrm{A}$ amostra do granito $(\bullet)$, assim como a maior parte das amostras com pouco hidrotermalizadas e o dique félsico, localiza-se entre o intervalo de 1,1 .

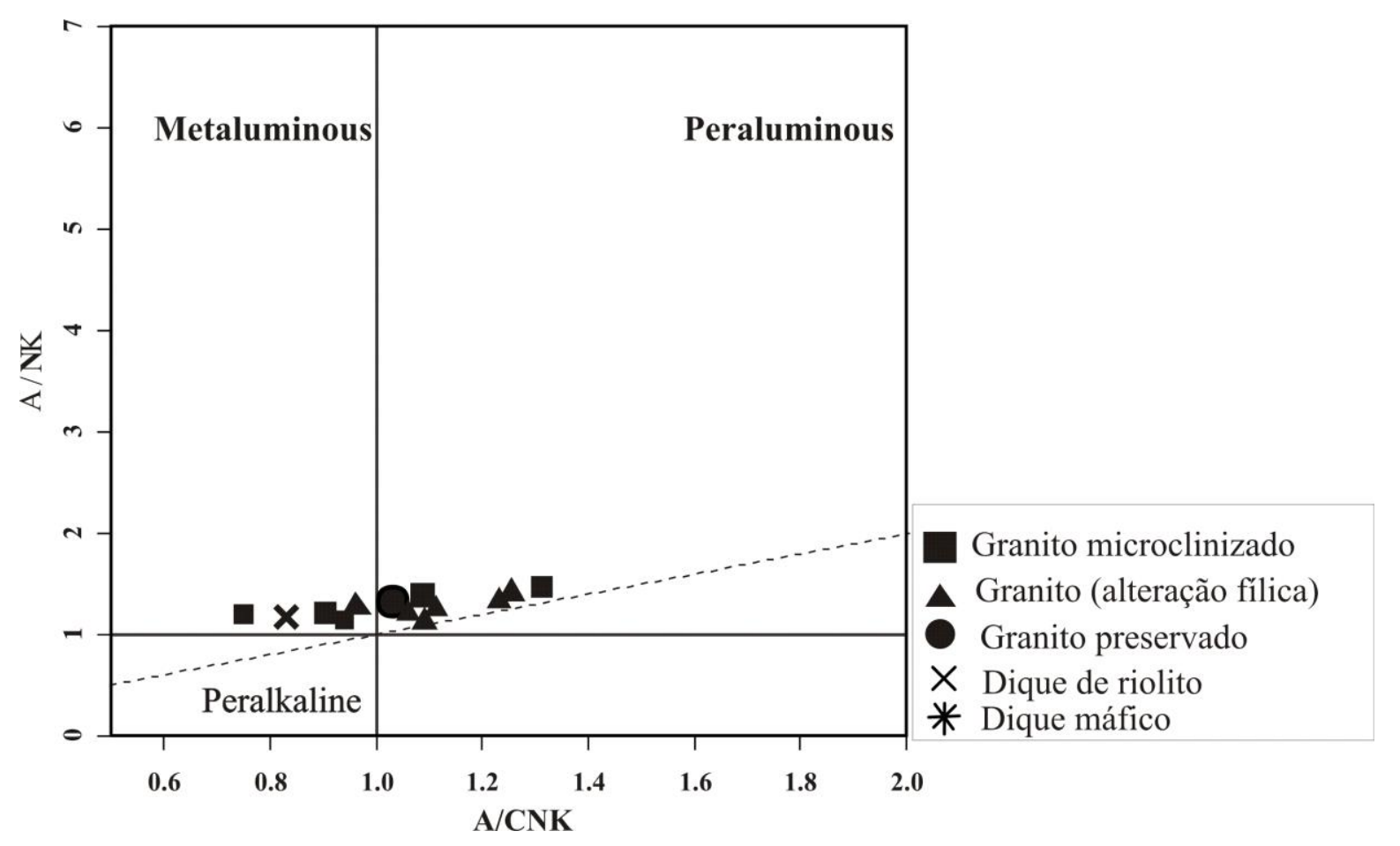

Figura 18: Diagrama de alcalinidade de Shand (1943) mostrando o caráter peraluminoso a metaluminoso das amostras mais preservadas do Depósito Tocantinzinho. 

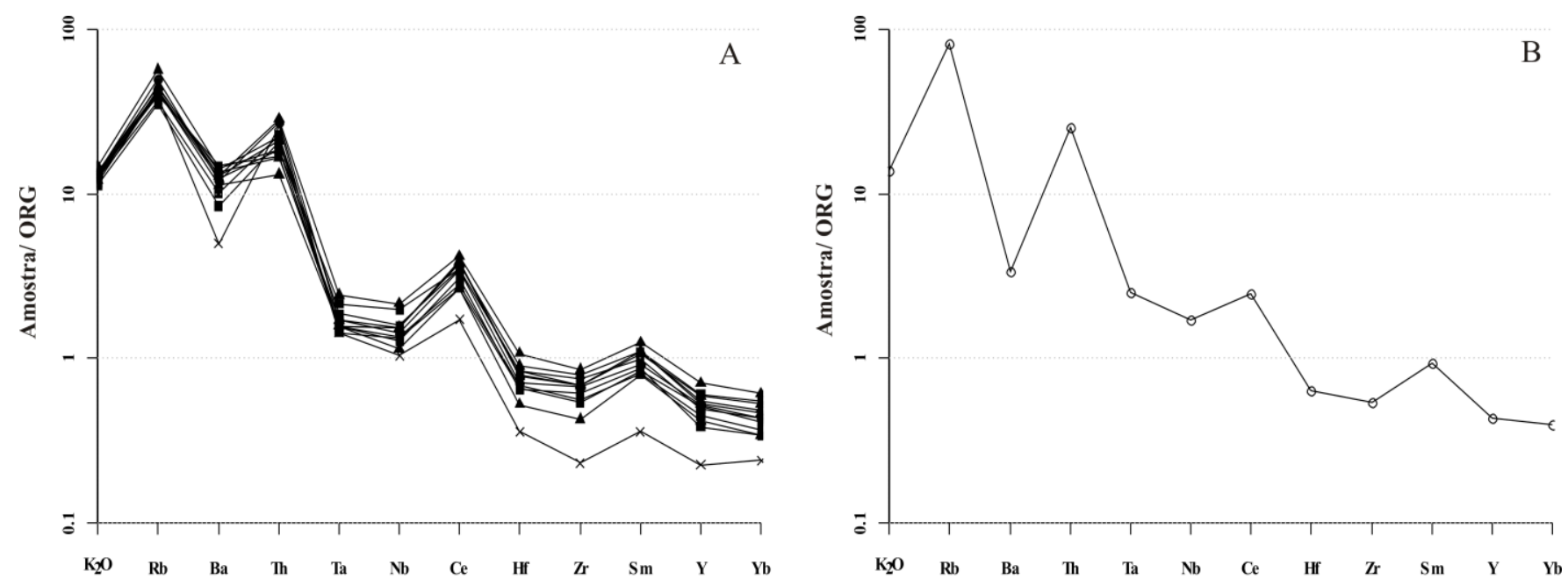

Figura 19: Diagrama de normalização a granitos de cadeias oceânicas (ORG) de amostras graníticas do Depósito Tocantinzinho (A) e padrão para granitos de arco vulcânico (B), com valores de normalização de Pearce et al. (1984). Granito não aletrado $(\bullet)$, amostras de granito pouco alteradas (resultado de alteração fílica $(\boldsymbol{\Delta})$ e microclinizadas ( $\mathbf{\square})$ ) e dique félsico $(\mathbf{X})$.
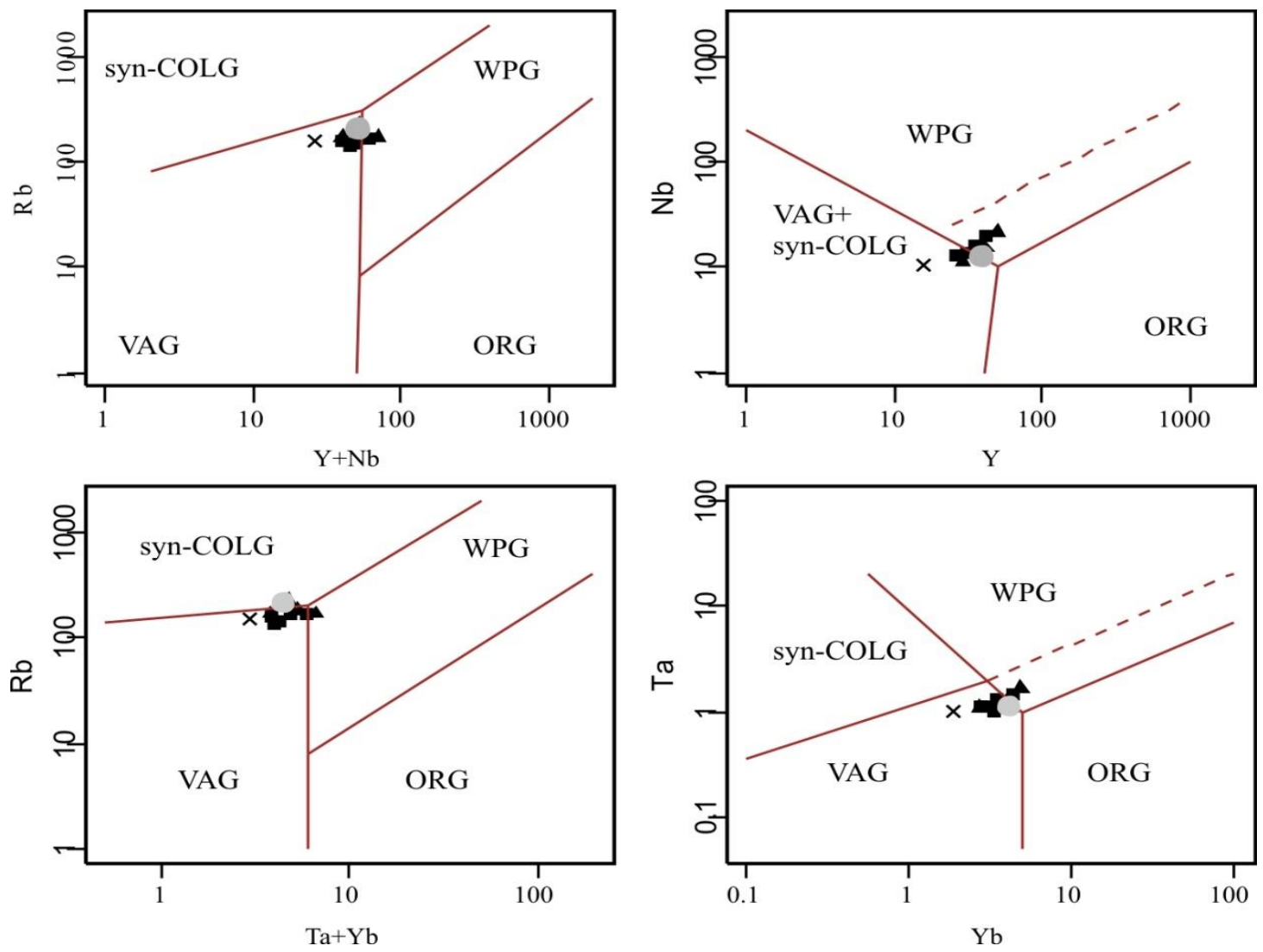

Figura 20: Diagrama de discriminação tectônica (Pearce et al. 1984) de amostras do granito não alterado (•) juntamente com amostras pouco alteradas de granitos hidrotermalizados (microclinizadas (ロ) e resultado da alteração fílica $(\mathbf{\Lambda}))$, além da amostra do dique félsico $(\mathbf{X})$. Post-COLG= pós-colisional; ORG= cadeia mesooceânica; syn-COLG= sin-colisional; $\mathrm{VAG}=$ arcos vulcânicos; WPG=intraplaca. 


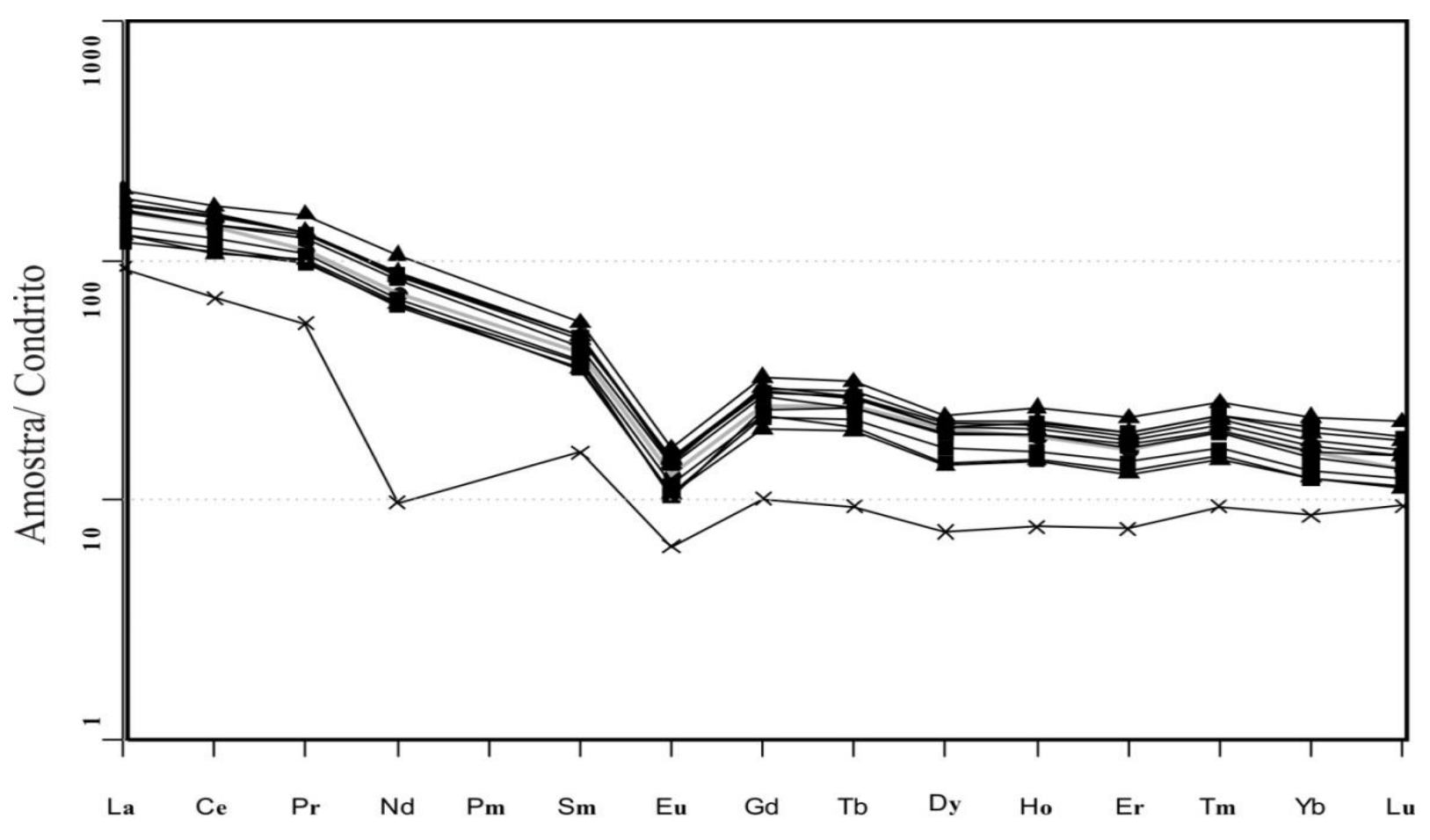

Figura 21: Padrão de distribuição, no granito, dos ETR normalizados ao condrito (Nakamura 1974), mostrando a anomalia negativa do Eu e o padrão semelhante entre as amostras dos granitos nada (•) ou pouco alterados (alteração fílica $(\boldsymbol{\Delta})$ e microclinizadas $(\boldsymbol{\square})$ ) do Depósito Tocantinzinho dique félsico $(\mathbf{X})$.

\subsection{DIQUE FÉLSICO}

O estudo geoquímico do dique félsico identificado no Depósito Tocantinzinho mostra que a rocha é levemente enriquecida em $\mathrm{SiO}_{2}$ em relação ao granito não alterado, apresentando valor de 73,47\% (tabela 1). Os diagramas de variação de elementos maiores do tipo Harker mostram a relativa proximidade dos valores de sílica entre as amostras de granito sem alteração e com baixo grau de alteração e o dique.

Na figura 22 tem-se o diagrama de variação para elementos maiores e nele consta as amostras graníticas analisadas: granito não alterado (1_24), granito com baixo grau de alteração/ hidrotermalismo (10_48 A, 10_48B, 4_57, 37_24, 23_24, 27_24, 4_48 A, 4_48 B, 25_24,18_24), amostras graníticas fortemente hidrotermalizadas (9_48, 19_48, 7_27, 54_24 e 55_24) e dique félsico (11_24). A relação entre as amostra divide- as claramente em dois grupos: $\mathrm{O}$ primeiro grupo formado pela maior parte das amostras, com teores de $\mathrm{Al}_{2} \mathrm{O}_{3}, \mathrm{Na}_{2} \mathrm{O}$ e $\mathrm{K}_{2} \mathrm{O}$ moderados a altos, enquanto que valores de $\mathrm{TiO}_{2}, \mathrm{MgO}, \mathrm{CaO}$ e $\mathrm{P}_{2} \mathrm{O}_{5}$ são, em geral, baixos. No segundo grupo formado pelas amostras 19_48, 54_24 e 55_25, tem-se $\mathrm{Al}_{2} \mathrm{O}_{3}$, $\mathrm{Na}_{2} \mathrm{O}, \mathrm{TiO}_{2}, \mathrm{CaO}, \mathrm{P}_{2} \mathrm{O}_{5}$ e $\mathrm{Fe}_{2} \mathrm{O}_{3}$ mais enriquecidos; equivalência em $\mathrm{MgO}$ e amostras empobrecidas em $\mathrm{K}_{2} \mathrm{O}$. No diagrama $\mathrm{Al}_{2} \mathrm{O} 3$ vs. $\mathrm{SiO}_{2}$ as amostras estão separadas em 3 grupos 
distintos: as amostras com alto teor de alumínio e sílica (19_48, 54_24 e 55_25), amostras com valores moderados nesses óxidos (granito não alterado, dique félsico e rochas com pouco a moderado grau de alteração) e amostras com baixos valores de $\mathrm{Al}_{2} \mathrm{O}_{3}$ e altos valores de $\mathrm{SiO}_{2}$ (10_48 A, 10_48B, 7_27 e 9_48).

A figura 23 mostra a relação de elementos-traço vs. $\mathrm{SiO}_{2}$ das amostras graníticas do Depósito Tocantinzinho. Assim como na figura 22, há a subdivisão das amostras em: um grupo formado pelo granito não alterado e rochas com baixo a moderado grau de alteração (10_48 A, 10_48B, 4_57, 37_24, 23_24, 27_24, 4_48 A, 4_48 B, 25_24,18_24) que apresentam, em geral, valores baixos de $\mathrm{Sr}$, baixos a moderados de Ba e Ni. E o ouro grupo de amostras que apresentam padrão geoquímico diferente: dique félsico e 7_27, 19_48, 54_24 e 55_24. Em geral são empobrecidas em $\mathrm{Rb}, \mathrm{Zr}$, Y, $\mathrm{La}, \mathrm{Ce}$, Ni e nas razões $\mathrm{K} / \mathrm{Rb}$ e $\mathrm{K}_{2} \mathrm{O} / \mathrm{Na}_{2} \mathrm{O}$.

Segundo o diagrama TAS de Le Bas et al. (1992), o dique félsico apresenta composição riolítica. Com base na classificação do diagrama de Shand (1943), as rochas que têm caráter metaluminoso são: 9_48, 18_24, 54_24, 10_48 B, 55_24, 19_48 e 25_24. As rochas com caráter peraluminoso são 1_24, 10_48 A, 4_48 A, 4_48 B, 27_24, 23_24, 37_24 e 7_27. O dique ocorre no campo das rochas metaluminosas, o que se deve, provavelmente, a mudanças pós-magmáticas nos teores de $\mathrm{NaO}_{2}$ e $\mathrm{K}_{2} \mathrm{O}$ (figura 24).

Valores de ETR para o dique félsico são baixos ( $\sum$ ETR=117,35 ppm), mostrando fracionamento moderado de ETR: $(\mathrm{La} / \mathrm{Yb})_{\mathrm{N}}=16,15$. A anomalia do Eu é negativa, porém é menos acentuada quando comparada às anomalias das rochas granito. Apresenta-se mais fracionado em relação aos ETRL $(\mathrm{La} / \mathrm{Sm})_{\mathrm{N}}=9,5$ do que nos ETRP (razão de $(\mathrm{Gd} / \mathrm{Yb})_{\mathrm{N}}$ =1,96). Observa-se acentuada anomalia negativa do $\mathrm{Nd}$ e fraca, porém existente, anomalia positiva do Sm. 

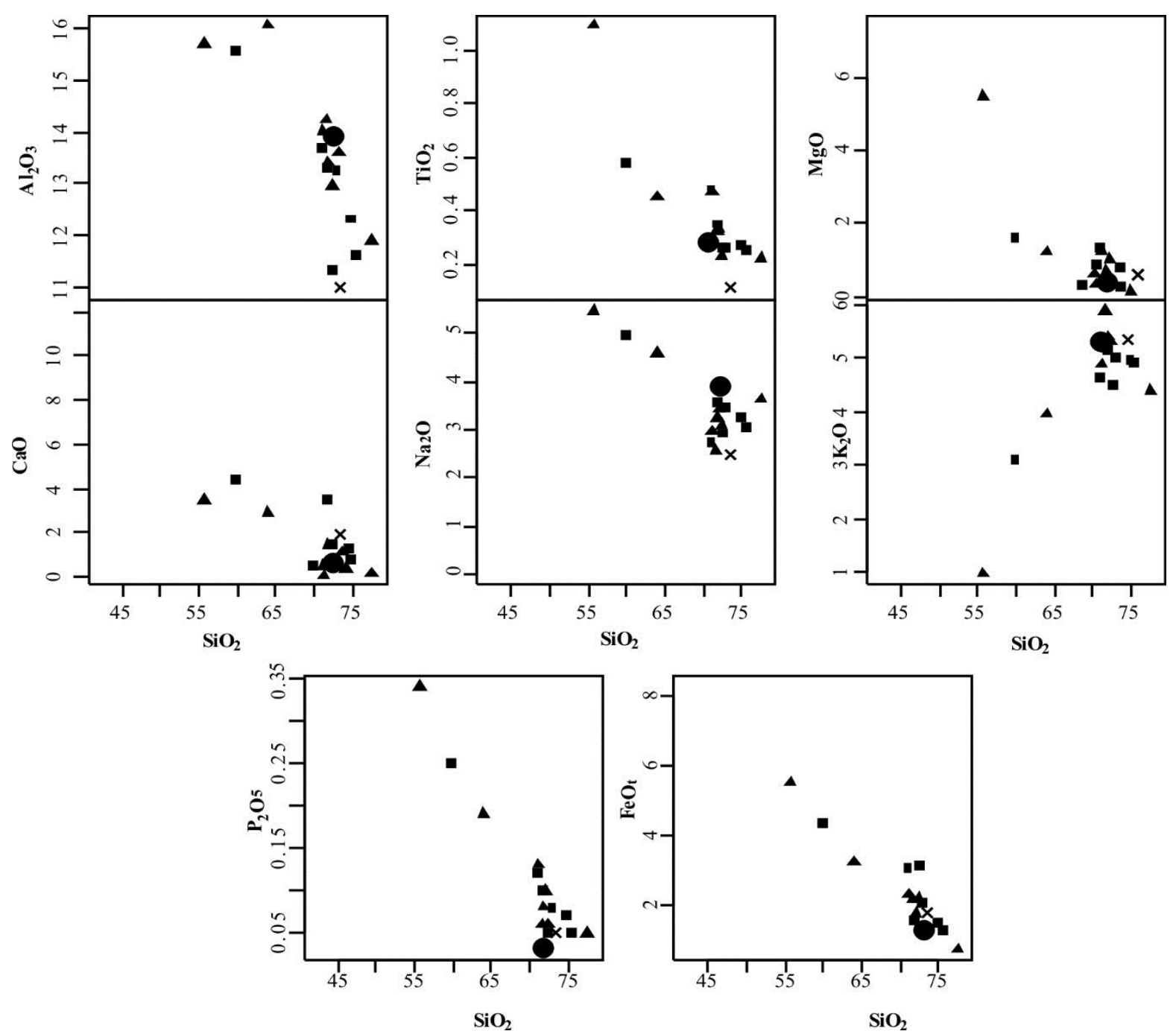

Figura 22: Diagrama de variação do tipo Harker para elementos maiores das amostras do dique félsico (X), do granito não alterado $(\bullet)$ e amostras pouco e fortemente alteradas/ hidrotermalizadas por microclinização (•) e alteradas por alteração fílica $(\boldsymbol{\Lambda})$. 

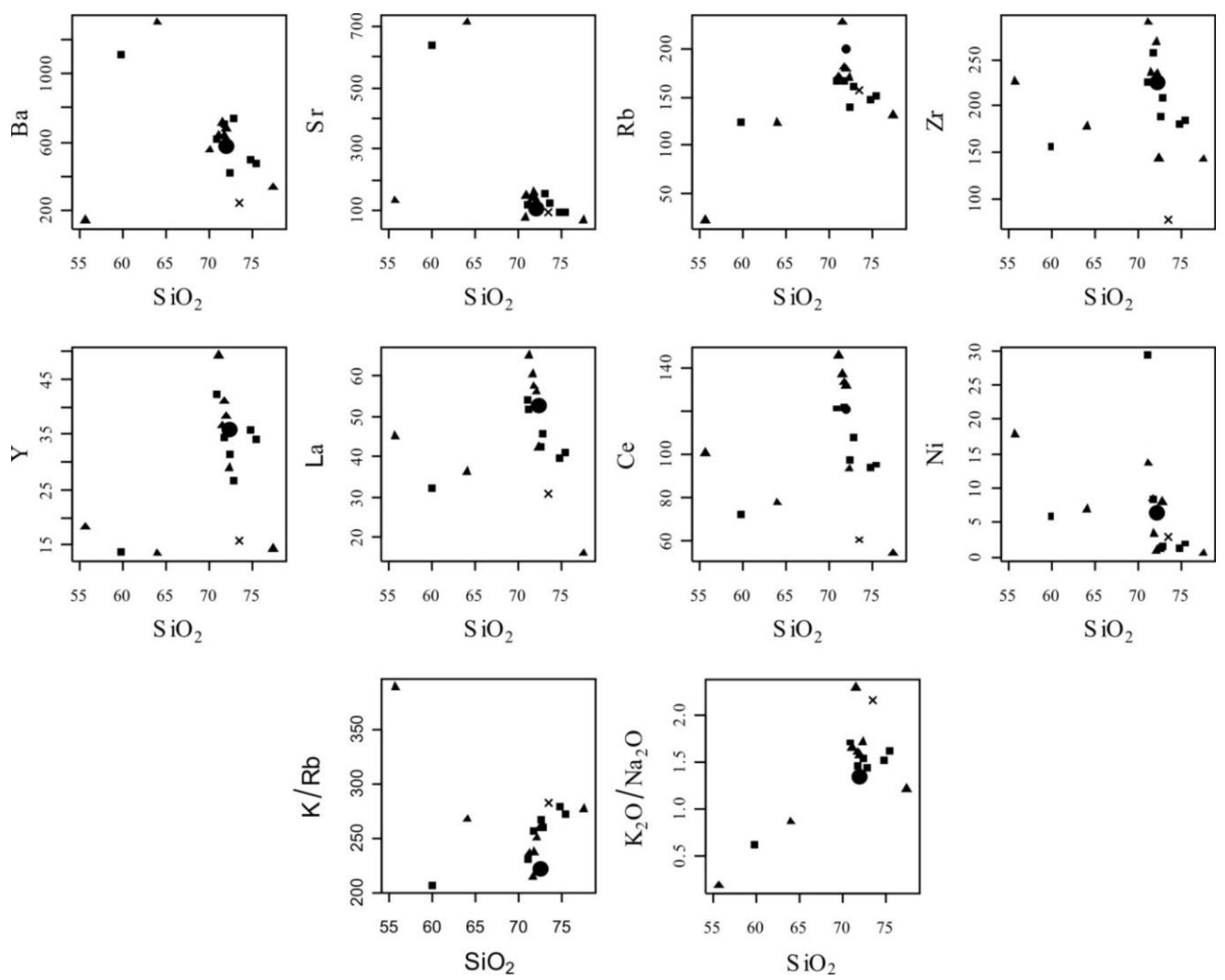

Figura 23: Diagrama de distribuição do tipo Harker para os elementos traço (ppm) vs.SiO2(Wt\%), do dique félsico $(\mathrm{X})$ amostras do granito não alterado $(\bullet)$ e amostras do granito pouco e muito alterados/ hidrotermalizados $(\boldsymbol{\Delta}$ e $\boldsymbol{\square})$ do Depósito Tocantinzinho. 


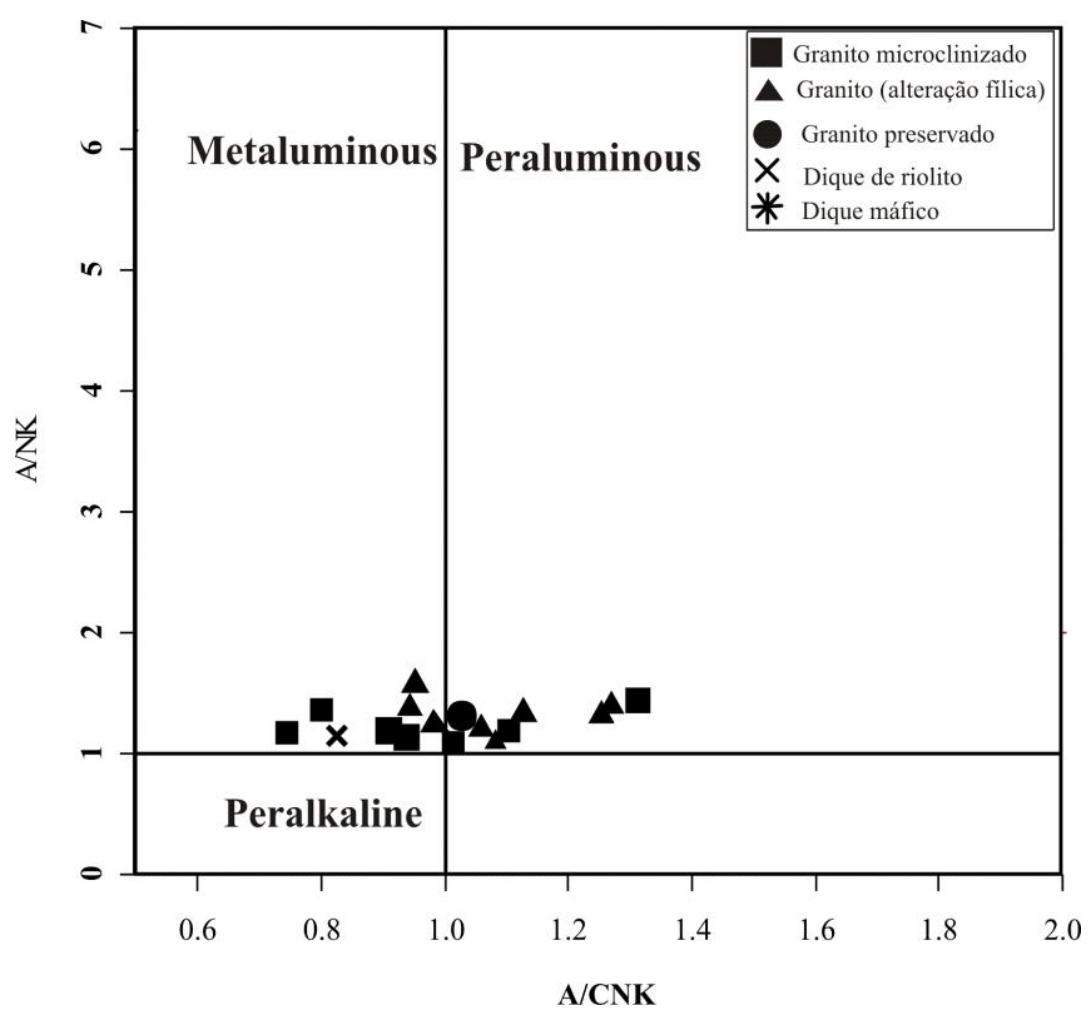

Figura 24: Diagrama de alcalinidade de Shand (1943) mostrando o caráter peraluminoso e metaluminoso de amostras do Depósito Tocantinzinho: 1) Peraluminoso: granito não alterado; amostras de granito pouco hidrotermalizados (10_48 A, 4_56, 4_48 A, 4_48B, 27_24, 23_24, 37_24) e granito muito hidrotermalizado (7_27); 2) Metaluminoso: dique félsico (X); amostras do granito pouco alterado (18_24, 10_48B, 25_24) e do granito fortemente hidrotermalizado (9_48, 19_48, 54_24, 55_24).

\subsection{GRANITOS HIDROTERMALIZADOS}

Ao todo foram 15 amostras analisadas correspondentes as rochas resultantes da alteração hidrotermal sobre o granito que se deu sobre o Depósito Tocantinzinho.

Geoquimicamente, o monzogranito alterado Tipo I (MAT-I) mostrou valores médios de $\mathrm{SiO}_{2}$ em torno de $71,19 \%$, valores de $\mathrm{Al}_{2} \mathrm{O}_{3}$ iguais a $13,01 \%, \mathrm{Na}_{2} \mathrm{O}$ de $3,42 \%$ e $1,77 \%$ de $\mathrm{CaO}$ (tabela 2). A razão $\mathrm{K}_{2} \mathrm{O} / \mathrm{Na}_{2} \mathrm{O}$ é de $1,35 \%$.

Amostras do monzogranito alterado Tipo II (MAT-II) apresentam, em média, valor mais baixo de $\mathrm{SiO}_{2}, 69,53 \%$, relativamente inferiores à média dos MAT-I. Os valores de $\mathrm{TiO}_{2}, \mathrm{MnO}$ e $\mathrm{MgO}(0,43 \%, 0,05 \%$ e $1,28 \%)$ são relativamente maiores que os valores desses óxidos no MAT-I, devendo-se provavelmente à maior quantidade de clorita nessas amostras do que nas do grupo MAT-I. O valor médio de $\mathrm{Al}_{2} \mathrm{O}_{3}$ nas rochas MAT-II (14,04\%) também é superior. Já a razão $\mathrm{K}_{2} \mathrm{O} / \mathrm{Na}_{2} \mathrm{O}$, de 1,24\%, mostra-se levemente inferior a do MAT-I.

Teores de $\mathrm{Fe}_{2} \mathrm{O}_{3}(\mathrm{t})$ são superiores nas variedades MAT-II (2,71\%), quando comparado à MAT-I, o que dificulta explicar a coloração avermelhada predominante nas amostras do MAT- em termos de teor de ferro. 
O diagrama de variação do tipo Harker mostra os principais padrões dos elementostraço das amostras alteradas do Depósito Tocantinzinho (figura 25). Dados de elementos-traço das amostras do MAT-I mostram valores médios de $\mathrm{Ba}$ (653 ppm), Sr (183,5 ppm) e Rb (127 ppm). Enquanto que os valores correspondentes das do MAT-II são respectivamente 626,1 ppm; 189,4 ppm; 150,5 ppm, ou seja, as amostras de MAT-I são mais enriquecidas em Ba e levemente empobrecidas em Sr e Rb. Nota-se também que as amostras mais enriquecidas em $\mathrm{SiO}_{2}$ apresentam diminuição progressiva de $\mathrm{Ba}$ em suas composições.

Quatro amostras apresentam comportamento diferente, na maioria dos gráficos, em relação às demais amostras graníticas estudadas: 19_48, 54_24, 55_24 e 7_27. A amostra $19 \_48$ se destaca por seu baixo percentual de $\mathrm{SiO}_{2}(55,66 \%$, o menor valor entre as rochas graníticas estudadas) e alto de $\mathrm{Al}_{2} \mathrm{O}_{3}(15,69 \%), \mathrm{Fe}_{2} \mathrm{O}_{3}(6,15 \%)$ e $\mathrm{CaO}(3,47 \%)$. Valores baixos de $\mathrm{Ba}, \mathrm{Zr}$ e $\mathrm{Rb}$ e valores moderados de $\mathrm{Sr}$ e $\mathrm{Zr}$ ). Já as amostras 54_24 e 55_24 apresentam comportamento semelhante entre si. Valores de $\mathrm{SiO}_{2}$ entre $60 \%-65 \%$, altos valores de $\mathrm{Al}_{2} \mathrm{O}_{3}$ $(15,54 \%$ e 16, 06\%, respectivamente), valores moderados de $\mathrm{CaO}(4,38 \%$ e 2,93\%, respectivamente). Quanto aos elementos traço, as duas amostras têm altos valores de Ba (1106 e 1298 ppm), Sr (638 e 714 ppm). Quanto ao Rb e Y, mostram valores mais baixos que a média das demais amostras. A 7_27 se destaca por seu seus baixos teores Ba, Sr, Y e Zr e alto valore de $\mathrm{SiO}_{2}$. No diagrama $\mathrm{Sr} / \mathrm{Ba}$ vs. $\mathrm{SiO}_{2}$ as amostras 19_48, 54_24 e 55_25 apresentam valores levemente superiores ao grupo homogêneo das demais amostras.

Os metais como $\mathrm{Au}$ e $\mathrm{Cu}$ estão em concentração superior, em média, nas amostras do monzogranito MAT-II (7090,2 ppb e 145,2 ppm, respectivamente) em relação as amostras do MAT-I (4089,3 ppb e 111,0 ppm). As amostras de MAT-II também são enriquecidas em Pb, As, Bi, Cd e Zn, (145,25 ppm, 6,06 ppm, 0,6 ppm, 1,88 e 163,8 ppm) em relação às de MATI (54,4 ppm, 4,9 ppm, 1,04 ppm, 0,10 ppm e 34,8 ppm).

Os valores referentes aos ETR foram normalizados ao condrito de Nakamura (1974) (figura 26 A-B). A figura 26-A corresponde às amostras do MAT-I e essas mostram valores médios de $\Sigma \mathrm{TR}_{=} 229,41$ e a razão $(\mathrm{La} / \mathrm{Yb})_{\mathrm{N}}$ varia de 12,22 a 40,8. A figura 26-B mostra os gráficos de padrão de distribuição dos ETR para as amostras do tipo MAT-II. Nela, a maioria das amostras exibe padrão de fracionamento moderado dos ETRL em relação aos ETRP com anomalia negativa do Eu. A amostra 9_48 apresenta anomalia negativa do Eu e Yb.

Para as amostras do MAT-II os valores médios dos ETR são de $\Sigma$ TR $=242,63$ e a razão $(\mathrm{La} / \mathrm{Yb})_{\mathrm{N}}$ varia de 13,39 a 16,39. Na figura 21-B a maioria das amostras tem leve fracionamento dos ETRL em relação aos pesados e anomalia negativa do Eu, com exceção 
das amostras 19_48, 55_24 e 7_27 as quais a razão de fracionamento entre ETRL e ETRP menos expressiva $\left((\mathrm{La} / \mathrm{Yb})_{\mathrm{N}}=17,74\right)$, além disso, as três amostras apresentam um leve enriquecimento em $\mathrm{Tm}$.
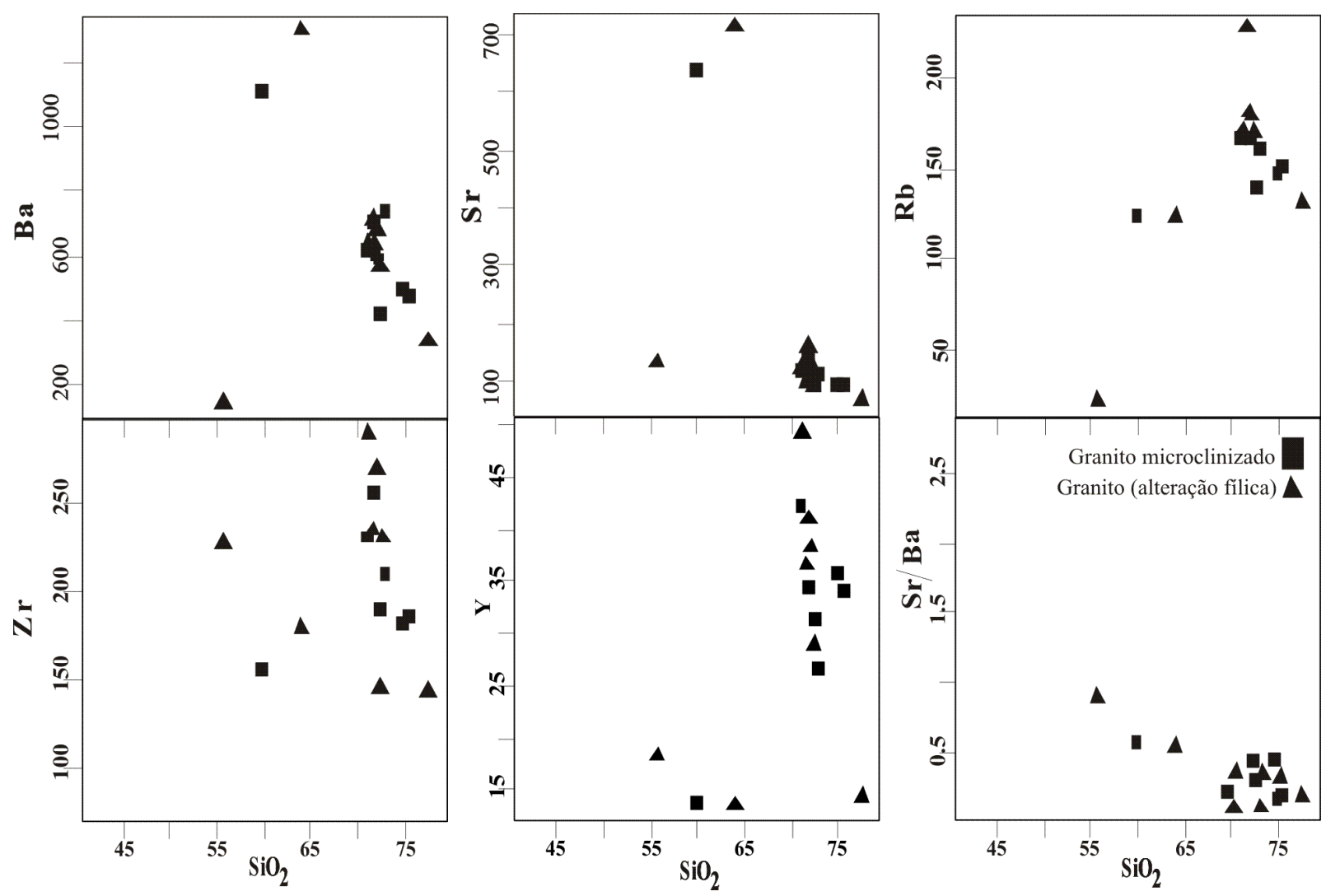

Figura 25: Diagrama de variação do tipo Harker mostrando o comportamento dos principais elementos-traço das amostras alteradas/ hidrotermalizadas (MAT-I e MAT-II) do Depósito Tocantinzinho. 

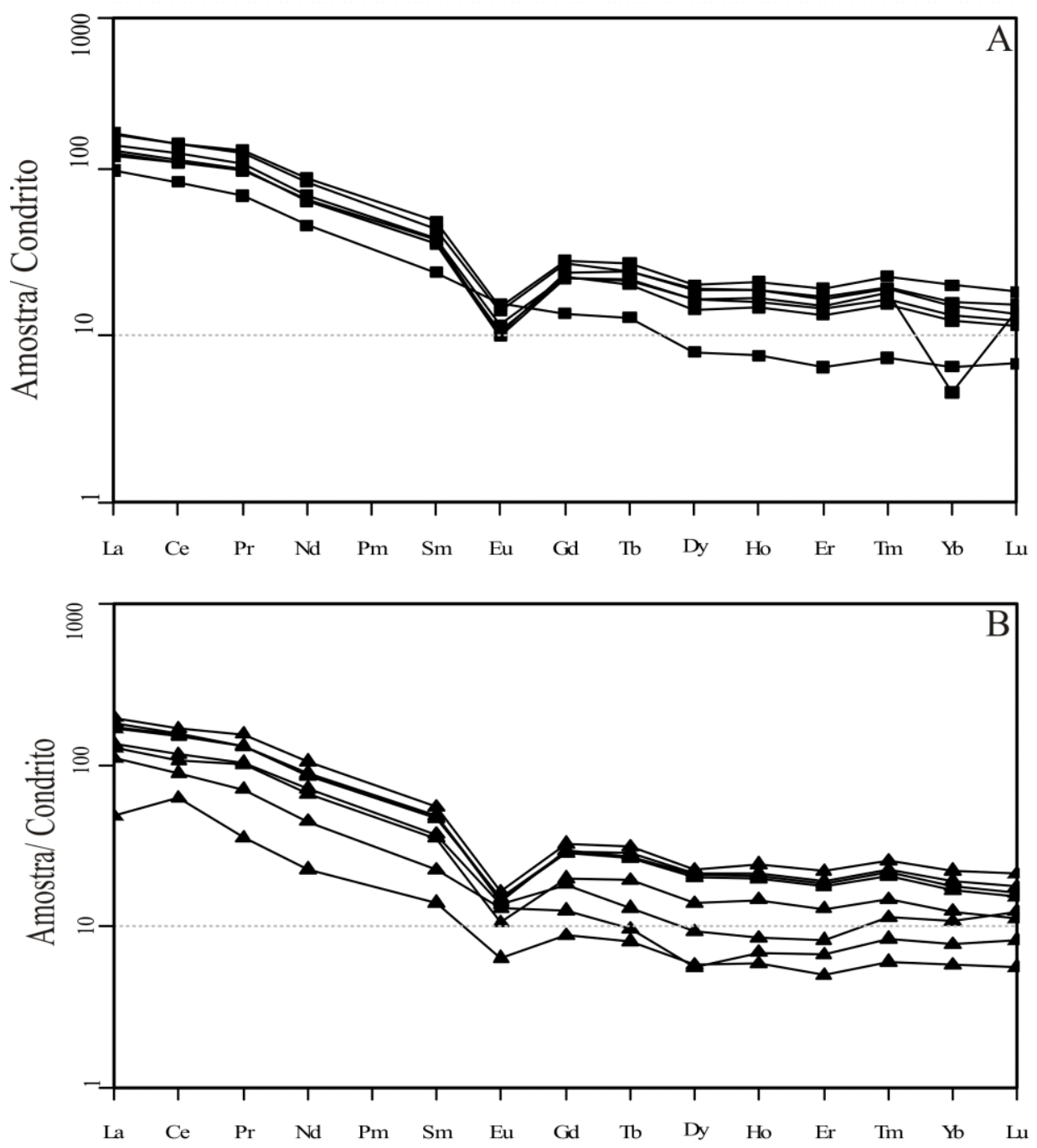

Figura 26: Padrões de distribuição dos elementos terras raras referentes aos monzogranitos alterados normalizadas ao condrito (Nakamura 1974). A) as amostras de granito microclinizado; B) amostras resultadas de alteração fílica. 


\subsection{DIQUE MÁFICO}

A caracterização e discriminação do dique máfico tem o objetivo de melhor compreendê-lo no contexto do Depósito Tocantinzinho. Desse modo, o estudo geoquímico dessa rocha é uma ferramenta fundamental para a compreensão da sua relação com as rochas ácidas e até mesmo com a mineralização.

$\mathrm{O}$ valor de $\mathrm{SiO}_{2}$ da amostra equivale a 42,43\% e altos valores de $\mathrm{MgO}(7,46 \%)$ e $\mathrm{Fe}_{2} \mathrm{O}_{3}(9,19 \%)$ ).É rico em $\mathrm{K}_{2} \mathrm{O}(1,72 \%)$, apresenta valor moderado a alto de $\mathrm{CaO}(12,06 \%)$ e baixos valores de $\mathrm{TiO}_{2}(0,51 \%)$.

$\mathrm{O}$ valor de \#mg $\left(\left[\mathrm{MgO} /\left(\mathrm{MgO}+\mathrm{Fe}_{2} \mathrm{O}_{3}\right)\right]\right.$ é baixo a moderado $(0,45)$ e o teor de $\mathrm{Ni}$ fica em torno de 75,1 ppm. Magmas toleiíticos derivados de manto possuem \#mg superior a 0,68 e teor de Ni entre 300 e 500 ppm, o que sugere que o dique máfico estudado representa, também, magma máfico diferenciado.

Com base no diagrama de TAS (Le Bas et al. 1992), o dique máfico se encaixa na classificação de basalto (figura 27). Segundo o diagrama de ambiente tectônico proposto por Pearce \& Cann (1973), o dique de composição basáltica é classificado como basalto calcioalcalino (figura 28).

Os elementos litófilos de grande raio (LIL) tais como $\mathrm{Ba}, \mathrm{Rb}, \mathrm{K}, \mathrm{Sr}$ e Th são em geral interpretados como móveis (Pearce 1982). Elementos incompatíveis, como Nb, Ti, Zr, P, Hf, Ta, Y, Ni e Cr, e ETRL, que são relativamente imóveis durante processos de alteração semelhantes aos experimentados pelas rochas estudadas e em metamorfismo de baixo grau, podem ser empregados em estudos petrológicos e geotectônicos. O diagrama da figura 29 trás o padrão de distribuição multielementar do manto primitivo (Sun \& McDonough, 1989), mostrando o comportamento desses elementos no dique máfico do Depósito Tocantinzinho. Observa-se, neste caso, acentuada anomalia positiva do K, $\mathrm{Pb}$ e $\mathrm{Sr}$ e negativa do $\mathrm{Ba}, \mathrm{Nb}$ e Ti. Baixos valores de $\mathrm{Ti}$ e $\mathrm{P}$ em diques máficos, o que nos permite sugerir que a rocha pode apresentar contaminação crustal (Carlson 1991).

A $\sum E T R$ é de 93,16 ppm. Seu padrão está normalizado ao condrito de Nakamura (1974) e se mostra pouco fracionado. O valor da razão $(\mathrm{La} / \mathrm{Yb})_{\mathrm{N}}$ é de 8,98 e a anomalia do $\mathrm{Eu}$ é ausente (figura 30). 


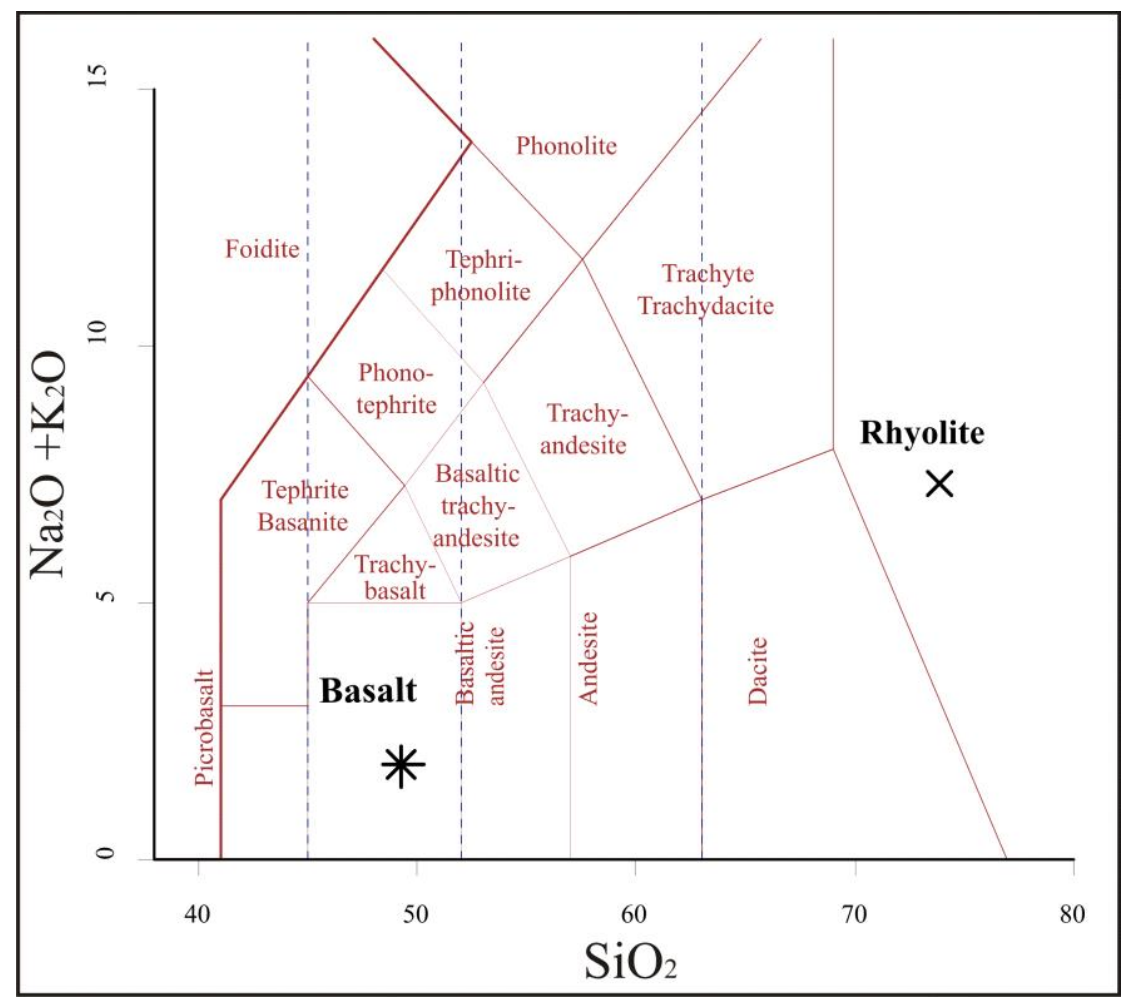

Figura 27: Amostras de dique máfico (*) e félsico (x) no diagrama TAS de Le Bas et al. (1992): dique máfico apresenta composição basáltica e o dique félsico, composição riolítica.

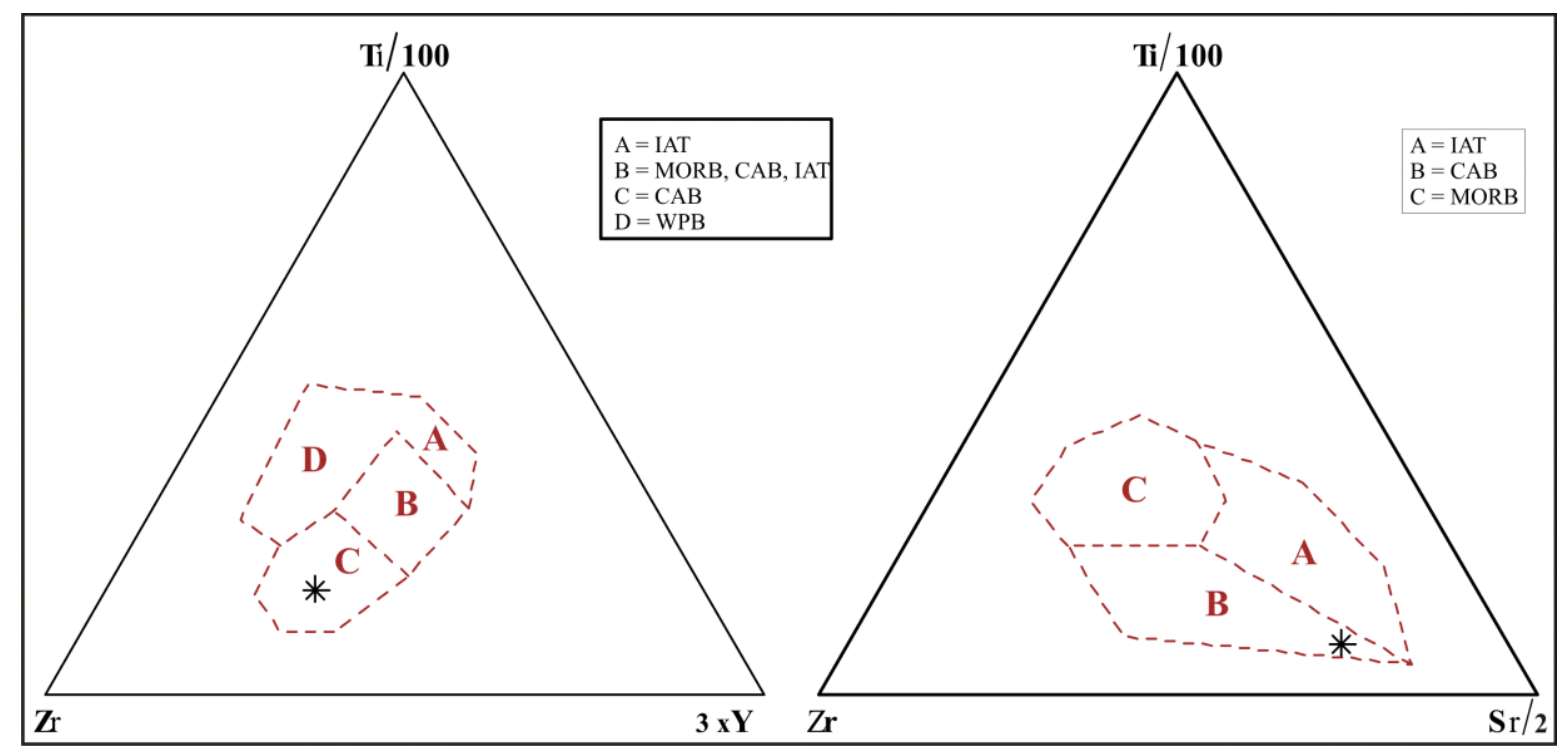

Figura 28: Diagrama de Pearce \& Cann (1973) para discriminação de ambiente tectônico. A amostra do dique máfico se posicionou no campo dos basaltos calcio-alcalinos. IAT: tholeíto de arco de ilha: MORB: basalto de cadeias meso-oceânicas; CAB: basalto cálcio-alcalino; WPB: basalto intra-placa. 
Com base na similaridade geológica e geoquímica, é possível associar os diques máficos que ocorrem no Depósito Tocantinzinho com os que foram estudados por Lamarão et al. (2005) na Formação Vila Riozinho. Desse modo, o dique máfico tem composição basáltica, é de ambiente calcio-alcalino de arco vulcano-magmático e que, devido aos indícios de diferenciação magmática, pode ter sofrido leve interação com crosta continental.

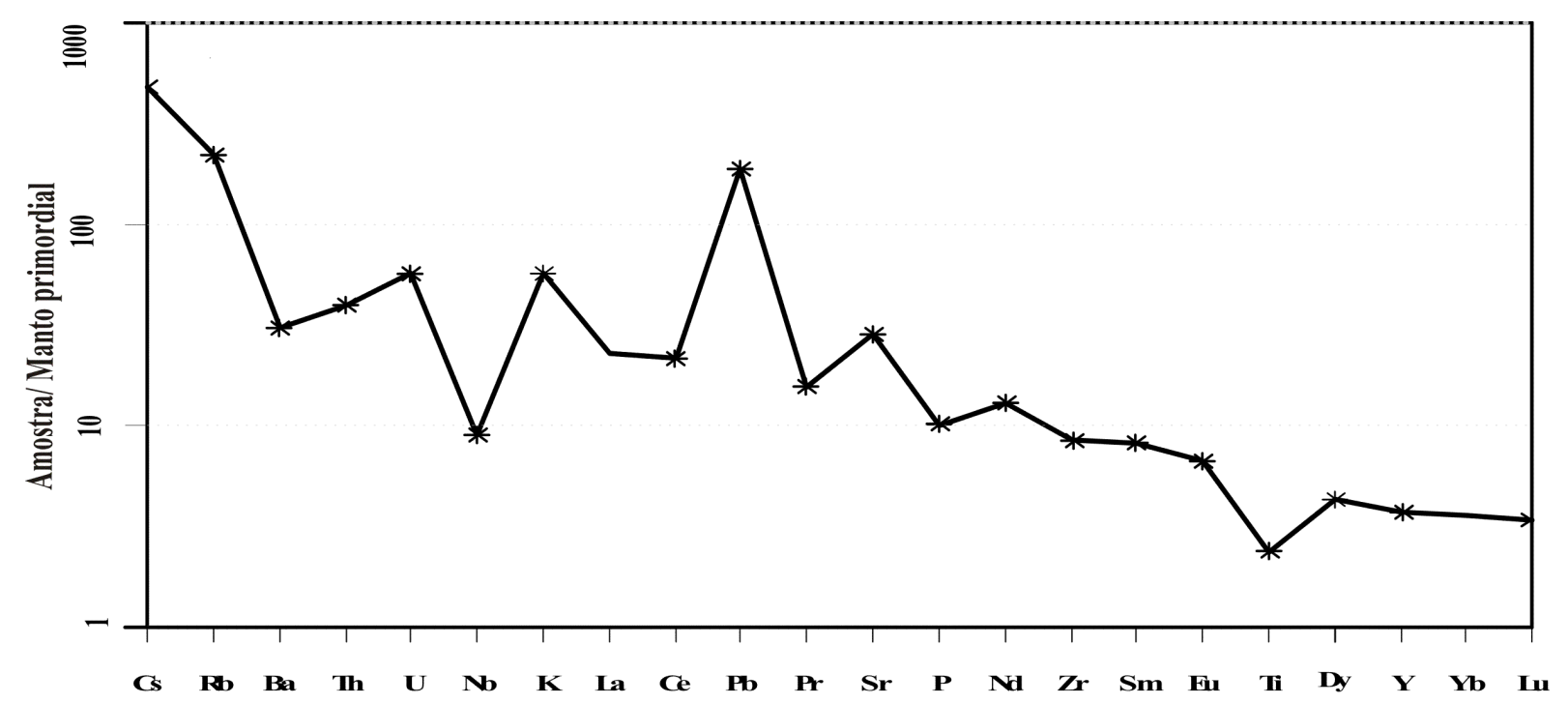

Figura 29: Diagrama de distribuição de elementos para diques máficos normalizados ao manto primordial (valores de normalização propostos por Sun \& McDonough 1989).

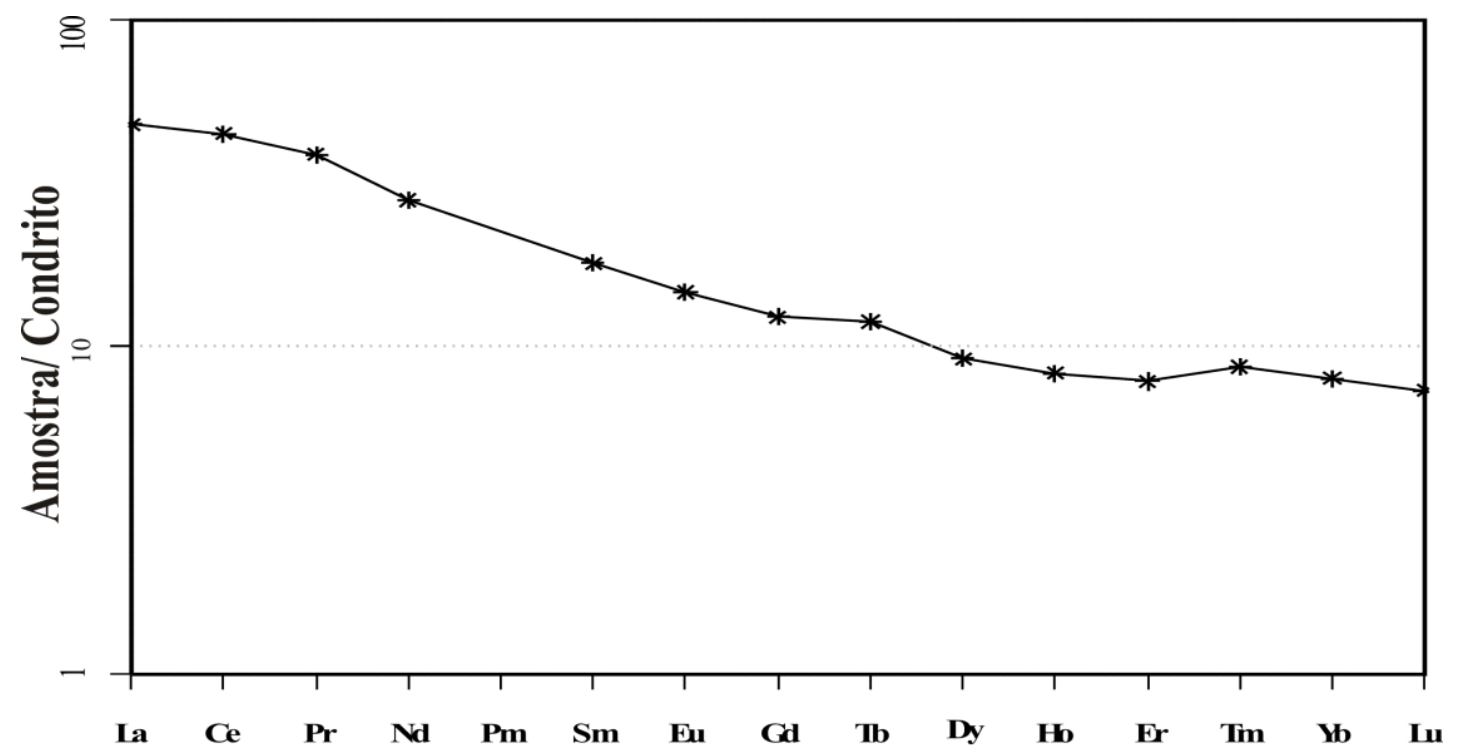

Figura 30: Padrão de elementos terras raras para o dique máfico, normalizado ao condrito (Nakamura 1974). 
Tabela 2: Análise de rocha total representativa dos elementos maiores e traços.

\begin{tabular}{|c|c|c|c|c|c|c|c|c|c|c|c|c|c|c|c|c|c|c|}
\hline \multirow{2}{*}{$\begin{array}{l}\text { Litologia } \\
\text { Amostras }\end{array}$} & \multirow{2}{*}{$\begin{array}{c}\text { Granito } \\
1 \_24\end{array}$} & \multirow{2}{*}{$\begin{array}{l}\text { Riolito } \\
11 \_24\end{array}$} & \multirow{2}{*}{$\begin{array}{c}\text { Basalto } \\
2 \_57\end{array}$} & \multicolumn{6}{|c|}{ MAT-I } & \multicolumn{9}{|c|}{ MAT-II } \\
\hline & & & & $9 \_48$ & $10 \_48 \mathrm{~A}$ & $37 \_24$ & $10 \_48 \mathrm{~B}$ & 4_ $48 \mathrm{~A}$ & $54 \_24$ & $18 \_24$ & $19 \_48$ & 4_57 & $7 \_27$ & $23 \_24$ & $25 \_24$ & $27 \_24$ & 4_48B & $55 \_24$ \\
\hline \multicolumn{19}{|l|}{ (\% peso) } \\
\hline $\mathrm{SiO}_{2}$ & 72,09 & 73,47 & 42,43 & 75,49 & 74,85 & 72,89 & 72,5 & 70,97 & 59,84 & 71,81 & 55,66 & 72,38 & 77,51 & 72,05 & 71,8 & 71,62 & 71,17 & 64,02 \\
\hline $\mathrm{Al}_{2} \mathrm{O}_{3}$ & 14,04 & 10,98 & 11,66 & 11,62 & 12,32 & 13,24 & 11,33 & 13,67 & 15,57 & 13,3 & 15,69 & 12,97 & 11,91 & 14 & 13,42 & 14,23 & 14,02 & 16,06 \\
\hline $\mathrm{TiO}_{2}$ & 0,27 & 0,11 & 0,51 & 0,25 & 0,27 & 0,26 & 0,26 & 0,48 & 0,58 & 0,35 & 1,09 & 0,23 & 0,22 & 0,33 & 0,32 & 0,32 & 0,47 & 0,45 \\
\hline $\mathrm{Fe}_{2} \mathrm{O}_{3}$ & 1,73 & 1,99 & 9,19 & 1,42 & 1,66 & 2,3 & 3,47 & 3,43 & 4,81 & 1,75 & 6,15 & 2,44 & 0,79 & 1,96 & 1,81 & 2,4 & 2,56 & 3,59 \\
\hline $\mathrm{MnO}$ & 0,04 & 0,17 & 0,5 & 0,04 & 0,02 & 0,03 & 0,05 & 0,04 & 0,12 & 0,05 & 0,16 & 0,03 & 0,03 & 0,03 & 0,06 & 0,02 & 0,03 & 0,07 \\
\hline $\mathrm{MgO}$ & 0,31 & 0,48 & 7,46 & 0,27 & 0,22 & 0,53 & 0,36 & 1,34 & 1,62 & 0,34 & 5,53 & 0,44 & 0,48 & 0,35 & 0,4 & 0,54 & 1,25 & 1,23 \\
\hline $\mathrm{CaO}$ & 0,92 & 1,95 & 12,06 & 1,15 & 0,77 & 0,49 & 1,51 & 0,54 & 4,38 & 3,55 & 3,47 & 0,8 & 0,16 & 0,64 & 1,46 & 0,39 & 0,52 & 2,93 \\
\hline $\mathrm{Na}_{2} \mathrm{O}$ & 3,87 & 2,47 & 0,02 & 3,05 & 3,27 & 3,46 & 2,92 & 2,72 & 4,95 & 3,55 & 5,47 & 3,1 & 3,62 & 3,43 & 3,23 & 2,57 & 2,96 & 4,57 \\
\hline $\mathrm{K}_{2} \mathrm{O}$ & 5,33 & 5,35 & 1,72 & 4,93 & 4,98 & 5,01 & 4,49 & 4,65 & 3,09 & 5,15 & 0,98 & 5,3 & 4,38 & 5,4 & 5,17 & 5,89 & 4,88 & 3,96 \\
\hline $\mathrm{P}_{2} \mathrm{O}_{5}$ & 0,03 & 0,05 & 0,22 & 0,05 & 0,07 & 0,08 & 0,05 & 0,12 & 0,25 & 0,1 & 0,34 & 0,06 & 0,05 & 0,1 & 0,08 & 0,06 & 0,13 & 0,19 \\
\hline $\mathrm{PF}$ & 1,2 & 2,8 & 13,8 & 1,5 & 1,4 & 1,4 & 2,8 & 1,7 & 4,4 & 2 & 5,2 & 2 & 0,7 & 1,5 & 2 & 1,7 & 1,7 & 2,6 \\
\hline Total & 99,83 & 99,82 & 99,57 & 99,77 & 99,83 & 99,69 & 99,74 & 99,66 & 99,61 & 101,95 & 99,74 & 99,75 & 99,85 & 99,79 & 99,75 & 99,74 & 99,69 & 99,67 \\
\hline \multicolumn{19}{|l|}{ (ppm) } \\
\hline $\mathrm{Ba}$ & 600 & 248 & 216 & 476 & 502 & 741 & 421 & 622 & 1106 & 703 & 144 & 565 & 337 & 678 & 638 & 712 & 637 & 1298 \\
\hline $\mathrm{Sr}$ & 111,8 & 90,9 & 602,2 & 91,4 & 93,9 & 108,5 & 94,1 & 117,5 & 638 & 141 & 130,1 & 92,1 & 66,1 & 131,9 & 158,4 & 98,3 & 123,4 & 714,5 \\
\hline $\mathrm{Rb}$ & 199,9 & 156,7 & 142 & 150,5 & 147,7 & 160 & 139,9 & 1667,4 & 124 & 166,9 & 20,9 & 169,9 & 131,4 & 179,1 & 181,1 & 227,9 & 171,2 & 122,8 \\
\hline $\mathrm{Zr}$ & 226,4 & 78,2 & 94,9 & 185,6 & 181,4 & 209,4 & 189,2 & 230,6 & 156,4 & 256,4 & 226,7 & 144,5 & 143,1 & 268,5 & 232,4 & 233,8 & 289,4 & 178,4 \\
\hline $\mathrm{Y}$ & 36,2 & 15,7 & 16,8 & 34,1 & 35,9 & 26,6 & 31,3 & 42,2 & 13,7 & 34,4 & 18,3 & 29 & 14,4 & 38,3 & 40,9 & 36,6 & 49,3 & 13,6 \\
\hline $\mathrm{Nb}$ & 14,3 & 10,4 & 6,4 & 12,5 & 13,2 & 12,7 & 13,5 & 19,6 & 8,5 & 15,8 & 21,2 & 11,3 & 9,3 & 15,3 & 15,2 & 15,2 & 21,4 & 11,9 \\
\hline $\mathrm{Ga}$ & 15,7 & 12 & 24,1 & 12,3 & 12,6 & 14,4 & 11,9 & 18,9 & 17 & 15 & 20,1 & 14,7 & 12,7 & 15,7 & 15,3 & 18,1 & 17,7 & 18,7 \\
\hline Th & 21,8 & 20,8 & 3,4 & 18,2 & 18,3 & 13,6 & 16,7 & 14,8 & 6,5 & 17,7 & 8,1 & 10,5 & 20,9 & 13,2 & 16,9 & 14,8 & 22,8 & 9,8 \\
\hline W & 178,4 & 231,4 & 28 & 220,3 & 130 & 123,2 & 202,6 & 108,7 & 67,2 & 86,6 & 90 & 251,7 & 99,4 & 126,2 & 123,9 & 68,2 & 94,1 & 105,2 \\
\hline Cs & 1,8 & 1,4 & 3,8 & 1,6 & 1,7 & 1,7 & 1,5 & 2,4 & 2 & 2,4 & 0,2 & 2,1 & 1,1 & 2,8 & 2,3 & 3,2 & 2,6 & 1,9 \\
\hline $\mathrm{Hf}$ & 6,4 & 3,2 & 2,4 & 5,6 & 5,9 & 5,8 & 6,1 & 7,5 & 4,5 & 7,5 & 5,8 & 4,7 & 5,3 & 8,1 & 7 & 7,1 & 9,6 & 5 \\
\hline $\mathrm{Ta}$ & 1,2 & 1 & 0,3 & 1 & 1 & 1,1 & 1,1 & 1,5 & 0,6 & 1,3 & 0,7 & 1,1 & 0,6 & 1,2 & 1,1 & 1,1 & 1,7 & 0,9 \\
\hline $\mathrm{U}$ & 3 & 4,9 & 1,2 & 4,5 & 3,7 & 2,9 & 3,2 & 4,2 & 2,2 & 3,4 & 1,9 & 3,1 & 2,5 & 2,7 & 4,3 & 3,3 & 6,6 & 3,8 \\
\hline $\mathrm{V}$ & 9 & $<8$ & 113 & 11 & 10 & 12 & 10 & 41 & 74 & 12 & 66 & 21 & 12 & 14 & 14 & 18 & 34 & 43 \\
\hline
\end{tabular}




\begin{tabular}{|c|c|c|c|c|c|c|c|c|c|c|c|c|c|c|c|c|c|c|}
\hline $\mathrm{Ag}$ & $<0,1$ & 1,1 & $<0,1$ & $<0,1$ & 0,4 & 3,4 & 1,6 & 1,1 & $<0,1$ & 8,5 & 0,2 & 1,2 & $<0,1$ & 0,4 & 0,1 & 0,3 & 0,3 & 0,2 \\
\hline As & 0,8 & 3,2 & 2 & 2,7 & 6 & 10,3 & 3,8 & 6 & 1 & 5,6 & 0,7 & 8,9 & $<0,5$ & 13,4 & 7,8 & 13,2 & 3,8 & 0,7 \\
\hline $\mathrm{Au}$ & 3,3 & 3239,1 & 4282 & 86,9 & 489,9 & 13033,7 & 4774,8 & 2061,3 & 4,1 & 38133 & 18,7 & 2722,2 & $<0,5$ & 771,8 & 133,6 & 474,1 & 306,5 & 19,9 \\
\hline $\mathrm{Bi}$ & $<0,1$ & 0,4 & 0,1 & 0,7 & 0,8 & 2,5 & 0,4 & 0,8 & $<0,1$ & 1,1 & 22,7 & 1,3 & 1,3 & 0,3 & 0,3 & 0,2 & 0,4 & 0,3 \\
\hline $\mathrm{Cd}$ & $<0,1$ & $<0,1$ & 0,2 & $<0,1$ & $<0,1$ & 0,6 & $<0,1$ & $<0,1$ & $<0,1$ & 11,3 & $<0,1$ & $<0,1$ & $<0,1$ & $<0,1$ & $<0,1$ & $<0,1$ & $<0,1$ & $<0,1$ \\
\hline $\mathrm{Cu}$ & 5 & 10,6 & 1,7 & 25,1 & 57,1 & 367 & 87,3 & 22,9 & 6,1 & 812,5 & 30,4 & 18,4 & 1,9 & 6,7 & 11,2 & 11,2 & 12,5 & 23,8 \\
\hline $\mathrm{Hg}$ & 0,01 & 0,1 & $<0,01$ & 0,08 & 0,03 & 0,05 & 0,06 & 0,03 & 0,01 & 0,03 & 0,01 & 0,09 & 0,04 & 0,04 & 0,04 & 0,03 & 0,06 & $<0,01$ \\
\hline Mo & 1,1 & 3,6 & 0,7 & 1,7 & 3 & 3 & 0,9 & 3 & 3,6 & 2,2 & 0,2 & 1,3 & 0,1 & 0,8 & 1,2 & 0,3 & 0,9 & 0,7 \\
\hline $\mathrm{Ni}$ & 6,8 & 2,9 & 75,1 & 2 & 1,4 & 1,6 & 1,4 & 29,3 & 5,9 & 8,5 & 17,8 & 6,9 & 0,6 & 1 & 3,5 & 8,5 & 13,6 & 6,9 \\
\hline $\mathrm{Pb}$ & 8,3 & 43,4 & 13,3 & 6,5 & 16 & 142,6 & 11,6 & 95,6 & 6,8 & 450,6 & 3,7 & 67,7 & 1,5 & 22,7 & 35 & 20,8 & 274,7 & 30,9 \\
\hline $\mathrm{Sb}$ & $<0,1$ & $<0,1$ & $<0,1$ & $<0,1$ & $<0,1$ & $<0,1$ & $<0,1$ & $<0,1$ & $<0,1$ & $<0,1$ & $<0,1$ & $<0,1$ & $<0,1$ & $<0,1$ & $<0,1$ & $<0,1$ & $<0,1$ & $<0,1$ \\
\hline $\mathrm{Se}$ & $<0,5$ & $<0,5$ & $<0,5$ & $<0,5$ & $<0,5$ & 0,8 & 0,5 & $<0,5$ & $<0,5$ & 0,5 & $<0,5$ & 0,6 & $<0,5$ & 0,9 & $<0,5$ & 0,9 & $<0,5$ & $<0,5$ \\
\hline $\mathrm{Tl}$ & $<0,1$ & $<0,1$ & $<0,1$ & $<0,1$ & $<0,1$ & $<0,1$ & 0,1 & $<0,1$ & $<0,1$ & $<0,1$ & $<0,1$ & $<0,1$ & $<0,1$ & $<0,1$ & $<0,1$ & 0,1 & $<0,1$ & $<0,1$ \\
\hline $\mathrm{Zn}$ & 25 & 21 & 155 & 18 & 15 & 102 & 24 & 15 & 75 & 844 & 196 & 21 & 22 & 24 & 26 & 22 & 24 & 54 \\
\hline $\mathrm{La}$ & 52,8 & 30,7 & 15,8 & 40,8 & 39,4 & 45,6 & 42,3 & 53,8 & 32,2 & 52,9 & 45 & 42,3 & 16 & 56 & 57,4 & 60,5 & 65,1 & 36,3 \\
\hline $\mathrm{Ce}$ & 120,3 & 60,2 & 38,8 & 95 & 93,5 & 107,4 & 97,5 & 121,1 & 72 & 121,9 & 100,6 & 93 & 54 & 131,8 & 133,1 & 136,8 & 145,8 & 77,4 \\
\hline $\operatorname{Pr}$ & 12,5 & 6,13 & 4,33 & 11,11 & 10,86 & 11,88 & 11,12 & 14,44 & 7,71 & 13,75 & 11,62 & 11,27 & 3,95 & 14,75 & 14,72 & 14,79 & 17,4 & 7,9 \\
\hline $\mathrm{Nd}$ & 45,7 & 6,13 & 17,7 & 40,3 & 41,1 & 43,7 & 40,5 & 55,1 & 28,8 & 52,5 & 45,2 & 41,5 & 14,2 & 54,4 & 54,2 & 56,1 & 66,1 & 28,1 \\
\hline Sm & 8,3 & 3,21 & 3,66 & 7,28 & 7,56 & 7,81 & 7,21 & 9,8 & 4,85 & 8,78 & 7,55 & 7,15 & 2,83 & 9,88 & 9,49 & 9,81 & 11,18 & 4,53 \\
\hline $\mathrm{Eu}$ & 0,98 & 0,49 & 1,13 & 0,76 & 0,79 & 0,89 & 0,81 & 1,14 & 1,19 & 1,08 & 1,05 & 0,81 & 0,49 & 1,09 & 1,15 & 1,14 & 1,26 & 0,99 \\
\hline Gd & 6,82 & 2,79 & 3,41 & 6,11 & 6,53 & 6,21 & 6,08 & 7,75 & 3,73 & 7,41 & 5,01 & 5,46 & 2,42 & 8,11 & 8,09 & 7,85 & 8,96 & 3,46 \\
\hline $\mathrm{Tb}$ & 1,15 & 0,44 & 0,56 & 1 & 1,14 & 0,95 & 1,02 & 1,28 & 0,6 & 1,14 & 0,61 & 0,91 & 0,38 & 1,28 & 1,33 & 1,25 & 1,46 & 0,45 \\
\hline Dy & 6,81 & 2,52 & 3,16 & 5,6 & 6,43 & 4,9 & 5,65 & 6,88 & 2,73 & 6,53 & 3,17 & 4,77 & 1,97 & 7,16 & 7,34 & 6,93 & 7,69 & 1,9 \\
\hline Но & 1,28 & 0,54 & 0,58 & 1,17 & 1,3 & 1,03 & 1,12 & 1,46 & 0,53 & 1,3 & 0,59 & 1,02 & 0,41 & 1,44 & 1,49 & 1,39 & 1,7 & 0,48 \\
\hline Er & 3,63 & 1,7 & 1,76 & 3,4 & 3,72 & 2,98 & 3,24 & 4,32 & 1,45 & 3,84 & 1,84 & 2,88 & 1,12 & 4,1 & 4,29 & 3,98 & 4,92 & 1,5 \\
\hline $\mathrm{Tm}$ & 0,58 & 0,28 & 0,26 & 0,54 & 0,57 & 0,46 & 0,49 & 0,68 & 0,22 & 0,58 & 0,34 & 0,44 & 0,18 & 0,65 & 0,67 & 0,61 & 0,76 & 0,25 \\
\hline $\mathrm{Yb}$ & 3,47 & 1,9 & 1,76 & 1 & 3,28 & 2,7 & 2,93 & 4,4 & 1,43 & 3,47 & 2,36 & 2,72 & 1,26 & 3,87 & 4,2 & 3,69 & 4,86 & 1,69 \\
\hline $\mathrm{Lu}$ & 0,46 & 0,32 & 0,25 & 0,47 & 0,46 & 0,39 & 0,42 & 0,62 & 0,23 & 0,52 & 0,42 & 0,38 & 0,19 & 0,55 & 0,6 & 0,52 & 0,72 & 0,28 \\
\hline
\end{tabular}




\section{QUÍMICA MINERAL}

Foram feitas análises de clorita, muscovita, rutilo e titanita, em amostras de litotipos diferentes, representativos dos diversos sistemas minerais encontrados no Depósito Tocantinzinho.

A fórmula estrutural da clorita foi calculada com base em 28 átomos de oxigênio, enquanto que a da muscovita com base em 24 átomos de oxigênio. As amostras selecionadas para a análise são provenientes dos furos de sondagem TOC-24, TOC-48 e TOC-57 para a clorita e TOC-57 para a sericita. A seleção das amostras dos testemunhos de sondagem foi feita com base na diversidade de ocorrência dos minerais na rocha (em veios/vênulas, disseminados na rocha e como mineral resultado de alteração de outro conhecido).

\subsection{CLORITA}

A clorita é um mineral abundante e ocorre como resultado de alteração hidrotermal no Depósito Tocantinzinho.

Em rochas pouco metassomatizadas, tem-se cloritas como resultado da desestabilização da biotita e, em geral, tem coloração verde e seu aparecimento é acompanhado de titanita + epidoto + muscovita \pm magnetita. Para este tipo de clorita deu-se a classificação de Chl1.

Em locais onde a alteração é mais intensa, como no estágio de alteração fílica, a clorita costuma ser amarronzada, com cor de interferência anômala, acompanhada de sericita + sulfetos \pm calcita. Nesta fase ela é classificada como Chl2. A outra forma comum do aparecimento da clorita é em massa, com coloração amarronzada, que ocorre de forma isolada em vênulas monominerálicas posteriores, associada ao estágio final da alteração fílica, citado no capítulo de Alteração Hidrotermal. E para esta clorita foi dada a classificação de Chl3.

Na figura 31 estão as fotomicrografias dos três tipos representantes de clorita encontrados no Depósito Tocantinzinho. Em 31-A está a Chl1, ainda com características do cristal de biotita. Em 31-B e 31-B-1 estão fotomicrografias da Chl2 em paragênese com sulfetos e sericita. Em 31-C está a Chl3 em massa, geralmente ocorrendo de forma isolada.

A fórmula química dos tipos de clorita e dados obtidos das análises de microssonda eletrônica (tabela 3), com base em 28 átomos de oxigênio é a seguinte: Chl1:

$$
\left(\mathrm{Mg}_{4,84} \mathrm{Fe}_{4,44} \mathrm{Mn}_{0,19} \mathrm{Ti}_{0,04} \mathrm{Al} l_{2,30}\right)_{11,81}\left(\mathrm{Si}_{5,67} \mathrm{Al} \mathrm{l}_{2,33}\right)_{8} \mathrm{O}_{20}(\mathrm{OH})_{16}
$$


Para as Chl2 a fórmula química é:

$$
\left(\mathrm{Mg}_{4,59} \mathrm{Fe}_{4,75} \mathrm{Mn}_{0,19} \mathrm{Al}_{2,36}\right)_{11,92}\left(\mathrm{Si}_{5,44} \mathrm{Al}_{2,56}\right)_{8} \mathrm{O}_{20}\left(\mathrm{OH}_{0,98} \mathrm{Cl}_{0,02}\right)_{16}
$$

Para as Chl3, tem-se:

$$
\left(\mathrm{Mg}_{4,12} \mathrm{Fe}_{4,56} \mathrm{Mn}_{0,16} \mathrm{Ti}_{0,02} \mathrm{Al}_{2,37}\right)_{11,23}\left(\mathrm{Si}_{5,53} \mathrm{Al}_{2,47}\right)_{8} \mathrm{O}_{20}\left(\mathrm{OH}_{0,99} \mathrm{Cl}_{0,01}\right)_{16}
$$

As diferenças nas características petrográficas entre os tipos de clorita são reflexo de importantes variações composicionais entre elas. E uma das mais importantes características química se trata dos teores de $\mathrm{MgO}$ e $\mathrm{FeO}$ de cada uma, para que com isso possa se classificar a clorita em Chamosita (rica em $\mathrm{Fe}$ ) ou clinocloro (rica em $\mathrm{MgO}$ ).

A clorita do tipo Chl1 ocorre, especialmente, em amostras com menor grau de alteração hidrotermal e possui teores médios de $\mathrm{MgO}$ de 17,20\% e de $\mathrm{FeO}$ 24,98\%, classificada como clorita do tipo clinocloro. Além dos teores de Fe e Mg, o Mn apresenta variação entre $0,37 \%$ e $1,40 \%$.

Enquanto que a Chl2 ocorre de forma mais intensa em amostras mais hidrotermalmente alteradas, em paragênese com a mineralização. Possui teores de $\mathrm{MgO}$ em torno de $16,09 \%$ e teores mais elevados de Fe 26,85\% e Mn varia entre 0,20\% e 1,35\% sendo predominantemente chamosita.

As Chl3 são, predominantemente, de composição clinocloro com valores de $\mathrm{MgO}$ e $\mathrm{FeO}$, respectivamente, 13,53\% e 25,37\%. Teores de Mn oscilam entre 0,40\% 1,70\%.

$\mathrm{O}$ diagrama da figura $32\left(\mathrm{Fe} /(\mathrm{Fe}+\mathrm{Mg})\right.$ vs. $\left.\mathrm{Al}^{\mathrm{IV}}\right)$ mostra a relação dos grupos de clorita. $\mathrm{O}$ clinocloro tem em média razão de $\mathrm{X}_{\mathrm{Fe}}=0,43$ e está presente principalmente em amostras menos alteradas (Chl1) e em amostras com grau de alteração moderado. O tipo de clorita com essa composição ocorre nos granitos e no dique máfico do Depósito Tocantinzinho. Entretanto, as de composição chamosítica apresentam valores de $\mathrm{X}_{\mathrm{Fe}}$ entre 0,56 e 0,62 e estão presente, majoritariamente, nas amostras mais alteradas do Depósito Tocantinzinho (MAT-I e MAT-II). 

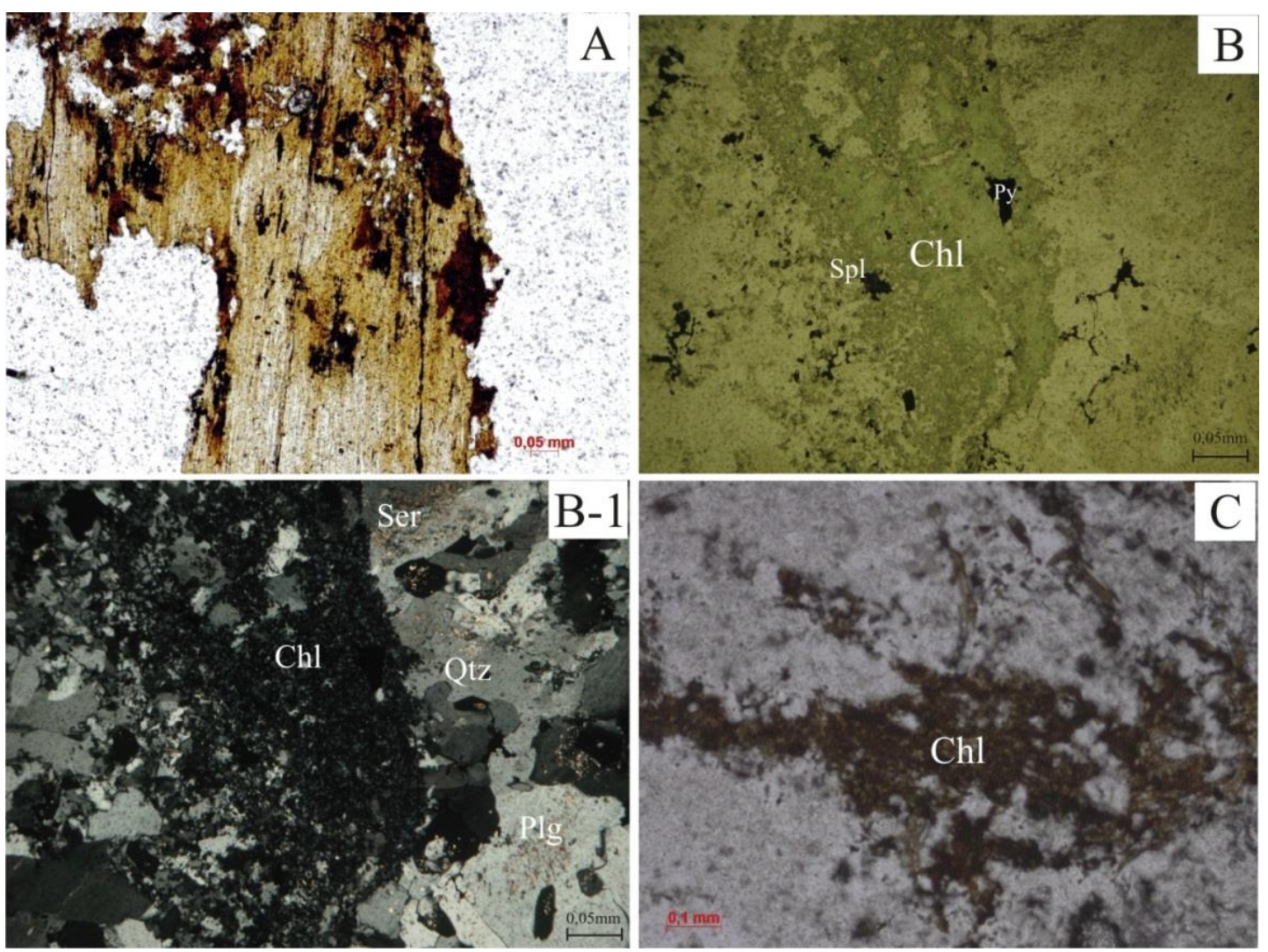

Figura 31: Fotomicrografias de amostras de clorita analisadas: A) Clorita do tipo 1 (Chl1), resultado da alteração da biotita; B) Chl2, em paragênese com sulfetos (pirita e esfalerita) e silica;B-1) foto anterior, nicóis x; C) Chl3 formando massas/ vênulas monominerálicas.

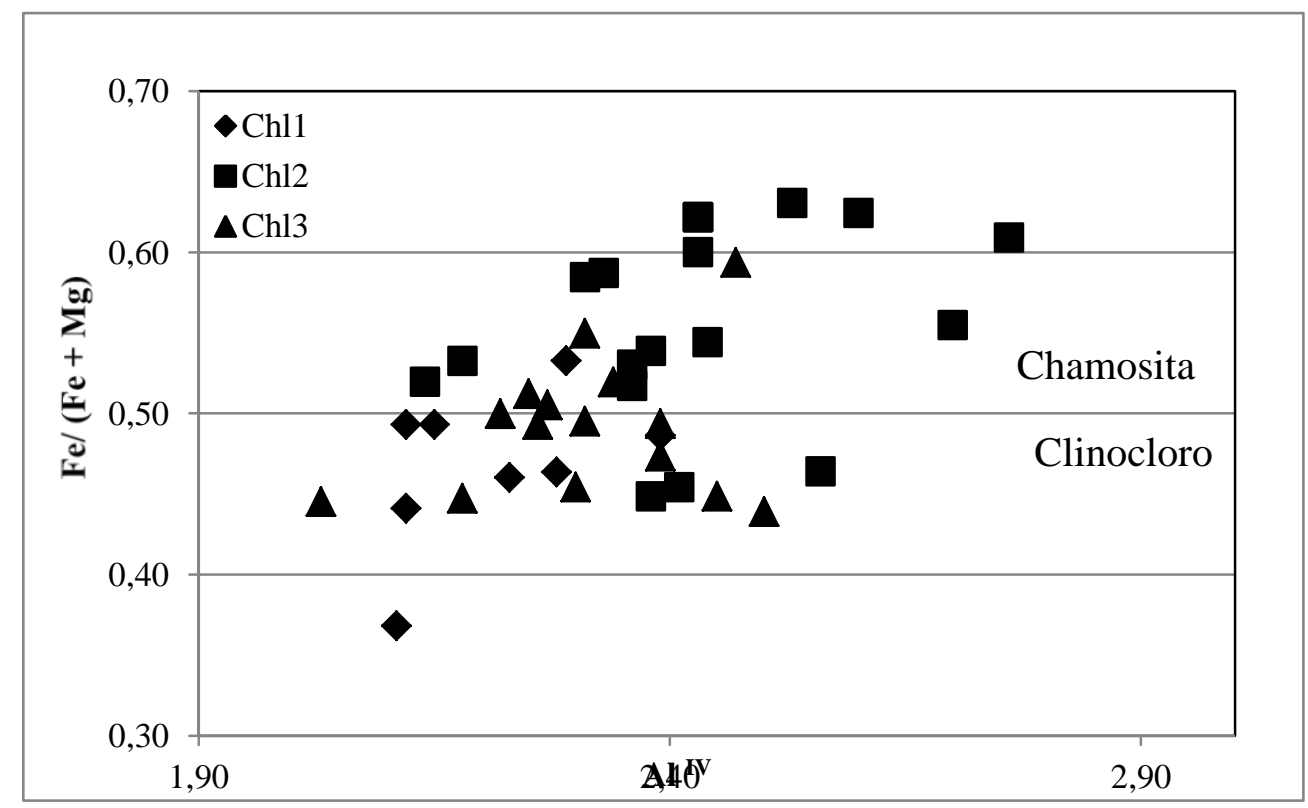

Figura 32: Diagrama de composição química $\mathrm{Fe} /(\mathrm{Fe}+\mathrm{Mg}) v s$. $\mathrm{Al}^{\mathrm{IV}}$ dos tipos de cloritas do Depósito. A linha que marca 0,50 no eixo horizontal representa o limite dos campos entre os cristais de clorita de composição clinocloro (baixo de 0,50), encontradas em amostras menos alteradas do Depósito e chamosita (acima de 0,50), encontradas nas porções mais alteradas e evoluídas do depósito Tocantinzinho. 
Tabela 3: Análises obtidas a partir de dados de microssonda eletrônica de cloritas.

\begin{tabular}{|c|c|c|c|c|c|c|c|c|c|c|c|c|c|c|c|c|c|c|c|c|c|c|}
\hline $\begin{array}{c}\text { Amostra/ } \\
\text { furo }\end{array}$ & $\begin{array}{c}1,24 \\
(1)\end{array}$ & $54 \_24(3)$ & 54_24(5) & $54 \_24(5)$ & $\begin{array}{l}54-24 \\
(2-3)\end{array}$ & $\begin{array}{c}54 \_24 \\
(6)\end{array}$ & $\begin{array}{c}\text { 4_48A } \\
\text { (1) }\end{array}$ & $\underset{(2)}{1 \_24}$ & 1_24(7) & 2_57(1) & $2 \_57(1-1)$ & $\begin{array}{l}\text { 2_57(1 } \\
-2)\end{array}$ & 4_48A(2) & 1_24(3) & $2-57(3)$ & 4_48A(3) & $\begin{array}{c}\text { 4_48A } \\
\text { (4) }\end{array}$ & $\begin{array}{l}\text { 4_48A(4- } \\
\text { 2) }\end{array}$ & 4_48A(3) & $\begin{array}{c}\text { 4_48A } \\
(4-2)\end{array}$ & $\begin{array}{c}\text { 4_48A } \\
(4-3)\end{array}$ & $\begin{array}{c}\text { 4_48A(4) } \\
-4)\end{array}$ \\
\hline & \multicolumn{6}{|c|}{ Chl1 } & \multicolumn{6}{|c|}{ Chl2 2} & \multicolumn{10}{|c|}{ Chl 3} \\
\hline Associação & 1 & 1 & 1 & 1 & 1 & 1 & 2 & 2 & 2 & 2 & 2 & 2 & 3 & 3 & 3 & 3 & 3 & 3 & 3 & 3 & 3 & 3 \\
\hline $\mathrm{SiO}_{2}$ & 27,011 & 27,352 & 27,19 & 27,19 & 27,352 & 25,48 & 25,691 & 22,996 & 27,222 & 25,165 & 26,121 & 25,616 & 25,108 & 26,919 & 26,112 & 26,416 & 22,453 & 20,636 & 26,416 & 20,636 & 23,351 & 25,542 \\
\hline $\mathrm{TiO}_{2}$ & 0,096 & 0,35 & 0,579 & 0,579 & 0,35 & 0 & 0,071 & 0 & 0,084 & 0,12 & 0,121 & 0 & 0,083 & 0,012 & 0,012 & 0 & 0,012 & 0,155 & 0 & 0,155 & 0 & 0,059 \\
\hline $\mathrm{Al}_{2} \mathrm{O}_{3}$ & 18,716 & 18,744 & 18,373 & 18,373 & 18,744 & 19,61 & 20,995 & 18,734 & 19,253 & 19,647 & 20,531 & 19,52 & 20,333 & 18,656 & 19,785 & 21,777 & 17,991 & 16,733 & 21,777 & 16,733 & 18,701 & 20,483 \\
\hline $\mathrm{FeO}$ & 23,271 & 24,696 & 24,634 & 24,634 & 24,696 & 27,973 & 34,276 & 24,171 & 21,761 & 23,244 & 23,69 & 25,1 & 31,515 & 22,465 & 23,738 & 30,536 & 23,399 & 22,848 & 30,536 & 22,848 & 30,733 & 29,922 \\
\hline MnO & 1,404 & 0,371 & 0,387 & 0,387 & 0,371 & 0,408 & 0,513 & 1,764 & 1,44 & 0,41 & 0,44 & 0,407 & 0,419 & 1,471 & 0,402 & 0,467 & 0,259 & 0,374 & 0,467 & 0,374 & 0,463 & 0,405 \\
\hline MgO & 16,535 & 16,011 & 16,564 & 16,564 & 16,011 & 14,014 & 10,398 & 13,824 & 15,061 & 16,155 & 16,529 & 16,276 & 10,34 & 16,248 & 17,027 & 10,4 & 9,222 & 8,528 & 10,4 & 8,528 & 11,051 & 11,273 \\
\hline $\mathrm{CaO}$ & 0,054 & 0,242 & 0,398 & 0,398 & 0,242 & 0,107 & 0,014 & 0,048 & 0,143 & 0,016 & 0,027 & 0,026 & 0 & 0,048 & 0,029 & 0,018 & 0,089 & 0,073 & 0,018 & 0,073 & 0,057 & 0,03 \\
\hline BaO & 0 & 0,017 & 0 & 0 & 0,017 & 0,08 & 0,023 & 0,054 & 0 & 0 & 0 & 0 & 0,026 & 0,016 & 0,021 & 0 & 0 & 0 & 0 & 0 & 0,098 & 0,009 \\
\hline $\mathrm{Na}_{2} \mathrm{O}$ & 0,051 & 0 & 0,004 & 0,004 & 0 & 0,025 & 0,023 & 0,015 & 0,024 & 0,007 & 0 & 0,008 & 0 & 0,03 & 0 & 0 & 0,035 & 0,027 & 0 & 0,027 & 0,045 & 0,024 \\
\hline $\mathbf{K}_{2} \mathrm{O}$ & 0,002 & 0 & 0,049 & 0,049 & 0 & 0 & 0,01 & 0,01 & 0 & 0,008 & 0,041 & 0 & 0,022 & 0,007 & 0,002 & 0,017 & 0,091 & 0,06 & 0,017 & 0,06 & 0,05 & 0,001 \\
\hline $\mathrm{Cl}$ & 0,013 & 0,028 & 0,025 & 0,025 & 0,028 & 0,01 & 0,01 & 0,01 & 0 & 0,02 & 0 & 0,008 & 0 & 0 & 0 & 0 & 0,212 & 0,282 & 0 & 0,282 & 0 & 0,012 \\
\hline $\mathbf{F}$ & 0,285 & 0,254 & 0,36 & 0,36 & 0,254 & 0,001 & 0 & 0,179 & 0,181 & 0,057 & 0,082 & 0,228 & 0 & 0,186 & 0,073 & 0,001 & 0,1 & 0,103 & 0,001 & 0,103 & 0,028 & 0,103 \\
\hline Total & 87,438 & 88,065 & 88,563 & 88,563 & 88,065 & 87,708 & 92,024 & 81,805 & 85,169 & 84,849 & 87,582 & 87,189 & 87,846 & 86,058 & 87,201 & 89,632 & 73,863 & 69,819 & 89,632 & 69,819 & 84,577 & 87,863 \\
\hline \multicolumn{23}{|c|}{ Fórmula estrutural calculada com base em 28 átomos de oxigênio } \\
\hline $\mathbf{S i}$ & 5,6812 & 5,7198 & 5,6643 & 5,6643 & 5,7198 & 5,4695 & 5,3978 & 5,2858 & 5,821 & 5,4516 & 5,4691 & 5,4443 & 5,4737 & 5,7327 & 5,4993 & 5,5967 & 5,6745 & 5,5682 & 5,5697 & 5,5682 & 5,3352 & 5,5103 \\
\hline $\mathrm{Al}^{\mathrm{IV}}$ & 2,3188 & 2,2802 & 2,3357 & 2,3357 & 2,2802 & 2,5305 & 2,6022 & 2,7142 & 2,179 & 2,5484 & 2,5309 & 2,5557 & 2,5263 & 2,2673 & 2,5007 & 2,4303 & 2,3255 & 2,4318 & 2,4303 & 2,4318 & 2,6648 & 2,4897 \\
\hline $\begin{array}{l}\text { Sítio T } \\
\text { (soma) }\end{array}$ & 8 & 8 & 8 & 8 & 8 & 8 & 8 & 8 & 8 & 8 & 8 & 8 & 8 & 8 & 8 & 8,027 & 8 & 8 & 8 & 8 & 8 & 8 \\
\hline $\mathrm{Al}^{\mathrm{VI}}$ & 2,3206 & 2,3395 & 2,1754 & 2,1754 & 2,3395 & 2,4307 & 2,5967 & 2,3609 & 2,6732 & 2,4679 & 2,5355 & 2,3338 & 2,698 & 2,4152 & 2,4102 & 2,9812 & 3,0333 & 2,8895 & 2,9812 & 2,8895 & 2,3709 & 2,7183 \\
\hline $\mathrm{Fe}$ & 3,2274 & 3,4043 & 3,387 & 3,387 & 0,4579 & 3,421 & 3,9603 & 3,6595 & 3,0644 & 3,3101 & 3,2624 & 3,515 & 4,5145 & 3,1507 & 3,2878 & 4,2306 & 3,8976 & 4,0667 & 4,2306 & 4,2306 & 4,6156 & 4,2472 \\
\hline $\mathrm{Mg}$ & 4,0878 & 3,9343 & 4,0596 & 4,0596 & 0,5292 & 4,01 & 2,38 & 3,731 & 3,7808 & 4,1008 & 4,0576 & 4,0638 & 2,6403 & 4,0621 & 4,204 & 2,5685 & 2,7383 & 2,706 & 2,5685 & 2,5685 & 2,9585 & 2,8524 \\
\hline Mn & 0,0262 & 0,007 & 0,0072 & 0,0072 & 0,007 & 0,0078 & 0,0097 & 0,3439 & 0,0291 & 0,008 & 0,0083 & 0,0077 & 0,0084 & 0,0282 & 0,0076 & 0,0096 & 0,0065 & 0,0098 & 0,0096 & 0,0098 & 0,0095 & 0,081 \\
\hline $\mathbf{T i}$ & 0,0016 & 0,055 & 0,0096 & 0,0096 & 0,0058 & 0 & 0,0012 & 0 & 0,0015 & 0,0021 & 0,002 & 0 & 0,0015 & 0,0002 & 0,0019 & 0 & 0,0023 & 0,0036 & 0 & 0,0036 & 0 & 0,0096 \\
\hline $\mathrm{Ca}$ & 0,0102 & 0,0542 & 0,0888 & 0,0888 & 0,0542 & 0,0246 & 0,0032 & 0,0118 & 0,0328 & 0,0037 & 0,0061 & 0,0059 & 0 & 0,011 & 0,0065 & 0,0041 & 0,0241 & 0,0211 & 0,0041 & 0,211 & 0,014 & 0,0069 \\
\hline $\mathrm{Na}$ & 0,0208 & 0 & 0,0016 & 0,0016 & 0 & 0,0104 & 0,0094 & 0,0067 & 0,01 & 0,0029 & 0 & 0,0033 & 0 & 0,0124 & 0 & 0 & 0,0172 & 0,0141 & 0 & 0,0141 & 0,0199 & 0,01 \\
\hline $\mathbf{K}$ & 0,0005 & 0 & 0,013 & 0,013 & 0 & 0 & 0,0027 & 0,0029 & 0 & 0,0022 & 0,011 & 0 & 0,0061 & 0,0019 & 0,0005 & 0,0046 & 0,0147 & 0,0207 & 0,0046 & 0,0207 & 0,0146 & 0,0003 \\
\hline Sítio $O$ & 9,6951 & 9,7943 & 9,7422 & 9,7422 & 3,3936 & 9,9045 & 8,9632 & 10,117 & 9,5918 & 9,8977 & 9,8829 & 9,9295 & 9,8688 & 9,6817 & 9,9185 & 9,7986 & 9,734 & 9,7315 & 9,7986 & 9,9478 & 10,003 & 9,9257 \\
\hline
\end{tabular}




\begin{tabular}{|c|c|c|c|c|c|c|c|c|c|c|c|c|c|c|c|c|c|c|c|c|c|c|}
\hline Cátions & 17,695 & 17,7943 & 17,7422 & 17,7422 & 11,3936 & 17,9045 & 16,9632 & 18,117 & 17,592 & 17,898 & 17,8829 & 17,9295 & 17,8688 & 17,682 & 17,919 & 17,8256 & 17,734 & 17,7315 & 17,7986 & 17,9478 & 18,003 & 17,9257 \\
\hline $\mathrm{Fe} / \mathrm{Fe}+\mathrm{Mg}$ & 0,4412 & 0,44119 & 0,45484 & 0,45484 & $\begin{array}{c}0,46388 \\
4\end{array}$ & 0,41538 & 0,62462 & 0,5952 & 0,5477 & 0,5467 & 0,54568 & 0,56379 & 0,63098 & 0,4368 & 0,5389 & 0,62223 & 0,58735 & 0,600455 & 0,62223 & $\begin{array}{c}0,50582 \\
3\end{array}$ & $\begin{array}{c}0,53935 \\
4\end{array}$ & 0,590252 \\
\hline Al Total & 4,6394 & 4,6197 & 4,5111 & 4,5111 & 4,6197 & 4,9612 & 5,1989 & 5,0751 & 4,8522 & 5,0163 & 5,0664 & 4,8895 & 5,2243 & 4,6825 & 4,9109 & 5,4115 & 5,3588 & 5,3213 & 5,4115 & 5,3213 & 5,0357 & 5,208 \\
\hline $\mathbf{T}^{\circ} \mathbf{C}$ & 311 & 305 & 314 & 314 & 309 & 345 & 356 & 375 & 288 & 348 & 346 & 350 & 323 & 303 & 341 & 329 & 312 & 330 & 329 & 330 & 329 & 312 \\
\hline
\end{tabular}

Cont. tabela 3.

\begin{tabular}{|c|c|c|c|c|c|c|c|c|c|c|c|c|c|c|c|c|c|c|c|c|c|c|}
\hline \multicolumn{5}{|c|}{ Chl1 } & \multicolumn{10}{|c|}{$\mathrm{Chl} 2$} & \multicolumn{8}{|c|}{$\mathrm{Chl3}$} \\
\hline & $7-27(1)$ & $7-7(2)$ & $7-7(3)$ & $7-27(3)$ & $7-27(4)$ & $7-7(5)$ & $7-7(6)$ & $7-27(7)$ & $7-7(8)$ & $7-27(9)$ & $7-27(10)$ & $7-27(11)$ & $7-27(12)$ & $7-27(13)$ & $7-27(14)$ & $7-27(15)$ & $7-27(16)$ & $7-27(17)$ & $7-27(18)$ & $7-27(19)$ & $7-27(20)$ & $7-27(21)$ \\
\hline $\mathrm{Na}_{2} \mathrm{O}$ & 0,144 & 0,085 & 0,118 & 0,108 & 0,144 & 0,256 & 0,187 & 0,266 & 0,194 & 0,133 & 0,147 & 0,138 & 0,113 & 0,192 & 0,196 & 0,186 & 0,275 & 0,109 & 0,106 & 0,062 & 0,168 & 0,131 \\
\hline $\mathrm{MgO}$ & 15,151 & 15,475 & 15,511 & 19,156 & 18,563 & 22,879 & 17,246 & 17,59 & 16,765 & 16,905 & 17,724 & 16,625 & 17,116 & 25,629 & 18,215 & 15,684 & 16,288 & 15,226 & 15,01 & 16,808 & 17,356 & 16,04 \\
\hline $\mathrm{Al}_{2} \mathrm{O}_{3}$ & 19,111 & 19,639 & 20,06 & 17,408 & 19,416 & 18,223 & 19,486 & 18,656 & 19,2 & 19,672 & 19,769 & 19,995 & 19,639 & 18,341 & 19,25 & 20,378 & 19,49 & 20,662 & 20,54 & 18,702 & 20,156 & 20,479 \\
\hline F & 0,118 & 0,272 & 0,149 & 0,406 & 0,341 & 0,323 & 0,224 & 0,415 & 0,262 & 0,328 & 0,3 & 0,317 & 0,353 & 0,585 & 0,183 & 0,295 & 0,349 & 0,148 & 0,14 & 0,256 & 0,216 & 0,171 \\
\hline $\mathrm{K}_{2} \mathrm{O}$ & 0,087 & 0,026 & 0,075 & 0,128 & 0,079 & 0,187 & 0,068 & 0,067 & 0,099 & 0,032 & 0,095 & 0,083 & 0,064 & 0,152 & 0,031 & 0,124 & 0,276 & 0,069 & 0,043 & 0,059 & 0,084 & 0,074 \\
\hline $\mathrm{CaO}$ & 0,009 & 0,014 & 0,057 & 0,064 & 0,038 & 0,081 & 0,012 & 0,064 & 0,015 & 0,034 & 0,051 & 0,029 & 0,047 & 0,085 & 0,057 & 0,051 & 0,101 & 0,054 & 0,047 & 0,041 & 0,048 & 0,033 \\
\hline $\mathrm{Cl}$ & 0,001 & 0,009 & 0,023 & 0,023 & 0,038 & 0,052 & 0,082 & 0,083 & 0,053 & 0,033 & 0,054 & 0,048 & 0,049 & 0,059 & 0,044 & 0,051 & 0,082 & 0,025 & 0,035 & 0,008 & 0,032 & 0,035 \\
\hline $\mathrm{SiO}_{2}$ & 26,231 & 26,048 & 26,427 & 29,323 & 26,801 & 27,695 & 26,49 & 26,723 & 26,466 & 25,998 & 26,488 & 26,2 & 26,416 & 28,93 & 27,145 & 26,136 & 26,153 & 25,717 & 25,651 & 26,671 & 25,63 & 25,94 \\
\hline $\mathrm{TiO}_{2}$ & 0,252 & 0 & 0,153 & 0 & 0 & 0,116 & 0,055 & 0,155 & 0,015 & 0,31 & 0,011 & 0,012 & 0 & 0,004 & 0,114 & 0 & 0 & 0,075 & 0,152 & 0 & 0,021 & 0 \\
\hline $\mathrm{MnO}$ & 1,427 & 1,512 & 1,444 & 0,602 & 0,934 & 0,532 & 1,1 & 0,997 & 1,214 & 1,209 & 1,246 & 1,241 & 1,258 & 0,203 & 0,435 & 1,027 & 1,319 & 1,26 & 1,458 & 1,213 & 1,35 & 1,418 \\
\hline $\mathrm{Cr}_{2} \mathrm{O}_{3}$ & 0 & 0 & 0 & 0 & 0,035 & 0,002 & 0 & 0,026 & 0 & 0,024 & 0 & 0 & 0 & 0,047 & 0 & 0,035 & 0,024 & 0 & 0,054 & 0,033 & 0 & 0,022 \\
\hline $\mathrm{FeO}$ & 25,854 & 26,86 & 26,573 & 19,978 & 23,063 & 17,875 & 24,996 & 22,698 & 24,805 & 25,231 & 24,756 & 25,147 & 25,05 & 13,758 & 24,793 & 26,794 & 25,421 & 26,707 & 26,745 & 24,805 & 24,875 & 26,097 \\
\hline $\mathrm{NiO}$ & 0,073 & 0,004 & 0,078 & 0,043 & 0,016 & 0,081 & 0 & 0,118 & 0 & 0 & 0,093 & 0 & 0,037 & 0 & 0,01 & 0,004 & 0,033 & 0 & 0,001 & 0,064 & 0 & 0 \\
\hline $\mathrm{V}_{2} \mathrm{O}_{3}$ & 0 & 0,05 & 0,085 & 0 & 0,059 & 0 & 0,064 & 0,034 & 0 & 0,019 & 0 & 0,026 & 0,039 & 0,065 & 0,049 & 0,028 & 0,002 & 0,029 & 0,042 & 0,025 & 0,045 & 0,058 \\
\hline$(\mathrm{OH})$ & 11,594 & 10,121 & 9,314 & 12,939 & 10,627 & 11,846 & 10,102 & 12,304 & 11,034 & 10,219 & 9,403 & 10,284 & 9,981 & 12,208 & 9,566 & 9,342 & 10,353 & 9,989 & 10,042 & 11,362 & 10,116 & 9,583 \\
\hline Total & 100,002 & 99,998 & 99,999 & 100,002 & 100,001 & 100 & 99,999 & 100,002 & 100 & 100,002 & 99,999 & 100,001 & 100,002 & 99,999 & 100,001 & 99,999 & 100 & 100,002 & 99,999 & 99,999 & 99,999 & 100,001 \\
\hline $\mathrm{Fe} / \mathrm{Fe}+\mathrm{Mg}$ & 0,41 & 0,45 & 0,49 & 0,446 & 0,37 & 0,53 & 0,55 & 0,45 & 0,54 & 0,45 & 0,58 & 0,44 & 0,46 & 0,53 & 0,53 & 0,60 & 0,62 & 0,62 & 0,61 & 0,47 & 0,56 & 0,49 \\
\hline
\end{tabular}




\subsection{MUSCOVITA}

O hidrotermalismo atuante sobre o Depósito Tocantinzinho proporcionou a formação de muscovita presente na maior parte dos litótipos estudados. Esse mineral se dispõe sob a forma de lamelas bem desenvolvidas ou na forma de massa de mica muito fina.

$\mathrm{Na}$ fase inicial do processo de alteração hidrotermal, denominado de estágio pósmagmático precoce, na qual a cloritização era um dos processos de alteração mais importantes, houve a formação de mica branca em lamelas bem desenvolvidas ou em lamelas finas devido à desestabilização do plagioclásio primário, feldspato e biotita primária. Porém, em locais onde o hidrotermalismo foi mais forte, correspondente à fase de alteração fílica, ocorreu à formação da mica branca em sua forma mais fina e, em geral, associada à clorita e também à calcita. Neste caso ela corresponde a grande parte da composição modal das rochas (acima de 20\%) em que ocorrem e comumente está associada a sulfetos.

Apesar de saber que existem variações quanto ao hábito, paragênese e mineral precursor, identificou-se um único tipo de mica branca no Depósito Tocantinzinho. As análises mostram valores de $\mathrm{Fe} /(\mathrm{Fe}+\mathrm{Mg})$ em torno de 0,62 . Sua fórmula química e dados obtidos das análises químicas de microssonda permitiram designá-la como muscovita com sua fórmula média na base com 24 átomos de oxigênio equivalentes:

$$
\left(\mathrm{K}_{0,98} \mathrm{Na}_{0,01} \mathrm{Ba}_{0,01}\right)_{1}\left(\mathrm{Ti}_{0,01} \mathrm{Al}_{2,99} \mathrm{Fe}_{0,23} \mathrm{Mg}_{0,31} \mathrm{Mn}_{0,12}\right)_{3.67}\left(\mathrm{Al}_{0,90} \mathrm{Si}_{7,10}\right)_{8} \mathrm{O}_{20}(\mathrm{OH})_{4}
$$

Foram estudadas amostras de testemunho de sondagem TOC-57 (amostra 8_57), priorizando sua maior e mais importante ocorrência referente à forma mais fina, associada à sulfetos e à mineralização (tabela 4).

As análises pontuais da parte central e da borda de cada amostra de muscovita apresentam valores muito discrepantes de $\mathrm{MgO}, \mathrm{FeO}$ e $\mathrm{TiO}$, sendo maiores no centro da amostra e outras amostras pontuadas na borda com maiores valores de $\mathrm{FeO}$ e $\mathrm{BaO}$. Os resultados obtidos por análise química de amostras de mica estão na tabela 4. E eles indicam que as amostras possuem excessos de cátions no sítio octaédrico e deficiência na posição intercamadas $(0,6<\mathrm{x}+\mathrm{y}<0,85$; todos os valores são superiores a 0,85$)$. Demais parâmetros como $\left(\mathrm{Mg}>\mathrm{Fe}^{\mathrm{II}}\right.$; $\left.{ }^{\mathrm{IV}} \mathrm{Al}>{ }^{\mathrm{IV}} \mathrm{Fe}^{\mathrm{III}} ;{ }^{\mathrm{VI}} \mathrm{Al} /\left({ }^{\mathrm{VI}} \mathrm{Al}^{\mathrm{VI}}+\mathrm{Fe}^{\mathrm{III}}\right)>0,6\right)$ ajudam a sustentar a base da muscovita (Cibin et al. 2008). 
Tabela 4: Dados de análise química obtidos por microssonda eletrônica de muscovita.

\begin{tabular}{|c|c|c|c|c|}
\hline Amostra/furo & 8_57(4) Centro & 8_57(4-1) Borda & 8_57(5) Centro & 8_57(5-1) Borda \\
\hline $\begin{array}{c}\text { Mineral/ } \\
\text { Associação }\end{array}$ & \multicolumn{4}{|c|}{ Muscovita } \\
\hline $\mathrm{SiO}_{2}(\%)$ & 48,159 & 48,415 & 47,210 & 47,334 \\
\hline $\mathrm{TiO}_{2}$ & 0,769 & 0,026 & 0,411 & 0,230 \\
\hline $\mathrm{Al}_{2} \mathrm{O}_{3}$ & 29,077 & 28,079 & 29,893 & 31,590 \\
\hline $\mathrm{FeO}$ & 3,802 & 4,546 & 3,219 & 3,543 \\
\hline $\mathrm{MnO}$ & 0,012 & 0,045 & 0,020 & 0,013 \\
\hline $\mathrm{MgO}$ & 0,203 & 2,554 & 2,172 & 1,306 \\
\hline $\mathrm{CaO}$ & 0,021 & 0,004 & 0,000 & 0,051 \\
\hline $\mathrm{BaO}$ & 0,067 & 0,172 & 0,169 & 0,352 \\
\hline $\mathrm{Na}_{2} \mathrm{O}$ & 0,107 & 0,126 & 0,163 & 0,107 \\
\hline $\mathrm{K}_{2} \mathrm{O}$ & 11,465 & 11,548 & 11,415 & 10,827 \\
\hline $\mathrm{Cl}$ & 0,003 & 0,003 & 0,003 & 0,015 \\
\hline $\mathrm{F}$ & 0,006 & 0,160 & 0,001 & 0,186 \\
\hline Total & 93,691 & 95,678 & 94,676 & 95,554 \\
\hline $\mathrm{O}$ & 15,999 & 15,999 & 15,983 & 15,986 \\
\hline $\mathrm{Cl}^{*}$ & 0,001 & 0,226 & 0,001 & 0,352 \\
\hline $\mathrm{F}^{*}$ & 0,003 & 0,421 & 0,004 & 0,563 \\
\hline Total $*$ & 16,003 & 16,646 & 15,987 & 16,901 \\
\hline $\mathrm{Si}$ & 7,232 & 7,184 & 7,010 & 6,956 \\
\hline $\mathrm{Al}^{\mathrm{IV}}$ & 0,768 & 0,824 & 0,989 & 1,044 \\
\hline Sítio T (soma) & 8,000 & 8,000 & 8,000 & 8,000 \\
\hline $\mathrm{Al}^{\mathrm{VI}}$ & 3,091 & 2,867 & 2,936 & 3,059 \\
\hline $\mathrm{Fe}$ & 0,239 & 0,282 & 0,200 & 0,218 \\
\hline $\mathrm{Mg}$ & 0,023 & 0,851 & 0,240 & 0,143 \\
\hline Mn & 0,001 & 0,505 & 0,001 & 0,001 \\
\hline $\mathrm{Ti}$ & 0,003 & 0,003 & 0,046 & 0,025 \\
\hline Sítio O & 3,357 & 4,508 & 3,423 & 3,446 \\
\hline $\mathrm{Ca}$ & 0,002 & 0,000 & 0,006 & 0,001 \\
\hline $\mathrm{Na}$ & 0,014 & 0,016 & 0,017 & 0,018 \\
\hline $\mathrm{Ba}$ & 0,004 & 0,010 & 0,010 & 0,020 \\
\hline K & 0,983 & 0,979 & 0,982 & 0,973 \\
\hline Inter-camadas & 0,998 & 0,996 & 1,005 & 0,991 \\
\hline $\mathrm{F}$ & 0,003 & 0,003 & 0,003 & 0,001 \\
\hline $\mathrm{Cl}$ & 0,001 & 0,001 & 0,001 & 0,001 \\
\hline $\mathrm{Fe} / \mathrm{Fe}+\mathrm{Mg}$ & 0,912 & 0,249 & 0,455 & 0,604 \\
\hline Al Total & 3,859 & 3,683 & 3,924 & 4,103 \\
\hline $\mathrm{AL}^{\mathrm{IV}} /\left(\mathrm{AL}^{\mathrm{IV}}+\mathrm{Fe}\right)$ & 0,763 & 0,745 & 0,832 & 0,827 \\
\hline
\end{tabular}




\subsection{SULFETOS}

A ocorrência dos sulfetos no Depósito Tocantinzinho se dá desde a fase magmática até a fase hidrotermal intensa, a qual está diretamente relacionada à mineralização local. As análises foram feitas em cristais de rutilo, titanita, pirita, calcopirita, esfalerita, galena, altaíta e ouro no Laboratório de Microssonda Eletrônica do IG da USP (rutilo e titanita) e no IG da UnB (pirita e ouro). Para tanto, foram usadas lâminas delgadas de amostras anteriormente descritas, correspondentes aos furos TOC-48, TOC-57 e TOC-24.

\subsubsection{Rutilo e titanita}

As análises de rutilo foram feitas no laboratório de Microssonda eletrônica do IG da USP, bem como as de titanita. As amostras selecionadas para ambos foram a 54_24 e 19_48A, respectivamente. A figura 33 mostra as fotomicrografias dos cristais selecionados para análise. Em 33-A a titanita e em 33-B os prismas de rutilo.

O rutilo ocorre apenas em amostras hidrotermalmente afetadas, geralmente associado com outros sulfetos e minerais de alteração (clorita, sericita e carbonato). Tem hábito prismático, os cristais estão alongados e têm cor escura (preta) em luz transmitida e em luz refletida, cinza.

Composicionalmente, apresentara teores de $\mathrm{TiO}_{2}$ em torno de $95 \%$ e $\mathrm{V}_{2} \mathrm{O}_{5}$ de $1,2 \%$, e teores desprezíveis de $\mathrm{Al}_{2} \mathrm{O}_{3}, \mathrm{CaO}$ e $\mathrm{SiO}_{2}(1,5 \%, 1,3 \%$ e 2,7\%, respectivamente).

O amplo campo de estabilidade da titanita faz com que este mineral seja um acessório muito comum em variados tipos de rochas ígneas, notadamente naquelas de composição granítica. No Depósito Tocantinzinho ela tem hábito euedral e cor castanha avermelhada. Em geral, está associada à magnetita e biotita e, devido a suas relações de contato, mostra-se precoce ou simultânea a formação da biotita e posterior a magnetita.

Foram feitas poucas análises nos cristais de titanita, porém a composição mostra-se homogênea, caracteristicamente magmática.

Os cristais de titanita mostram teores moderados à baixos de $\mathrm{Al}_{2} \mathrm{O}_{3}$, em torno de $1,4 \%$, que são típicos de titanitas magmáticas. Titanita secundária apresenta no geral valores de $\mathrm{Al}_{2} \mathrm{O}_{3}$ bem mais elevados, usualmente acima de 6,0\%. Da mesma forma, os valores de $\mathrm{Fe}_{2} \mathrm{O}_{3}$ também são compatíveis aos de titanita primária (Tuloch 1979). Os valores de $\mathrm{CaO}$ e $\mathrm{SiO}_{2}$ são próximos de $29 \%$ e $30,5 \%$, respectivamente e quantidades de $\mathrm{Na}_{2} \mathrm{O}, \mathrm{K}_{2} \mathrm{O}$ e $\mathrm{MgO}$ desprezíveis $(0,001 \%, 0,02 \%$ e $0,001 \%$, respectivamente). Dados referentes à composição química das análises de rutilo e titanita estão na tabela 5. 
Sabe-se que a titanita magmática é estável em magmas silicosos a baixas temperaturas, relativamente saturados em água e oxidados (Nakada 1991), semelhante ao granito, conforme mostra a presença de biotita como fase máfica dominante e magnetita como um dos principais minerais opacos na fase magmática.

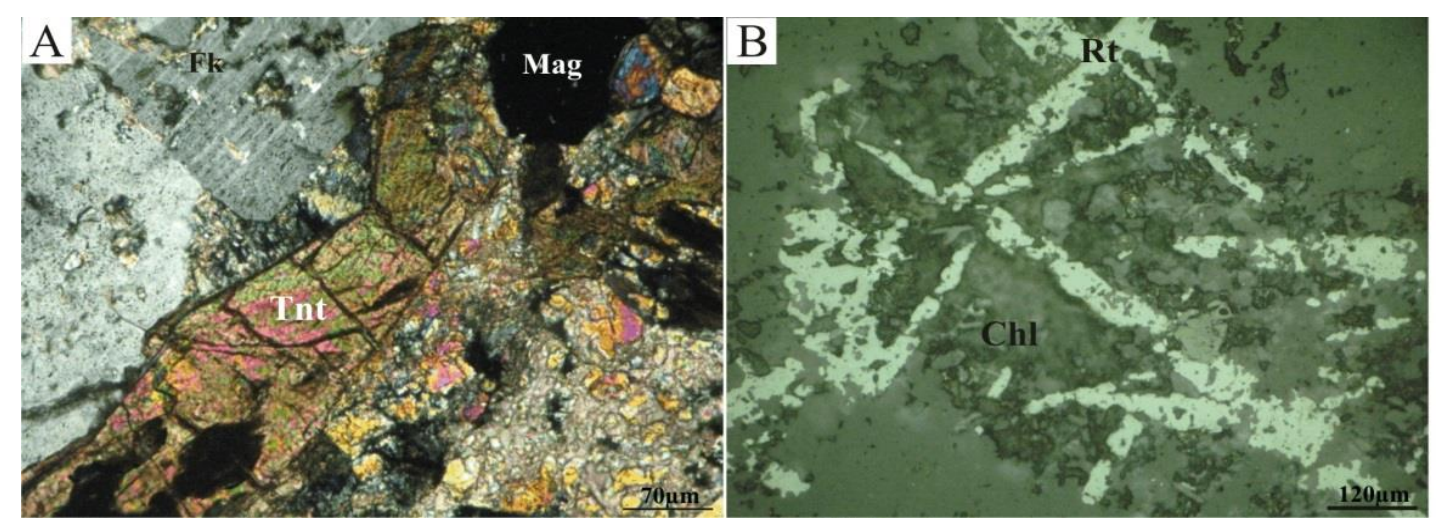

Figura 33: Fotomicrografia de cristal de titanita associado à massa de alteração e em contato com plagioclásio (amostra 55-24); B) fotomicrografia de cristais do grupo do rutilo inseridos em massa de Chl (amostra 19-48 A).

Tabela 5: Dados de análise de microssonda eletrônica de rutilo e titanita.

\begin{tabular}{|lcccccccccr|r|}
\hline \multicolumn{10}{c|}{ TITANITA } \\
\hline Amostra/ óxido (wt\%) & $\mathrm{SiO}_{2}$ & $\mathrm{TiO}_{2}$ & $\mathrm{Al}_{2} \mathrm{O}_{3}$ & $\mathrm{Fe}_{2} \mathrm{O}_{3}$ & $\mathrm{MnO}$ & $\mathrm{MgO}$ & $\mathrm{CaO}$ & $\mathrm{Na}_{2} \mathrm{O}$ & $\mathrm{K}_{2} \mathrm{O}$ \\
54_24(P8) & 30,515 & 41,467 & 1,411 & 1,907 & 0,199 & 0,005 & 29,461 & 0,023 & 0 \\
54_24(P10) & 30,435 & 40,506 & 1,408 & 1,788 & 0,155 & 0,023 & 29,147 & 0 & 0,04 \\
\hline \multicolumn{10}{c}{$\mathrm{RUTILO}$} \\
\hline Amostra/ oxido (wt\%) & $\mathrm{SiO}_{2}$ & $\mathrm{Al}_{2} \mathrm{O}_{3}$ & $\mathrm{CaO}$ & $\mathrm{TiO}_{2}$ & $\mathrm{Cr}_{2} \mathrm{O}_{3}$ & $\mathrm{~V}_{2} \mathrm{O}_{5}$ & $\mathrm{FeO}$ & $\mathrm{Nb}_{2} \mathrm{O}_{5}$ & $\mathrm{ZrO}_{2}$ \\
19-48A (P1) & 2,763 & 1,26 & 1,379 & 92,119 & 0 & 0,863 & 1,616 & 0 & 0 \\
19-48A (P2) & 3,389 & 1,833 & 1,313 & 97,655 & 0 & 1,611 & 1,611 & 0,407 & 0,01 \\
\hline
\end{tabular}




\section{CAPÍTULO IV: $\underline{\text { Mineralização de ouro }}$}

\section{MINERALOGIA DO OURO E MINERAIS ASSOCIADOS}

O estudo petrográfico de amostras hidrotermalizadas do Depósito Tocantinzinho objetivou a caracterização petrográfica e mineralógica do Depósito, a compreensão da relação entre a mineralização de ouro e o granito, além da compreensão da gênese, transporte e precipitação do minério.

Dados petrográficos e químicos foram integrados às análises de microssonda eletrônica na tentativa de propor um modelo genético para o Depósito.

$\mathrm{O}$ ouro ocorre, geralmente e em maior proporção, associado à pirita, e ambos associados a processos de sericitização e silicificação e, em alguns casos, cloritização. Seu estágio de formação está intimamente relacionado ao estágio de alteração fílica do Depósito Tocantinzinho, relacionado às amostras do grupo MAT-II.

Foram feitas análises de microssonda eletrônica em todos os sulfetos encontrados no Depósito: pirita, calcopirita, esfalerita, galena, altaíta e ouro. A tabela 6 apresenta os dados das análises dos sulfetos.

Os cristais de pirita foram selecionados de amostras mineralizadas, associados a grãos de Au, das lâminas 8_57 E 18_24 e seção polida S18_24. As amostras de ouro foram selecionadas em seus diferentes aspectos: amostra com ouro incluso e em fraturas (em cristais de pirita, calcopirita, esfalerita, galena e quartzo) e amostras onde o minério ocorre livre.

A pirita ocorre como partículas angulosas e cúbicas, variando entre 30 a $400 \mu \mathrm{m}$, com uma média entre 100 e $200 \mu \mathrm{m}$. Ocorre também como intercrescimento com galena, calcopirita e esfalerita. Nos locais onde se associa a massas de sericita, a pirita é rica em inclusões de outros sulfetos, predominantemente a calcopirita, porém também apresenta inclusões de esfalerita e galena e, neste caso, o ouro costuma está incluso na pirita e/ ou preenchendo fraturas. Já nos locais onde a pirita está associada à silicificação e sericitização (sericita + Qtz2 + pirita + ouro), outros sulfetos não são recorrentes e a pirita ocorre preenchendo vênulas e/ou fraturas. O ouro, neste caso, está incluso na pirita e/ou em sua forma livre. 
Apesar de haver diferença quanto à relação textural entre o ouro e a pirita, as análises de diferentes grãos de pirita em microssonda eletrônica apontam que esse mineral é composicionalmente homogêneo, ou seja, a pirita que está em apenas em paragênese com o ouro e àquela que se encontra em paragênese com ouro e demais sulfetos apresentam a mesma composição química (vide tabela 8, anterior).

A calcopirita ocorre como partículas de forma irregular variando de 50 a $100 \mu \mathrm{m}$. Os cristais de calcopirita se mostram livres na trama da rocha, mas sua principal ocorrência se dá como inclusões em pirita ou como intercrescimento juntamente à galena, esfalerita e rutilo.

Minerais de $\mathrm{Pb}$ e Te ocorrem inclusos na pirita. Apesar de pouco expressivos e recorrência local de difícil acesso ao alcance das análises de petrográficas e da microssonda, foi possível identifica-los: galena e altaíta $(\mathrm{PbTe})$. Esse último é um telureto de chumbo, do grupo da galena. 
Tabela 6: Resultados representativos de análise de microssonda eletrônica em minerais de esfalerita, pirita, galena e altaíta.

\begin{tabular}{|c|c|c|c|c|c|c|c|c|c|c|c|c|}
\hline Pirita & As & $\mathbf{S}$ & $\mathbf{B i}$ & Ag & Te & $\mathbf{P b}$ & $\mathbf{A u}$ & $\mathbf{F e}$ & $\mathbf{C u}$ & $\mathbf{Z n}$ & $\mathrm{Ni}$ & Total \\
\hline 8-57_C2 & 0 & 52,92 & 0,208 & 0 & 0,043 & 0,15 & 0,056 & 46,59 & 0 & 0 & 0 & 99,967 \\
\hline 8-57_C1 & 0 & 53,107 & 0,123 & 0,024 & 0 & 0,109 & 0,052 & 46,611 & 0,084 & 0 & 0,001 & 100,111 \\
\hline 8-57_C3 & 0 & 53,73 & 0,141 & 0,018 & 0,036 & 0,103 & 0,089 & 47,371 & 0 & 0,094 & 0 & 101,582 \\
\hline $18-24$ & 0 & 53,354 & 0,086 & 0 & 0,051 & 0,073 & 0 & 46,798 & 0,258 & 0 & 0 & 100,62 \\
\hline Esfalerita & As & $\mathbf{S}$ & $\mathbf{B i}$ & Ag & Te & $\mathbf{P b}$ & $\mathbf{A u}$ & $\mathbf{F e}$ & $\mathbf{C u}$ & Zn & $\mathbf{N i}$ & Total \\
\hline $18-24$ & 0 & 33,584 & 0,156 & 0,012 & 0,023 & 0,068 & 0,033 & 7,367 & 8,576 & 49,426 & 0,09 & 99,335 \\
\hline $18-24$ & 0,01 & 33,259 & 0,051 & 0 & 0,001 & 0 & 0 & 0,74 & 0,583 & 64,563 & 0 & 99,207 \\
\hline $18-24$ & 0,017 & 33,004 & 0,13 & 0,008 & 0,03 & 0 & 0 & 0,874 & 0,444 & 64,344 & 0,038 & 98,889 \\
\hline S18-24 & 0 & 32,82 & 0,096 & 0 & 0,03 & 0 & 0 & 0,131 & 0 & 64,816 & 0,032 & 97,925 \\
\hline Galena & As & $\mathbf{S}$ & $\mathbf{B i}$ & Ag & Te & $\mathbf{P b}$ & Au & $\mathrm{Fe}$ & $\mathbf{C u}$ & Zn & $\mathbf{N i}$ & Total \\
\hline $18-24$ & 0 & 13,386 & 0,327 & 0 & 0,051 & 85,417 & 0 & 0,037 & 0,024 & 0,063 & 0,147 & 99,452 \\
\hline $18-24$ & 0 & 13,401 & 0,366 & 0 & 0,091 & 85,345 & 0 & 0,039 & 0,109 & 0,11 & 0,108 & 99,569 \\
\hline $18-24$ & 0 & 13,278 & 0,352 & 0 & 0,11 & 85,065 & 0 & 0,048 & 0,035 & 0 & 0,019 & 98,907 \\
\hline S18-24 & 0 & 13,341 & 0,376 & 0,033 & 0 & 84,135 & 0 & 0 & 0,116 & 0 & 0 & 98,001 \\
\hline S18-24 & 0 & 13,402 & 0,465 & 0,04 & 0,03 & 84,29 & 0 & 0,015 & 0 & 0 & 0,032 & 98,274 \\
\hline S18-24 & 0 & 13,433 & 0,265 & 0 & 0,065 & 85,344 & 0 & 0,014 & 0 & 0 & 0 & 99,121 \\
\hline S18-24 & 0 & 13,388 & 0,347 & 0 & 0,046 & 83,532 & 0 & 1,184 & 0 & 0 & 0,055 & 98,552 \\
\hline S18-24 & 0 & 13,473 & 0,36 & 0 & 0,034 & 84,426 & 0 & 0,934 & 0 & 0 & 0,116 & 99,343 \\
\hline S18-24 & 0 & 13,439 & 0,437 & 0 & 0,044 & 84,126 & 0 & 0,02 & 0 & 0,606 & 0,04 & 98,712 \\
\hline $\begin{array}{l}\text { Altaita } \\
\text { (PbTe) }\end{array}$ & As & $\mathbf{S}$ & $\mathbf{B i}$ & Ag & Te & $\mathbf{P b}$ & $\mathbf{A u}$ & $\mathrm{Fe}$ & $\mathrm{Cu}$ & Zn & $\mathbf{N i}$ & Total \\
\hline S18-24 & 0 & 0,072 & 0,578 & 0,07 & 37,101 & 58,711 & 0 & 0,975 & 0,242 & 0 & 0,046 & 97,795 \\
\hline
\end{tabular}




\subsection{QUÍMICA E DISTRIBUIÇÃO DO OURO NO DEPÓSITO TOCANTINZINHO}

Com objetivo de caracterizar quimicamente o depósito de ouro Tocantinzinho e na tentativa de distinguir gerações distintas com base em sua química, foi feita a análise de ouro em microssonda eletrônica e os resultados estão representados na tabela 7, a qual mostra as análises de ouro em seu estado livre, incluso e preenchendo fraturas em sulfetos e quartzo.

Os resultados mostram que o ouro do Tocantinzinho é, basicamente, composto por $\mathrm{Au}$ e Ag. Existem dois tipos principais de paragênese do minério de ouro no depósito Tocantinzinho, e eles são: 1) Quando o ouro nativo ocorre, em geral, associado à pirita, este sendo o principal sulfeto e mais abundante do depósito. Neste caso a ocorrência se dá, geralmente, como partículas inclusas em grãos de quartzo e em sulfeto, em fraturas ou em limites de cristais de sulfetos e na forma livre na trama da rocha (figura 34). As partículas do minério variam entre 5 e $100 \mu \mathrm{m}$ em tamanho, com média de 30 a $50 \mu \mathrm{m}$. Geralmente, está disposto de forma arredondada globulosa ou em lamelas irregulares e/ou alongadas; 2) $\mathrm{O}$ outro tipo de paragênese do minério é observada entre ouro + pirita + calcopirita + galena + esfalerita + altaíta. Neste caso o minério também ocorre na forma inclusa e preenchendo as microfraturas dos sulfetos. Na figura 35 as fotomicrografias mostram os dois tipos de associações minerais. Em 35-A/ B/ C ocorre a paragênese pirita + ouro \pm Qtz2. De 35-D até 35-I tem-se o segundo tipo de paragênese do minério.

Com base na análise química, comparando-se as formas de ocorrência do minério (livre, incluso ou preenchendo fraturas), aquela que se dá de maneira livre, em geral em paragênese com grãos de quartzo, é a mais rica em Au e mais pobre em Ag que as demais, com porcentagem média de 91,03\%, e 8,78\%, respectivamente. As proporções dos demais elementos encontrados na composição química do ouro são pouco expressivas.

O segundo tipo de ocorrência de ouro, que se dá de forma inclusa, foi analisado em cristais de pirita e em esfalerita, e as respostas composicionais são distintas. Em cristais de pirita o ouro nela incluso apresentou composição mais rica em Au (média de 88,94\%) e relativamente equivalente de prata $(10,51 \%)$. O ouro incluso em esfalerita respondeu com composição de 78,10\% de Au e 10,25\% de Ag.

O terceiro tipo, o encontrado em fraturas, foi analisado em fraturas de cristais de pirita e esfalerita. Neste caso, os resultados obtidos das análises de ouro em fratura nos cristais de esfalerita foram maiores, com Au em média de 89,66\% e Ag com 9,62\%, enquanto que o ouro em fraturas de pirita é mais pobre tanto em $\mathrm{Au}$ quanto em $\mathrm{Ag}$, mostrando média de $71,95 \%$ e $7,06 \%$, respectivamente. 
Também relacionando os teores de ouro, a pirita, que é o sulfeto mais importante relacionado à mineralização do Depósito Tocantinzinho, não mostra variações composicionais significativas entre os cristais que apresentam ouro incluso ou em fraturas.

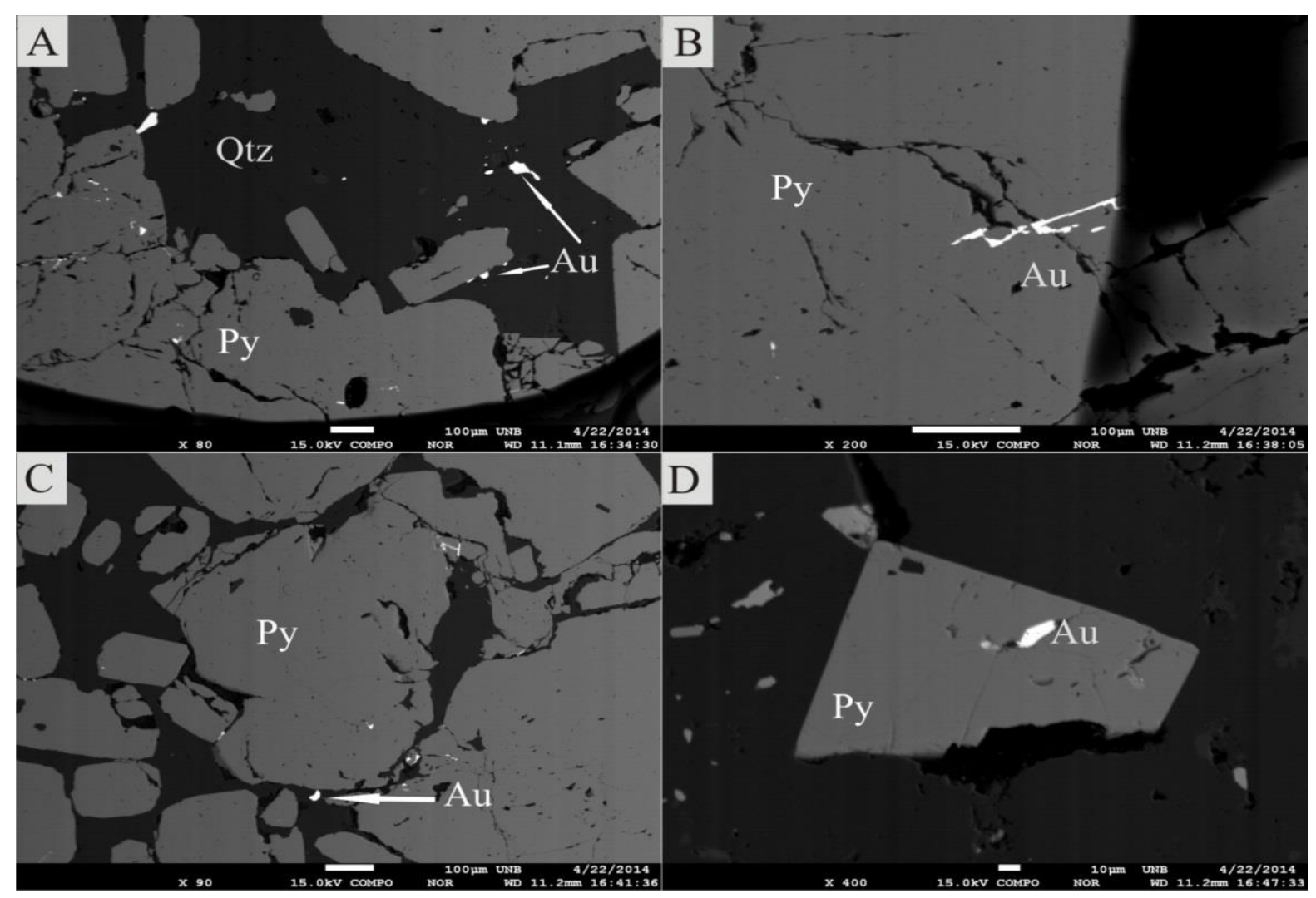

Figura 34: Imagens de elétrons retroespalhados de análise de microssonda eletrônica mostrando as principais ocorrências de ouro nativo no Depósito Tocantinzinho: A) ouro livre em massa de silicificação e veio de pirita (amostra S18_24); B) ouro em fratura na pirita (amostra 8_57); C) ouro incluso e preenchendo fraturas de pirita (amostra 8_57); D) ouro incluso em pirita. 


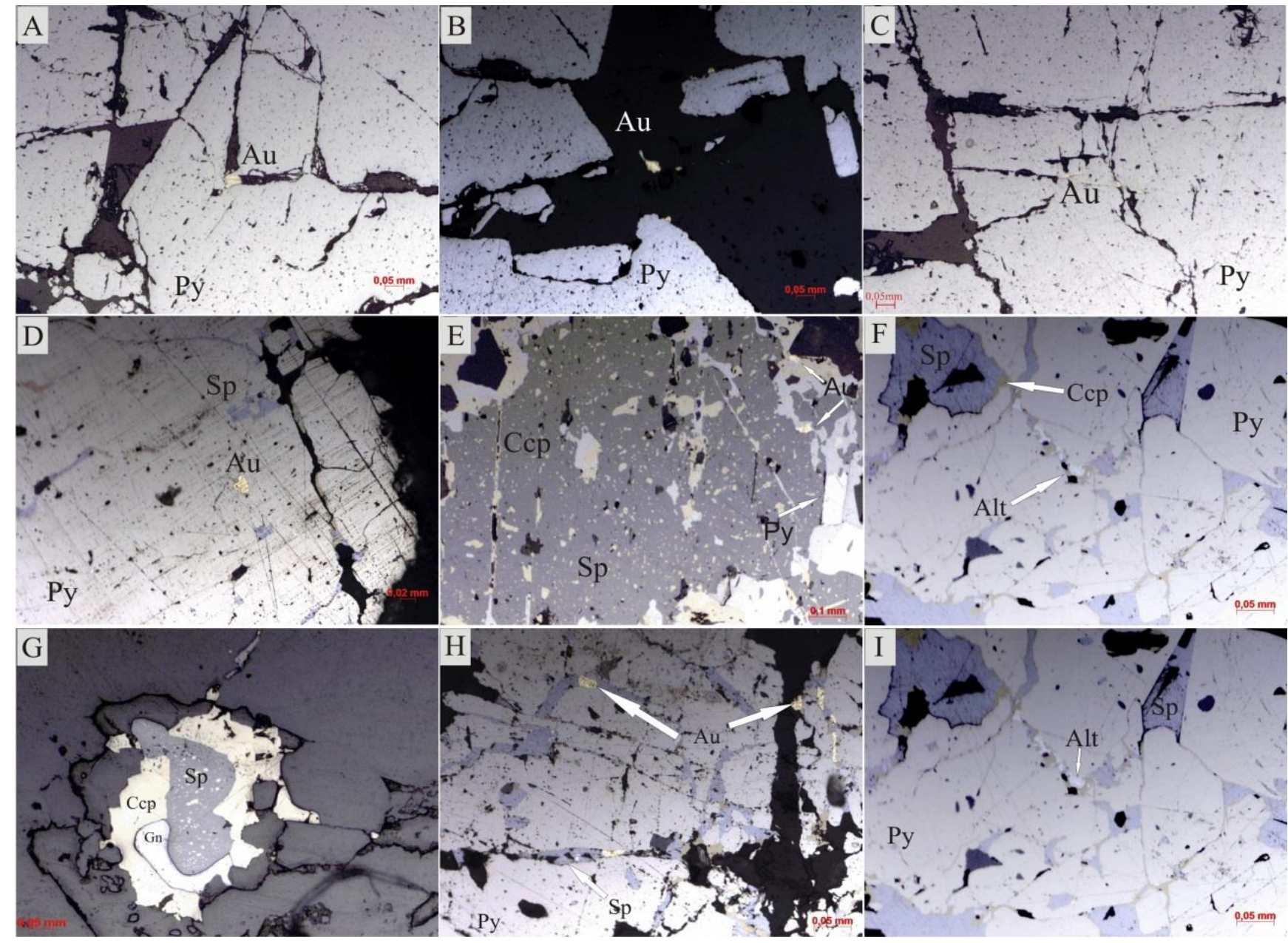

Figura 35: Fotomicrografias de amostras sulfetadas e mineralizadas do Depósito Tocantinzinho: A/ B/C) Paragênese de Py + Au, destaque para o cristal de pirita com poucas a nenhuma inclusão de sulfetos. Em A e C o Au está incluso em fraturas e em B ele está livre, em cristal de Qtz; D/E/F) Py em paragênese com demais sulfetos; em D a Py apresenta intercrescimento/substituição por esfalerita, além do Au incluso em Py; em E há o intercrescimento/substituição da calcopirita e esfalerita. Em D tem-se cristal de pirita sofrendo substituição/ intercrescimento por esfalerita, além de Ccp e Alt preenchendo fraturas da Py; G) grãos de esfalerita (Sp), calcopirita (Ccp) e galena (Gn) (amostra 18_24); H) associação de pirita (Py), Sp e ouro (Au) (amostra S18_24); Paragde Py, Sp e Alt (telureto de chumbo-TePb) (amostra S18_24). 
Tabela 7: Dados representativos de análises de microssonda eletrônica em ouro do Depósito Tocantinzinho.

\begin{tabular}{|c|c|c|c|c|c|c|c|c|c|c|c|c|c|c|c|c|c|}
\hline \multicolumn{4}{|c|}{$\underline{\text { Au Livre }}$} & \multicolumn{8}{|c|}{$\underline{\text { Au Incluso }}$} & \multicolumn{6}{|c|}{$\underline{\text { Au em Fraturas }}$} \\
\hline & Qtz & Qtz & Qtz & $\mathbf{P y}$ & $\mathbf{P y}$ & $\mathbf{P y}$ & Py & Sp & Sp & Sp & Sp & $\mathbf{P y}$ & $\mathbf{P y}$ & Sp & Sp & Sp & Sp \\
\hline $\begin{array}{l}\text { Samples } \\
\text { no. }\end{array}$ & $\begin{array}{c}8- \\
57 \_ \text {C3_- } \\
\text { Au } 5\end{array}$ & $\begin{array}{c}8- \\
57 \_\mathrm{C}^{2}- \\
\mathrm{Au} 1\end{array}$ & $\begin{array}{c}8- \\
57 \_\mathrm{C}^{2}- \\
\mathrm{Au} 2\end{array}$ & $\begin{array}{c}8- \\
57 \_\mathrm{C} 2 \\
\text { _Au } 3\end{array}$ & 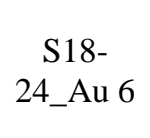 & $\begin{array}{c}\text { S18- } \\
24 \_\mathrm{Au} 5\end{array}$ & $\begin{array}{c}\text { S18- } \\
24_{-} \text {Au } \\
12\end{array}$ & $\begin{array}{c}\text { S18- } \\
24 \_\mathrm{Au} 4\end{array}$ & $\begin{array}{c}\text { S18- } \\
24 \_\mathrm{Au} 9\end{array}$ & $\begin{array}{c}\text { S18- } \\
24 \_\mathrm{Au} 10\end{array}$ & $\begin{array}{c}\text { S18- } \\
24 \_\mathrm{Au} 11\end{array}$ & $\begin{array}{c}8- \\
57 \_ \text {C3_- } \\
\text { Au } 6\end{array}$ & $\begin{array}{c}18- \\
24 \_\mathrm{Au} 1\end{array}$ & $\begin{array}{c}\text { S18- } \\
24 \_ \text {Au } 1\end{array}$ & $\begin{array}{c}\text { S18- } \\
24 \_\mathrm{Au} 2\end{array}$ & $\begin{array}{c}\text { S18- } \\
24 \_\mathrm{Au} 3\end{array}$ & $\begin{array}{c}\text { S18- } \\
24 \_\mathrm{Au} 8\end{array}$ \\
\hline As & 0 & 0 & 0 & 0 & 0 & 0 & 0 & 0 & 0,004 & 0 & 0,013 & 0 & 0,037 & 0,023 & 0 & 0,012 & 0,027 \\
\hline $\mathrm{S}$ & 0,115 & 0,06 & 0,086 & 0,137 & 0,032 & 0,06 & 0,064 & 0,033 & 0,063 & 12,116 & 0,05 & 20,238 & 4,079 & 0,027 & 0,005 & 0 & 0,056 \\
\hline $\mathrm{Bi}$ & 0,522 & 0,527 & 0,385 & 0,296 & 0,252 & 0,491 & 0,297 & 0,447 & 0,399 & 0,276 & 0,425 & 0,242 & 0,324 & 0,519 & 0,294 & 0,548 & 0,36 \\
\hline $\mathrm{Ag}$ & 8,359 & 9,665 & 8,337 & 8,633 & 11,249 & 10,678 & 11,499 & 9,151 & 12,743 & 7,184 & 11,961 & 5,128 & 8,999 & 8,501 & 6,548 & 11,134 & 12,316 \\
\hline $\mathrm{Te}$ & 0,051 & 0,014 & 0 & 0,077 & 0,063 & 0,019 & 0,032 & 0,061 & 0,045 & 0,147 & 0,052 & 0,002 & 0,029 & 0,072 & 0,018 & 0,001 & 0,041 \\
\hline $\mathrm{Pb}$ & 0 & 0 & 0 & 0 & 0 & 0 & 0 & 0 & 0 & 22,075 & 0 & 0 & 0 & 0 & 0 & 0 & 0,14 \\
\hline $\mathrm{Au}$ & 90,964 & 90,302 & 91,831 & 90,46 & 88,816 & 89,603 & 86,918 & 91,271 & 82,31 & 51,969 & 86,863 & 62,811 & 81,1 & 90,106 & 94,744 & 87,588 & 86,222 \\
\hline $\mathrm{Fe}$ & 0,519 & 0,068 & 0,079 & 0,212 & 0,729 & 0,539 & 0,253 & 0 & 0,69 & 9,019 & 0,003 & 16,094 & 4,688 & 0,04 & 0 & 0,014 & 0,734 \\
\hline $\mathrm{Cu}$ & 0 & 0,053 & 0 & 0 & 0 & 0 & 0 & 0,059 & 0 & 0,683 & 0 & 0 & 0 & 0 & 0,262 & 0 & 0 \\
\hline $\mathrm{Zn}$ & 0 & 0 & 0 & 0 & 0 & 0 & 0 & 0 & 0 & 0 & 0,392 & 0 & 0,06 & 0 & 0 & 0 & 0 \\
\hline $\mathrm{Ni}$ & 0,093 & 0 & 0 & 0,084 & 0 & 0,004 & 0 & 0,027 & 0 & 0,049 & 0 & 0,083 & 0,032 & 0,048 & 0 & 0 & 0,102 \\
\hline Total & 100,623 & 100,689 & 100,718 & 99,899 & 101,141 & 101,394 & 99,063 & 101,049 & 96,254 & 103,518 & 99,759 & 104,598 & 99,348 & 99,336 & 101,871 & 99,297 & 99,998 \\
\hline
\end{tabular}




\section{CAPÍTULO V: Estudo dos Fluidos Mineralizantes}

\section{INCLUSÕES FLUIDAS}

\subsection{INTRODUÇÃO}

Os resultados obtidos a partir do estudo de inclusões fluidas contribuem significativamente para o entendimento das condições físico-químicas à época em que ocorreu a entrada e o aprisionamento dos fluidos hidrotermais e mineralizadores.

Essa ferramenta é de grande importância para auxiliar no entendimento de processos geológicos regidos por fluidos, com o intuito de descobrir origem, transporte e condições de aprisionamento do fluido.

O principal objetivo neste estudo é caracterizar os fluidos associados às fácies hidrotermais do Depósito Tocantinzinho associados à mineralização de ouro e estabelecer os principais parâmetros físico-químicos do processo de mineralização que ocorreu no depósito.

\subsection{MÉTODOS}

O estudo de inclusões fluidas foi realizado em lâminas delgadas bipolidas de amostras representativas dos dois tipos de fácies fortemente alteradas e mineralizadas assim como em amostras com pouco a nenhum indício de alteração hidrotermal, para efeito de comparação. A relação de amostras selecionadas para esse estudo consta na tabela 8.

Este estudo foi realizado em etapas. $\mathrm{Na}$ primeira etapa foram selecionadas as amostras para a confecção de lâminas bipolidas de diferentes furos de sondagem. Essas amostras foram escolhidas por apresentarem forte alteração hidrotermal e associação com a mineralização $(\mathrm{Au})$, mesmo que em algumas delas ainda fosse possível reconhecer traços mais preservados, ou seja, menos alterados. Com isso foram confeccionadas oito (8) lâminas bipolidas. Em seguida, foi feito o mapeamento petrográfico e seleção dos grãos de quartzo adequados para o estudo (figura 36).

O estudo petrográfico de inclusões fluidas foi feito em microscópio de luz transmitida e refletida Zeiss modelo Axioplam 2 no Laboratório de Microscopia do IG, UnB, equipado com objetivas de até 100x e oculares de 10x. 
As medidas das temperaturas de mudanças de fase foram obtidas com o uso de platina Linkam THMSG600 acoplada a um microscópio Olympus BX 50, no Laboratório de Inclusões Fluidas do Instituto de Geociências da UnB. A calibração do equipamento foi feita por meio de medições de $\operatorname{Tf}_{(\mathrm{CO} 2)}$ (temperatura de fusão do $\left.\mathrm{CO}_{2}\right)$, $\mathrm{Tf}$ (gelo) $($ temperatura de fusão do gelo) e $\mathrm{Th}_{(\mathrm{H} 2 \mathrm{O})}$ (temperatura de homogeneização da água pura) em inclusões fluidas de padrões sintéticos. Os erros são de $\pm 0,1^{\circ} \mathrm{C}$ para o resfriamento e de $\pm 1{ }^{\circ} \mathrm{C}$ para temperaturas de homogeneização acima de $200{ }^{\circ} \mathrm{C}$.

A primeira fase do estudo microtermométrico consistiu em resfriar as inclusões fluidas e, após término do processo, foi iniciado o aquecimento. Este tem que ser feito na fase final do estudo microtermométrico devido à possibilidade de ocorrerem mudanças de volume e visibilidade, pois com o aquecimento progressivo algumas inclusões vêm a escurecer e até decrepitar. Ao todo foram analisadas mais de 200 inclusões fluidas, das quais 183 responderam positivamente aos ensaios de aquecimento e resfriamento (tabela 9).

Não foi possível identificar a temperatura do eutético das inclusões estudadas, o que limitou a identificação de possíveis variações composicionais nos sistemas aquosos. Os valores de salinidade foram estimados usando a equação de Bodnar (2003), para sistemas salinidade baixa a moderada: Salinidade $=1,78^{*}\left(-\mathrm{Tf}_{(\text {gelo })}\right)-0,0442^{*}\left(\left(-\mathrm{Tf}_{\text {(gelo })}\right)^{\wedge}\right.$ $2)+0,000557 *\left(\left(-\operatorname{Tf}_{(\text {gelo })}\right) \wedge 3\right)$, onde $\operatorname{Tf}($ gelo $)$ é a temperatura de fusão do gelo.

Os resultados de densidade são representados pela seguinte equação (Bodnar 2003): $\mathrm{dP} / \mathrm{dT}\left(\mathrm{bar} /{ }^{\circ} \mathrm{C}\right)=\mathrm{as}+\mathrm{bs}^{*} \mathrm{Th}+\mathrm{cs}^{*} \mathrm{Th}^{\wedge} 2$, onde Th é a temperatura de homogeneização total.

\subsection{PETROGRAFIA E DADOS MICROTERMOMÉTRICOS}

Foram estudadas inclusões fluidas isoladas e em grupamentos/alinhadas; grãos de quartzo em equilíbrio com o estágio de microclinização, em paragênese com microclínio (Qtz1) e grãos de quartzo que estão em equilíbrio com a paragênese hidrotermal mineralizada, associada a fase de alteração fílica (Qtz2).

As lâminas foram separadas em dois grupos:

1) Amostras do grupo MAT-I, com alteração hidrotermal fraca, relacionadas à fase de microclinização, com a maior parte dos grãos de quartzo em paragênese direta com microclínio + albita \pm pirita (amostras 20_24_14; 36_24_14; 24_24_14);

2) Amostras do grupo MAT-II, fortemente hidrotermalizadas, sendo a alteração fílica a mais representativa (sericita + clorita + ouro), apresentando padrão de alteração 
stockwork, com sulfetos associados (pirita + calcopirita + esfalerita + galena + altaíta) (amostras 5_48_14; 8_48_14; 13_48_14; 18_48_14; 10_24_14).

Tabela 8: Resumo dos dados das amostras selecionadas para o estudo de inclusões fluidas.

\begin{tabular}{|c|c|c|c|c|c|c|}
\hline Amostra & Furo & Prof (m) & X (UTM) & Y (UTM) & Alteração & $\begin{array}{c}\text { Au_ppm } \\
\text { (intervalo) }\end{array}$ \\
\hline $5-48-14$ & 48 & $103,47-103,63$ & & & $\begin{array}{c}\text { Microclinização e } \\
\text { sericitização moderada. }\end{array}$ & 3,531 \\
\hline $8-48-14$ & 48 & $\begin{array}{l}131,34- \\
131,45\end{array}$ & 578397,35 & 9330639,16 & $\begin{array}{l}\text { Microclinização forte, } \\
\text { sericitização e cloritização } \\
\text { fracas a moderadas; } \\
\text { carbonatação fraca. } \\
\text { Silicificação forte. }\end{array}$ & 0,793 \\
\hline $13-48-14$ & 48 & $\begin{array}{l}203,30- \\
203,40\end{array}$ & & & $\begin{array}{l}\text { Sericitização e cloritização } \\
\text { moderadas a fortes. }\end{array}$ & 1,606 \\
\hline $18-48-14$ & 48 & $\begin{array}{c}252,20- \\
252,30\end{array}$ & & & $\begin{array}{l}\text { Sericitização e silicificação } \\
\text { fortes; cloritização moderada. }\end{array}$ & 23,579 \\
\hline $10-24-14$ & 24 & $67,05-67,15$ & & & $\begin{array}{l}\text { Microclinização forte, } \\
\text { sericitização e cloritização } \\
\text { fracas; carbonatação fraca. }\end{array}$ & 0,018 \\
\hline 20-24-14 & 24 & $\begin{array}{c}112,40- \\
112,54 \\
133,40-\end{array}$ & 578330,89 & 9330397,48 & $\begin{array}{l}\text { Sericitização e cloritização } \\
\text { moderadas. Silicificação. } \\
\text { Sericitizacão e cloritizacão }\end{array}$ & 0,342 \\
\hline 24-24-14 & 24 & $\begin{array}{c}153,40- \\
133,50 \\
192,88\end{array}$ & & & $\begin{array}{c}\text { moderadas. Silicificação. } \\
\text { Sericitizacão.silicificacão e }\end{array}$ & 0,283 \\
\hline $36-24-14$ & 24 & 192,98 & & & $\begin{array}{l}\text { cloritização fortes. } \\
\text { cina }\end{array}$ & 5,676 \\
\hline
\end{tabular}

Os grãos de quartzo do primeiro grupo foram classificados por Qtz1, já os do grupo dois foram denominados Qtz2.

Sequencialmente, as observações petrográficas permitiram reconhecer e classificar as inclusões fluidas, levando-se em consideração principalmente a cor, natureza e proporções relativas (grau de preenchimento, tamanho, etc.): 1) aquelas que ocorrem de forma isolada e/ ou são aleatoriamente distribuídas nos grãos de quartzo (primárias); 2) as alinhadas ou não ao longo de microfraturas ou agrupadas (secundárias) (Shepherd et al.1985).

Com base no estudo petrográfico, nos dados microtermométricos obtidos em testes de resfriamento e aquecimento e apoiado na nomenclatura sugerida por Shepherd et al. (1985), foi possível reconhecer cinco (5) tipos diferentes de inclusões fluidas nos grãos de Qtz1 e Qtz2 (figura 38). A tabela 9 apresenta o resumo dos dados petrográficos e microtermométricos dos cinco principais tipos de inclusões fluidas encontrados durante este estudo. 


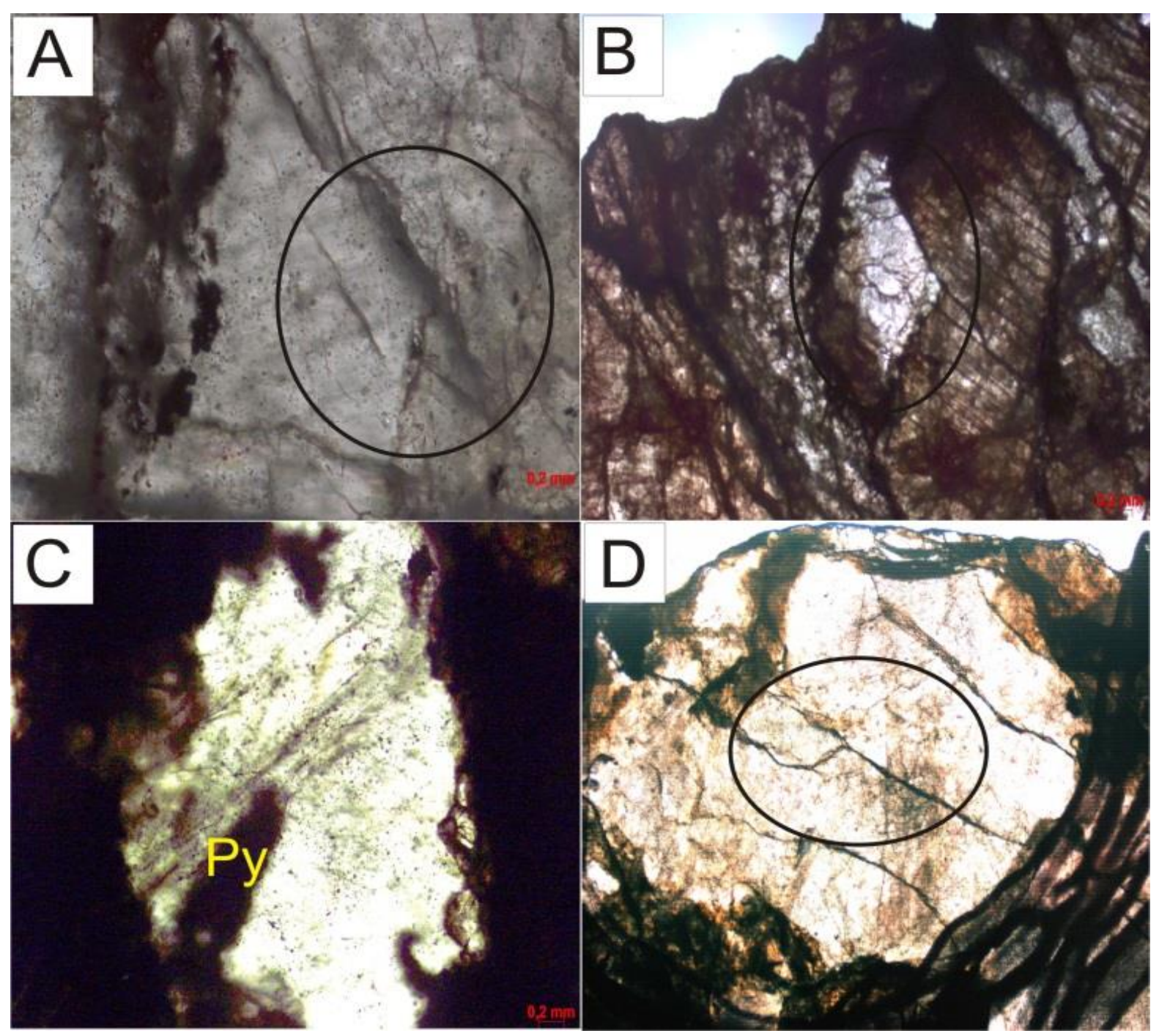

Figura 36: Fotomicrografias de amostras de quartzo selecionadas para o estudo de inclusões fluidas. A) Qtz1 mostrando os contatos poligonais existentes nos grãos; B) Qtz2 fortemente fraturado e incluso por material de alteração hidrotermal (sericita + clorita); C) Qtz2 envolto por minerais opacos, dentre eles a pirita (Py); D) Qtz1: contornos poligonais e grão pouco alterado.

\section{Tipo I}

Inclusões fluidas primárias, bifásicas, ricas em vapor $(\mathrm{V}+\mathrm{L})$ em temperatura ambiente e que homogeneízam para a fase vapor. São ovais e/ou arredondadas, a bolha de gás é escura e com grau de preenchimento em torno de 0,60 a 0,50. Possuem, frequentemente, entre 8 e16 $\mu \mathrm{m}$. Sua ocorrência se dá apenas em grãos de Qtz2 em rochas do grupo MAT-II, aqueles que representam a de alteração fílica do depósito e estão geneticamente associadas à mineralização do Depósito Tocantinzinho. 
As inclusões fluidas do tipo I possuem temperatura de fusão do gelo entre $-11,2{ }^{\circ} \mathrm{C}$ e $-2,5{ }^{\circ} \mathrm{C}$, com maior intervalo de recorrência entre $-4,7{ }^{\circ} \mathrm{C}$ e $-2,5{ }^{\circ} \mathrm{C}$. A temperatura de homogeneização (Th $(\mathrm{L})$ ) varia de $303,7{ }^{\circ} \mathrm{C}$ a $432,6{ }^{\circ} \mathrm{C}$. A salinidade, calculada com base na $\mathrm{Tf}_{\text {(gelo) }}$ para o sistema $\mathrm{H}_{2} \mathrm{O}-\mathrm{NaCl}$ (Bodnar 2003), varia entre 4,18 e 15,17\% em wt\%. de $\mathrm{NaCl}$ eq. e os valores de densidade variam entre 0,43 a $0,84 \mathrm{~g} / \mathrm{cm}^{3}$, também calculada com base em Bodnar (2003).

\section{Tipo II}

São inclusões fluidas primárias aquosas bifásicas $(\mathrm{L}+\mathrm{V})$ em temperatura ambiente e homogeneízam para a fase líquida. Morfologicamente, são, na maioria das vezes, elipsoidais e raramente arredondadas. Sua coloração é leve a fortemente escura devido à sua fase gasosa (bolha escura). Oscilam entre 8 a $14 \mu \mathrm{m}$ e o grau de preenchimento é de 0,70 a 0,80 . Sua ocorrência se dá em grãos de quartzo Qtz1 e Qtz2, no estágio de microclínização e na fase de alteração fílica, sendo mais frequentes em paragênese com o Qtz2 + sericita + pirita.

Os dados microtermométricos foram resumidos a seguir: Tf (gelo) com ampla variação entre $-11,9^{\circ} \mathrm{C} \mathrm{a}-1,2{ }^{\circ} \mathrm{C}$, com uma medida com valor de $-16,9^{\circ} \mathrm{C}$ e moda em torno de $-5,5^{\circ} \mathrm{C}$. A $\mathrm{Th}_{(\mathrm{L})}$ variam de $280,0{ }^{\circ} \mathrm{C}$ a $425,8{ }^{\circ} \mathrm{C}$; salinidade entre 3,54 e $20,14 \mathrm{wt} \%$ de $\mathrm{NaCl}$ eq. e a densidade entre $0,32 \mathrm{~g} / \mathrm{cm}^{3}$ e $0,90 \mathrm{~g} / \mathrm{cm}^{3}$.

\section{Tipo III}

Inclusões fluidas primárias, aquosas bifásicas ricas em líquido $(\mathrm{L}+\mathrm{V})$ em temperatura ambiente e homogeneízam para o líquido. Ocorrem, em geral, com forma ovalar a elipsoidal. São incolores á acastanhadas/ acinzentadas. Oscilam entre 6 a $10 \mu \mathrm{m}$ e apresentam grau de preenchimento entre 0,80 a 0,90. Sua ocorrência se dá em grãos de quartzo Qtz1 e Qtz2, em paragênese com a alteração fílica elas são mais raras, no entanto são recorrentes em grãos de Qtz 1 do estágio de microclinização. São inclusões que, segundo análises interpretativas, assim como o Tipo I, estão associadas a fase mais representativa da alteração/mineralização do depósito, ou seja, estão em paragênese com a alteração fílica (Ser + $\mathrm{Chl}+\mathrm{Py}+\mathrm{Au})$.

Neste grupo, a $\mathrm{Tf}_{\text {(gelo) }}$ ocorre entre $-5,9{ }^{\circ} \mathrm{C}$ a $-1,5{ }^{\circ} \mathrm{C}$, a $\mathrm{Th}_{(\mathrm{L})}$ varia de $203,2{ }^{\circ} \mathrm{C}$ a $369,5^{\circ} \mathrm{C}$, a salinidade varia entre de 1,22 a $8,27 \mathrm{wt} \%$ de $\mathrm{NaCl}$ eq. e a densidade, entre $0,61 \mathrm{e}$ $0,94 \mathrm{~g} / \mathrm{cm}^{3}$.

\section{Tipo IV}


São inclusões fluidas secundárias aquosas bifásicas $(L+V)$ ricas na fase líquida e, em geral, têm forma oval e/ou elipsoidal, são incolores, oscilam entre 3 a $10 \mu \mathrm{m}$ e apresentam grau de preenchimento $(\mathrm{F})$ entre 0,85 a 0,95 . Estão presentes em ambos os tipos de quartzo analisados. As que ocorrem no tipo Qtz1, relacionadas ao estágio de microclinização, não foram analisadas devido ao tamanho $(\leq 3 \mu \mathrm{m})$ e à difícil visualização de suas respostas microtermométricas. Sendo assim, as inclusões representativas do Tipo IV são aquelas analisadas nos grãos de Qtz2 encontradas em paragênese com a mineralização e o estágio de alteração fílica.

Os dados microtermométricos desse grupo de inclusões estão resumidos a seguir: Tf (gelo) $-3,5{ }^{\circ} \mathrm{C}$ a $-0,1{ }^{\circ} \mathrm{C}$, tendo como moda o valor de $-1,1{ }^{\circ} \mathrm{C}$. A temperatura de homogeneização do gelo (Th $(\mathrm{L})$ ) em torno de $100,3{ }^{\circ} \mathrm{C}$ a $290,9{ }^{\circ} \mathrm{C}$; valores de salinidade entre 0,17 e $5,10 \mathrm{wt} \%$ de $\mathrm{NaCl}$ eq. e a densidade oscilando entre 0,72 e $0,96 \mathrm{~g} / \mathrm{cm}^{3}$.

\section{Tipo V}

Inclusões fluidas monofásicas ricas em vapor (V) ou em líquido (L). São, geralmente, disformes e escuras. O tamanho oscila consideravelmente (de 8 a $30 \mu \mathrm{m}$ ). Ocorrem em todos os campos de grãos de quartzo aqui analisados (Qtz1 e Qtz2). Não foi possível medir as características microtermométricas do Tipo $\mathrm{V}$, pois as inclusões não responderam ao aquecimento nem resfriamento realizado nas amostras. Dessa forma, foram interpretadas como inclusões de vapor $\left(\mathrm{H}_{2} \mathrm{O}\right)$. 
Tipos de inclusão

Tipo I

Tipo II

Tipo III

\section{Tipo IV}

Tipo de quartzo/

ocorrência

Qtz2

Alteração fílica

Qtz1

Qtz2

Qt?

Qtz2

Qtz1

Qtz2

Alteração hidrotermal

\section{Estágio de} microclinização; alteração fílica

cantinzinho.

\section{Petrográficas}

Inclusões primárias de ocorrência rara; bifásicas: arredondadas a ovaladas; escuras; 8 a $16 \mu \mathrm{m}$; VG

$$
\text { de } 0,40 \text { a } 0,50 \text {. }
$$

Primárias; bifásicas;

elipsoidais e

Alteração fílica; estágio de microclinização

arredondadas; escuras; 8

e $14 \mu \mathrm{m} ; \mathrm{VG}$ de 0,30 a

$$
0,40 \text {. }
$$

Primárias; bifásicas;

Alteração fílica estágios de microclinização

Secundárias; bifásicas;

$$
\text { arredondadas a }
$$

disformes; incolores; oscilam entre 3 e $10 \mu \mathrm{m}$;
Dados Microtermométricos

Tf (gelo): $-11,2{ }^{\circ} \mathrm{C} \mathrm{a}-2,5^{\circ} \mathrm{C}$,

intervalo principal: $-4,7{ }^{\circ} \mathrm{C}$ a $-2,5$

${ }^{\circ} \mathrm{C}$; Th (t) de $303,7{ }^{\circ} \mathrm{C}$ a $432,6{ }^{\circ} \mathrm{C}$; salinidade de 4,18 a $15,17 \mathrm{wt} \%$ de $\mathrm{NaCl}$ eq. , densidade entre 0,43 a

$$
0,84 \mathrm{~g} / \mathrm{cm}^{3} \text {. }
$$

Tf (gelo) de $-11,9^{\circ} \mathrm{C} \mathrm{a}-1,2{ }^{\circ} \mathrm{C}$, intervalo principal de $-5,5^{\circ} \mathrm{C}$ a $-1,2$

${ }^{\circ} \mathrm{C}$; Th (t) de 280,0 a 425,8 ${ }^{\circ} \mathrm{C}$;

salinidade de 3,54 a 20,14 wt $\%$ de $\mathrm{NaCl}$ eq.; densidade entre 0,32 e

$$
0,90 \mathrm{~g} / \mathrm{cm}^{3} \text {. }
$$

$\mathrm{Tf}$ (gelo) de $-5,9^{\circ} \mathrm{C} \mathrm{a}-1,5^{\circ} \mathrm{C}$; Th (t) de $203,2{ }^{\circ} \mathrm{C}$ a $369,5^{\circ} \mathrm{C}$;

salinidade de 1,22 a 8,27 wt. $\%$ de

$\mathrm{NaCl}$ eq.; densidade entre 0,61 e

$$
0,94 \mathrm{~g} / \mathrm{cm}^{3} \text {. }
$$

Modelo de Sistema

$\mathrm{H}_{2} \mathrm{O}-\mathrm{NaCl}$

$\mathrm{H}_{2} \mathrm{O}-\mathrm{NaCl}$

$\mathrm{H}_{2} \mathrm{O}-\mathrm{NaCl}$

Tf (gelo) $-3,5^{\circ} \mathrm{C}$ a $-0,1^{\circ} \mathrm{C}$, com moda de $-1,1^{\circ} \mathrm{C}$; $\mathrm{Th}_{(\mathrm{t})}$ de $100,3{ }^{\circ} \mathrm{C}$ a $290,9{ }^{\circ} \mathrm{C}$; salinidade entre $0,17 \mathrm{e}$ $5,10 \mathrm{wt} \%$ de $\mathrm{NaCl}$ eq.; densidade entre 0,72 e $0,96 \mathrm{~g} / \mathrm{cm}^{3}$. 
VG de 0,15 a 0,05 .

Tipo V
Qtz1

Qtz2
Escuras; disformes e

raramente arredondadas; oscilam entre 8 e $30 \mu \mathrm{m}$.
$\mathrm{H}_{2} \mathrm{O}-\mathrm{NaCl}$ 


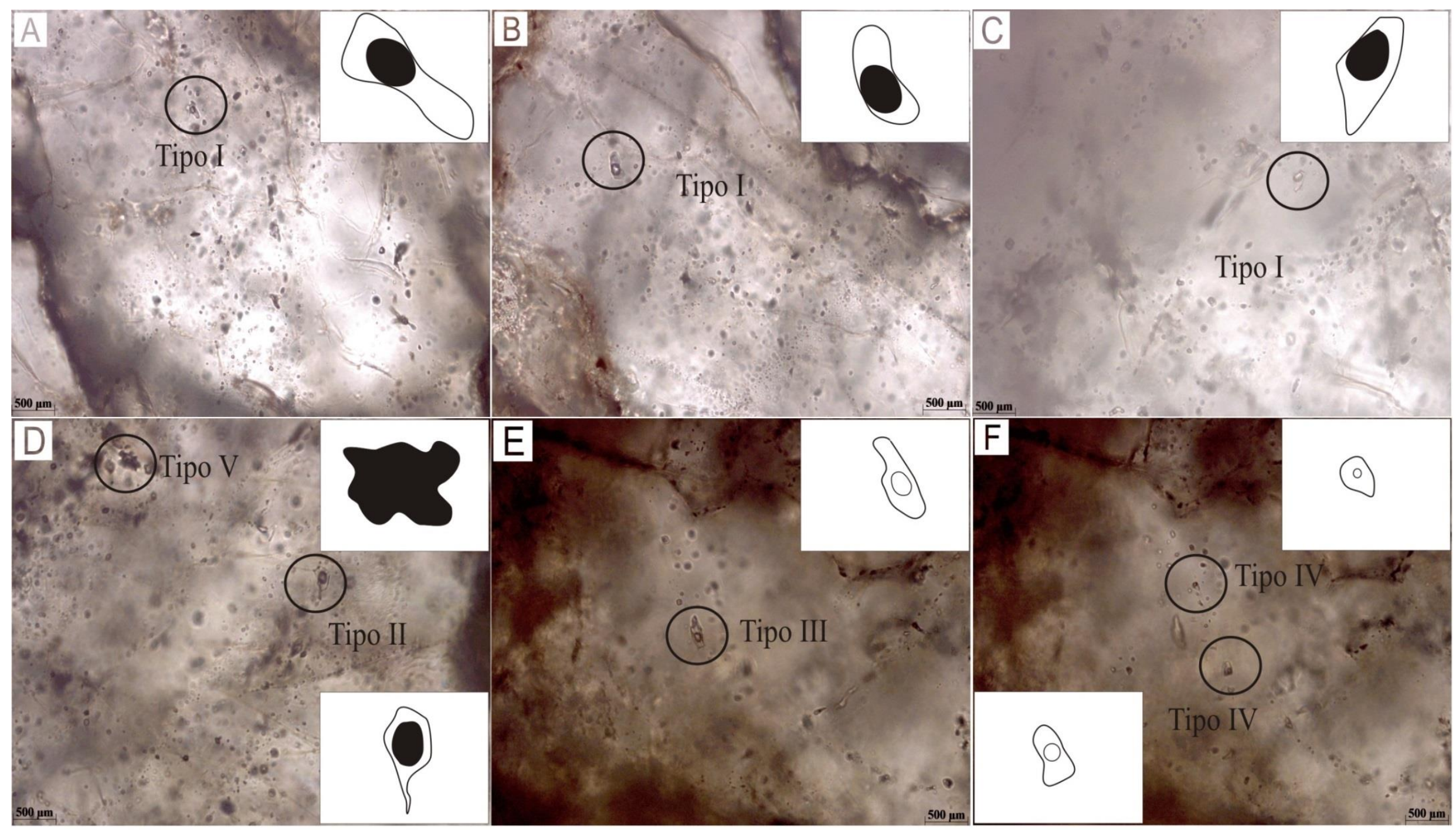

Figura 37: Fotomicrografias mostrando os diferentes tipos de inclusões fluidas: A, B e C= Tipo I; D = Tipos II e V; E = Tipo III; F = Tipo IV. 
Tabela 10: Os principais dados microtermométricos das inclusões fluidas analisadas correspondentes aos tipos I, II, III e IV do Depósito Tocantinzinho.

\begin{tabular}{|c|c|c|c|c|c|c|c|c|c|c|c|}
\hline Qtz & $\begin{array}{l}\text { Tipo de inclusão } \\
\text { fluida }\end{array}$ & $\begin{array}{c}\text { Tf } \\
\left(\mathbf{H}_{2} \mathbf{O}\right) \\
\end{array}$ & Th $(\mathbf{t})$ & Salinidade & Densidade & Qtz & $\begin{array}{l}\text { Tipo de inclusão } \\
\text { fluida }\end{array}$ & $\begin{array}{c}\mathbf{T f} \\
\left(\mathbf{H}_{2} \mathbf{O}\right) \\
\end{array}$ & Th $(t)$ & Salinidade & Densidade \\
\hline 2 & I & $-11,2$ & 331,3 & 15,1741 & 0,847 & 2 & IV & $-0,1$ & 176,3 & 0,1776 & 0,896 \\
\hline 2 & I & $-2,8$ & 303,7 & 4,6497 & 0,485 & 2 & IV & $-0,8$ & 174,4 & 1,3960 & 0,879 \\
\hline 2 & I & $-4,9$ & 405,8 & 7,7263 & 0,578 & 2 & IV & $-0,6$ & 172,4 & 1,0522 & 0,907 \\
\hline 2 & I & $-5,1$ & 323,5 & 8,0022 & 0,765 & 2 & IV & $-0,9$ & 178,8 & 1,5666 & 0,903 \\
\hline 2 & I & $-2,5$ & 309,9 & 4,1825 & 0,733 & 2 & IV & $-0,6$ & 219,6 & 1,0522 & 0,848 \\
\hline 2 & I & $-3,2$ & 309,3 & 5,2616 & 0,750 & 2 & IV & $-0,3$ & 158,0 & 0,5300 & 0,918 \\
\hline 2 & $\mathrm{I}$ & $-3,2$ & 432,6 & 5,2616 & 0,434 & 2 & IV & $-0,4$ & 165,5 & 0,7050 & 0,911 \\
\hline 1 & $\overline{\mathrm{II}}$ & $-8,7$ & 377,8 & 12,5073 & 0,738 & 2 & IV & $-1,0$ & 181,9 & 1,7364 & 0,901 \\
\hline 1 & II & $-16,9$ & 399,4 & 20,1466 & 0,814 & 2 & IV & $-0,2$ & 160,2 & 0,3542 & 0,914 \\
\hline 1 & II & $-10,2$ & 273,2 & 14,1485 & 0,905 & 2 & IV & $-0,9$ & 190,2 & 1,5666 & 0,891 \\
\hline 1 & II & $-3,5$ & 265,7 & 5,7124 & 0,830 & 2 & IV & $-0,2$ & 159,0 & 0,3542 & 0,915 \\
\hline 1 & II & $-2,3$ & 308,4 & 3,8670 & 0,731 & 2 & IV & $-0,3$ & 130,8 & 0,5300 & 0,942 \\
\hline 1 & II & $-2,9$ & 373,6 & 4,8039 & 0,597 & 2 & IV & $-0,5$ & 137,4 & 0,8790 & 0,938 \\
\hline 1 & II & $-8,8$ & 326,5 & 12,6207 & 0,824 & 2 & IV & $-0,2$ & 197,3 & 0,3542 & 0,872 \\
\hline 1 & II & $-7,2$ & 309,2 & 10,7326 & 0,826 & 2 & IV & $-0,3$ & 142,9 & 0,5300 & 0,932 \\
\hline 1 & II & $-9,1$ & 332,9 & 12,9575 & 0,819 & 2 & IV & $-0,3$ & 145,7 & 0,5300 & 0,929 \\
\hline 1 & II & $-3,2$ & 289,0 & 5,2616 & 0,787 & 2 & IV & $-0,9$ & 229,8 & 1,5666 & 0,839 \\
\hline 1 & II & $-4,9$ & 409,7 & 7,7263 & 0,568 & 2 & IV & $-0,9$ & 221,7 & 1,5666 & 0,850 \\
\hline 1 & II & $-4,6$ & 290,0 & 7,3069 & 0,812 & 2 & IV & $-1,2$ & 142,4 & 2,0733 & 0,984 \\
\hline 1 & II & $-5,9$ & 314,7 & 9,0778 & 0,796 & 2 & IV & $-1,8$ & 140,1 & 3,0640 & 0,990 \\
\hline 1 & II & $-3,9$ & 328,5 & 6,3028 & 0,729 & 2 & IV & $-1,2$ & 211,2 & 2,0733 & 0,869 \\
\hline 1 & II & $-5,5$ & 262,8 & 8,5456 & 0,865 & 2 & IV & $-0,9$ & 288,9 & 1,5666 & 0,736 \\
\hline 1 & II & $-3,9$ & 326,4 & 6,3028 & 0,732 & 2 & IV & $-2,3$ & 290,9 & 3,8670 & 0,765 \\
\hline 1 & II & $-9,0$ & 395,0 & 12,8459 & 0,771 & 2 & IV & $-3,1$ & 249,3 & 5,1098 & 0,847 \\
\hline 1 & II & $-7,9$ & 261,5 & 11,5781 & 0,896 & 2 & IV & $-1,7$ & 289,5 & 2,9010 & 0,754 \\
\hline 2 & II & $-2,5$ & 375,3 & 4,1825 & 0,579 & 2 & IV & $-2,1$ & 298,6 & 3,5482 & 0,745 \\
\hline
\end{tabular}




\begin{tabular}{|c|c|c|c|c|c|c|c|c|c|c|c|}
\hline 2 & II & $-2,3$ & 375,7 & 3,8670 & 0,571 & 2 & IV & $-0,7$ & 228,5 & 1,2245 & 0,837 \\
\hline 2 & II & $-7,4$ & 336,1 & 10,9773 & 0,794 & 2 & IV & $-0,6$ & 246,1 & 1,0522 & 0,808 \\
\hline 2 & II & $-2,1$ & 374,1 & 3,5482 & 0,568 & 2 & IV & $-0,5$ & 289,4 & 0,8790 & 0,724 \\
\hline 2 & II & $-2,1$ & 392,8 & 3,5482 & 0,514 & 2 & IV & $-0,4$ & 265,0 & 0,7050 & 0,770 \\
\hline 2 & II & $-11,8$ & 422,1 & 15,7648 & 0,713 & 2 & IV & $-0,8$ & 245,2 & 1,3960 & 0,813 \\
\hline 2 & II & $-9,5$ & 425,8 & 13,3985 & 0,658 & 2 & IV & $-1,1$ & 264,5 & 1,9053 & 0,786 \\
\hline 2 & II & $-2,5$ & 354,4 & 4,1825 & 0,325 & 2 & IV & $-0,9$ & 260,9 & 1,5666 & 0,789 \\
\hline 2 & II & $-6,6$ & 379,5 & 9,9828 & 0,689 & 2 & IV & $-0,9$ & 200,4 & 1,5666 & 0,878 \\
\hline 2 & II & $-7,8$ & 351,2 & 11,4592 & 0,768 & 2 & IV & $-1,3$ & 198,5 & 2,2405 & 0,886 \\
\hline 2 & II & $-4,2$ & 397,1 & 6,7376 & 0,577 & 2 & IV & $-1,9$ & 228,4 & 3,2263 & 0,857 \\
\hline 2 & II & $-3,4$ & 417,8 & 5,5629 & 0,490 & 2 & IV & $-1,6$ & 200,2 & 2,7371 & 0,889 \\
\hline 2 & II & $-4,9$ & 300,3 & 7,7263 & 0,801 & 2 & IV & $-0,8$ & 174,3 & 1,3960 & 0,909 \\
\hline 2 & II & $-3,1$ & 293,8 & 5,1098 & 0,777 & 2 & IV & $-0,3$ & 201,6 & 0,5300 & 0,868 \\
\hline 2 & II & $-3,8$ & 378,3 & 6,1563 & 0,614 & 2 & IV & $-1,0$ & 226,0 & 1,7364 & 0,846 \\
\hline 2 & II & $-4,6$ & 365,9 & 7,3069 & 0,667 & 2 & IV & $-1,1$ & 245,3 & 1,9053 & 0,811 \\
\hline 2 & II & $-3,5$ & 338,5 & 5,7124 & 0,698 & 2 & IV & $-1,3$ & 230,3 & 2,2405 & 0,845 \\
\hline 2 & II & $-9,4$ & 365,2 & 13,2891 & 0,773 & 2 & IV & $-1,3$ & 252,4 & 2,2405 & 0,811 \\
\hline 2 & II & $-9,1$ & 309,3 & 12,9575 & 0,851 & 2 & IV & $-2,9$ & 234,5 & 4,8039 & 0,879 \\
\hline 2 & II & $-11,9$ & 405,8 & 15,8615 & 0,744 & 2 & IV & $-2,7$ & 208,4 & 4,4948 & 0,906 \\
\hline 1 & III & $-5,3$ & 322,3 & 8,2754 & 0,771 & 2 & IV & $-2,4$ & 260,2 & 4,0251 & 0,819 \\
\hline 1 & III & $-3,5$ & 308,9 & 5,7124 & 0,758 & 2 & IV & $-2,5$ & 201,0 & 4,1825 & 0,899 \\
\hline 1 & III & $-3,0$ & 298,6 & 4,9572 & 0,766 & 2 & IV & $-2,2$ & 143,2 & 3,7080 & 0,950 \\
\hline 1 & III & $-1,8$ & 202,8 & 3,0640 & 0,888 & 2 & IV & $-1,9$ & 150,3 & 3,2263 & 0,941 \\
\hline 1 & III & $-1,6$ & 325,0 & 2,7371 & 0,676 & 2 & IV & $-2,7$ & 234,4 & 4,4948 & 0,901 \\
\hline 1 & III & $-1,2$ & 256,7 & 2,0733 & 0,802 & 2 & IV & $-1,5$ & 277,2 & 2,5724 & 0,772 \\
\hline 1 & III & $-4,2$ & 310,9 & 6,7376 & 0,769 & 2 & IV & $-1,8$ & 212,8 & 3,0640 & 0,876 \\
\hline 1 & III & $-3,6$ & 239,2 & 5,8612 & 0,869 & 2 & IV & $-1,4$ & 268,5 & 2,4069 & 0,786 \\
\hline 1 & III & $-3,5$ & 311,5 & 5,7124 & 0,753 & 2 & IV & $-0,8$ & 277,4 & 1,3960 & 0,756 \\
\hline 1 & III & $-3,6$ & 297,4 & 5,8612 & 0,781 & 2 & IV & $-1,1$ & 237,8 & 1,9053 & 0,830 \\
\hline
\end{tabular}




\begin{tabular}{|c|c|c|c|c|c|c|c|c|c|c|}
\hline III & $-3,2$ & 300,2 & 5,2616 & 0,767 & 2 & IV & $-2,1$ & 198,5 & 3,5482 & 0,931 \\
\hline III & $-1,2$ & 258,5 & 2,0733 & 0,799 & 2 & IV & $-0,9$ & 186,4 & 1,5666 & 0,895 \\
\hline Uు & $-0,8$ & 264,2 & 1,3960 & 0,781 & 2 & IV & $-1,4$ & 197,7 & 2,4069 & 0,889 \\
\hline III & $-0,7$ & 202,9 & 1,2245 & 0,872 & 2 & IV & $-1,0$ & 180,6 & 1,7364 & 0,903 \\
\hline III & $-5,6$ & 303,5 & 8,6797 & 0,808 & 2 & IV & $-0,7$ & 185,3 & 1,2245 & 0,886 \\
\hline III & $-3,6$ & 323,8 & 5,8612 & 0,731 & 2 & IV & $-0,3$ & 98,6 & 0,5300 & 0,964 \\
\hline III & $-1,6$ & 301,1 & 2,7371 & 0,728 & 2 & IV & $-0,1$ & 197,2 & 0,1776 & 0,871 \\
\hline & $-2,3$ & 289,6 & 3,8670 & 0,767 & 2 & IV & $-0,5$ & 190,8 & 0,8790 & 0,885 \\
\hline III & $-1,8$ & 338,5 & 3,0640 & 0,650 & 2 & IV & $-0,2$ & 202,4 & 0,3542 & 0,866 \\
\hline III & $-2,1$ & 340,1 & 3,5482 & 0,655 & 2 & IV & $-0,7$ & 139,2 & 1,2245 & 0,939 \\
\hline III & $-1,9$ & 280,5 & 3,2263 & 0,775 & 2 & IV & $-0,9$ & 140,5 & 1,5666 & 0,940 \\
\hline & $-1,7$ & 219,0 & 2,9010 & 0,867 & 2 & IV & $-0,2$ & 192,4 & 0,3542 & 0,878 \\
\hline & $-2,1$ & 265,0 & 3,5482 & 0,806 & 2 & IV & $-0,5$ & 185,8 & 0,8790 & 0,890 \\
\hline III & $-3,8$ & 351,5 & 6,1563 & 0,678 & 2 & IV & $-1,8$ & 151,7 & 3,0640 & 0,958 \\
\hline III & $-1,5$ & 205,0 & 2,5724 & 0,881 & 2 & IV & $-3,5$ & 135,3 & 5,7124 & 0,967 \\
\hline III & $-4,1$ & 301,3 & 6,5934 & 0,784 & 2 & IV & $-3,2$ & 190,8 & 5,2616 & 0,918 \\
\hline III & $-2,1$ & 247,1 & 3,5482 & 0,834 & 2 & IV & $-1,8$ & 212,8 & 3,0640 & 0,876 \\
\hline U & $-1,2$ & 280,0 & 2,0733 & 0,760 & 2 & IV & $-0,6$ & 152,3 & 1,0522 & 0,926 \\
\hline Ш & $-2,3$ & 350,0 & 3,8670 & 0,638 & 2 & IV & $-0,8$ & 162,5 & 1,3960 & 0,919 \\
\hline III & $-1,5$ & 260,9 & 2,5724 & 0,801 & 2 & IV & $-0,1$ & 167,4 & 0,1776 & 0,913 \\
\hline III & $-2,2$ & 356,8 & 3,7080 & 0,617 & 2 & IV & $-0,4$ & 173,5 & 0,7050 & 0,903 \\
\hline III & $-2,3$ & 236,4 & 3,8670 & 0,853 & 2 & IV & $-0,1$ & 182,2 & 0,1776 & 0,897 \\
\hline III & $-2,1$ & 310,2 & 3,5482 & 0,722 & 2 & IV & $-0,5$ & 161,2 & 0,8790 & 0,917 \\
\hline UL & $-1,9$ & 300,2 & 3,2263 & 0,737 & 2 & IV & $-2,2$ & 220,2 & 3,7080 & 0,899 \\
\hline IIl & $-3,9$ & 192,1 & 6,3028 & 0,944 & 2 & IV & $-0,7$ & 136,2 & 1,2245 & 0,941 \\
\hline III & $-1,4$ & 302,4 & 2,4069 & 0,720 & 2 & IV & $-0,3$ & 130,8 & 0,5300 & 0,942 \\
\hline III & $-2,3$ & 345,0 & 3,8670 & 0,650 & 2 & IV & $-0,4$ & 152,9 & 0,7050 & 0,924 \\
\hline III & $-5,9$ & 303,2 & 9,0778 & 0,814 & 2 & IV & $-0,5$ & 159,5 & 0,8790 & 0,917 \\
\hline II & $-3,9$ & 307,9 & 6,3028 & 0,680 & 2 & IV & $-0,3$ & 136,8 & 0,5300 & 0,937 \\
\hline
\end{tabular}




\begin{tabular}{|c|c|c|c|c|c|c|c|c|c|c|c|}
\hline 2 & III & $-5,1$ & 369,5 & 8,0022 & 0,673 & 2 & IV & $-0,5$ & 132,5 & 0,8790 & 0,942 \\
\hline 2 & IV & $-0,6$ & 210,5 & 1,0522 & 0,861 & 2 & IV & $-0,1$ & 100,3 & 0,1776 & 0,962 \\
\hline 2 & IV & $-0,8$ & 203,5 & 1,3960 & 0,873 & 2 & IV & $-1,1$ & 142,7 & 1,9053 & 0,958 \\
\hline 2 & IV & $-1,0$ & 217,9 & 1,7364 & 0,857 & 2 & IV & $-0,2$ & 105,2 & 0,3542 & 0,959 \\
\hline 2 & IV & $-0,3$ & 289,0 & 0,5300 & 0,720 & 2 & IV & $-2,1$ & 135,2 & 3,5482 & 0,955 \\
\hline 2 & IV & $-0,8$ & 178,3 & 1,3960 & 0,903 & 2 & IV & $-1,2$ & 190,3 & 2,0733 & 0,895 \\
\hline 2 & IV & $-0,9$ & 182,5 & 1,5666 & 0,899 & 2 & IV & $-1,3$ & 173,4 & 2,2405 & 0,914 \\
\hline 2 & IV & $-0,5$ & 208,9 & 0,8790 & 0,862 & 2 & IV & $-0,2$ & 182,7 & 0,3542 & 0,890 \\
\hline
\end{tabular}




\subsubsection{Interpretação dos dados de inclusões fluidas}

Esse sistema é constituído, basicamente, por inclusões bifásicas. Inclusões fluidas com sólido foram identificadas, porém não puderam ser analisadas microtermometricamente, pois o sólido não fundiu o que pode sugerir, juntamente com as características petrográficas, que são sólidos aprisionados.

O congelamento das inclusões fluidas se deu em dois intervalos principais: entre -30 ${ }^{\circ} \mathrm{C}$ e $-48{ }^{\circ} \mathrm{C}$ (inclusões bifásicas do tipo III e IV em geral) e entre $-60{ }^{\circ} \mathrm{C}$ e $-95{ }^{\circ} \mathrm{C}$ (inclusões bifásicas dos tipos I e II, principalmente).

$\mathrm{Na}$ fase de reaquecimento, a temperatura da primeira fusão é a temperatura do eutético. Segundo Goldstein \& Reynolds (1994), a Te é normalmente difícil de ser distinguida e o nível de dificuldade aumenta muito para inclusões menores que $10 \mu \mathrm{m}$ e para inclusões pouco salinas (<5\% em peso de $\mathrm{NaCl}$ eq.). Porém, estudos de inclusões fluidas no Depósito Tocantinzinho realizados por Queiroz (2013) mostraram que a Te estimada dos fluidos enquadrou-se em dois sistemas distintos: A) $\mathrm{H}_{2} \mathrm{O}-\mathrm{NaCl}-\mathrm{FeCl}_{2} \pm \mathrm{MgCl}_{2}$, com Te entre -35 ${ }^{\circ} \mathrm{Ce}-35,5^{\circ} \mathrm{C}$; e B) $\mathrm{H}_{2} \mathrm{O}-\mathrm{NaCl}-\mathrm{CaCl}_{2}$, pois obteve Te de $-55^{\circ} \mathrm{C}$ a $-42{ }^{\circ} \mathrm{C}$.

$\mathrm{Na}$ figura 38 constam os histogramas de variação correspondentes aos dados de temperatura de fusão do gelo dos grupos I a IV. Os histogramas 38-A e 38-B, referentes às inclusões Tipos I e II, correspondem a inclusões primárias, com os menores valores de fusão (alcançando valores próximos a $-17^{\circ} \mathrm{C}$, no tipo II). O histograma 38-C também apresenta inclusões do tipo primárias, aquela que compõem o Tipo III. O último histograma, 38-D, representando o tipo IV, faz referência às inclusões secundárias, com os valores mais altos, alguns próximos a zero, e em maior representatividade nas amostras estudadas.

No histograma de frequência mostrado na figura 39 (de A a C) estão os dados de temperatura de homogeneização total $(\mathrm{Th}(\mathrm{t})$ ) das inclusões primárias (Tipos I, II e III) e secundárias (Tipo IV). Em 49-A estão os dados correspondentes às inclusões do tipo I com altos valores de Th(t) e intervalo de ocorrência entre $300-350{ }^{\circ} \mathrm{C}$ e $400-450{ }^{\circ} \mathrm{C}$; em 49 -B estão os dados de do tipo II: juntamente com o tipo I, apresentam os mais altos valores de $\mathrm{Th}(\mathrm{t})$ do sistema com intervalo variando entre $250-450{ }^{\circ} \mathrm{C}$; em $39-\mathrm{C}$ as inclusões do tipo III mostram valores de $\mathrm{Th}(\mathrm{t})$ levemente inferiores, com moda entre 250-350 ${ }^{\circ} \mathrm{C}$; em $49-\mathrm{D}$, inclusões do tipo IV, as inclusões com menores valores de Th(t) e maior frequência do depósito, o intervalo apresenta moda entre $150-250{ }^{\circ} \mathrm{C}$. 
A figura 40 mostra gráficos de plotagem relacionando a Th (t) vs. salinidade. Os gráficos 40-A/B/C são inclusões primárias. Apesar de as temperaturas de homogeneização serem relativamente semelhantes entre os três tipos, os tipos I e II têm maior salinidade e se concentram na porção superior do gráfico, em especial entre 5 e $20 \%$ de wt.\% de $\mathrm{NaCl}$ eq., enquanto que o Tipo III se concentra na parte inferior, no intervalo de 2 a $8 \%$ wt. $\%$ de $\mathrm{NaCl}$ eq. No gráfico 40-D, referente às inclusões secundárias do tipo IV, têm-se os valores mais baixos de salinidade e menores valores de temperatura de homogeneização.

A figura 41 apresenta a relação entre temperatura de homogeneização vs. densidade, essa última obtida a partir da equação de Bodnar (2003). Na figura constam os gráficos de 41A a 41-D: 42-A, contendo as inclusões do Tipo I; 42-B com as inclusões do Tipo II; 41-C contendo inclusões do tipo III e 41-D as inclusões do tipo IV. Com exceção do gráfico 41-A, os demais mostram relação inversamente proporcional entre os valores de densidade e temperatura de homogeneização, em que quanto maior a temperatura de homogeneização da inclusão, menor é seu valor de densidade, tendendo a formação de uma reta.

Para os cinco tipos de inclusões, as interpretações petrográficas e microtermométricas mostram um quadro complexo em relação aos fluidos que circularam pelo Depósito Tocantinzinho. Os dados indicam a existência de fluidos aquosos, de baixa a moderada salinidade e grande oscilação nas temperaturas de homogeneização e fusão. A coexistência em um único sistema mineral de inclusões que homogeneízam para fases diferentes é um forte indicativo de que tenha ocorrido o processo de imiscibilidade no sistema (Shepherd et al. 1985). A coexistência de inclusões ricas em vapor e ricas em líquido sugere ter havido boiling. Essa interpretação baseia-se na presença das inclusões do Tipo I, grupo de que homogeneíza para o vapor, além da grande quantidade de inclusões fluidas monofásicas ricas em vapor. O tipo I é encontrado apenas nos grãos Qtz2, ou seja, o tipo de quartzo que ocorre em paragênese com a alteração fílica, interpretada como associada à mineralização de ouro do depósito.

Vale ressaltar que a modificação e o reequilíbrio das inclusões após seu aprisionamento, ao longo da história do sistema hidrotermal, e mesmo o vazamento parcial durante os testes microtermométricos, também podem gerar características semelhantes àquelas relacionadas à imiscibilidade (Bodnar 2003). Vazamento parcial e estrangulamento foram largamente registrados e, de modo geral, é possível que em maior ou menor proporção as inclusões estudadas tenham sido afetadas por esses processos. Entretanto, as inclusões fluidas aqui submetidas a análises microtermométricas não apresentaram evidências claras de 
modificações pós-aprisionamento e suas características são, portanto, interpretadas como produto de boiling. 


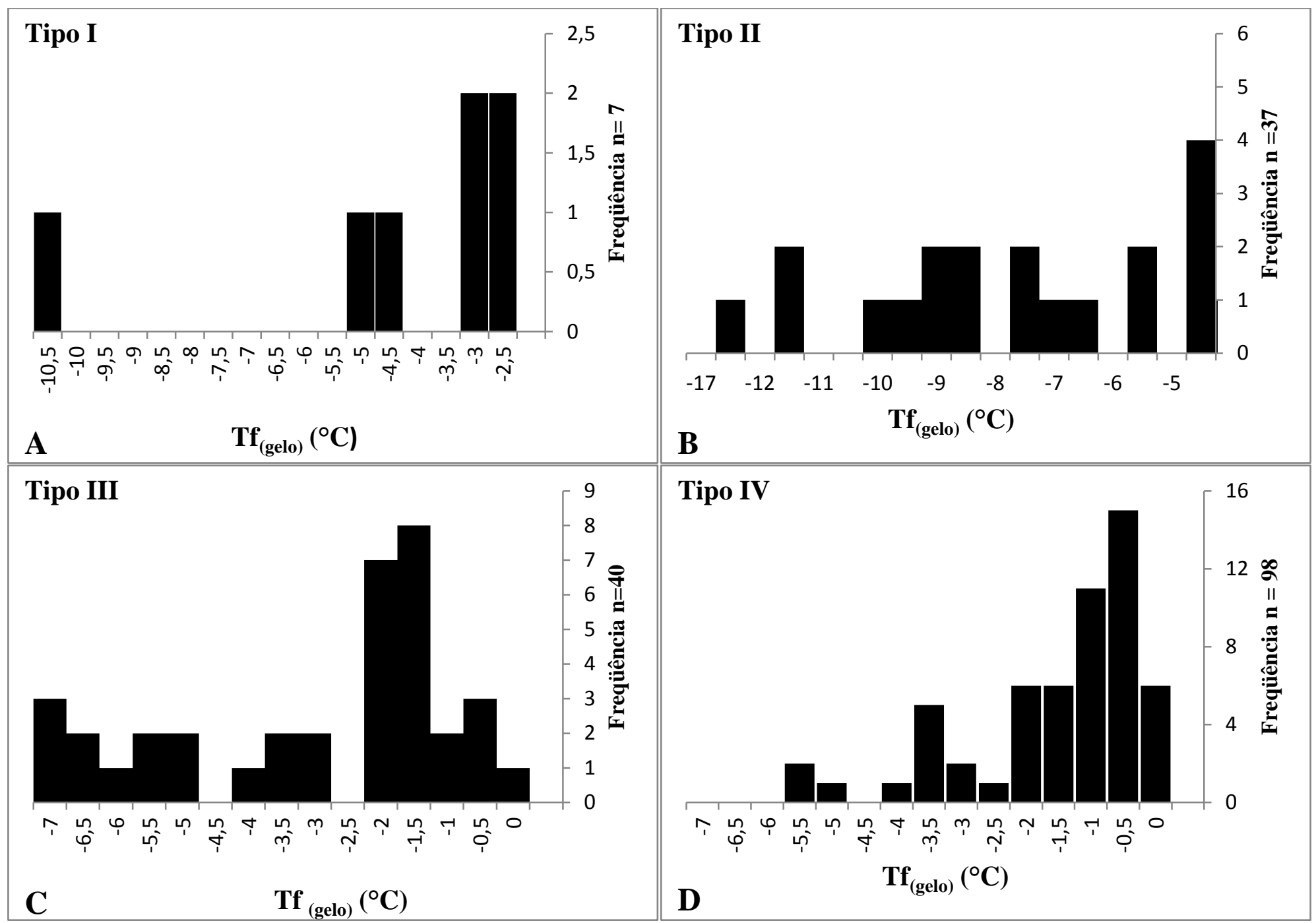

Figura 38: Histogramas de variação de temperaturas de fusão do gelo (Tf(gelo)) vs. frequência dos quatro principais tipos de inclusões fluidas do Depósito Tocantinzinho. 

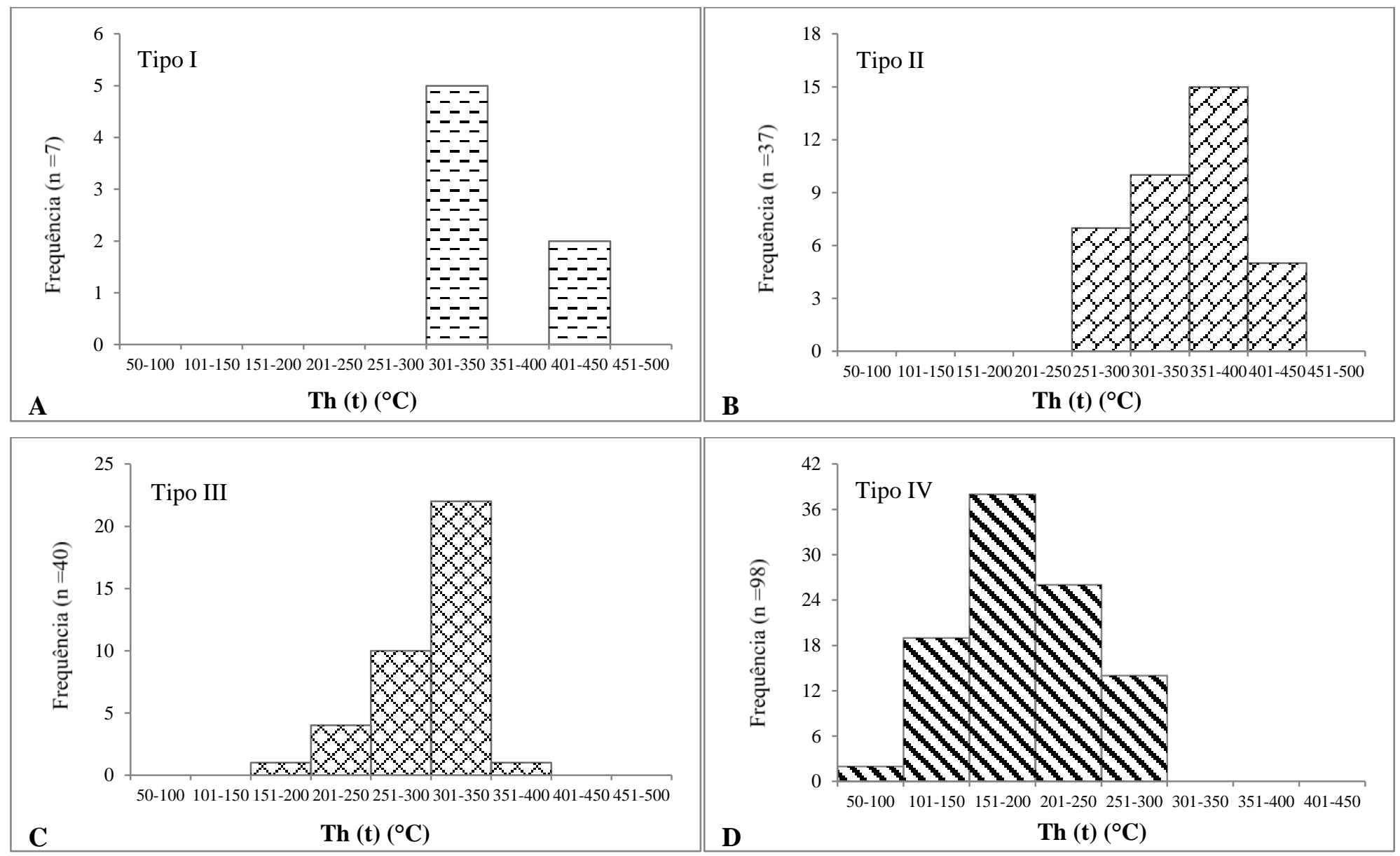

Figura 39: Histogramas de Temperatura de homogeneização total (Th (t)) vs. frequência, em inclusões fluidas primárias (gráficos A, B e C) e secundárias (gráfico D). 

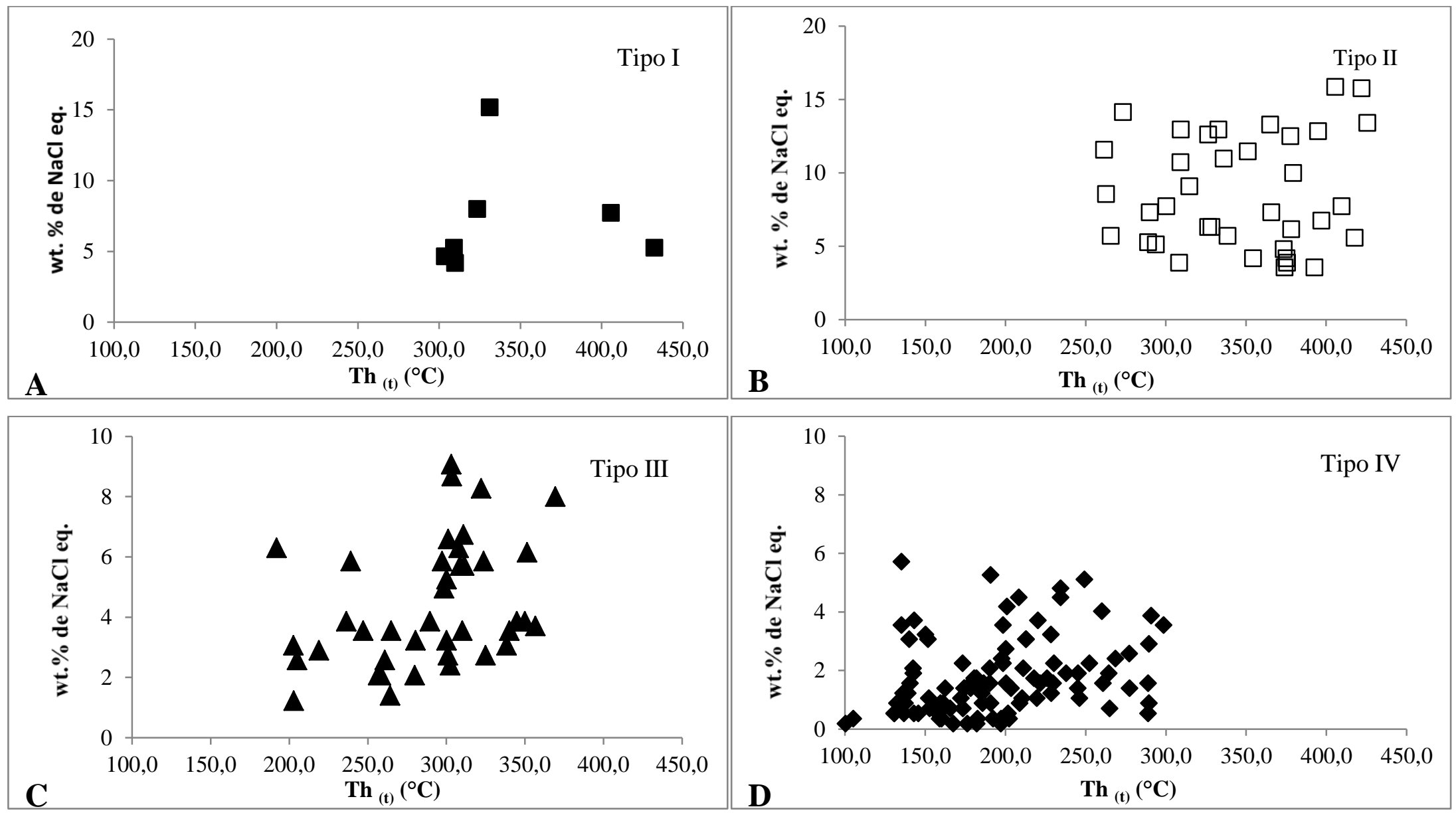

Figura 40: Gráficos de plotagem representando a temperatura de homogeneização $\left(\mathrm{Th}_{(\mathrm{t})}\right)$ vs. salinidade de inclusões fluidas primárias $(\mathrm{A}, \mathrm{B}$ e C) e secundárias (D). 


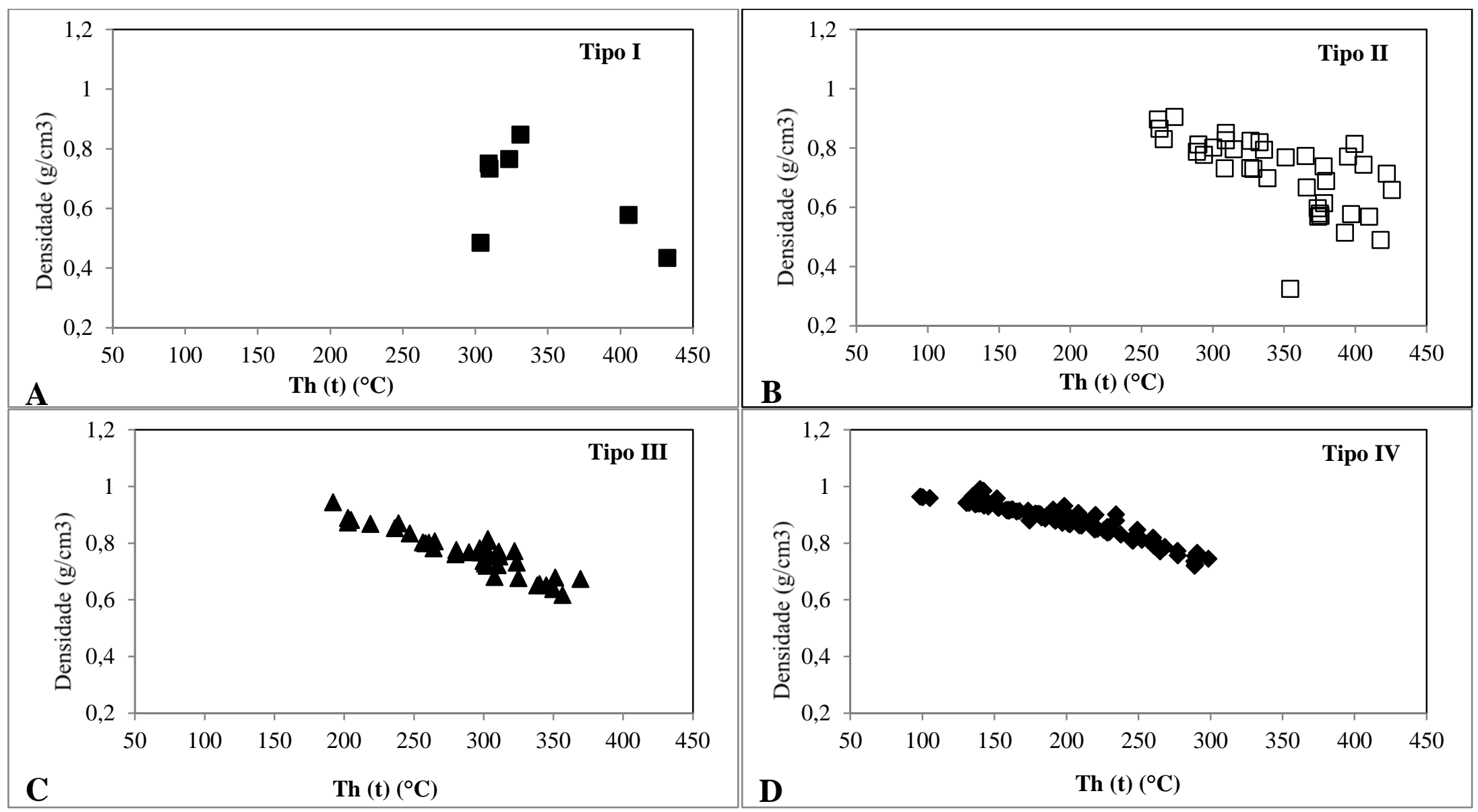

Figura 41: Gráfico mostrando a relação entre temperatura de homogeneização total vs. cálculo da densidade de inclusões fluidas dos tipos primárias (gráficos A, B e C), secundárias (D). 


\section{GEOTERMOMETRIA DA CLORITA}

Para definir a temperatura e pressão de formação do Depósito Tocantinzinho foi necessário complementar os dados microtermométricos com um geotermômetro independente. Segundo a literatura, o aumento da profundidade de soterramento, o aumento do grau de metamorfismo que atuou sobre a rocha ou do grau de alteração hidrotermal tem influência direta na diminuição de $\mathrm{Si}^{\mathrm{IV}}, \mathrm{Al}^{\mathrm{VI}},[]^{\mathrm{VI}}$ e aumento de $\mathrm{Al}^{\mathrm{IV}},(\mathrm{Fe}+\mathrm{Mg})$ e $\sum \mathrm{Al}^{\mathrm{VI}}$ da estrutura da clorita (Cathelineau 1988, Caritat et al. 1993).

Foi usado o geotermômetro clorita estabelecido por Cathelineau (1988) e Cathelineau \& Nieva (1985), os quais se baseiam na proporção catiônica do alumínio tetraédrico da clorita $\left(\mathrm{Al}^{\mathrm{IV}}\right)$, permitindo, dessa forma, calcular sua temperatura a partir da seguinte equação: $T\left({ }^{\circ} \mathrm{C}\right)=321,98 *\left(A l^{I V} / 2\right)-61,92$.

Essa equação pode ser utilizada para o cálculo do geotermômetro da clorita de amostras pertencentes a ambientes diagenéticos, hidrotermais e metamórficos. No entanto, apesar da aplicabilidade dessa fórmula proposta por Cathelineau (1988) e da eficácia comprovada, existe consenso de que os dados obtidos são semi-quantitativos, tendo que ser combinados com outros métodos de análise.

Para o estudo do geotermômetro no Depósito Tocantinzinho foram realizadas 42 análises em microssonda eletrônica nas três gerações de clorita hidrotermais identificadas durante o estudo petrográfico: clorital (Chl1), resultante de alteração de biotita do granito; clorita2 (Chl2), associada ao minério sulfetado nos veios mineralizados; e clorita3 (Chl3), em vênulas monominerálicas, em geral, tardias.

Os dados analíticos da clorita do Depósito mostraram que suas composições situamse na transição clinocloro-chamosita, com $\mathrm{Al}^{\mathrm{IV}}$ entre 2,03 e 2,76. A tabela 11 mostra as temperaturas que cristalização dos diferentes tipos de clorita, além dos valores de $\mathrm{Fe}, \mathrm{Mg}$ e $\mathrm{Al}^{\mathrm{IV}}$.

Com base na interpretação dos dados analíticos e geotermométricos das cloritas, é possível inferir que o processo hidrotermal teve início com processos de magmatismo ocorridos na PMT, os quais possibilitaram a maior circulação de fluidos hidrotermais com a abertura de fraturas e de processos de brechação incipientes, formando Chl1 (clinocloro), em temperaturas moderadas (média de $295{ }^{\circ} \mathrm{C}$ ), com fração molar do $\mathrm{Fe}^{+2}$ igual a 3,38. A ocorrência mais comum desse tipo de clorita se dá no granito do Depósito Tocantinzinho, nas fases iniciais/ incipientes do processo de alteração hidrotermal. 
Com a progressão e o ápice dos processos hidrotermais começou a se formar a Chl2 (predominantemente chamosita), a qual está associada a veios/ vênulas poliminerálicas e deve representar o intervalo de temperatura do minério, associada à fase de microclinização, com fração molar de $\mathrm{Fe}^{+2}$ entre 4,68 e temperatura máxima de $382{ }^{\circ} \mathrm{C}$ (Figura 42).

Nos estágios finais do processo hidrotermal (estágio de alteração tardia), formou-se o Chl3 (clinocloro), ocorrendo preferencialmente em vênulas/acúmulos monominerálicos, em temperaturas entre $266^{\circ} \mathrm{C}$ e $337^{\circ} \mathrm{C}$ e fração molar de $\mathrm{Fe}^{+2}$ de 3,95 .

Segundo Veloso et al. (2013), a evolução termal e composicional de cristais de clorita durante o processo hidrotermal em um depósito evidencia um aporte contínuo de ferro reduzido no sistema. Nesses sistemas, em geral, o aumento de $\mathrm{Fe}^{+2}$ se dá por conta da decomposição dos minerais ferromagnesianos da rocha hospedeira, favorecendo a formação de clorita chamosita e pirita juntamente com o minério.

Comparando-se os dados do geotermômetro da clorita dos dois grupos presentes no depósito (chamosita e clinocloro), foram obtidas temperaturas com intervalo médio de $382{ }^{\circ} \mathrm{C}$ a $302{ }^{\circ} \mathrm{C}$ para a clorita chamosítica, e $300{ }^{\circ} \mathrm{C}$ a $266{ }^{\circ} \mathrm{C}$ para clorita clinocloro. Santiago et al. (2013) obtiveram temperaturas semelhantes para o estudo do geotermômetro da clorita em amostras do Depósito Tocantinzinho (entre $313{ }^{\circ} \mathrm{C}$ e $327{ }^{\circ} \mathrm{C}$ para a chamosita e $275^{\circ} \mathrm{C}$ para o clinocloro). 

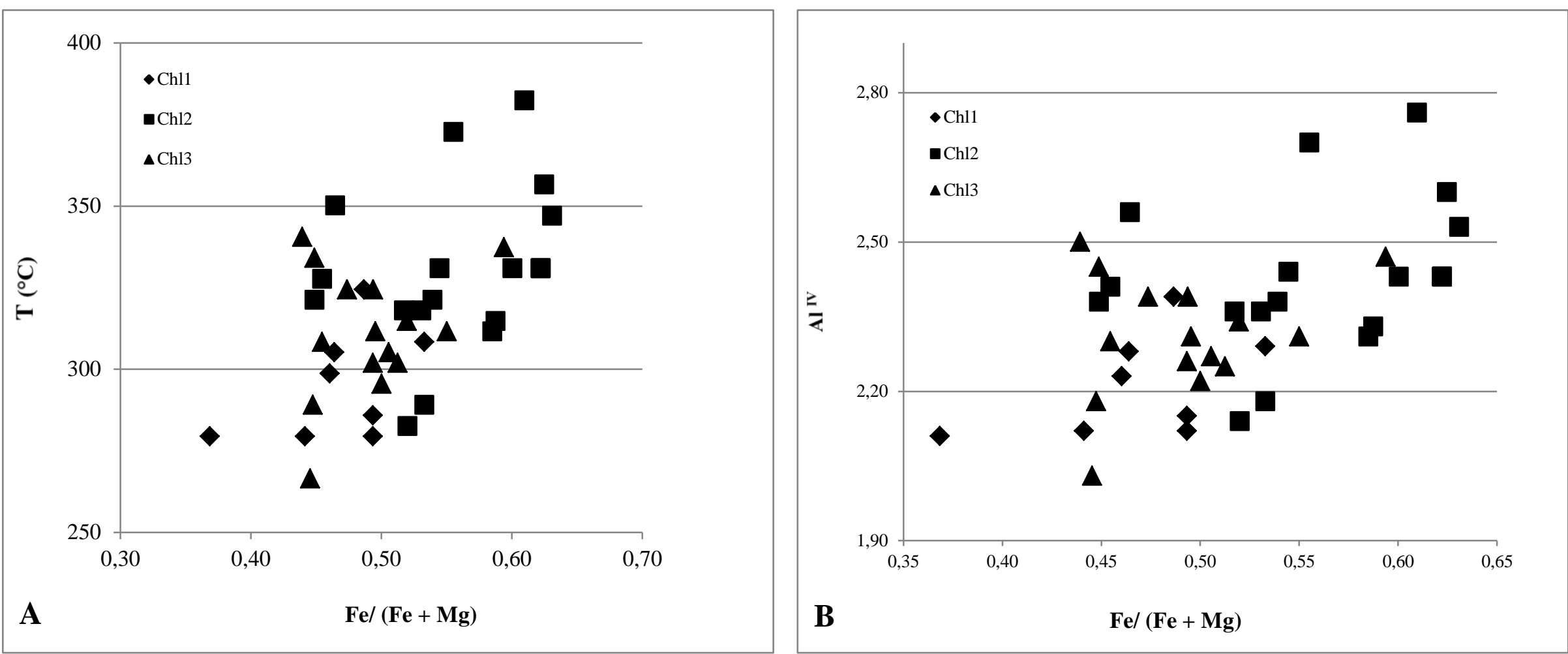

Figura 42: Diagramas de variação: A) temperatura $\left(\mathrm{T}^{\circ} \mathrm{C}\right)$ vs. composição ferromagnesiana $\left(\mathrm{Fe}^{+2} /\left(\mathrm{Fe}^{+2} / \mathrm{Mg}\right)\right)$ dos tipos Chl 1, Chl2 e Chl3; B) Alumínio tetraédrico (Al $\left.{ }^{\mathrm{IV}}\right)$. vs. composição ferromagnesiana $\left(\mathrm{Fe}^{+2} /\left(\mathrm{Fe}^{+2} / \mathrm{Mg}\right)\right)$. 
Tabela 11: Temperaturas de cristalização da clorita hidrotermal do Depósito Tocantinzinho calculadas com base na equação de Cathelineau (1988), a partir de análises químicas da clorita em microssonda eletrônica.

\begin{tabular}{|c|c|c|c|c|c|c|c|c|}
\hline Amostra & $A l^{I V}$ & $A l^{I V / 14} O$ & $A l^{I V}(c)$ & $\mathrm{Fe}^{2+}$ & $M g$ & $\begin{array}{c}F e / \\
\left(F e^{2+}+M g\right)\end{array}$ & $\begin{array}{c}T\left({ }^{\circ} \mathrm{C}\right) \text { Cathelineau } \\
(1988)\end{array}$ & $\left(T^{\circ} \mathrm{C}\right)$ Caritat (1994) \\
\hline Chl1 & 2,39 & 1,20 & 2,73 & 3,60 & 3,80 & 0,49 & 324 & 307 \\
\hline Chl1 & 2,12 & 1,06 & 2,47 & 3,70 & 3,80 & 0,49 & 279 & 279 \\
\hline Chl1 & 2,15 & 1,08 & 2,50 & 3,70 & 3,80 & 0,49 & 286 & 283 \\
\hline Chl1 & 2,11 & 1,06 & 2,37 & 2,80 & 4,80 & 0,37 & 279 & 269 \\
\hline Chl1 & 2,12 & 1,06 & 2,43 & 3,23 & 4,09 & 0,44 & 279 & 275 \\
\hline Chl1 & 2,28 & 1,14 & 2,60 & 3,40 & 3,93 & 0,46 & 305 & 294 \\
\hline Chl1 & 2,29 & 1,15 & 2,66 & 3,25 & 2,85 & 0,53 & 308 & 300 \\
\hline Chl1 & 2,23 & 1,12 & 2,55 & 3,42 & 4,01 & 0,46 & 299 & 289 \\
\hline Chl2 & 2,36 & 1,18 & 2,73 & 5,20 & 4,60 & 0,53 & 318 & 308 \\
\hline Chl2 & 2,18 & 1,09 & 2,55 & 6,50 & 5,70 & 0,53 & 289 & 289 \\
\hline $\mathrm{Chl} 2$ & 2,38 & 1,19 & 2,69 & 3,50 & 4,30 & 0,45 & 321 & 304 \\
\hline Chl2 & 2,31 & 1,16 & 2,72 & 6,20 & 4,40 & 0,58 & 312 & 306 \\
\hline Chl2 & 2,36 & 1,18 & 2,72 & 4,50 & 4,20 & 0,52 & 318 & 307 \\
\hline Chl2 & 2,41 & 1,21 & 2,73 & 3,50 & 4,20 & 0,45 & 328 & 307 \\
\hline Chl2 & 2,70 & 1,35 & 3,09 & 5,49 & 4,40 & 0,56 & 373 & 345 \\
\hline Chl2 & 2,44 & 1,22 & 2,82 & 4,90 & 4,10 & 0,54 & 331 & 317 \\
\hline Chl2 & 2,38 & 1,19 & 2,76 & 4,91 & 4,20 & 0,54 & 321 & 310 \\
\hline Chl2 & 2,14 & 1,07 & 2,50 & 6,93 & 6,40 & 0,52 & 283 & 283 \\
\hline Chl2 & 2,56 & 1,28 & 2,89 & 3,52 & 4,06 & 0,46 & 350 & 324 \\
\hline Chl2 & 2,60 & 1,30 & 3,04 & 3,96 & 2,38 & 0,62 & 357 & 340 \\
\hline Chl2 & 2,53 & 1,27 & 2,97 & 4,51 & 2,64 & 0,63 & 347 & 333 \\
\hline Chl2 & 2,43 & 1,22 & 2,87 & 4,23 & 2,57 & 0,62 & 331 & 322 \\
\hline Chl2 & 2,33 & 1,17 & 2,74 & 3,90 & 2,74 & 0,59 & 315 & 309 \\
\hline Chl2 & 2,43 & 1,22 & 2,85 & 4,07 & 2,71 & 0,60 & 331 & 320 \\
\hline Chl2 & 2,43 & 1,22 & 2,87 & 4,23 & 2,57 & 0,62 & 331 & 322 \\
\hline Chl2 & 2,43 & 1,22 & 2,87 & 4,23 & 2,57 & 0,62 & 331 & 322 \\
\hline
\end{tabular}




\begin{tabular}{|c|c|c|c|c|c|c|c|c|}
\hline Chl2 & 2,76 & 1,38 & 3,19 & 4,62 & 2,96 & 0,61 & 382 & 356 \\
\hline Chl3 & 2,31 & 1,16 & 2,66 & 3,66 & 3,73 & 0,50 & 312 & 300 \\
\hline Chl3 & 2,31 & 1,16 & 2,70 & 5,50 & 4,50 & 0,55 & 312 & 304 \\
\hline Chl3 & 2,47 & 1,24 & 2,89 & 5,70 & 3,90 & 0,59 & 337 & 324 \\
\hline Chl3 & 2,39 & 1,20 & 2,74 & 3,90 & 4,00 & 0,49 & 324 & 308 \\
\hline Chl3 & 2,26 & 1,13 & 2,61 & 3,70 & 3,80 & 0,49 & 302 & 294 \\
\hline Chl3 & 2,22 & 1,11 & 2,57 & 3,70 & 3,70 & 0,50 & 295 & 290 \\
\hline Chl3 & 2,30 & 1,15 & 2,62 & 3,50 & 4,20 & 0,45 & 308 & 296 \\
\hline Chl3 & 2,45 & 1,23 & 2,76 & 3,50 & 4,30 & 0,45 & 334 & 311 \\
\hline Chl3 & 2,39 & 1,20 & 2,72 & 3,60 & 4,00 & 0,47 & 324 & 306 \\
\hline Chl3 & 2,34 & 1,17 & 2,70 & 4,39 & 4,06 & 0,52 & 315 & 305 \\
\hline Chl3 & 2,50 & 1,25 & 2,81 & 3,29 & 4,20 & 0,44 & 341 & 316 \\
\hline Chl3 & 2,27 & 1,14 & 2,62 & 4,15 & 4,06 & 0,51 & 305 & 296 \\
\hline Chl3 & 2,18 & 1,09 & 2,49 & 3,06 & 3,78 & 0,45 & 289 & 282 \\
\hline Chl3 & 2,25 & 1,13 & 2,61 & 4,31 & 4,10 & 0,51 & 302 & 295 \\
\hline Chl3 & 2,03 & 1,02 & 2,34 & 3,26 & 4,06 & 0,45 & 266 & 266 \\
\hline
\end{tabular}




\section{DISCUSSÃO}

\subsection{PETOGRAFIA E CARACTERIZAÇÃO LITOGEOQUÍMICA DO MONZOGRANITO E DIQUES}

Considera-se o Depósito Tocantinzinho estando hospedado em rocha granítica da Suíte intrusiva Creporizão, que se instalou na Província nos estágios finais da Orogênese Mundurucus (Villas et al. 2013). O monzogranito é a rocha dominante na área do Depósito, porém também ocorrem diques de composição basáltica e riolítica. O corpo está alongado na direção NW-SE, coincidindo com o lineamento Tocantinzinho, e apresenta deformações rúpteis consequentes de intenso faturamento e brechação.

Minerais magmáticos como biotita, titanita e magnetita fazem parte da assembleia da rocha granítica não alterada. A rocha é isotrópica, fanerítica e com deformação incipiente.

Devido à coloração avermelhada, suspeitou-se que as rochas do tipo MAT-I fossem mais ricas em $\mathrm{Fe}_{2} \mathrm{O}_{3}$, porém, em geral, as maiores razões desse óxido foram obtidas das do tipo MAT-II. Importante diferença foi apontada em recente estudo sobre balanço de massa de Santiago et al. (2013) que concluiu ter havido relativo ganhos de massa em MAT-II em relação as amostras do MAT-I, sobretudo nas zonas sericitizadas.

$\mathrm{O}$ granito não alterado a pouco alterado é classificado como peraluminoso a metaluminoso com base no índice de saturação em alumina (ISA $=\left(\mathrm{Al}_{2} \mathrm{O}_{3} / \mathrm{CaO}+\mathrm{Na}_{2} \mathrm{O}+\right.$ $\left.\mathrm{K}_{2} \mathrm{O}\right)$ vs. $\mathrm{SiO}_{2}$. Os diagramas de variação dos elementos-traço mostram acentuadas anomalias positivas de $\mathrm{Rb}$, Th, $\mathrm{Zr}$, Hf e $\mathrm{Y}$ e negativa de $\mathrm{Sr}, \mathrm{P}, \mathrm{Nb}$ e Ti, situando os granitos pouco a não alterados no campo de granitos de arco vulcânico a pós-colisionais. Os dados indicam, também, ausência de material residual na sua fonte.

$\mathrm{Na}$ figura 43 consta o diagrama multielementar normalizado ao manto primordial (Sun \& McDonough 1989), no qual os elementos das amostras de granito e dique félsico estão ordenados segundo compatibilidade crescente em relação à fonte mantélica. Os elementos estão normalizados de modo a caracterizar o grau de fracionamento químico dos granitos a partir de uma fonte mantélica possivelmente comum. De forma resumida, este diagrama representa os efeitos integrados de todos os episódios de fusão e processos de fracionamento que contribuíram para a produção dos granitos. 


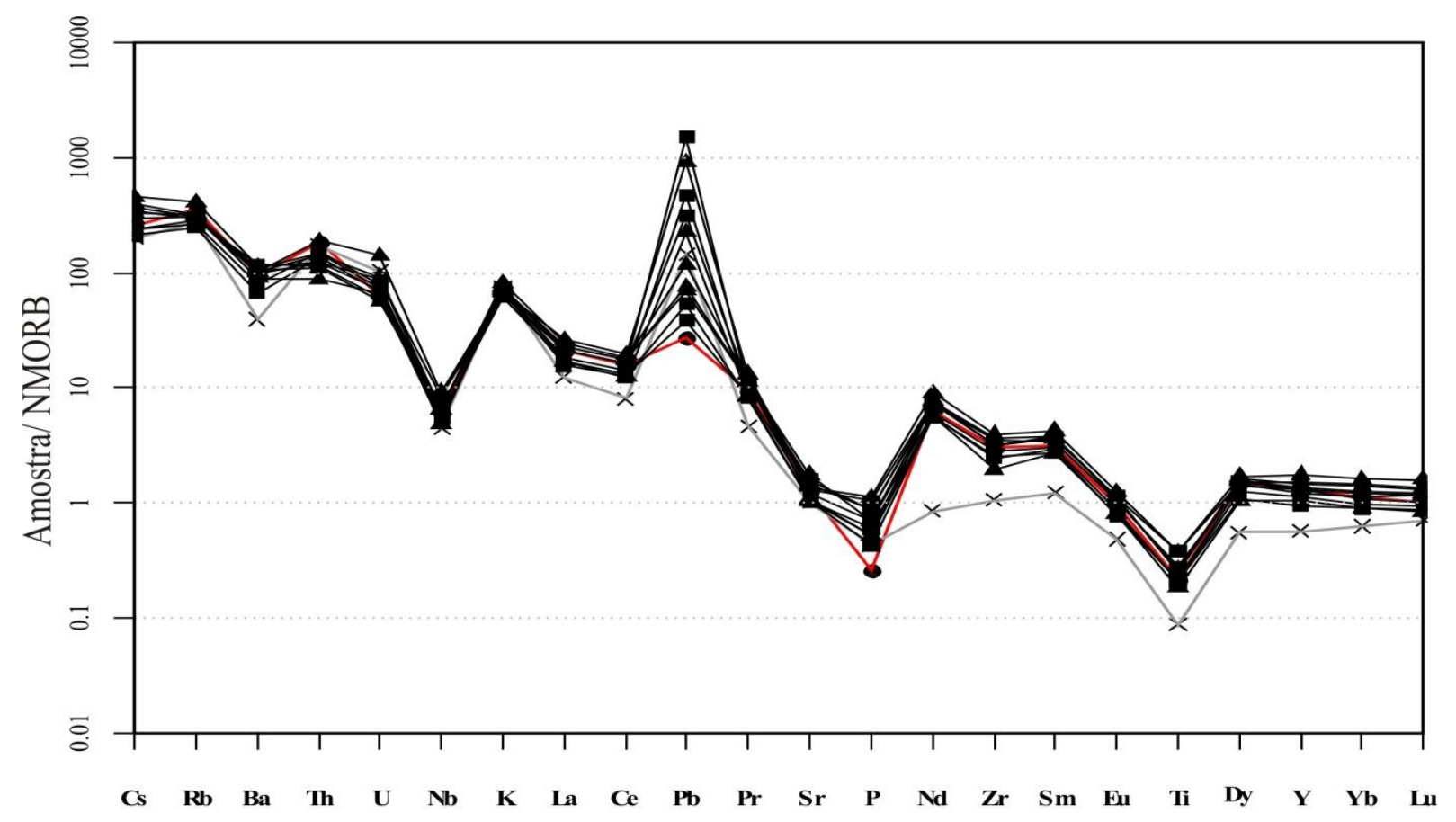

Figura 43: Diagrama de variação de elementos normalizados ao manto primordial (Sun \& McDonough 1989) das amostras de granito não alterado $(\bullet)$, granitos pouco alterados (microclinizados $(\mathbf{\square})$ e granitos resultados de alteração fílica $(\boldsymbol{\Delta}))$ e dique félsico $(\mathrm{X})$.

Com base na interpretação do diagrama, a amostra do granito não alterado (1_24) e as amostras de granito com baixo grau de alteração (10_48 A, 10_48 B, 37_24, 4_48 A, 4_48B, 4_57, 18_24, 23_24, 25_24 e 27_24) apresentam padrão similar entre si: acentuada anomalia negativa de $\mathrm{Ba}, \mathrm{Nb}, \mathrm{Ti}, \mathrm{Sr}$ e $\mathrm{P}$, e anomalia positiva de $\mathrm{Pb}, \mathrm{K}, \mathrm{Rb}, \mathrm{Sm}$ e $\mathrm{Nd}$, e ausência de anomalia de Y e Yb, o que as fazem petrográfica e geoquimicamente ausentes de material residual da sua fonte. Da mesma forma, o dique félsico apresenta anomalia negativa de $\mathrm{Ba}, \mathrm{Nb}, \mathrm{P}$ e Ti; anomalia positiva de $\mathrm{Pb}$ e $\mathrm{Nd}$; e nenhuma anomalia de $\mathrm{Y}$, semelhante aos resultados do granito. Essas características químicas das amostras de granito estudadas indicam que a cristalização fracionada foi importante na evolução magmática e, muito provavelmente, responsável pelo enriquecimento progressivo em $\mathrm{Rb}$ e empobrecimento em $\mathrm{Ba}, \mathrm{Sr}, \mathrm{V}$ e $\mathrm{Zr}$ (Pearce 1984), e o fato de dique e granito apresentarem semelhanças geoquímicas pode se dever a origem comagmáticas. $\mathrm{O}$ fracionamento de feldspato potássico do líquido félsico durante a cristalização do granito permitiu a concentração de $\mathrm{Rb}$ e o empobrecimento de $\mathrm{Ba}$ e Sr. Da mesma forma que a diminuição de concentrações de óxidos como $\mathrm{TiO}_{2}, \mathrm{Fe}_{2} \mathrm{O}_{3}$, e $\mathrm{MgO}$ em relação às rochas mais alteradas deve-se ao fracionamento da biotita. 
Outra característica relevante dos granitos australianos é a composição dominantemente granodiorítica a monzogranítica e conteúdo de $\mathrm{SiO}_{2}$ entre $72 \%$ e $76 \%$. Ainda com base em critérios petrográficos e geoquímicos, as rochas graníticas não alteradas ou com baixo grau de alteração hidrotermal do Depósito Tocantinzinho não apresentam encraves máficos, têm anomalia negativa do Eu e ausência de anomalia negativa do $\mathrm{Y}$, baixos conteúdos de $\mathrm{Sr}$, sugerindo condições de pressões menores de $10 \mathrm{~kb}$, onde granada está ausente e plagioclásio residual é mais abundante, indicando evolução crustal, provavelmente, por cristalização fracionada (Wyborn et al. 1992).

Quanto ao ambiente tectônico, as amostras de granito do Depósito Tocantinzinho situam-se no campo de granitos de arco vulcânico e na transição para granitos intraplaca nos diagramas discriminantes de ambiente tectônico de Pearce et al. (1984) (figura 20). O riolito possui composição compatível com aqueles formados em ambiente de arco vulcânico (VAG). Pearce et al. (1984) observaram que no diagrama $\mathrm{Rb} v s$. (Y+ Nb) os granitos pós-colisionais típicos situam-se próximo ao topo do campo VAG, mas também podem se situar em mais de um campo, como arco vulcânico + sin-colisional ou arco vulcânico + intraplaca. Os autores indicam que os granitos pós-colisionais apresentam um sério problema em torno das classificações tectono-geoquímicas, não podendo ser explicados em termos de uma única fonte, se mantélica ou crustal, mas sim podendo resultar tanto da fusão da crosta inferior quanto da fusão do manto superior, além do que uma nova subducção pós-colisão pode gerar magmas de arco vulcânico em ambiente de pós-colisão. Os dados geológicos e petrológicos do monzogranito, entretanto, são coerentes com granito gerado em ambiente de arco vulcânico.

Os diques de composição basáltica são, possivelmente, originados de magmas máficos já diferenciados, devido a seu baixo valor de \#mg e Ni. No entanto, valores de $\mathrm{SiO}_{2}$ e $\mathrm{MgO}(42,43 \%$ e 7,46\%, respectivamente) são típicos de rochas máficas de acumulação de piroxênios ou olivinas. Além disso, o dique máfico apresenta valor de $\mathrm{TiO}_{2}$ relativamente baixo $(0,51 \%)$, similar aos resultados obtidos por Lamarão et al. (2005) para diques máficos introduzidos em rochas da Província Mineral do Tapajós. Dessa forma, a composição dos diques máficos sugere geração em ambiente de arco vulcânico. 


\subsection{SISTEMA HIDROTERMAL FORMADOR DA MINERALIZAÇÃO DO DEPÓSITO TOCANTINZINHO}

Os processos hidrotermais que afetaram as rochas do Depósito Tocantinzinho tiveram caráter pervasivo, que variou de fraco-moderado a forte, mas também ocorreu em veios/vênulas constituindo padrão stockwork.

$\mathrm{Na}$ região, as principais fácies de granito hidrotermalizados são as rochas de cor avermelhada, decorrente de intensa microclinização. Este estágio hidrotermal foi designado por Estágio de microclinização e nele ocorrem as rochas agrupadas no tipo MAT-I (monzogranito alterado do tipo I). Nessas rochas ocorrem, principalmente, albita, quartzo hidrotermal (Qtz1) e microclínio. Outra característica marcante é a mineralização, onde o ouro ocorre em geral em paragênese com a pirita.

A outra fácies hidrotermalizada é formada por rochas graníticas fortemente sericitizadas, além de apresentarem silicificação e fraturamento relevantes. O grupo que comporta essa fácies foi classificado como MAT-II (monzogranito alterado do tipo II). São rochas fortemente fraturadas, forte silicificação que produziu o quartzo do tipo 2 (Qtz2) além de intensa sericitização e aumenta na quantidade e variedade de sulfetos (pirita + calcopirita + esfalerita + galena + altaíta). As principais paragêneses mineralizadoras dessa fácies correspondem à: ouro + pirita + sericita + Qtz2 +; ouro + pirita + calcopirita + esfalerita + galena + altaíta.

Organizando cronologicamente, os estágios de alteração hidrotermal tiveram início com metassomatismo inicial, que provocou alteração do oligoclásio para albita, e a substituição do ortoclásio para microclínio. Esse estágio é aqui designado de fase pósmagmática precoce. A fase seguinte é caracterizada por forte microclinização das rochas graníticas, representando o estágio de microclinização.

O terceiro estágio compreende a alteração fílica no sistema (Estágio de alteração fílica). Nesta fase há maior expressão da sericitização e silicificação com a formação de quartzo 2 (Qtz2). Constitui o estágio principal da mineralização.

O estágio final da alteração hidrotermal no Depósito Tocantinzinho corresponde ao Estágio de Alteração Tardia o qual é representado pela intensa carbonatização e uma terceira fase de cloritização (Chl3).

Silva et al. (2000) e Juliani et al. (2002) também descrevem forte pigmentação de $\mathrm{Fe}_{2} \mathrm{O}_{3}$ em rochas graníticas que ocorrem no granito Batalha, Província Mineral do Tapajós. Echeverri-Misas (2010) também registrou no granito Palito a mesma feição em rochas graníticas. Em todos os trabalhos essa característica foi relacionada ao metassomatismo 
potássico. Acredita-se que as rochas descritas nesses trabalhos citados dizem respeito às rochas microclinizadas do grupo MAT-I do Depósito Tocantinzinho.

Duas gerações de quartzo hidrotermal são bem distintas nas amostras do granito e nos fácies alteradas do depósito. O primeiro é o quartzo intersticial (Qtz1), o qual é geralmente encontrado em massas de quartzo + albita + microclínio. A segunda fase de quartzo hidrotermal (Qtz2) é recristalizada e está fortemente relacionada à fase de alteração fílica.

A cloritização teve início no processo de alteração da biotita magmática (Chl1), nesta situação ela ocorre na cor verde, nos estágios precoces do processo de alteração hidrotermal. A composição da Chl1 é predominantemente clinocloro. Uma segunda manifestação da cloritização ocorre no Estágio de microclinização (Chl2). Aqui a clorita tem cor marrom, está em veios e vênulas e se associa à pirita e ouro (mineralização). Esta clorita é rica em $\mathrm{Fe}_{(\mathrm{t})}$, com composição predominantemente de chamosita. E na fase de alteração tardia tem-se a Chl3, que ocorre em vênulas monominerálicas e tem composição predominantemente clinocloro.

As rochas microclinizadas (MAT-I) e resultado da alteração fílica (MAT-II) são geoquimicamente semelhantes. Quanto aos elementos maiores, as principais diferenças se dão entre os valores de $\mathrm{TiO}_{2}, \mathrm{MnO}$ e $\mathrm{MgO}$, que são relativamente mais elevados no tipo MAT-II que em MAT-I, devendo-se provavelmente à maior ocorrência de clorita naquele grupo.

Os diagramas de variação de Harker (figura 22) indicam que as amostras pertencentes ao grupo MAT-I são mais enriquecidas em $\mathrm{Ba}$ e $\mathrm{Sr}$ e empobrecidas em $\mathrm{Rb}$. Além disso, a relação $\mathrm{SiO}_{2}$ vs. $\mathrm{Ba}$ é inversamente proporcional. Adicionalmente, a maior incorporação de Ba no sistema MAT-I em comparação às amostras de MAT-II é resultado, provavelmente, da entrada do elemento na estrutura da muscovita, devido à substituição de $\mathrm{K}$ por $\mathrm{Ba}$, fazendo com que as amostras do MAT-I apresentem maior grau de alteração do feldspato potássico. A perda do Sr também indica a quebra do plagioclásio.

Os resultados de geoquímica mostram, ainda, que as amostra do tipo MAT-II são, em média, mais enriquecidas em ouro e cobre que as amostras MAT-I, o que permite associar a precipitação do ouro e cobre à alteração fílica. 


\subsection{FLUIDOS HIDROTERMAIS}

O estudo de inclusões fluidas é de grande importância para a elaboração do modelo de mineralização do Depósito Tocantinzinho. Entender as condições de temperatura e pressão nas quais o minério foi transportado e depositado é extremamente relevante.

São cinco os principais tipos de inclusões fluidas encontrados no depósito: Os tipos I e II são inclusões primárias, com grau de preenchimento relativamente alto ( $\mathrm{VG}=50-70)$, são escuras e com tamanhos variando de 8 a $16 \mu \mathrm{m}$. O tipo III é composto por inclusões primárias, incolores, com alto grau de preenchimento $(\mathrm{VG}=80)$, e tamanho que variam entre 10 e $8 \mu \mathrm{m}$. O tipo IV é formado por inclusões secundárias, em geral incolores, com grau de preenchimento em média de 85-95 e ocorrem entre 8 a $3 \mu \mathrm{m}$. O tipo $\mathrm{V}$ equivale a inclusões monofásicas ricas em vapor ou em líquido, ocorrendo geralmente com $15 \mu \mathrm{m}$.

Com base nos dados obtidos através da petrografia e microtermometria das inclusões, entendeu-se que o sistema fluido atuante no depósito Tocantinzinho foi o Sistema $\mathrm{H}_{2} \mathrm{O}-\mathrm{NaCl}$. Esse sistema é formado por inclusões bifásicas e de salinidade moderada. A $\mathrm{Th}(\mathrm{t})$ dos tipos primários varia entre $203,2{ }^{\circ} \mathrm{C}$ a $432,6{ }^{\circ} \mathrm{C}$; a $\mathrm{Tf}_{\text {(gelo) }}$ é de $-11,9{ }^{\circ} \mathrm{C} \mathrm{a}-1,5{ }^{\circ} \mathrm{C}$; a salinidade decai em intervalo de 1,22 a 20,14 wt.\% de $\mathrm{NaCl}$ eq. e densidade de 0,43 a 0,94 $\mathrm{g} / \mathrm{cm}^{3}$.

As inclusões secundárias são mais abundantes no sistema e apresentam $\mathrm{Th}(\mathrm{t})$ de $100,3{ }^{\circ} \mathrm{C}$ a $290,9{ }^{\circ} \mathrm{C}$; $\mathrm{Th}_{(\mathrm{t})}$ de $-3,5$ a $0,1{ }^{\circ} \mathrm{C}$; salinidades baixas entre 0,17 e $5,10 \mathrm{wt} \%$ de $\mathrm{NaCl}$ eq. e densidade de 0,72 e $0,96 \mathrm{~g} / \mathrm{cm}^{3}$.

Há a coexistência de inclusões que homogeneízam para o vapor (Tipo I) e para o líquido (Tipos II, III e IV), o que permite sugerir que o fluido mineralizante do depósito Tocantinzinho tenha sido submetido à boiling .

Tentando-se complementar os estudos de inclusões fluidas e estabelecer valores para temperatura e pressão do depósito, foi feito o estudo do geotermômetro da clorita, com base em Cathelineau (1988). A partir de dados analíticos e geotermométricos, foi possível reconhecer três diferentes tipos deste mineral: Chl1 (clinocloro), mostrando temperaturas mais baixas $\left(295{ }^{\circ} \mathrm{C}\right)$, com ocorrência mais comum em amostras de granito; Chl2 (predominantemente chamosita), com temperatura máxima de $382{ }^{\circ} \mathrm{C}$, associada a veios/ vênulas poliminerálicas, possivelmente representante do intervalo de temperatura do minério; Chl3 (clinocloro), com temperatura de $266{ }^{\circ} \mathrm{C}$ a $337{ }^{\circ} \mathrm{C}$, ocorrendo preferencialmente em vênulas monominerálicas nas fases finais da entrada de fluidos hidrotermais. 
$\mathrm{O}$ aumento do aporte de $\mathrm{Fe}^{+2}$ nesse sistema se dá por conta da decomposição dos minerais ferromagnesianos da rocha hospedeira, favorecendo a formação de clorita rica em ferro (chamosita) e pirita.

Observações relativas à alteração gerada a partir de fluidos enriquecidos em potássio tais como a ampla sericitização do plagioclásio e a sugestão de elevadas temperaturas (>600 ${ }^{\circ} \mathrm{C}$ ) associadas à alteração potássica, pode sugerir uma origem magmática precoce para esse fluido, o que reforça a ideia da existência de um fluido inicial, hipersalino e de alta temperatura (Hedenquist \& Lowenstern 1994). Porém este fluido hipersalino e de altas temperaturas não está associado diretamente a mineralização do Depósito Tocantinzinho, mas sim teria sido o fluido precoce a circular no depósito, derivado da exsolução do magma granítico.

Para Wilkinson (2001), em depósitos do tipo pórfiro, a infiltração de fluidos externos de temperaturas mais baixas pode ser o principal responsável pelo início do processo de deposição do minério, especialmente por meio de arrefecimento e de diluição dos fluidos magmáticos. No caso do Depósito Tocantinzinho, a coexistência espacial entre inclusões fluidas aquosas de maior salinidade que homogenizam para o líquido e inclusões aquosas que homogenizam para o vapor mostra uma evidência de ligação temporal entre elas. Uma possibilidade é que tenha havido imiscibilidade de fluidos, havendo o boiling no sistema. A imiscibilidade, associada à infiltração de água meteórica no sistema durante a evolução hidrotermal resultou em diluição, o que explicaria a ampla variedade de salinidade $(20,14$ wt.\% de $\mathrm{NaCl}$ eq. a 0,17 wt. $\%$ de $\mathrm{NaCl}$ eq.).

Fluidos aquosos de origem magmática não, obrigatoriamente, apresentam altas salinidades, pois esta varia em função da pressão e do grau de cristalização do magma. Para pressões maiores que 1,3 kb, os primeiros fluidos exsolvidos apresentam salinidade baixa a moderada e esta continua a decrescer durante a cristalização até que o fluido final exsolvido do magma seja quase água pura (Bodnar 1992), no qual se encaixa as características de formação do fluido aquoso do Depósito Tocantinzinho.

\subsection{MINERALIZAÇÃO DO OURO: FONTE, TRANSPORTE E DEPOSIÇÃO.}

O estudo petrográfico de amostras mineralizadas do Depósito Tocantinzinho mostrou que o ouro ocorre predominantemente na paragênese sericita + pirita + Qtz2 + ouro. Outra paragênese comum é sericita + Qtz2 + pirita + calcopirita + galena + esfalerita + altaíta + ouro. 
O ouro ocorre livre, incluso e em fraturas de sulfetos. Análise de microssonda eletrônica apontou que os grãos de ouro na forma livre são levemente mais enriquecidos em ouro empobrecidos em prata $(\mathrm{Ag})$.

A relação do minério com os sulfetos e a alteração fílica é altamente relevante no Depósito Tocantinzinho. Os dados sugerem que a deposição do minério ocorreu no estágio de alteração MAT-II, de alteração fílica.

A constante e marcante associação do minério com cristais de pirita ou com a paragênese de sulfetos permite inferir que os fluidos continham espécies dissolvidas de enxofre e, sob aquelas condições de temperatura, o transporte do ouro deve ter sido dominantemente realizado através de complexos de bissulfeto, à exemplo do $\mathrm{Au}(\mathrm{HS})_{2}{ }^{-}$ (Gammons \& Williams 1997, Kerkhof 1988, Williams-Jones et al. 1989). A deposição poderia ter ocorrido de acordo com a reação $\mathrm{Au}(\mathrm{HS})_{2}{ }^{-}+\mathrm{FeO}=\mathrm{Au}+\mathrm{FeS}_{2}+\mathrm{H}_{2} \mathrm{O}$, na qual o componente $\mathrm{FeO}$ provém da desestabilização de minerais máficos da rocha hospedeira pelos fluidos hidrotermais.

Outro indício importante é a relação de superposição de esfalerita (apresentando ouro em fraturas) em cristais de pirita disseminadas em massas de alteração fílica, o que permitiu supor que há relação genética entre o fluido mineralizador e o fluido que participou da alteração fílica.

Com base nos dados petrográficos, químicos e de inclusões fluidas é possível sugerir que o fluido hidrotermal responsável pelo transporte do ouro tenha, provavelmente, origem magmática, com forte influência de fluidos meteóricos. O monzogranito do Depósito Tocantinzinho desempenhou importante papel, ou como fonte dos fluidos mineralizantes, ou como fonte de fluidos e de metais, pois uma das possibilidades é de que a introdução do ouro tenha se dado durante a fase de geração do magma cálcio-alcalino oxidado, a partir da fusão parcial da placa oceânica subductada, da cunha do manto metassomatizado, ou da fusão da crosta (Hedenquist \& Lowenstern 1994).

O sistema hidrotermal do Depósito Tocantinzinho contou, inicialmente, com a presença de um fluido e alta salinidade e temperatura que foi exsolvido pelo magma, responsável pelo desequilíbrio dos minerais magmáticos (feldspato e biotita). No entanto, o fluido hidrotermal diretamente associado com a mineralização apresenta salinidade moderada (intervalo principal de 15 a 5 wt. $\%$ de $\mathrm{NaCl}$ eq.), temperaturas com valores inferiores a 450 ${ }^{\circ} \mathrm{C}$, o qual apresenta condições para transportar o ouro em complexos cloretados e bissulfetados. 
Os dados de inclusões fluidas sugerem que a paragênese mineralizadora está em equilíbrio com o fluido estável correspondente ás inclusões fluidas do tipo III, que mostram o intervalo de temperatura predominante entre $280{ }^{\circ} \mathrm{C}$ a $380^{\circ} \mathrm{C}$.

\subsection{MODELO GENÉTICO DO DEPÓSITO TOCANTINZINHO}

Muitos sistemas hidrotermais foram desenvolvidos dentro e acima de intrusões magmáticas, comumente interagindo com fluidos meteóricos e, em alguns casos, interagindo com água do mar. Segundo Sinclair (2007), durante os momentos finais do estágio magmático-hidrotermal, o sistema entra em colapso interno devido à interação com fluidos externos, havendo a redistribuição e possível concentração de metais.

Mello (2007) e Juras et al. (2011) propuseram a inclusão do depósito Tocantinzinho na categoria de depósitos relacionados a intrusões (intrusion-related gold deposits), de acordo com a concepção de Thompson et al. (1999). Posteriormente, Villas et al. (2012) e Santiago et al. (2013) classificaram o Depósito Tocantinzinho como reduced intrusion-related gold systems - RIRGS, associados a granitos reduzidos e províncias que podem conter mineralização de W e Sn, segundo a concepção de Hart (2007).

Com base nos dados da literatura e nas características petrográficas/ petrogenéticas, químicas e mineralógicas obtidos neste trabalho para o Depósito Tocantinzinho, considera-se inadequada a classificação do depósito na categoria de depósitos relacionados a intrusões (RIRGS). Apesar de o termo sugerir vasta gama de depósitos geneticamente relacionados a diferentes tipos de intrusões, a caracterização proposta por Hart (2007) a partir dos trabalhos iniciais de Thompson et al. (1998) restringiu a categoria a depósitos de Au caracterizados pela associação Au-Bi-Te-W, geneticamente relacionados a granitos moderadamente reduzidos, o que não é observado no depósito Tocantinzinho (tabela 12).

Os dados deste trabalho são coerentes com mineralização de ouro gerada a partir de alteração hidrotermal de monzogranito cálcio-alcalino, oxidado, do tipo I, em sistema magmático-hidrotermal. As fontes dos fluidos e ligantes podem ser o próprio granito ou até mesmo magma de composição basáltica. Foi identificado no depósito dique de composição de basalto de arco continental cortando o monzogranito. São necessários dados geocronológicos da mineralização e desses diques para aprofundar essa discussão.

Comparando-se com modelos genéticos descritos na literatura, o depósito Tocantinzinho assemelha-se com depósitos classificados como do tipo ouro pórfiro (tabela 12), principalmente no que diz respeito ao tipo de magma e ambiente tectônico associado, 
características da alteração hidrotermal e da mineralização (Hedenquist \& Lowenstern 1994, Pirajano 2009, Sinclair 2007).

A paragênese de sericitização e sua relação genética com a disseminação de sulfetos $($ sericita + sulfetos $+\mathrm{Au})$ juntamente ao padrão do tipo stockwork é compatível com algumas das características essenciais listadas por Pirajno (2009) para os depósitos do tipo pórfiro, como: presença de veios e vênulas formando padrão stockwork, dentro do qual há disseminação de sulfetos associados ao ouro nativo; baixo conteúdo metálico $(<5 \%)$; presença de minerais de minério oxidados, sendo a pirita o principal; presença de magnetita magmática; fluidos ricos em potássio com tendência a gerar magmas com alta $f \mathrm{O}_{2}$, desestabilizando sulfetos primários e promovendo a deposição de $\mathrm{Cu}-\mathrm{Au}$. Esse é o caso de muitos sistemas pórfiros-epitermais, como ocorre, por exemplo, em Indio, Chuquicamata, Ladolam e Panguna.

Os depósitos do tipo pórfiro estão, em geral, intimamente relacionados com suítes graníticas da série magnetita, do tipo I, e são resultado de grandes sistemas hidrotermais relacionados com plútons introduzidos a profundidades entre 2 e $5 \mathrm{~km}$. As intrusões apresentam-se alteradas e são, em geral, constituídas por uma zona central de biotita \pm feldspato potássico (zona potássico silicática), a qual dá sequência a uma zona com quartzo + clorita, geralmente sobreposta por sericita + pirita (zona sericítica). Em geral, as rochas encaixantes apresentam grau leve de alteração contendo epidoto + clorita + albita (zona propilítica) (Sillitoe 2000).

Os depósitos de ouro pórfiro ocorrem, em geral, em arcos vulcano-plutônicos, em ambientes de arcos de ilhas ou margens continentais, de todas as idades e associados a granitos do tipo I, da série magnetita (Sinclair 2007). Os tipos de alteração hidrotermal que se associam a este tipo de depósito são: potássio-silicática, propilítica, argílica intermediária, argílica avançada e sericítica. Apesar de as zonas de alteração fílica não serem muito comuns em depósito do tipo pórfiro, elas podem ocorrer, como exemplifica Sinclair (2007) com o Depósito de Chuquicamata (Chile), o qual apresenta importante zona de alteração fílica associada à pirita, porém de forma superimposta à assembleia da alteração potássica.

Desse modo, fazendo-se a junção dos dados, é possível sugerir que o magma granítico oxidado do Depósito Tocantinzinho tenha sido gerado durante a fusão parcial da placa oceânica subductada ou residual da crosta e/ou de cunha do manto envolvida no processo. $\mathrm{O}$ metal pode ter entrado no magma por várias formas, incluindo fusão do manto, transferência de massa da placa subductada e fusão da crosta (Sinclair 2007). 
A titanita encontrada no granito não alterado é de origem magmática e está em equilíbrio com os cristais de biotita, sendo uma característica adicional para a classificação do magma como oxidado (Wones 1989). Em relação à quebra da biotita, estudos feitos por Xie et al. (2010) sugerem temperaturas inferiores a $400{ }^{\circ} \mathrm{C}$ para a cristalização do rutilo nos planos de clivagem da clorita, o que é recorrente em amostras hidrotermalizadas do Depósito.

A deposição do ouro no Depósito Tocantinzinho pode ter sido proporcionada pela mistura de fluido salino precoce quente com água meteórica e/ou de boiling. Esse processo, por sua vez, resultou em fluido modelado pelo sistema $\mathrm{H}_{2} \mathrm{O}-\mathrm{NaCl}$, no qual há grande intervalo de temperaturas e salinidade. O transporte do ouro se deu por meio de $\mathrm{AuCl}_{2}{ }^{-}$ou $\mathrm{Au}(\mathrm{HS})_{2}{ }^{-}$, este último fluido sendo responsável pela principal associação de minério reconhecida no Depósito (sericita + quartzo + pirita + ouro).

O ouro nativo na forma livre mostra-se mais puro, com menor teor em prata que aqueles encontrados em fraturas e inclusos em sulfetos. Esse dado levanta a hipótese da existência de, pelo menos, duas gerações de mineralização do Depósito Tocantinzinho. A primeira, de mais alta temperatura, em que o ouro associa-se apenas à pirita, e a segunda, associada também a telureto (altaíta- PbTe) e minerais de Bi. 
Tabela 12 Tabela com as principais características do Depósito Tocantinzinho em comparação com depósitos de ouro pórfiro e depósitos do tipo reduced-intrusion-related-gold sistems (RIRGIS). Os parâmetros do depósito de ouro pórfiro são embasados em Sillitoe (2000) e Sinclair (2007); os parâmetros dos RIRGIS estão de acordo com Hart (2007).

\begin{tabular}{|c|c|c|c|}
\hline PARÂMETROS & $\begin{array}{c}\text { DEPÓSITO } \\
\text { TOCANTINZINHO }\end{array}$ & $\begin{array}{c}\text { DEPÓSITOS DO TIPO } \\
\text { Au PÓRFIRO }\end{array}$ & $\begin{array}{l}\text { DEPÓSITO DO TIPO } \\
\text { RIRGS }\end{array}$ \\
\hline Ambiente Tectônico & Arco magmático & Arcos vulcano-plutônicos & $\begin{array}{l}\text { Fraca extensão pós- } \\
\text { colisional atrás de } \\
\text { margem continental. }\end{array}$ \\
\hline Idade da intrusão & $1982 \pm 8$ & $\begin{array}{c}\text { Variável; } \\
\text { predominantemente } \\
\text { Mesozóica e Cenozóica. }\end{array}$ & $\begin{array}{c}\text { Predominantemente } \\
\text { Fanerozóico. Idades } \\
\text { Arqueana e Proterozóica } \\
\text { controversas. }\end{array}$ \\
\hline $\begin{array}{l}\text { Composição da } \\
\text { rocha hospedeira }\end{array}$ & $\begin{array}{l}\text { Granito de composição } \\
\text { monzogranítica; calcio- } \\
\text { alcalino; tipo I; oxidado, } \\
\text { da série magnetita. }\end{array}$ & $\begin{array}{l}\text { Calcio-alcalina; do tipo I; } \\
\text { oxidado; da série magnetita. }\end{array}$ & $\begin{array}{l}\text { Plutons félsicos } \\
\text { reduzidos, da série da } \\
\text { ilmenita, de composição } \\
\text { variada; tipos I, S e A. }\end{array}$ \\
\hline $\begin{array}{l}\text { Alteração } \\
\text { hidrotermal } \\
\text { associada à } \\
\text { mineralização }\end{array}$ & $\begin{array}{l}\text { Alteração fílica, Alteração } \\
\text { K-feldspática } \\
\text { (microclinização). }\end{array}$ & $\begin{array}{l}\text { K-silicática; magnetita } \\
\text { associada; alteração fílica }\end{array}$ & $\begin{array}{l}\text { Principalmente sericita- } \\
\text { calcita; restrita; ausência } \\
\text { de extensos halos de } \\
\text { alteração hidrotermal. }\end{array}$ \\
\hline $\begin{array}{c}\text { Tipo de } \\
\text { mineralização }\end{array}$ & $\begin{array}{l}\text { Disseminada e em vênulas } \\
\text { e fraturas (stockwork). }\end{array}$ & $\begin{array}{l}\text { Disseminada; stockwork; } \\
\text { controlada por fraturas. }\end{array}$ & $\begin{array}{l}\text { Preferencialmente } \\
\text { enxames de veios de } \\
\text { quartzo no topo de } \\
\text { pequenos plutons. } \\
\text { Ausência de stockworks. }\end{array}$ \\
\hline Principais metais & $\mathrm{Au}$ & $\mathrm{Au}-(\mathrm{Cu})$ & $\mathrm{Au}-\mathrm{Bi}-\mathrm{Te}-\mathrm{W}$ \\
\hline $\begin{array}{l}\text { Principais sulfetos } \\
\text { associados }\end{array}$ & Pirita & $\begin{array}{l}\text { Pirita - (calcopirita; } \\
\text { bornita). }\end{array}$ & Pirrotita; arsenopirita \\
\hline $\begin{array}{c}\text { Fluido } \\
\text { Mineralizante }\end{array}$ & $\begin{array}{c}\text { Fluido do sistema } \mathrm{H}_{2} \mathrm{O}- \\
\mathrm{NaCl} \text {, resultante de } \\
\text { mistura de fluido } \\
\text { magmático com água } \\
\text { meteórica. Th(t) }>450^{\circ} \mathrm{C} \mathrm{e} \\
\text { salinidade variando entre } \\
0,17 \text { e } 20,14 \text { wt.\% de } \mathrm{NaCl} \\
\text { eq. Temperatura do fluido } \\
\text { mineralizante }\left(289^{\circ} \mathrm{C} \mathrm{a}\right. \\
\left.382^{\circ} \mathrm{C}\right) \text {. Inclusões que } \\
\text { homogenizam para o } \\
\text { vapor e para o líquido. } \\
\text { Presença de boiling. }\end{array}$ & $\begin{array}{l}\text { Inicialmente quente }(>500- \\
\left.600{ }^{\circ} \mathrm{C}\right) \text { e dominado por } \\
\text { líquido magmático e } \\
\text { hipersalino (30-60 wt.\% de } \\
\mathrm{NaCl} \text { eq). É comum boiling } \\
\text { e mistura com água } \\
\text { meteórica. }\end{array}$ & $\begin{array}{l}\text { Predomínio de fluidos de } \\
\text { baixa salinidade e aquo- } \\
\text { carbônicos, com altas } \\
\text { concentrações de } \mathrm{CO}_{2} \text {. } \\
\text { Podem conter } \mathrm{CH}_{4} \text {. }\end{array}$ \\
\hline
\end{tabular}




\section{CONCLUSÕES}

O depósito de ouro Tocantinzinho, localizado a $200 \mathrm{~km}$ ao sul da cidade de Itaituba, região sudoeste do Estado do Pará, Província Mineral do Tapajós, está inserido em rocha hospedeira monzogranítica de idade de $1982 \pm 8$ Ma. interpretado como manifestação precoce da suíte intrusiva Creporizão, inserida na PMT nos estágios finais da orogênese Mundurucus.

A integração dos dados geológicos e petrográficos permitiu definir o Depósito Tocantinzinho como um sistema hidrotermal disseminado do tipo stockwork hospedado em granito de composição monzogranítica, sem controle estrutural considerável, de caráter cálcio-alcalino, da série magnetita, do tipo I, situado em ambiente de arco vulcânico.

O monzogranito é cortado por dique máfico, com características químicas de basalto calcio-alcalino de arco vulcânico. O dique félsico tem composição riolítica e é posterior tanto ao monzogranito como ao dique máfico.

O monzogranito é cálcio-alcalino, peraluminoso, semelhante aos granitos do tipo I. Tem $\mathrm{SiO}_{2}$ com valor de $72 \%$, razões de $\mathrm{MgO} / \mathrm{TiO}_{2}$ e $\mathrm{K}_{2} \mathrm{O} / \mathrm{Na}_{2} \mathrm{O}$ de 1,15 e 2,3. É pobre em $\mathrm{CaO}(<1 \%)$ e enriquecido em $\mathrm{Ba}$ e possui valores moderados a baixos de $\mathrm{Sr}(600$ e 111,8 ppm, respectivamente). Possui valores moderados de ETR ( $\Sigma$ ETR $=264,78$ ppm $)$ e acentuada anomalia negativa do Eu. O empobrecimento de $\mathrm{Al}_{2} \mathrm{O}_{3}, \mathrm{FeO}_{(\mathrm{t})}, \mathrm{TiO}_{2} \mathrm{CaO}, \mathrm{MgO}, \mathrm{P}_{2} \mathrm{O}_{5}, \mathrm{~V}$ e o alto conteúdo de $\mathrm{SiO}_{2}$ sugere ter havido cristalização fracionada no granito encaixante do Depósito Tocantinzinho, assemelhando-se a granitos fracionados do tipo I, os quais são empobrecidos em Sr mas não empobrecidos em Y.

O granito de composição monzogranítica foi submetido a forte ação hidrotermal, a qual deu origem a diferentes fácies hidrotermais, dentre elas duas ganham destaque por apresentarem-se mineralizadas: MAT-I e MAT-II.

Cronologicamente, após a fase magmática, ocorreu a alteração hidrotermal classificada como Estágio Pós-magmático Precoce: alteração do plagioclásio para albita, juntamente com a alteração do feldspato potássico para microclínio, seguidos do início da substituição da biotita magmática por clorita verde. Nesta fase estão inclusas as rochas não alterada e/ou pouco alteradas do Depósito.

Em seguida se deu a Fase de Microclinização: rochas microclinizadas com quantidade moderada de sulfeto (pirita e calcopirita). Apresentam contribuição da cloritização (Chl2). Nesta fase se encaixam as rochas do grupo MAT-I.

Na Fase de Alteração Fílica há a entrada significativa de sulfetos no sistema (pirita, calcopirita, galena, esfalerita e altaíta) em paragênese com a sericitização e o ouro. A 
principal paragênese mineralizada corresponde a sericita + sulfetos + ouro + qtz2. Nesta etapa ocorrem as rochas do grupo MAT-II.

O Estágio de Alteração Tardia corresponde a última fase de alteração hidrotermal do depósito. Neste estágio estão a carbonatização e a cloritização tardia (Chl3).

A fengita apresenta composição química de muscovita. A clorita do tipo Chl1, de cor verde, com baixos valores de Fe e moderados valores de $\mathrm{Mn}$ e $\mathrm{Mg}$, apresenta composição predominantemente clinocloro. A Chl2, clorita marrom com valores mais expressivos de $\mathrm{Fe}$ e mais baixos de $\mathrm{Mn}$ e $\mathrm{Mg}$, tem composição predominantemente chamosita. A Chl3, clorita marrom tardia, com valores de Mn e valores de Fe mais baixos, apresentando composição predominantemente clinocloro.

As inclusões fluidas foram estudadas em dois tipos de quartzo hidrotermal: o Qtz1, que está em paragênese com albita + microclínio, ou seja, aqueles grãos que correspondem aos estágios iniciais da alteração hidrotermal; e Qtz2, grãos em paragênese com a fase mais importante da mineralização (sericita + pirita + ouro). Foi possível distinguir cinco tipos de inclusões fluidas: I) Ocorre apenas em Qtz2. São inclusões primárias, aquosas bifásicas, escuras, moderadamente salinas e com altos valores de temperaturas de homogeneização total $\left(\mathrm{Th}_{(\mathrm{t})}\right)$ e homogeneizam para o vapor; II) Ocorrem em Qtz1 e Qtz2; inclusões fluidas primárias, aquosas bifásicas, de cor escura e apresentando moderada salinidade e alta $\operatorname{Th}_{(\mathrm{t})} \mathrm{e}, \mathrm{a}$ partir deste ponto, as demais homogeneizam para o líquido; III) Ocorrem em Qtz1 e Qtz2; são inclusões primárias, aquosas bifásicas, incolor, moderadas temperaturas de homogeneização, baixos a moderados valores de salinidade; IV) Medidas apenas em Qtz2; são inclusões secundárias, com baixa salinidade e $\mathrm{Th}_{(\mathrm{t})}$.

O intervalo de temperatura de aprisionamento dos fluidos mineralizantes das inclusões fluidas é de $289{ }^{\circ} \mathrm{C}$ a $382{ }^{\circ} \mathrm{C}$. O sistema assumido para as inclusões bifásicas de salinidade moderada do Depósito Tocantinzinho é o $\mathrm{H}_{2} \mathrm{O}-\mathrm{NaCl}$.

O ouro se dá de forma nativa, em geral, associado à pirita o qual é o principal sulfeto do Depósito Tocantinzinho. Nesta situação, o ouro é enriquecido em Au e empobrecido em $\mathrm{Ag}$, e também ocorre incluso em grãos de quartzo, associados à sericitização, em fraturas de pirita e esfalerita, em paragênese com galena, calcopirita e altaíta. Nesta associação o minério é levemente empobrecido em Au, supondo, assim, a existência de duas gerações de ouro no sistema mineralizador do Depósito Tocantinzinho, a primeira em paragênese com a pirita e clorita e a segunda, em paragênese com os sulfetos (pirita + calcopirita + esfalerita + galena + altaíta) + Qtz2 e com a sericitização. 
De acordo com as características petrográficas, geoquímicas, de inclusões fluidas e da mineralização, é possível sugerir que o Depósito Tocantinzinho seja semelhante a depósitos do tipo Au pórfiro. Devem-se aprofundar os estudos para a melhor caracterização das condições físico-químicas da mineralização e entendimento do papel do monzogranito e do dique de composição basáltica como fonte de metais e ligantes. Os dados obtidos, além de contribuir para o melhor entendimento do depósito Tocantinzinho e de depósitos semelhantes na Província Mineral do Tapajós, podem ser usados para elaborar e orientar modelos prospectivos na região e em terrenos proterozóicos semelhantes. 


\section{REFERÊNCIAS BIBLIOGRÁFICAS}

ALMEIDA, M.E; BRITO, M.F.L; FERREIRA, A.L; MONTEIRO, M.A.S. 2000. Geologia e Recursos Minerais da Folha Mamãe Anã (SB.21-V-D). Estados do Amazonas e Pará. Escala 1:250.000. Nota explicativa. Projeto Especial Província Mineral do Tapajós. Brasília: PROMIM Tapajós/CPRM.

BAHIA, R.B.C; QUADROS, M.L.E.S. 2000. Geologia e recursos minerais da Folha Caracol (SB-21-X-C). Estado do Pará Escala 1:250.000. Nota explicativa. Projeto Especial Província Mineral do Tapajós. Brasília: PROMIM Tapajós/CPRM.

BIONDI, J.C. 2009. Condições de gênese do depósito de Au-Cu (Bi) Pombo (Terra Nova do Norte-MT) estimadas com microtermometria de inclusões fluidas e termometria da clorita. Revista Brasileira de Geociências. 39(2): 213-229.

BODNAR, R. J. 1992. Can we recognize magmatic fluid inclusions in fossil systems based on room temperature phase relations and microthermometric behavior. In: Hedenquist J. W. (ed.) Magmatic contributions to hydrothermal systems. Geol. Survey of Japan, Report 279, p. 2630 .

BODNAR, R.J. 1993. Revised equation and table for freezing point depressions of $\mathrm{H}_{2} \mathrm{O}-\mathrm{NaCl}$ solutions. In: Geochim. Cosmochim. Acta 12. vol. 57. pp. 683-684.

BODNAR R.J. and Vityk M.O. 1994. Interpretation of Microthermometric Data for $\mathrm{H}_{2} \mathrm{O}-$ $\mathrm{NaCl}$ fluid inclusions. In Fluid Inclusions in Minerals, Methods and Applications, B. de Vivo and Frezzotti, M. L., EDS., PUB. BY Virginia Tech, Blacksburg, VA, p. 117-130.

BODNAR R.J. 2003. Introduction to fluid inclusions. In I. Samson, A. Anderson, \& D. Marshall, eds. Fluid Inclusions: Analysis and Interpretation. CHAPTER 1. INTRODUCTION TO FLUID INCLUSIONS. Mineral. Assoc. Canada, Short Course 32, 1-8.

BODNAR R.J. 2003. Introduction to fluid inclusions. In I. Samson, A. Anderson, \& D. Marshall, eds. Fluid Inclusions: Analysis and Interpretation. CHAPTER 4. INTRODUCTION TO AQUEOUS-ELECTROLYTE FLUID INCLUSIONS. Mineral. Assoc. Canada, Short Course 32, 81-100.

BOTELHO N.F. \& MOURA M.A. 1998. Granite-ore deposit relationship in central Brazil. J. South Am. Earth Sci., 11(5):427-438.

BOTELHO N.F., MOURA M.A., TEIXEIRA L.M., OLIVO G.R., CUNHA L.M., SANTANA M.U. 2005. Caracterização geológica e metalogenética do depósito de $\mathrm{Cu} \pm$ (Au, W, Mo, Sn) Breves, Carajás. In: Marini O.J., Queiroz E.T., Ramos B.W. (eds.) Caracterização de Depósitos Minerais em Distritos Mineiros da Amazônia. Capítulo VI, DNPM, CT-Mineral/ FINEP, ADIMB, 56 p., CD-Rom.

CARITAT, P. de; HUTCHEON, I.; WALSHE, J.L. 1993. Chlorite geotermometry: a review. Clay and Clay Minerals, 41(2): 219-239. 
CASTILHO M.P., VILLAS R.N.N., GALARZA M.A.T., PEREIRA E.L.S. 2010. Estudo isotópico $(\mathrm{Pb}-\mathrm{Pb}, \mathrm{C}$ e $\mathrm{O})$ do depósito aurífero Tocantinzinho, Província Aurífera do Tapajós, Pará-Brasil. In: Congresso Brasileiro de Geologia, 45, Belém, Anais. [CD-ROM].

CASTRO, A.A.; VILLAS, R.N.N.; PEREIRA, E.L.S. 2010. Geologia e alteração hidrotermal do depósito aurífero Tocantinzinho, Província Aurífera do Tapajós. In: Congresso Brasileiro de Geologia, 45, Belém, Anais. [CD-ROM].

CATHELINEAU, M. 1988. Cation site occupancy in chlorites and illites as a function of temperature. Clay Minerals 23: 471-485.

CIBIN G.; CINQUE G.; MARCELLI A.; MONTTANA A.; SASSI R. 2008. The octahedral sheet of metamorphic 2M1-phengites: A combined EMPA and AXANES study. American Mineralogist, 93: 414-425.

COUTINHO, M.G. da N. (Org.) 2008. Província Mineral do Tapajós: geologia, metalogenia e mapa previsional para ouro em SIG. Rio de Janeiro: CPRM. 420p.

DALL'AGNOL R.; PICHAVANT M.; CHAMPENOIS M. 1997. Iron-Titanium Oxide Minerals of the Jamon Granite, Eastern Amazonian Region, Brazil: Implications for the Oxigen Fugacity in Proterozoic, A-type Granites. An. Acad. Bras. Ci., 69:325-347.

DALL'AGNOL R.; SILVA C.M.G.; SCHELLER T. 1999. Fayalite-hendebergite rhyolites of Iriri Formation, Tapajós Gold Province, Amazonian Craton: implications for the Uatumã Volcanism. In: Simpósio sobre Vulcanismo e Ambientes Associados, 1. Boletim de Resumos, Gramado. [CD-ROM].

DIAMOND L.W. 2003. Introduction to fluid inclusions. In I. Samson, A. Anderson, \& D. Marshall, eds. Fluid Inclusions: Analysis and Interpretation. Chapter 3. Systematics of H2O Inclusions Mineral. Assoc. Canada, Short Course 32, 55-79.

DREHER A.M; VLACH S.R.F; MARTINI S.L. 1998. Adularia associated with epithermal gold veins in the Tapajós Mineral Province, Pará State, northern Brazil. Rev. Bras. Geoc. 28(3):397-404.

ECHEVERRI-MISSAS, C.M. 2010. Evolução magmática, alteração hidrotermal e gênese da mineralização de ouro e cobre do Palito, Província Aurífera do Tapajós (PA). Dissertação (Mestrado em mineralogia e Petrologia) - Instituto de Geociências, da Universidade de São Paulo, São Paulo.

ECHEVERRI-MISAS, C.M.; JULIANI, C.; AGUJA-BOCANEGRA, M.A.; MONTEIRO, L.V.S.; DIAS FERNANDES, C.M. 2014. Mineralizações magmáticas hidrotermais associadas ao evento Uatumã na Província Mineral do Tapajós, Cráton Amazônico. Anais do $47^{\circ}$ Congresso brasileiro de geologia. Salvador (BA).

FARACO M.T.L; CARVALHO J.M de A; KLEIN E.L. 1996. Carta metalogenética da Província Aurífera do Tapajós, Nota explicativa. Belém: CPRM. 13p.

FARACO, M.T.L; CARVALHO, J.M de A; KLEIN, E.L. 1997. Carta Metalogenética da Província Aurífera do Tapajós. In: M.L. Costa \& R.S. Angélica (eds.), Contribuições á Geologia da Amazônia. Belém, SBG-NO, p. 423 - 437. 
FERREIRA, A.L; ALMEIDA M.E; BRITO, M.F.L; MONTEIRO, M.A.S. 2000. Geologia e recursos minerais da Folha Jacareacanga (SB.21-Y-B), Estados do Amazonas e Pará, Escala 1: 250.000. Nota explicativa, Projeto Especial Província Mineral do Tapajós. Manaus, PROMIM Tapajós/CPRM. [CD-ROM].

FERREIRA, A. L. et al., 2004. Folha SB.21 - Tapajós. In: SCHOBBENHAUS, C. et al. (Ed.) Carta geológica do Brasil ao milionésimo: Sistema de informações geográficas-SIG. Programa Geologia do Brasil. Brasília,Brasília: CPRM. 1 CD-ROM.

GALINDO, A.C.; DA SILVA, F.C.A.; DE SOUZA, Z.S. 2012. Química mineral de leucogranitos Neoproterozóicos do Domínio Rio Grande do Norte. Programa de pós graduação em geodinâmica. Departamento de Geologia (UFRGN). Geoquimica Brasiliensis, Ouro Preto, 26(1) 19-28.

GAMMONS, C. H.; WILLIAMS-JONEs, A.E., 1997. Chemical mobility of gold in the epithermal environment. Econ. Geol, v. 92, p. 45-59.

GOLDSTEIN, R. H.; REYNOLDS, T.J. 1994. Sistematics of fluid inclusion in diagenetic minerals. SEPM Short Course 31.Oklahoma: SEPM. 198p.

HARRIS, N.B.W.; PEARCE, J.A.; TINDLE, A.G. 1986. Geochemical characteristics of collisional-zone magmatism. In: COWARD, M.P.; Ries, A.C., ed. Collision Tectonics. London: The Geological Society. p. 67-81 (Geological Society Special Publication, n. 19).

HART, C.J.K. 2007. Reduced intrusion-related gold systems, in Goodfellow, W.D., ed., Mineral deposits of Canada: A Synthesis of Major Deposit Types, District Metallogeny, the Evolution of Geological Provinces, and Exploration Methods: Geological Association of Canada, Mineral Deposits Division, Special Publication No. 5, p. 95-112.

HENDENQUIST, J.W.; LOWENSTERN, J.B. 1994. The role of magmas in the formation of hydrothermal ore deposits. Nature, v.370, p.519-527.

JACOBI, P. 1999. The discovery of epithermal Au-Cu-Mo Proterozoic deposits in the Tapajós Province, Brazil. Rev. Bras. Geoc. 29:277-279.

JULIANI, C; CORRÊA SILVA, R.H; MONTEIRO, L.V.S; BETTENCOURT, J.S; NUNES, C.M.D. 2002. The Batalha Au-Granite system - Tapajós Province, Amazonian Craton, Brazil: Hydrothermal alteration and regional implication. Precambrian Research.119:225-256.

JULIANI, C.; Rye, R.O.; NUNES,, C.M.D.; SNEE L.W.; CORRÊA SILVA, R.H.; MONTEIRO, L.V.S; BETTENCOURT,, J.S; NEUMANN, R; Alcover, A. 2005. Paleoproterozoic high-sulfidation mineralization in the Tapajós gold province, Amazonian Craton, Brazil: geology, mineralogy, alunite argon age, and stable-isotope constraints. Chemical Geology, 215:95-125.

JURAS, S.; GREGERSEN, S.; ALEXANDER, R. 2011. Technical report for the Tocantinzinho Gold Project, Brazil. Vancouver: Eldorado Gold Corporation. 
KLEIN E. L. et al. 2001.a. Geologia e recursos minerais da Província Mineral do Tapajós, Estados do Pará e Amazonas: folhas SB.21-V-D, SB.21-Y-B, SB.21-X-C, SB.21-Z-A e SB.21-Z-C. Escala 1:500.000. Brasília: CPRM. CD-ROM. Programa Levantamentos Geológicos Básicos do Brasil (PLGB). Projeto Especial Província Mineral do Tapajós (Promin Tapajós).

KERKHOF, A. M. V. D. 1988. Fluid Inclusions: petrography and genetic interpretation of fluid Inclusions. Geowiissenschaftlliiches Zentrum der Uniiversiität Göttiingen (Germany). P 44.

KLEIN E. L. et al. 2001b. Hydrothermal fluid evolution and structural control of the brittlestyle Guarim lode-gold mineralization, Tapajós Province, Amazonian Craton, Brazil. Mineralium Deposita, v. 36, n. 2, p. 149-164, mar.

KLEIN E.L.; VASQUEZ, M. L.; ROSA COSTA, L. T.; CARVALHO, J. M. A. 2002. Geology of Paleoproterozoic gneiss- and granitoid-hosted gold mineralization in southern Tapajós gold province, Amazonian Craton, Brazil. Intern. Geol. Review, 44: 544-558.

LAMARÃO, C.N. 2001. Geoquímica, petrologia e geocronologia das associações magmáticas da região de Vila Riozinho, Província Aurífera do Tapajós, sudeste do estado do Pará. Universidade Federal do Pará. Centro de Geociências (Tese de Doutorado).

LAMARÃO C.N., DALL'AGNOL R., LAFON J.M., LIMA E.F. 2002. Geology, geochemistry and $\mathrm{Pb}-\mathrm{Pb}$ zircon geochronology of the Paleoproterozoic magmatism of Vila Riozinho, Tapajós Gold Province Amazonian Craton, Brazil. Precambrian Research 119: 189223.

LAMARÃO C.N., DALL'AGNOL R., PIMENTEL M.M. 2005. Nd isotopic composition of Paleoproterozoic volcanic rocks of Vila Riozinho: implications for the crustal evolution of the Tapajós gold province, Amazon craton. Journal of South America Earth Sciences, 18:277292.

MELLO, R. B. 2007. A preliminary assessment of the Tocantinzinho Gold Project, Tapajós Gold District, Pará State, Brazil - Three million tons/ year scenario. Nova Lima: Brazauros Resources Corporation. (Relatório Inédito).

MONTEIRO, M.A.S. 2000. Diabásio Crepori. In: Almeida M.E., Brito M.F.L., Ferreira A. L., Monteiro M.A.S. (Org.). Geologia e recursos minerais da Folha Vila Mamãe Anã - SB.21- VD: Estados do Pará e Amazonas, escala 1:250.000: Brasília: CPRM, Programa Levantamentos Geológicos Básicos do Brasil (PLGB). Projeto Especial Província Mineral do Tapajós (Promin Tapajós). [CD-ROM]

MOURA, M. A., 1998. O maciço granítico Matupá no depósito de ouro Serrinha (MT): petrologia, alteração hidrotermal e metalogenia. Tese (Doutorado) - Instituto de Geociências, Universidade de Brasília, Brasília, DF.

MOURA, M. A.; BOTELHO, N. F. 2006. Granite-Related Paleoproterozoic, Serrinha Gold Deposit, Southern Amazonia, Brazil: Hydrothermal Alteration, Fluid Inclusion and Stable Isotope Constraints on Genesis and Evolution. In: Economic Geology. V. 101, pp, 585-605. 
NAKADA, S. 1991. Magmatic processes in titanite-bearing dacites, central Andes of Chile and Bolívia. American Mineralogist, 76:548-560.

NAKAMURA, N.1974. Determination of REE, Ba, Fe, Mg, Na, and K in carbonaceous and ordinary chondrites. Geochimica et Cosmochimica Acta 38, 757-775.

NAST, H.J., \& WILLIAMS-JONES, A.E. 1991. The role of water-rock interaction in forming the porphyry-related Sisson Brook W-Cu-Mo deposit, New Brunswick. Econ. Geol., v. 86, 302-317.

NUNES, C.M.D; JULIANI, C; CORRÊA SILVA, R.H; BETTENCOURT, J.S; JACOBI, P. 2000. Paleoproterozoic quartz-alunite epithermal gold mineralization from Tapajós (Brazil). In: International Geological Congress, 31. Rio de Janeiro, Brazil. [CD-ROM].

NUNES, C.M.D. 2001. Caracterização de um sistema epitermal high-sulfidation paleoproterozóico na Província Aurífera do Tapajós, Pará. Dissertação de Mestrado, Universidade de São Paulo, São Paulo.

PEARCE, J. 1996. Sources and settings of granitic rocks. Episodes 19: 120-125

PEREIRA E. 2006. Tocantinzinho: Geology and mineralization of the first large gold deposit of the Tapajós-PA. In: SIMEXMIN, ADIMB. [CD-ROM].

PIRAJNO, F. 2009. Hydrothermal processes and mineral systems. Australia: Springer.

PRAZERES, W. V. et al. 1979. Projeto Estanho dos Granitos Maloquinha: relatório final. Texto. Manaus: DNPM/CPRM. v. 1-A, 301, p., il.

PESSOA, M.R.; SANTIAGO, A.F; ANDRADE, A.; NASCIMENTO, J.O.; SANTOS, J.O.; OLIVEIRA, J.R.; LOPES, R.C.; PRAZERES, W.V. 1977. Projeto Jamanxim. Relatório Final. 1(A), DNPM/CPRM.

QUEIROZ, J.D.S. 2013. Estudos dos fluidos hidrotermais relacionados ao Depósito Tocantinzinho, Província Mineral Tapajós, com base em inclusões fluidas. Trabalho de Conclusão de Curso (TCC). Instituto de Geociências- Universidade Federal do Pará. p.83.

SANTANA, M.M.U.; MOURA, M.A.; OLIVO, G.R.; BOTELHO, N.F.; KYSER, T.K.; BUHN, B. 2010. The La Unión Au \pm Cu prospect, Camagüey District, Cuba: fluid inclusion and stable isotope evidence for ore-forming processes. Mineralium Deposita, 46, 91-104.

SANTIAGO, E.S.B. 2012. Rochas hospedeiras, alteração hidrotermal e avaliação do balanço geoquímico de massa do Depósito Aurífero Tocantinzinho, Província do Tapajós-PA. Dissertação (mestrado) - Instituto de Geociências, Universidade Federal do Pará, Belém.

SANTIAGO, E. S. B.; VILLAS, R. N. N.; OCAMPO, R. C. 2013. The Tocantinzinho gold deposit, Tapajós province, state of Pará: host granite, hydrothermal alteration and mineral chemistry. Brazilian Journal of Geology.43(1): 185- 208.

SANTOS, J.O.S.; HARTMANN, L.A.; GAUDETTE, H.E.; GROVES D.I.; ALMEIDA, M.E.; MCNAUGHTON, N.J.; FLETCHER, I.R. 2000. A new understanding of the provinces 
of the Amazon Craton based on integration of filed mapping and $\mathrm{U}-\mathrm{Pb}$ and $\mathrm{Sm}-\mathrm{Nd}$ geochronology. Gondwana Research, 3: 453-488.

SANTOS, J.O.S.; GROVES, D.I.; HARTMANN, L.A.; MOURA, M.A.; MCNAUGHTON, N.J. 2001. Gold deposits of the Tapajós and Alta Floresta Domains, Tapajós-Parima orogenic belt, Amazon Craton, Brazil. Mineralium Deposita, 36: 453-488.

SANTOS, J.O.S.; VAN BREEMEN, O.T.; GROVES, D. I.; HARTMANN, L.A.; ALMEIDA, M.E.; MCNAUGHTON, N.J.; FLETCHER, I. R. 2004. Timing and evolution of multiple paleoproterozoic magmatic arcs in the Tapajós Domain, Amazon Craton: constraints from SHRIMP and TIMS zircon, baddeleyite and titanite U-Pb geochronology. Prec. Research, 131: 73-109.

SATO, K. \& TASSINARI, C.C.G. 1997. Principais eventos de acresção continental no Cráton Amazônico, baseados em idade modelo Sm-Nd, calculada em evoluções de estágio único e estágio duplo. In: Costa M.L. \& Angélica R.S. (Coord.). Contribuições à Geologia da Amazônia. Belém: SBG. v. 1, p. 91-142.

SHEPHERD, T.J.; RANKING, A.H.; ALDERTON, D.H.M. 1985. A practical guide to fluid inclusion studies. Blackie \& Son Ltd., Glasgow, 239p.

SILVA, R.H.C.; JULIANI, C.; NUNES, C.M.D.; BETTENCOURT, J.S. 2000. Petrographic characterization of the hydrothermal alteration zones associated with gold mineralization in granitic rocks of the Batalha gold field, Tapajós (Pará) - Brazil. Revista Brasileira de Geociências, v.30, p.242-245.

SINCLAIR, W.D. 2007, Porphyry deposits, in Goodfellow, W.D., ed., Mineral Deposits of Canada: A Synthesis of Major Deposit-Types, District Metallogeny, the Evolution of Geological Provinces, and Exploration Methods: Geological Association of Canada, Mineral Deposits Division, Special Publication No. 5, p. 223-243.

TASSINARI, C.C.G. \& MACAMBIRA, M.J.B. 1999. Geochronological provinces of the Amazonian Craton. Episodes 22: 174-186.

TASSINARI, C.C.G. \& MACAMBIRA, M.J.B. 2004. A evolução tectônica do Cráton Amazônico. In:Mantesso-Neto, V., Bartorelli, A., Carneiro, C.D.R., Brito Neves, B.B. (Eds.), Geologia do Continente Sul-Americano: Evolução da Obra de Fernando Flávio Marques de Almeida, p. 471-485.

THOMPSON, J.F.H., SILLITOE, R.H., BAKER, T.J.R., MORTENSEN, J.K. 1999. Intrusion-related gold deposits associated with tungsten-tin provinces. Mineralium Deposita 34, 323-334.

TULLOCH, A.J. 1979. Secondary Ca-Al silicates as low-grade alteration products of granitoid biotite. Contrib.Mineral.Petrol., 69:105-117.

VILLAS, R.N.N.; SANTIAGO, E.S.B.; CASTILHO, M.P. 2012. Contexto geológico, estudos isotópicos $(\mathrm{C}, \mathrm{O}$ e $\mathrm{Pb})$ e associação metálica do depósito aurífero Tocantinzinho, domínio Tapajós, Província Tapajós-Parima. Revista do Instituto de Geociências. V. 13, n.1, p. 119 138. 
VASQUEZ, M.L.; RICCI, P.S.F.; KLEIN, E.L. 2002. Granitoides pós-colisionais da porção Leste da Província Tapajós. In: Klein E.L., Vasquez M.L., Rosa-Costa L.T. (Org.). Contribuições à Geologia da Amazônia. 1 ed. Belém: SBG - Núcleo Norte, v. 3, p. 67-84.

VASQUEZ, M. L.; ROSA-COSTA, L.T. 2008. Geologia e recursos minerais do Estado do Pará: sistema de informações geográficas - SIG: texto explicativo dos mapas geológico e tectônico e de recursos minerais do Estado do Pará. Escala 1:1. 000.000. VASQUEZ, M. L.; ROSACOSTA, L. T. da (Eds.). Belém: CPRM.

VELOSO, A.S.R.; SANTOS, M.D.; RIOS, F.J. 2013. Evolução dos fluidos mineralizantes e modelo genético dos veios de quartzo auríferos em zona de cisalhamento do depósito Ouro Roxo, Província Tapajós, Jacareacanga (PA) Brasil. Brazilian Journal of Geology.43(4):725744.

XIE, L.; WANG, R.; CHEN, J.; ZHU, J. 2010. Mineralogical evidence for magmatic and hydrothermal processes in the Qitianling oxidezed tin-bearing (Hunan, South China): EMP and (MC)-LA-ICPMS investigations of three types of titanite. Chemical Geology, v.276, p.53-68.

WILKINSON J.J. 2001. Fluid inclusions in hydrothermal ore deposits. Lithos, 55: 229-272.

WILLIAMS-JONES, A.E., SAMSON, I.M., \& LINNEN, R.L. 1989. Fluid evolution and its role in the genesis of the granite-related Madeleine copper deposit, Gaspé, Quebec. Econ. Geol., v. 84, p. 1515-1524.

WONES, D.R. 1989. Significance of the assemblage titanite + magnetite + quartz in granitic rocks. Am. Mineral. 74:744-749. 
